\title{
nanomaterials
}

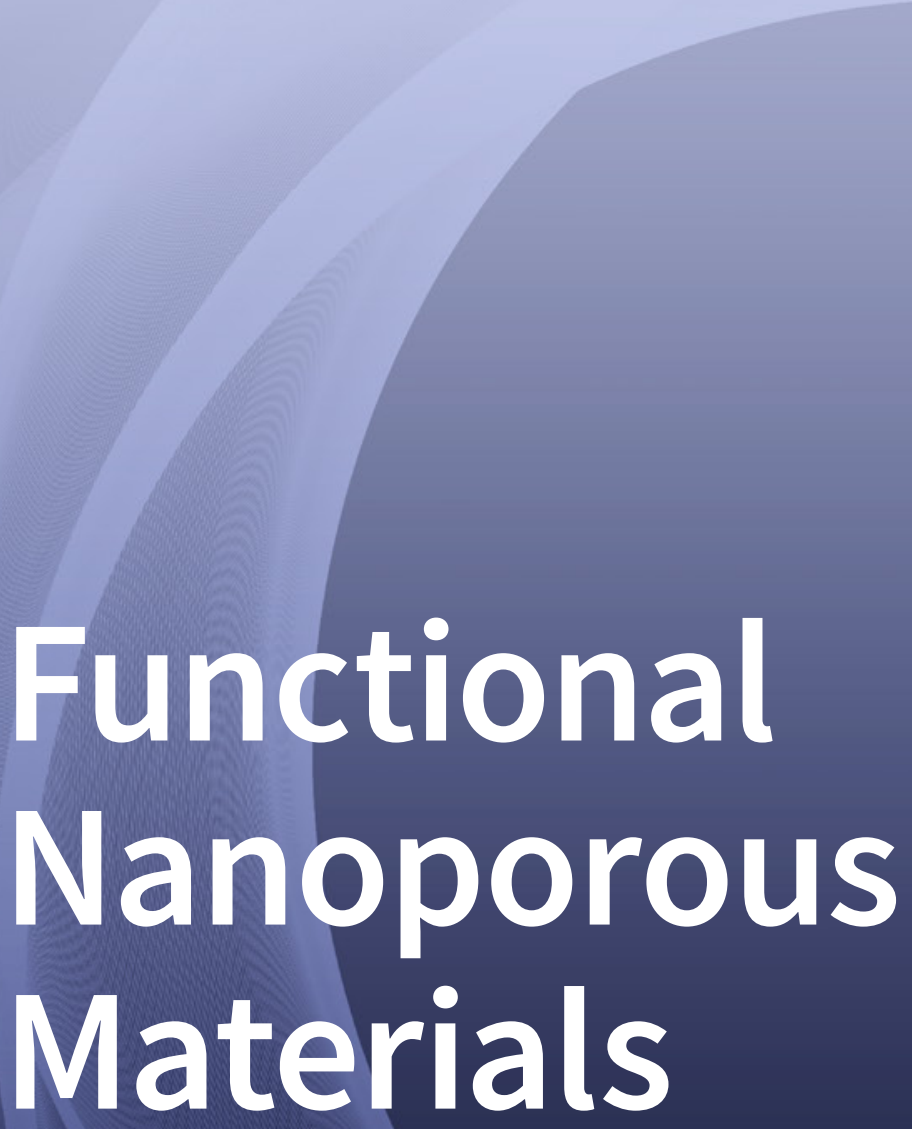

Edited by

Christian Weinberger and Michael Tiemann

Printed Edition of the Special Issue Published in Nanomaterials 
Functional Nanoporous Materials 



\section{Functional Nanoporous Materials}

Special Issue Editors

Christian Weinberger

Michael Tiemann

MDPI • Basel • Beijing • Wuhan • Barcelona • Belgrade • Manchester • Tokyo • Cluj • Tianjin

\section{MDPI}


Special Issue Editors

Christian Weinberger

Michael Tiemann

Universitat Paderborn

Universitat Paderborn

Germany

Germany

\section{Editorial Office}

MDPI

St. Alban-Anlage 66

4052 Basel, Switzerland

This is a reprint of articles from the Special Issue published online in the open access journal Nanomaterials (ISSN 2079-4991) (available at: https://www.mdpi.com/journal/nanomaterials/ special_issues/nano_porous).

For citation purposes, cite each article independently as indicated on the article page online and as indicated below:

LastName, A.A.; LastName, B.B.; LastName, C.C. Article Title. Journal Name Year, Article Number, Page Range.

ISBN 978-3-03928-895-3 (Pbk)

ISBN 978-3-03928-896-0 (PDF)

(C) 2020 by the authors. Articles in this book are Open Access and distributed under the Creative Commons Attribution (CC BY) license, which allows users to download, copy and build upon published articles, as long as the author and publisher are properly credited, which ensures maximum dissemination and a wider impact of our publications.

The book as a whole is distributed by MDPI under the terms and conditions of the Creative Commons license CC BY-NC-ND. 


\section{Contents}

About the Special Issue Editors $\ldots \ldots \ldots \ldots \ldots \ldots$ vii

Christian Weinberger and Michael Tiemann

Functional Nanoporous Materials

Reprinted from: Nanomaterials 2020, 10, 699, doi:10.3390/nano10040699 . . . . . . . . . . . . 1

Xueying Kong, Shangsiying Li, Maria Strømme and Chao Xu

Synthesis of Porous Organic Polymers with Tunable Amine Loadings for $\mathrm{CO}_{2}$ Capture:

Balanced Physisorption and Chemisorption

Reprinted from: Nanomaterials 2019, 9, 1020, doi:10.3390/nano9071020 . . . . . . . . . . 5

Marko Škrabić, Marin Kosović, Marijan Gotić, Lara Mikac, Mile Ivanda and Ozren Gamulin Near-Infrared Surface-Enhanced Raman Scattering on Silver-Coated Porous Silicon Photonic Crystals

Reprinted from: Nanomaterials 2019, 9, 421, doi:10.3390/nano9030421 . . . . . . . . . . . 17

Yufei Zhang and Fei Zhang

Vibration and Buckling of Shear Deformable Functionally Graded Nanoporous Metal Foam Nanoshells

Reprinted from: Nanomaterials 2019, 9, 271, doi:10.3390/nano9020271 . . . . . . . . . . . . 33

Nayda P. Arias, María E. Becerra and Oscar Giraldo

Structural and Electrical Studies for Birnessite-Type Materials Synthesized by Solid-State Reactions

Reprinted from: Nanomaterials 2019, 9, 1156, doi:10.3390/nano9081156 . . . . . . . . . . . 59

Muhammad Talha Masood, Syeda Qudsia, Mahboubeh Hadadian, Christian Weinberger, Mathias Nyman, Christian Ahläng, Staffan Dahlström, Maning Liu, Paola Vivo,

RonaldÖsterbacka and Jan-Henrik Smått

Investigation of Well-Defined Pinholes in $\mathrm{TiO}_{2}$ Electron Selective Layers Used in Planar Heterojunction Perovskite Solar Cells

Reprinted from: Nanomaterials 2020, 10, 181, doi:10.3390/nano10010181 _ . . . . . . . . . 77

Pei-Hsuan Wu, Peter Mäkie, Magnus Odén and Emma M. Björk

Growth and Functionalization of Particle-Based Mesoporous Silica Films and Their Usage in Catalysis

Reprinted from: Nanomaterials 2019, 9, 562, doi:10.3390/nano9040562 . . . . . . . . . . . 93

Christian Weinberger, Tatjana Heckel, Patrick Schnippering, Markus Schmitz, Anpeng Guo, Waldemar Keil, Heinrich C. Marsmann, Claudia Schmidt, Michael Tiemann and

René Wilhelm

Straightforward Immobilization of Phosphonic Acids and Phosphoric Acid Esters on Mesoporous Silica and Their Application in an Asymmetric Aldol Reaction

Reprinted from: Nanomaterials 2019, 9, 249, doi:10.3390/nano9020249 . . . . . . . . . . . . . 107 



\section{About the Special Issue Editors}

Christian Weinberger studied at Paderborn University from 2007 to 2010 and was awarded the Best Master Degree of the Year in chemistry. During his Ph.D. (2012-2016) thesis (summa cum laude) in the group of Prof. Michael Tiemann, he was supported by a scholarship from the German Fonds der Chemischen Industrie. In 2016, he was awarded a postdoctoral scholarship by the German Research Foundation to work at the Institute of Physical Chemistry of Abo Akademi University dealing with perovskite solar cells under the supervision of Dr. Jan-Henrik Smått. Since his return to Paderborn University in 2017, Christian Weinberger has been a senior scientist under the chair of Prof. Tiemann. His scientific work is focused on the synthesis and simulation of functional porous materials, investigating their chemical and physical properties. Additionally, Christian has been a visiting lecturer at the Qingdao University of Science and Technology (QUST, China) since 2019.

Michael Tiemann, After studying chemistry, he was a scientific coworker at the Institute of Inorganic and Applied Chemistry at the University of Hamburg from 1997 to 2001. He finished his Ph.D. (Dr. rer. nat.) in 2001 under the chair of Prof. Armin Reller in the group of Dr. Michael Fröba (summa cum laude). In 2001, he moved to Turku (Finland) to work as a postdoctoral research assistant at the Institute of Physical Chemistry of Abo Akademi University. From 2002 to 2009, Michael Tiemann was a group leader at the Institute for Inorganic and Analytical Chemistry of the Justus Liebig University in Giessen (Germany). He received his habilitation and held an interim Chair of Inorganic Solid State Chemistry in 2008. In 2009, he was appointed professor of Inorganic Chemistry at Paderborn University. Since 2014, he has been a chair holder. He declined a call for a chair at Clausthal University of Technology (2014). Since 2011, he has also been a visiting professor at the Sino-German Technical Faculty (CDTF) of the Qingdao University of Science and Technology (QUST) in Qingdao (China); on the Paderborn side, he coordinates the joint Bachelor's Chemistry program with the Chinese-German Technical Faculty. 



\title{
Editorial
}

\section{Functional Nanoporous Materials}

\author{
Christian Weinberger * and Michael Tiemann * \\ Department of Chemistry, Paderborn University, Warburger Str. 100, D-33098 Paderborn, Germany \\ * Correspondence: christian.weinberger@upb.de (C.W.); michael.tiemann@upb.de (M.T); \\ Tel.: +49-5251-60-2496 (C.W.); +49-5251-60-2154 (M.T.)
}

Received: 18 March 2020; Accepted: 3 April 2020; Published: 7 April 2020

This Special Issue on "Functional Nanoporous Materials" in the MDPI journal nanomaterials features seven original papers. Six of them deal with experimental work, and one of them investigates nanoporous materials from a theoretical point of view. They cover a wide range of materials, starting from porous organic polymers over silicon and silver to metal oxides and silica. A wide range of applications, such as gas adsorption and separation, sensing, solar cells, and catalysis are discussed.

$\mathrm{Xu}$ et al. [1] utilize a Sonogashira coupling of 1,3,5-triethynylbenzene with terephthaloyl chloride to form a novel ynone-linked microporous organic polymer (y-POP). Postsynthetic functionalization of $\mathrm{y}$-POP with tris(2-aminoethyl) amine (tren) enables access to amino-functionalized polymers. The pristine material reaches a surface area up to $230 \mathrm{~m}^{2} \mathrm{~g}^{-1}$. Increasing the number of amino groups within the material reduces the surface area. The authors propose that this is due to the pore-blocking effect of the tren species. The highest amine loading is $19 \%$, which reduces the surface area derived by Brunauer-Emmett-Teller method [2] (BET surface area) to $85 \mathrm{~m}^{2} \mathrm{~g}^{-1}$. Due to the microporous structure and the high amount of amine species, the authors investigate the $\mathrm{CO}_{2}$ adsorption capacity and $\mathrm{CO}_{2}$-over- $\mathrm{N}_{2}$ selectivity of the pristine and functionalized y-POP materials. Experimental data prove that the amine loaded samples exhibit a higher $\mathrm{CO}_{2}$ capacity and preferential adsorption of $\mathrm{CO}_{2}$ in the presence of $\mathrm{N}_{2}$.

Ivanada, Gamulin, and coworkers [3] exploit silver-coated porous photonic crystals as surface-enhanced Raman scattering (SERS) substrates utilizing a near-infrared excitation wavelength of $1064 \mathrm{~nm}$. Its considerable penetration depth into silicon causes photoluminescence, which conceals with the SERS signal with a broad photoluminescence peak. Thus, a porous photonic crystal is used to quench the photoluminescence of the crystalline silicon. The SERS activity was investigated in an aqueous/ethanolic solution of two dyes, namely, rhodamine $6 \mathrm{G}$ (R6G) and crystal violet (CV). The investigators show that the detection limit of the dyes is $10^{-7} \mathrm{M}(\mathrm{R} 6 \mathrm{G})$ and $5 \cdot 10^{-8} \mathrm{M}(\mathrm{CV})$, respectively. These concentrations are about five orders of magnitude lower compared to bare porous silicon.

Zhang and Zhang [4] investigate the free vibration and buckling of functionally graded (FG) nanoporous metal foam (NPMF) nanoshells. The authors are using the established first-order shear deformation (FSD) shell theory and Mindlin's (most general) strain gradient theory. With regards to the structural composition, symmetric and unsymmetric nanoporosity distributions are taken into account. The study analyses the effect of a nanoporosity coefficient, as well as the length scale and geometrical parameters on the mechanical behavior of FG NPMF nanoshells.

A study from Giraldo and his team [5] describes the thermal decomposition of potassium permanganate at $400{ }^{\circ} \mathrm{C}$ and $800{ }^{\circ} \mathrm{C}$. As a function of the temperature, the composition of the decomposition product varies between triclinic $\mathrm{K}_{0.29}^{+}\left(\mathrm{Mn}_{0.84}^{4+} \mathrm{Mn}_{0.16}^{3+}\right) \mathrm{O}_{2.07} \cdot 0.61 \mathrm{H}_{2} \mathrm{O}$ and hexagonal $\mathrm{K}_{0.48}^{+}\left(\mathrm{Mn}_{0.64}^{4+} \mathrm{Mn}_{0.36}^{3+}\right) \mathrm{O}_{2.06} \cdot 0.50 \mathrm{H}_{2} \mathrm{O}$, respectively. The materials exhibit a BET surface area between $5-16 \mathrm{~m}^{2} \mathrm{~g}^{-1}$ with a broad pore size distribution. The authors suggest that their synthesized materials might be utilized as a catalyst, and therefore they studied the charge transport mechanism by electrical impedance analysis. The crystallite size, manganese's average oxidation state, and the crystal 
symmetry influence the impedance measurements. Both materials exhibit semiconducting properties and thermally activated electron "hopping".

Smått et al. [6] investigate how well-defined pinholes in $\mathrm{TiO}_{2}$ electron selective layers (ESL) in planar heterojunction perovskite solar cells influence the device performance. Defects such as pinholes compromise the cell performance due to enhanced surface recombination of electron-hole pairs. Sol-gel derived porous titania layers were exploited as ESL, synthesized in a dip coating process, in which block copolymers were utilized as templates. The porosity of $\mathrm{TiO}_{2}$ was varied between $0 \%$ and $47 \%$, as well as the film thickness between 20 and $75 \mathrm{~nm}$. It turns out that narrow pinholes $(<10 \mathrm{~nm}) \mathrm{do}$ not affect the device performance, which might be attributed to the fact that the perovskite crystals do not form a connecting path through the pores in the titania layer up to the electrode. Thin titania layers ( $<20 \mathrm{~nm}$ ), lead to incomplete surface coverage. Hence a drop in performance of the device can be observed. The scientists around Smått present an ideal model system to investigate the effect of pinholes on the solar cell performance, leading to efficiency values up to $14.1 \%$.

Björk and her colleagues [7] show how ordered mesoporous SBA-15 silica particles grow on surfaces. The particle-based approach to synthesize silica films that can be functionalized and used as catalysts for esterification reactions leads to a film thickness between 80 and $750 \mathrm{~nm}$. It can be tuned by the addition of $\mathrm{NH}_{4} \mathrm{~F}$ during synthesis because it influences the formation rate of silica particles. The time of the addition into the mixture is crucial for the quality of the resulting film. Under optimal conditions, the homogenous surface coverage of an area larger than $75 \mathrm{~cm}^{2}$ is possible and independent of the shape of the substrate (flat or three dimensional). Furthermore, they present surface functionalization with acetic acid through co-condensation and a post-synthetic coating with furfuryl alcohol foams. In the latter case, the alcohol can be converted to carbon. A second surface functionalization leads to a sulfonated CMK-5 carbon-SBA-15 silica composite material. The carbon-coated films were used as a catalyst for the esterification between acetic acid and ethanol, reaching conversion up to $30 \%$ within one hour compared to a $5 \%$ conversion rate compared to the catalyst-free reaction.

Another study dealing with ordered mesoporous silica materials is presented by Wilhelm et al [8]. They show how to functionalize porous silica materials with various phosphonic acids, phosphonic acid esters as well as adenosine monophosphate. A wide range of silica materials were investigated to cover a broad range of surface areas and pore sizes, e.g., MCM-41 with a pore size around 4 $\mathrm{nm}$ and a BET surface area of around $1300 \mathrm{~m}^{2} \mathrm{~g}^{-1}$. Furthermore, ordered mesoporous SBA-15 silica (pore size $6 \mathrm{~nm}$, surface area $630 \mathrm{~m}^{2} \mathrm{~g}^{-1}$ ) was utilized. Additionally, commercially available LiChrosorb SI $100\left(14 \mathrm{~nm}, 280 \mathrm{~m}^{2} \mathrm{~g}^{-1}\right)$ and synthesized disordered silica with hierarchical mesoand macro-porosity were exploited. Lichrosorb and SBA-15 silica samples with immobilized (4R)-4-phosphonooxy-L-proline were investigated in terms of their catalytic potential in the conversion cyclohexanone with 4-nitrobenzaldehyde in an asymmetric aldol reaction.

This collection of fine articles shows the potential and challenges in the characterization and application of functional nanoporous materials. Both from a theoretical and experimental point of view, the authors present novel ideas, showing the prospects and exciting developments in the field of porous materials.

Funding: This research received no external funding.

Conflicts of Interest: The authors declare no conflict of interest.

\section{References}

1. Kong, X.; Li, S.; Strømme, M.; Xu, C. Synthesis of Porous Organic Polymers with Tunable Amine Loadings for $\mathrm{CO}_{2}$ Capture: Balanced Physisorption and Chemisorption. Nanomaterials 2019, 9, 1020. [CrossRef] [PubMed]

2. Brunauer, S.; Emmett, P.H.; Teller, E. Adsorption of Gases in Multimolecular Layers. J. Am. Chem. Soc. 1938, 60, 309-319. [CrossRef] 
3. Škrabić, M.; Kosović, M.; Gotić, M.; Mikac, L.; Ivanda, M.; Gamulin, O. Near-Infrared Surface-Enhanced Raman Scattering on Silver-Coated Porous Silicon Photonic Crystals. Nanomaterials 2019, 9, 421. [CrossRef] [PubMed]

4. Zhang, Y.; Zhang, F. Vibration and Buckling of Shear Deformable Functionally Graded Nanoporous Metal Foam Nanoshells. Nanomaterials 2019, 9, 271. [CrossRef] [PubMed]

5. Arias, P.N.; Becerra, E.M.; Giraldo, O. Structural and Electrical Studies for Birnessite-Type Materials Synthesized by Solid-State Reactions. Nanomaterials 2019, 9, 1156. [CrossRef] [PubMed]

6. Masood, T.M.; Qudsia, S.; Hadadian, M.; Weinberger, C.; Nyman, M.; Ahläng, C.; Dahlström, S.; Liu, M.; Vivo, P.; Österbacka, R.; et al. Investigation of Well-Defined Pinholes in $\mathrm{TiO}_{2}$ Electron Selective Layers Used in Planar Heterojunction Perovskite Solar Cells. Nanomaterials 2020, 10, 181. [CrossRef] [PubMed]

7. Wu, P.H.; Mäkie, P.; Odén, M.; Björk, M.E. Growth and Functionalization of Particle-Based Mesoporous Silica Films and Their Usage in Catalysis. Nanomaterials 2019, 9, 562. [CrossRef] [PubMed]

8. Weinberger, C.; Heckel, T.; Schnippering, P.; Schmitz, M.; Guo, A.; Keil, W.; Marsmann, H.C.; Schmidt, C.; Tiemann, M.; Wilhelm, R. Straightforward Immobilization of Phosphonic Acids and Phosphoric Acid Esters on Mesoporous Silica and Their Application in an Asymmetric Aldol Reaction. Nanomaterials 2019, 9, 249. [CrossRef] [PubMed]

(C) 2020 by the authors. Licensee MDPI, Basel, Switzerland. This article is an open access article distributed under the terms and conditions of the Creative Commons Attribution (CC BY) license (http://creativecommons.org/licenses/by/4.0/). 



\title{
Synthesis of Porous Organic Polymers with Tunable Amine Loadings for $\mathrm{CO}_{2}$ Capture: Balanced Physisorption and Chemisorption
}

\author{
Xueying Kong ${ }^{1,2}$, Shangsiying $\mathrm{Li}^{1}{ }^{1}$, Maria Strømme ${ }^{2}$ and Chao $\mathrm{Xu}{ }^{1,2, *}$ \\ 1 Key Laboratory of Flexible Electronics (KLOFE), Institute of Advanced Materials (IAM), Nanjing Tech \\ University (Nanjing Tech), 30 South Puzhu Road, Nanjing 211800, China \\ 2 Division of Nanotechnology and Functional Materials, Department of Engineering Sciences, \\ Uppsala University, SE-75121 Uppsala, Sweden \\ * Correspondence: chao.xu@angstrom.uu.se
}

Received: 1 July 2019; Accepted: 13 July 2019; Published: 17 July 2019

\begin{abstract}
The cross-coupling reaction of 1,3,5-triethynylbenzene with terephthaloyl chloride gives a novel ynone-linked porous organic polymer. Tethering alkyl amine species on the polymer induces chemisorption of $\mathrm{CO}_{2}$ as revealed by the studies of ex situ infrared spectroscopy. By tuning the amine loading content on the polymer, relatively high $\mathrm{CO}_{2}$ adsorption capacities, high $\mathrm{CO}_{2}$-over- $\mathrm{N}_{2}$ selectivity, and moderate isosteric heat $\left(Q_{\mathrm{st}}\right)$ of adsorption of $\mathrm{CO}_{2}$ can be achieved. Such amine-modified polymers with balanced physisorption and chemisorption of $\mathrm{CO}_{2}$ are ideal sorbents for post-combustion capture of $\mathrm{CO}_{2}$ offering both high separation and high energy efficiencies.
\end{abstract}

Keywords: porous organic polymers; amine modification; $\mathrm{CO}_{2}$ separation; adsorption mechanism; chemisorption of $\mathrm{CO}_{2}$

\section{Introduction}

The long-term increasing $\mathrm{CO}_{2}$ emission from combustion of fossil fuels is widely considered as the main reason for the global climate change and associated environmental issues [1]. Post-combustion carbon capture dealing with separation of $\mathrm{CO}_{2}$ from flue gases is a feasible approach to reduce industrial $\mathrm{CO}_{2}$ emissions and to gain control over the atmospheric $\mathrm{CO}_{2}$ concentration, and the method has the advantage of allowing quite simple retrofit design of required instrumentation into existing power plants [2]. However, the main challenge for the post-combustion technology is that the low concentration of $\mathrm{CO}_{2}$ (ca. $5 \%-15 \mathrm{v} \%$ ) in flue gases usually results in low separation efficiency [3]. Amine scrubbing, a mature technique using aqueous amine solution to absorb $\mathrm{CO}_{2}$ from mixed gases, has been applied in natural gas purification and $\mathrm{CO}_{2}$ capture for more than a half century [4] and the technique is currently employed to create large scale pilot facilities in, amongst others, Norway [5]. The strong chemical interactions between amine and $\mathrm{CO}_{2}$ molecules endow the high efficiency for $\mathrm{CO}_{2}$ capture and separation. However, the energy consumption for amine reactivation arising from heating the aqueous amine solution is high. In addition, the use of amine might cause amine leakage and serious corrosion to the equipment. Therefore, it is highly desirable to develop new materials for post-combustion carbon capture that can be operated in an economical and environmentally friendly manner.

Porous materials with high surface areas and high volumes of narrow pores are ideal solid sorbents for adsorption-driven $\mathrm{CO}_{2}$ capture, in which $\mathrm{CO}_{2}$ molecules can be selectively adsorbed onto the surface or captured in the narrow pores [6,7]. For example, traditional zeolites and activated carbons have been extensively studied for $\mathrm{CO}_{2}$ capture owing to their high microporosities and relatively high $\mathrm{CO}_{2}$ adsorption capacities [8-14]. However, the hydrophilicity of zeolites and the broad pore size 
distributions of activated carbons have significantly limited their performances in $\mathrm{CO}_{2}$ capture and separation. Emerging porous materials such as metal-organic frameworks (MOFs) [15-17] and porous organic polymers (POPs) [18-23] are of great interest for $\mathrm{CO}_{2}$ capture because of their large surface areas and tunable pore sizes. POPs constitute a type of porous materials created by linking pure organic monomers, usually aromatic or conjugated, via strong covalent bonds [24,25]. The diverse synthesis possibilities of POPs allows precise control of their nanoporous structure and surface chemistry at the molecular level, aiming to increase the $\mathrm{CO}_{2}$ adsorption capacity and selectivity of $\mathrm{CO}_{2}$ over other gases by thermodynamic effects [26-31]. Several studies reported on post-modification of POPs with alkyl amines for $\mathrm{CO}_{2}$ capture [32-39]. The strong $\mathrm{CO}_{2}$-amine interactions on the amine-modified POPs led to significantly enhanced $\mathrm{CO}_{2}$ adsorption capacity and increased $\mathrm{CO}_{2}$-over- $\mathrm{N}_{2}$ selectivity. However, the strong interactions, interpreted by the high isosteric heat $\left(Q_{\mathrm{st}}\right)$ of adsorption (up to $80 \mathrm{~kJ} \mathrm{~mol}^{-1}$ ) [35,37], require high energy input to reactivate the sorbents in the process of temperature swing adsorption (TSA) or vacuum swing adsorption (VSA) [40]. In this context, it would be great of interest to balance the trade-off between the separation efficiency and energy efficiency. Here, we report a strategy to tune the amine density on a novel ynone-linked POP (y-POP) by the post-modification approach, which enables balancing of the effects of physisorption and chemisorption of $\mathrm{CO}_{2}$ and optimization of the $\mathrm{CO}_{2}$ adsorption capacity, $\mathrm{CO}_{2}$-over- $\mathrm{N}_{2}$ selectivity and heat of adsorption of $\mathrm{CO}_{2}$.

\section{Results and Discussion}

POPs can be synthesized from various organic reactions, of which coupling reactions constitute the most commonly used routes [41]. For example, Zhu et al. reported on the Yamamoto homo-coupling reaction of tetrakis(4-bromophenyl)methane for the synthesis of a porous aromatic framework (PAF-1) [42]. The tetrahedral shaped monomer resulted in a three-dimensional framework of PAF-1 possessing an ultrahigh surface area of $5600 \mathrm{~m}^{2} \mathrm{~g}^{-1}$. Cooper and Jiang's groups synthesized a number of conjugated microporous polymers (CMPs) by Suzuki, Sonogashira, and Glaser coupling reactions, which showed great potential in photocatalysis, light harvesting, etc. [43-46]. Recently, Son et al. developed a carbonylative Sonogashira coupling reaction of phenyl alkynes and phenyl halides in the presence of carbon monoxide, which gave a redox-active CMP that can be used as electrode material for electrochemical energy storage devices [47]. Therefore, the exploration of organic reactions to form novel structures in POPs could enrich their properties and applications. As we know, the cross-coupling reaction between terminal alkynes and acyl chloride under Sonogashira conditions forms conjugated $\alpha, \beta$-alkynic ketones, also known as ynones [48]. More interestingly, further reaction of the ynones with alkyl amines could form imine compounds by two possible routes [48-52]. One is that of conjugate addition of the amine to $\alpha, \beta$-alkynic ketone with formation of enaminone, which can be further converted into the imine compound via the nucleophilic addition in the presence of excess of amine. Another approach is direct nucleophilic addition of the amine to the ketone group forming the imine or enaminone compound. However, to the best of our knowledge, the direct coupling of terminal alkyne with acyl chloride has never been reported for the synthesis of POPs. In this context, we attempted the cross-coupling of 1,3,5-triethynylbenzene with terephthaloyl chloride under Sonogashira conditions for the synthesis of y-POP, which was catalyzed by bis(triphenylphosphine)palladium(II) dichloride and copper(I) iodide in the presence of trimethylamine as a base (Scheme 1a). The conjugated structure of the ynones and the aromatic monomers endow rigidity and stability of y-POP. In order to graft amine species onto the polymer, the as-synthesized y-POP was treated by tris(2-aminoethyl)amine (tren) in a methanol solution (Scheme 1b). The density of amine species tethered on the polymer was finely controlled by tuning the concentration of tren in the methanol solution. Specifically, treatment of $\mathrm{y}$-POP in the methanol solution of tren $(1,5,20 \mathrm{v} \%)$ yields the amine modified polymer $\mathrm{y}-\mathrm{POP}-\mathrm{NH}_{2}$, denoted as $\mathrm{y}$-POP-A1, $\mathrm{y}-\mathrm{POP}-\mathrm{A} 2$, and $\mathrm{y}-\mathrm{POP}-\mathrm{A} 3$, respectively. Based on the thermogravimetric analyses (Figure S1), the amine loading content on the $\mathrm{y}-\mathrm{POP}-\mathrm{NH}_{2}$ can be roughly calculated to $12 \%$, $16 \%$, and $19 \%$ for $y$-POP-A1, y-POP-A2, and y-POP-A3, respectively. 

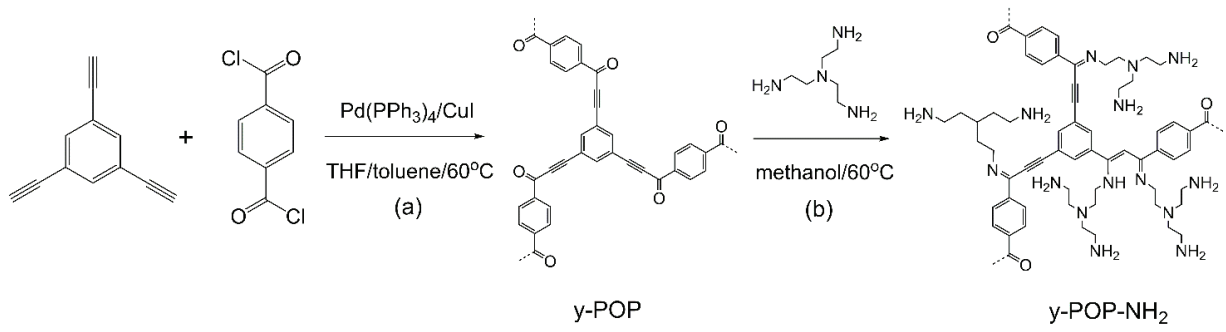

Scheme 1. (a) Synthesis of ynone-linked porous organic polymer (y-POP) by the Sonogashira coupling reaction; (b) amine modification of $y-P O P$.

The molecular structures of y-POP and y-POP- $\mathrm{NH}_{2}$ were examined by both Fourier transform infrared (IR) and solid-state ${ }^{13} \mathrm{C}$ nuclear magnetic resonance (NMR) spectroscopy. The IR spectrum of $\mathrm{y}$-POP shows strong bands at 2200 and $1720 \mathrm{~cm}^{-1}$, corresponding to the stretching vibrations of alkyne $(-\mathrm{C} \equiv \mathrm{C}-)$ and carbonyl $(-\mathrm{C}=\mathrm{O})$, respectively (Figure $1 \mathrm{a})$. In general, the central $-\mathrm{C} \equiv \mathrm{C}-$ group with a high degree of symmetry displays a very weak IR stretching band [45]; however, the intensity of the IR band can be significantly increased by introducing conjugated structures [47,53]. Therefore, the intense IR band observed for the alkyne group can be correlated to the formation of conjugated structure with a carbonyl group $(-\mathrm{C} \equiv \mathrm{C}(=\mathrm{O})-)$. The study of the solid-state ${ }^{13} \mathrm{C}$ NMR spectrum also confirms the formation of ynone species in the polymer. The bands at chemical shifts of 91 and 83 ppm can be assigned to carbon atoms $(1,2)$ of alkyne bonds (Figure $1 \mathrm{~b}$ and Figure S2). The characteristic band for carbon atoms (3) in carbonyl groups was observed at $176 \mathrm{ppm}$. Upon amine modification, the intensity of the IR band at $1720 \mathrm{~cm}^{-1}$ was gradually decreased with increasing amine loading, indicating that the carbonyl groups were consumed by the amine. In addition, the IR band intensity at $2200 \mathrm{~cm}^{-1}$ and NMR band intensity at 91 and 83 ppm were decreased in y-POP- $\mathrm{NH}_{2}$ compared to y-POP due to the transformation of the alkyne groups to enaminones. The broad shoulder bands at $\sim 1660 \mathrm{~cm}^{-1}$ in the IR spectra of $y-\mathrm{POP}-\mathrm{NH}_{2}$ can be assigned to the imine stretching vibrations. Consistently, the broad shoulder bands at the NMR chemical shift of $175-168$ ppm for $y-P O P-\mathrm{NH}_{2}$ indicate the formation of enamine and imine bonds [52,54]. The broad IR bands at $3370 \mathrm{~cm}^{-1}$ observed for $\mathrm{y}-\mathrm{POP}-\mathrm{NH}_{2}$ are assigned to the characteristic $\mathrm{N}-\mathrm{H}$ stretching modes for the primary amine. The chemical shifts at 52 and $39 \mathrm{ppm}$ for $\mathrm{y}-\mathrm{POP}-\mathrm{NH}_{2}$ correspond to the carbons in tethered tren species. The three major peaks at 137,130 and $123 \mathrm{ppm}$ are assigned to the aromatic carbons in $\mathrm{y}-\mathrm{POP}$ and $\mathrm{y}-\mathrm{POP}-\mathrm{NH}_{2}$. Other peaks in the range of 60-10 ppm can be assigned to the carbon atoms in solvent molecules (tetrahydrofuran, methanol, triethylamine) adsorbed in the pores of y-POP. Collectively, the studies of the IR and ${ }^{13} \mathrm{C}$ NMR spectra confirmed that ynone-linked POP was successfully synthesized and the tren molecules were chemically tethered on $\mathrm{y}-\mathrm{POP}-\mathrm{NH}_{2}$.

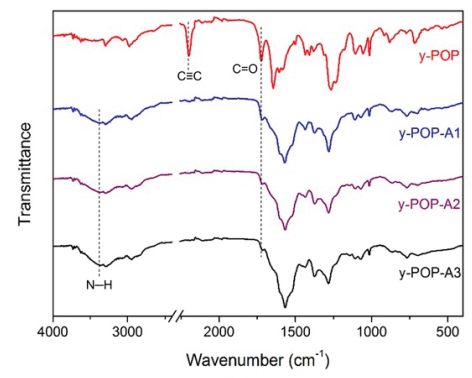

(a)

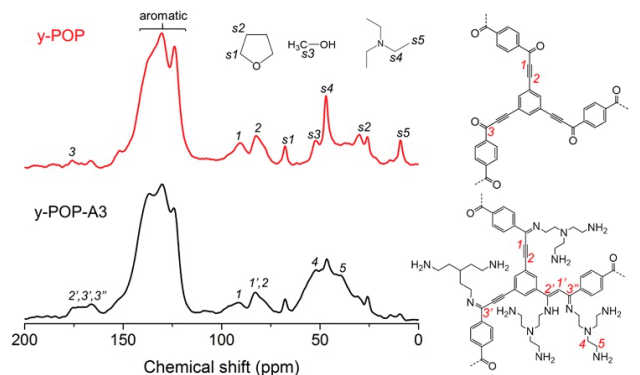

(b)

Figure 1. (a) Infrared (IR) and (b) ${ }^{13} \mathrm{C}$ nuclear magnetic resonance (NMR) spectra of ynone-linked porous organic polymer (y-POP) and y-POP-NH . 
As a strong organic base with a $\mathrm{pKb}$ value $\approx 4$, the tethered tren species on $\mathrm{y}-\mathrm{POP}-\mathrm{NH}_{2}$ could potentially attract $\mathrm{CO}_{2}$ molecules by the chemisorption effect. To investigate the $\mathrm{CO}_{2}$ adsorption mechanism, we designed an ex situ IR experiment to study the molecular interactions between $\mathrm{CO}_{2}$ and the polymers. The polymer sample was grinded with $\mathrm{KBr}$ and pressed into a transparent pellet, followed by drying at $100{ }^{\circ} \mathrm{C}$ for $12 \mathrm{~h}$. The degassed pellet was used to record the IR background spectrum in a transmission model. The pellet was subsequently flashed with $\mathrm{CO}_{2}$ for $2 \mathrm{~h}$ at room temperature and thereafter a transmission IR spectrum was recorded again. The differences between the two spectra revealed the adsorbed $\mathrm{CO}_{2}$ on the polymers, as shown in Figure 2. The intense bands at frequencies of 2335 and $653 \mathrm{~cm}^{-1}$ in the spectra correspond to the physisorbed $\mathrm{CO}_{2}$ molecules, which can be assigned to the asymmetric stretching and deformation vibration of $\mathrm{C}=\mathrm{O}$, respectively [55]. Physisorption clearly dominates the $\mathrm{CO}_{2}$ adsorption on y-POP as no extra band was observed in the IR spectrum. In contrast, significant IR bands in the frequency region of $1750-1000 \mathrm{~cm}^{-1}$ were observed for $\mathrm{y}-\mathrm{POP}-\mathrm{NH}_{2}$, which indicates that the tethered amine species induced chemisorption of $\mathrm{CO}_{2}$. Obviously, a higher amine loading content in $\mathrm{y}-\mathrm{POP}-\mathrm{NH}_{2}$ resulted in a stronger IR intensity, suggesting the enhanced effect of chemisorption of $\mathrm{CO}_{2}$. The band at the frequency of $1704 \mathrm{~cm}^{-1}$ was assigned to $\mathrm{C}=\mathrm{O}$ stretching (amide $\mathrm{I}$ ), which is a characteristic indication of the formation of carbamic acid or carbamate species from the reaction between $\mathrm{CO}_{2}$ and the amine groups on $\mathrm{y}-\mathrm{POP}-\mathrm{NH}_{2}$ [56-58]. The broad band at $1243 \mathrm{~cm}^{-1}$ was assigned to a combination of $\mathrm{N}-\mathrm{H}$ bending and $\mathrm{C}-\mathrm{N}$ stretching (amide III) [59]. In addition, the bands at 1655, 1618, and $1475 \mathrm{~cm}^{-1}$ can be assigned to asymmetric deformation of $\mathrm{NH}_{3}{ }^{+}$and the signals at 1538 and $1385 \mathrm{~cm}^{-1}$ can be associated to asymmetric stretching of $\mathrm{COO}^{-}$[55,60-63]. Therefore, we could speculate that chemisorption of $\mathrm{CO}_{2}$ on $\mathrm{y}-\mathrm{POP}-\mathrm{NH}_{2}$ forms ammonium carbamate ion pairs (Scheme S1).

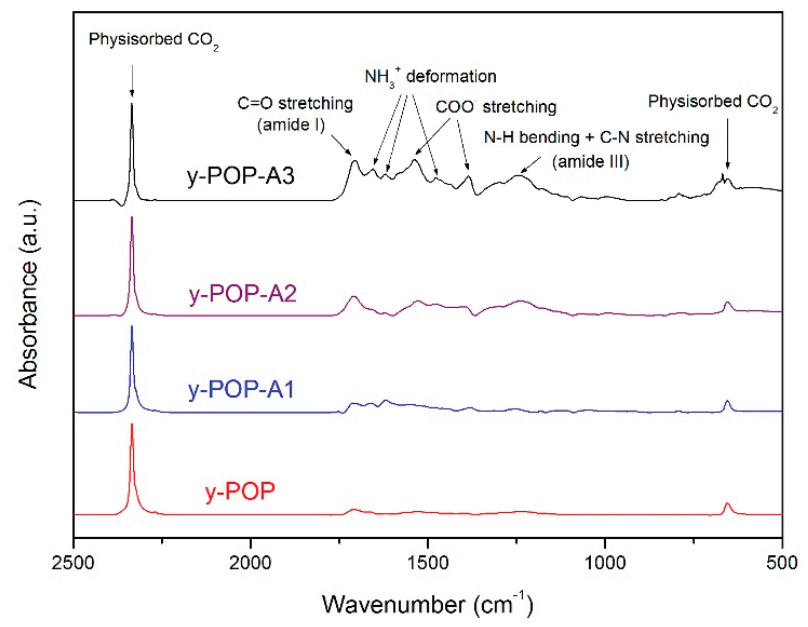

Figure 2. Infrared (IR) spectra of adsorbed $\mathrm{CO}_{2}$ on ynone-linked porous organic polymer (y-POP) and $\mathrm{y}-\mathrm{POP}-\mathrm{NH}_{2}$.

The porosities of the polymers were analyzed by $\mathrm{N}_{2}$ sorption measurements at $77 \mathrm{~K}$, as illustrated in Figure 3a. The sorption isotherm of $\mathrm{y}$-POP displays rapid $\mathrm{N}_{2}$ adsorption at low relative pressures $\left(p / p_{0}<0.05\right)$, which is characteristic for microporous materials. The significant $\mathrm{N}_{2}$ uptake at high relative pressures $\left(p / p_{0}>0.8\right)$ and the accompanied hysteresis loop between the adsorption and desorption branches suggest the presence of mesopores in y-POP arising from the inter-particle cavities observed in SEM images (Figure S3). Such mesopores would facilitate the mass transportation and increase the adsorption kinetics during the sorption processes. Pore size distribution analyses showed that y-POP had ultramicropores (pore size: $0.74 \mathrm{~nm}$ ), micropores (pore size: $1.2 \mathrm{~nm}$ ) and mesopores (pore size: 
$34 \mathrm{~nm}$ ). As expected, amine modification on y-POP resulted in disappearance of the ultramicropores and decrease in both micropore volumes and total pore volumes due to the pore blocking effect of the tren species (Figure 3b). Consistently, the specific surface area of the $\mathrm{y}-\mathrm{POP}-\mathrm{NH}_{2}$ was gradually decreased with increasing amine loading: the specific surface area values being 226, 145, 107, and $84 \mathrm{~m}^{2}$ $\mathrm{g}^{-1}$, for of $\mathrm{y}-\mathrm{POP}, \mathrm{y}-\mathrm{POP}-\mathrm{A} 1, \mathrm{y}-\mathrm{POP}-\mathrm{A} 2$, and $\mathrm{y}-\mathrm{POP}-\mathrm{A} 3$, respectively.

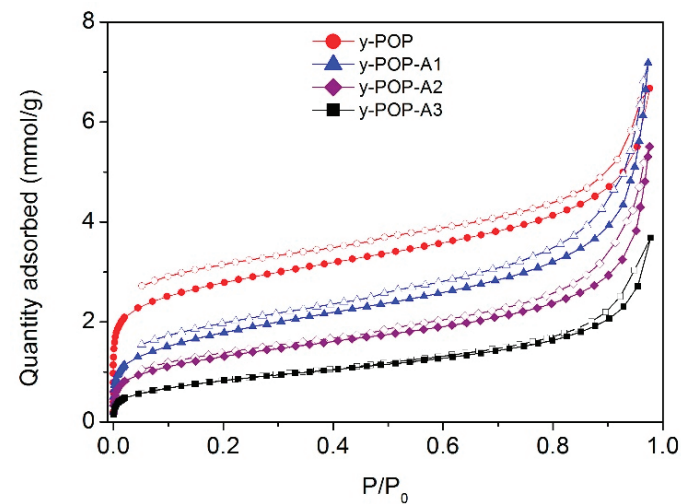

(a)

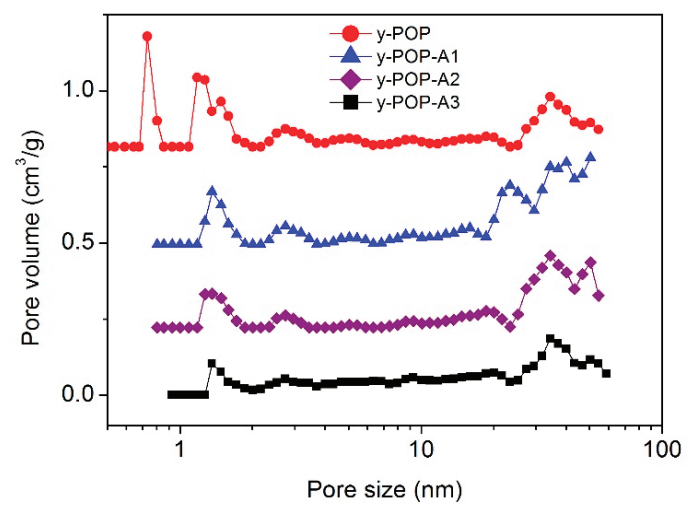

(b)

Figure 3. (a) $\mathrm{N}_{2}$ adsorption/desorption isotherms of ynone-linked porous organic polymer (y-POP) and $\mathrm{y}-\mathrm{POP}-\mathrm{NH}_{2}$ recorded at $77 \mathrm{~K}$; (b) Pore size distribution analyses of $\mathrm{y}-\mathrm{POP}$ and $\mathrm{y}-\mathrm{POP}-\mathrm{NH}_{2}$ based on the adsorption branches using the density functional theory model.

Given the microporous structure and the strong chemisorption of $\mathrm{CO}_{2}$ induced by the high amount of amine species, we anticipated that y-POP- $\mathrm{NH}_{2}$ would have much higher $\mathrm{CO}_{2}$ adsorption capacities and higher $\mathrm{CO}_{2}$-over- $\mathrm{N}_{2}$ selectivity than the corresponding values of unmodified $\mathrm{y}$-POP. Figure $4 \mathrm{a}$ compares the $\mathrm{CO}_{2}$ adsorption isotherms of $\mathrm{y}-\mathrm{POP}$ and $\mathrm{y}-\mathrm{POP}-\mathrm{NH}_{2}$ with different amine densities at $273 \mathrm{~K}$. Although the specific surface areas of the polymers were reduced after the amine modification, $\mathrm{y}$-POP-NH $\mathrm{N}_{2}$ had significantly higher $\mathrm{CO}_{2}$ adsorption capacities than the substrate polymer of $\mathrm{y}$-POP. With the increase of amine loading, the $\mathrm{CO}_{2}$ adsorption capacity of $\mathrm{y}-\mathrm{POP}-\mathrm{NH}_{2}$ gradually increased up to 1.11 and $1.88 \mathrm{mmol} \mathrm{g}^{-1}$ at 0.15 and 1 bar $(273 \mathrm{~K})$, respectively, which were $158 \%$ and $40 \%$ higher than the corresponding values of $\mathrm{y}$-POP $\left(0.43 \mathrm{mmol} \mathrm{g}^{-1}\right.$ at $0.15 \mathrm{bar} ; 1.34 \mathrm{mmol} \mathrm{g}^{-1}$ at 1 bar, $\left.273 \mathrm{~K}\right)$. In addition, the sorbents can be easily reactivated and showed excellent adsorption recyclability. For example, y-POP-A1 retained $97 \%$ of its $\mathrm{CO}_{2}$ adsorption capacity after 5 cycles at $293 \mathrm{~K}$ (Figure S6). In order to evaluate the potential of the polymers for capturing $\mathrm{CO}_{2}$ from flue gases, we calculated the 
$\mathrm{CO}_{2}$-over- $\mathrm{N}_{2}$ selectivity from their single component adsorption data recorded at $273 \mathrm{~K}$ (Figure $4 \mathrm{a}$ and Figure S7) using ideal adsorption solution theory (IAST) $[13,35,64,65]$. The $\mathrm{CO}_{2}$ and $\mathrm{N}_{2}$ adsorption isotherms were fitted by dual-site and single-site Langmuir equation, respectively (Figure S8 and Table $\mathrm{S} 1)$. The $\mathrm{CO}_{2}$-over- $\mathrm{N}_{2}$ selectivity is defined as $\mathrm{S}=\left(\mathrm{xCO}_{2} / \mathrm{yCO}_{2}\right) /\left(\mathrm{xN}_{2} / \mathrm{yN}\right)_{2}$, where $\mathrm{x}$ and $\mathrm{y}$ are the molar fractions of the gas in the adsorbed and bulk phases, respectively. A simulated gas mixture of $15 \mathrm{v} \% \mathrm{CO}_{2} / 85 \mathrm{v} \% \mathrm{~N}_{2}$ was used for the calculation. As illustrated in Figure $4 \mathrm{~b}$, the substrate polymer $\mathrm{y}$-POP showed a relatively low $\mathrm{CO}_{2}$-over- $\mathrm{N}_{2}$ selectivity of 20 . In contrast, $\mathrm{y}-\mathrm{POP}-\mathrm{NH}_{2}$ containing amine species displayed much higher selectivity up to $4.15 \times 10^{3}$. In addition, we have calculated Henry's law initial slope selectivity for the polymers (Figure S9), which are comparable to the values obtained from the IAST calculations.

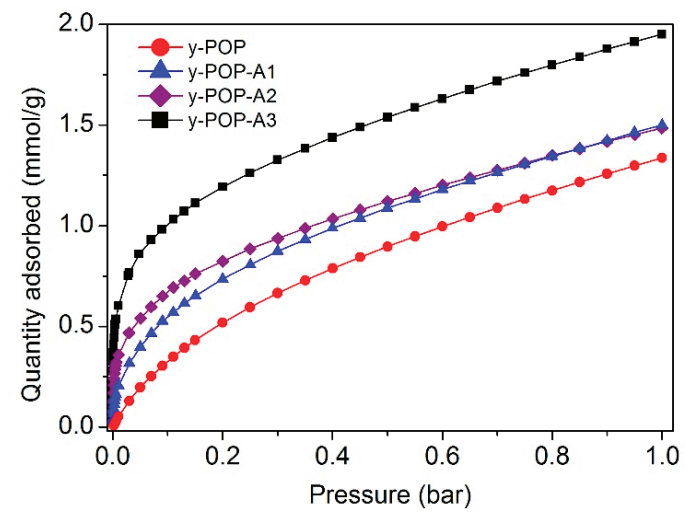

(a)

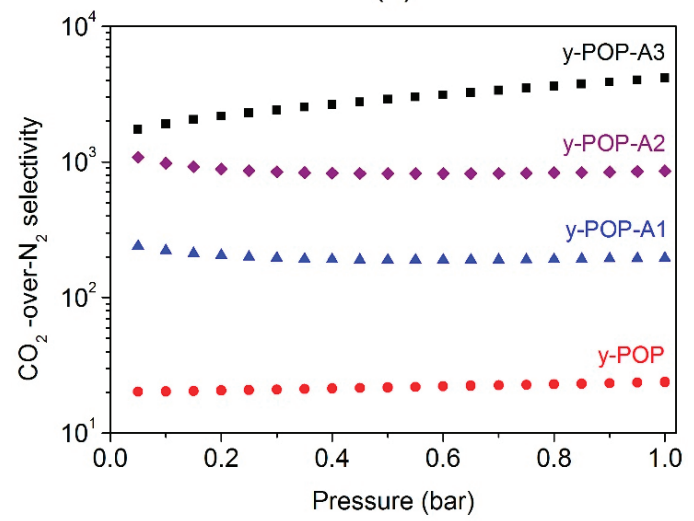

(b)

Figure 4. (a) $\mathrm{CO}_{2}$ adsorption isotherms of ynone-linked porous organic polymer (y-POP) and $\mathrm{y}$-POP- $\mathrm{NH}_{2}$ with different amine loadings at $273 \mathrm{~K}$; (b) $\mathrm{CO}_{2}$-over- $\mathrm{N}_{2}$ selectivity of $\mathrm{y}-\mathrm{POP}$ and $\mathrm{y}-\mathrm{POP}-\mathrm{NH}_{2}$ calculated by ideal adsorbed solution theory.

The binding affinity of the studied polymers toward $\mathrm{CO}_{2}$ was revealed by the $Q_{\text {st }}$ values, which can be calculated from the temperature dependent $\mathrm{CO}_{2}$ adsorption isotherms (273, 283, and $\left.293 \mathrm{~K}\right)$ using the Clausius-Clapeyron equation. The substrate polymer of y-POP had a relatively low $Q_{\text {st }}$ value of $29.0 \mathrm{~kJ} \mathrm{~mol}^{-1}$, which is characteristic for the physisorption of $\mathrm{CO}_{2}$. As expected, $\mathrm{y}-\mathrm{POP}-\mathrm{NH}_{2}$ showed gradually increased $Q_{\text {st }}$ values (y-POP-A1: $46.8 \mathrm{~kJ} \mathrm{~mol}^{-1}$; y-POP-A2: $62.2 \mathrm{~kJ} \mathrm{~mol}^{-1}$; y-POP-A3: 
$76.5 \mathrm{~kJ} \mathrm{~mol}^{-1}$ ) with increasing amine loading (Figure S5). The high $Q_{\mathrm{st}}$ values indicate the effect of chemisorption of $\mathrm{CO}_{2}$ on y-POP-NH $\mathrm{N}_{2}$, which is consistence with the ex situ IR results.

Table 1 summarizes $\mathrm{CO}_{2}$ adsorption capacities, $\mathrm{CO}_{2}$-over- $\mathrm{N}_{2}$ selectivity, and $Q_{\text {st }}$ values for the four studied polymers. It is immediately clear that amine modification on the polymer significantly increases the efficiency for $\mathrm{CO}_{2}$ capture and separation due to the effect of chemisorption of $\mathrm{CO}_{2}$. In addition, the efficiency was proportional to the amine loading density on the polymer. However, the polymers containing high amine loading contents had relatively high $Q_{\text {st }}$ values, which means that reactivation of the sorbents requires a high energy consumption. Noteworthy, the sample y-POP-A1 had relatively high $\mathrm{CO}_{2}$ adsorption capacities $\left(0.65 \mathrm{mmol} \mathrm{g}^{-1}\right.$ at $\left.0.15 \mathrm{bar} ; 1.50 \mathrm{mmol} \mathrm{g}^{-1} ; 273 \mathrm{~K}\right)$ and high $\mathrm{CO}_{2}$-over- $\mathrm{N}_{2}$ selectivity of $271(273 \mathrm{~K})$. The selectivity is comparable to some top-performing sorbents of amine-modified POPs [32], MOFs [66] and silica [67] that indicates the potential of using y-POP-A1 for efficient $\mathrm{CO}_{2}$ capture. In contrast, y-POP-A1 demonstrates a moderate $Q_{\text {st }}$ value of $46.8 \mathrm{~kJ} \mathrm{~mol}^{-1}$ at a low coverage of $\mathrm{CO}_{2}\left(0.2 \mathrm{mmol} \mathrm{g}^{-1}\right)$, which is much lower than those of amine-modified sorbents (mmen-CuBTTri: $96 \mathrm{~kJ} \mathrm{~mol}^{-1}$; [66] PP1-2-tren: $80 \mathrm{~kJ} \mathrm{~mol}^{-1}$; [37] NTU-1: $75 \mathrm{~kJ} \mathrm{~mol}^{-1}$; [35] PEI (40 wt\%) C PAF-5: $68.7 \mathrm{~kJ} \mathrm{~mol}^{-1}$ [38]; PPN-6-CH$-\mathrm{CH}_{2}$ TETA: $63 \mathrm{~kJ} \mathrm{~mol}^{-1}$ [32]). Therefore, the balanced effects of physisorption and chemisorption of $\mathrm{CO}_{2}$ on y-POP-A1 would offer both high separation efficiency and high energy efficiency for post-combustion capture of $\mathrm{CO}_{2}$ from flue gases.

Table 1. A summary of specific surface area $\left(\mathrm{S}_{\mathrm{BET}}\right), \mathrm{CO}_{2}$ adsorption capacity $(273 \mathrm{~K}), \mathrm{CO}_{2}$-over- $\mathrm{N}_{2}$ selectivity $(273 \mathrm{~K})$, and $Q_{\text {st }}$ of $\mathrm{CO}_{2}$ adsorption at the low coverage of $\mathrm{CO}_{2}$ for ynone-linked porous organic polymer (y-POP) and $y-\mathrm{POP}-\mathrm{NH}_{2}$ with different amine densities.

\begin{tabular}{|c|c|c|c|c|c|c|c|}
\hline \multirow{2}{*}{ Sample } & \multirow{2}{*}{$\begin{array}{l}\text { Amine } \\
\text { Loading }\end{array}$} & \multirow{2}{*}{$\begin{array}{c}\mathrm{S}_{\mathrm{BET}} \\
\left(\mathrm{m}^{2} \mathrm{~g}^{-1}\right)\end{array}$} & \multicolumn{2}{|c|}{$\mathrm{CO}_{2}$ Uptake (mmol g ${ }^{-1}$ ) } & \multicolumn{2}{|c|}{$\mathrm{CO}_{2} / \mathrm{N}_{2}$ Selectivity } & \multirow{2}{*}{$\underset{\left(\mathrm{kJ} \mathrm{mol}^{-1}\right)}{Q_{\mathrm{st}}}$} \\
\hline & & & 0.15 bar & $1 \mathrm{bar}$ & IAST & Henry's Law & \\
\hline $\mathrm{y}$-POP & 0 & 226 & 0.43 & 1.34 & 20 & 22 & 29.0 \\
\hline y-POP-A1 & $12 \%$ & 145 & 0.65 & 1.50 & 239 & 216 & 46.8 \\
\hline $\mathrm{y}-\mathrm{POP}-\mathrm{A} 2$ & $16 \%$ & 107 & 0.76 & 1.49 & 1083 & 750 & 62.2 \\
\hline $\mathrm{y}-\mathrm{POP}-\mathrm{A} 3$ & $19 \%$ & 84 & 1.11 & 1.95 & 4154 & 3806 & 76.5 \\
\hline
\end{tabular}

\section{Conclusions}

To conclude, a novel ynone-linked POP was synthesized and its molecular structure was fully characterized by IR and ${ }^{13} \mathrm{C}$ NMR spectroscopy. The polymer was further used as a substrate to tether alkyl amine species by post modification. The ex situ IR results revealed that the amine species on the polymers could induce chemisorption of $\mathrm{CO}_{2}$ with formation of ammonium carbamate ion pairs. As a result, the amine-modified polymers showed high $\mathrm{CO}_{2}$ adsorption capacities, high $\mathrm{CO}_{2}$-over- $\mathrm{N}_{2}$ selectivity, as well as high $Q_{\text {st }}$ values. Remarkably, the amine density on the polymers can be finely controlled by a molecular engineering approach, which allows balancing the physisorption and chemisorption of $\mathrm{CO}_{2}$ to reach a high separation efficiency, excellent recyclability, high energy efficiency for $\mathrm{CO}_{2}$ capture and separation. The use of this strategy in the design of amine-modified porous solids (e.g., mesoporous silica, MOFs, clay, etc.) would offer highly efficient sorbents for post-combustion capture of $\mathrm{CO}_{2}$.

Supplementary Materials: The following are available online at http://www.mdpi.com/2079-4991/9/7/1020/s1. Figure S1. Thermogravimetric analysis curves of y-POP and y-POP-NH2. Figure S2. Solid-state 13C NMR spectra of y-POP, y-POP-A1, y-POP-A2, and y-POP-A3. Figure S3. SEM images of y-POP, y-POP-A1, y-POP-A2, and $y-P O P-A 3$. Figure S4. Powder X-ray diffraction patterns of $y-P O P$ and $y-P O P-N H 2$ showing the polymers are mainly amorphous. Figure S5. $\mathrm{CO}_{2}$ adsorption isotherms of y-POP, y-POP-A1, y-POP-A2, and y-POP-A3 recorded at $293 \mathrm{~K}$. Figure S6. CO $\mathrm{CO}_{2}$ adsorption-desorption cycles for y-POP-A1 recorded at $293 \mathrm{~K}$. Figure S7. $\mathrm{N}_{2}$ adsorption isotherms of y-POP, y-POP-A1, y-POP-A2, and y-POP-A3 recorded at $273 \mathrm{~K}$. Figure S8. $\mathrm{CO}_{2}(\boldsymbol{\square})$ and $\mathrm{N}_{2}(\mathbf{\Lambda})$ adsorption data and of $\mathrm{y}$-POP and $\mathrm{y}-\mathrm{POP}-\mathrm{NH} 2$ recorded at $273 \mathrm{~K}$. The red solid lines show the fitting results of the data: The $\mathrm{CO}_{2}$ and $\mathrm{N}_{2}$ adsorption data was fitted by a dual-site and single-site Langmuir model, respectively. Detail fitting results are given in Table $\mathrm{S} 1$. The fitted parameters from the single adsorption data were used to predict the IAST selectivity. Figure S9. The $\mathrm{CO}_{2}$ and $\mathrm{N}_{2}$ adsorption data of (a) y-POP, (b) y-POP-A1, (c) y-POP-A2, and (d) y-POP-A3 at low partial pressures at $273 \mathrm{~K}$ and the linearly fitted results. Henry's law $\mathrm{CO}_{2}$-over- $\mathrm{N}_{2}$ 
selectivities were calculated from the initial slopes of the $\mathrm{CO}_{2}$ and $\mathrm{N}_{2}$ isotherms. Table S1. Fitting parameters for the $\mathrm{CO}_{2}$ and $\mathrm{N}_{2}$ adsorption data recorded at $273 \mathrm{~K}$. Scheme $\mathrm{S} 1$. Possible mechanism of chemisorption of $\mathrm{CO}_{2}$ on $\mathrm{y}$-POP-NH2 with high amine loadings.

Author Contributions: X.K. and S.L. contributed equally to this work. Synthesis and characterization: X.K., S.L., C.X.; Data analysis: X.K., S.L., M.S., and C.X.; Writing: M.S. and C.X.

Funding: This research was funded by the Åforsk research grant, STINT (The Swedish Foundation for International Cooperation in Research and Higher Education) initiation grant, the Natural Science Foundation of Jiangsu Province (BK20170994), and the Natural Science Fund for Colleges and Universities in Jiangsu Province (17KJB430018).

Acknowledgments: We thank Samson Afewerki for valuable discussions.

Conflicts of Interest: The authors declare no conflict of interest.

\section{References}

1. Climate Change 2014: Synthesis Report; Contribution of Working Groups I, II and III to the Fifth Assessment Report of the Intergovernmental Panel on Climate Change; IPCC: Geneva, Switzerland, 2014.

2. Haszeldine, R.S. Carbon Capture and Storage: How Green Can Black Be? Science 2009, 325, 1647-1652. [CrossRef]

3. Agarwal, A.; Biegler, L.T.; Zitney, S.E. A superstructure-based optimal synthesis of PSA cycles for post-combustion $\mathrm{CO}_{2}$ capture. AlChE J. 2010, 56, 1813-1828. [CrossRef]

4. Rochelle, G.T. Amine scrubbing for $\mathrm{CO}_{2}$ capture. Science 2009, 325, 1652-1654. [CrossRef]

5. CCS in Norway Entering a New Phase. Available online: https://www.gassnova.no/en/ccs-in-norwayentering-a-new-phase (accessed on 29 June 2018).

6. D'Alessandro, D.M.; Smit, B.; Long, J.R. Carbon Dioxide Capture: Prospects for New Materials. Angew. Chem. Int. Ed. 2010, 49, 6058-6082. [CrossRef]

7. Samanta, A.; Zhao, A.; Shimizu, G.K.H.; Sarkar, P.; Gupta, R. Post-Combustion $\mathrm{CO}_{2}$ Capture Using Solid Sorbents: A Review. Ind. Eng. Chem. Res. 2012, 51, 1438-1463. [CrossRef]

8. Chue, K.T.; Kim, J.N.; Yoo, Y.J.; Cho, S.H.; Yang, R.T. Comparison of Activated Carbon and Zeolite 13X for $\mathrm{CO}_{2}$ Recovery from Flue Gas by Pressure Swing Adsorption. Ind. Eng. Chem. Res. 1995, 34, 591-598. [CrossRef]

9. Zhao, J.; Xie, K.; Singh, R.; Xiao, G.; Gu, Q.; Zhao, Q.; Li, G.; Xiao, P.; Webley, P.A. Li+/ZSM-25 Zeolite as a $\mathrm{CO}_{2}$ Capture Adsorbent with High Selectivity and Improved Adsorption Kinetics, Showing $\mathrm{CO}_{2}$-Induced Framework Expansion. J. Phys. Chem. C 2018, 122, 18933-18941. [CrossRef]

10. Jiang, Y.; Ling, J.; Xiao, P.; He, Y.; Zhao, Q.; Chu, Z.; Liu, Y.; Li, Z.; Webley, P.A. Simultaneous biogas purification and $\mathrm{CO}_{2}$ capture by vacuum swing adsorption using zeolite NaUSY. Chem. Eng. J. 2018, 334, 2593-2602. [CrossRef]

11. Sethia, G.; Sayari, A. Comprehensive study of ultra-microporous nitrogen-doped activated carbon for $\mathrm{CO}_{2}$ capture. Carbon 2015, 93, 68-80. [CrossRef]

12. Sevilla, M.; Mokaya, R.; Al-Jumialy, A.S.M.; Fuertes, A.B. Optimization of the Pore Structure of Biomass-Based Carbons in Relation to Their Use for $\mathrm{CO}_{2}$ Capture under Low- and High-Pressure Regimes. ACS Appl. Mater. Interfaces 2018, 10, 1623-1633. [CrossRef]

13. Xu, C.; Ruan, C.-Q.; Li, Y.; Lindh, J.; Strømme, M. High-Performance Activated Carbons Synthesized from Nanocellulose for $\mathrm{CO}_{2}$ Capture and Extremely Selective Removal of Volatile Organic Compounds. Adv. Sustain. Syst. 2018, 2, 1700147. [CrossRef]

14. Xu, C.; Strømme, M. Sustainable Porous Carbon Materials Derived from Wood-Based Biopolymers for $\mathrm{CO}_{2}$ Capture. Nanomaterials 2019, 9, 103. [CrossRef]

15. Nugent, P.; Belmabkhout, Y.; Burd, S.D.; Cairns, A.J.; Luebke, R.; Forrest, K.; Pham, T.; Ma, S.; Space, B.; Wojtas, L.; et al. Porous materials with optimal adsorption thermodynamics and kinetics for $\mathrm{CO}_{2}$ separation. Nature 2013, 495, 80-84. [CrossRef]

16. Xiang, S.; He, Y.; Zhang, Z.; Wu, H.; Zhou, W.; Krishna, R.; Chen, B. Microporous metal-organic framework with potential for carbon dioxide capture at ambient conditions. Nat. Commun. 2012, 3, 954. [CrossRef]

17. McDonald, T.M.; Mason, J.A.; Kong, X.; Bloch, E.D.; Gygi, D.; Dani, A.; Crocellà, V.; Giordanino, F.; Odoh, S.O.; Drisdell, W.S.; et al. Cooperative insertion of $\mathrm{CO}_{2}$ in diamine-appended metal-organic frameworks. Nature 2015, 519, 303-308. [CrossRef] 
18. Chen, Q.; Luo, M.; Hammershøj, P.; Zhou, D.; Han, Y.; Laursen, B.W.; Yan, C.-G.; Han, B.-H. Microporous Polycarbazole with High Specific Surface Area for Gas Storage and Separation. J. Am. Chem. Soc. 2012, 134, 6084-6087. [CrossRef]

19. Dawson, R.; Stöckel, E.; Holst, J.R.; Adams, D.J.; Cooper, A.I. Microporous organic polymers for carbon dioxide capture. Energy Environ. Sci. 2011, 4, 4239-4245. [CrossRef]

20. Shan, M.; Liu, X.; Wang, X.; Yarulina, I.; Seoane, B.; Kapteijn, F.; Gascon, J. Facile manufacture of porous organic framework membranes for precombustion $\mathrm{CO}_{2}$ capture. Sci. Adv. 2018, 4, eaau1698. [CrossRef]

21. Yan, J.; Zhang, B.; Wang, Z. Highly Selective Separation of $\mathrm{CO}_{2}, \mathrm{CH}_{4}$, and $\mathrm{C}_{2}-\mathrm{C}_{4}$ Hydrocarbons in Ultramicroporous Semicycloaliphatic Polyimides. ACS Appl. Mater. Interfaces 2018, 10, 26618-26627. [CrossRef]

22. Gao, H.; Ding, L.; Bai, H.; Li, L. Microporous Organic Polymers Based on Hyper-Crosslinked Coal Tar: Preparation and Application for Gas Adsorption. ChemSusChem 2017, 10, 618-623. [CrossRef]

23. Tan, M.X.; Zhang, Y.; Ying, J. Mesoporous Poly(Melamine-Formaldehyde) Solid Sorbent for Carbon Dioxide Capture. ChemSusChem 2013, 6, 1186-1190. [CrossRef]

24. Xu, C.; Hedin, N. Microporous adsorbents for $\mathrm{CO}_{2}$ capture - a case for microporous polymers? Mater. Today 2014, 17, 397-403. [CrossRef]

25. Chaoui, N.; Trunk, M.; Dawson, R.; Schmidt, J.; Thomas, A. Trends and challenges for microporous polymers. Chem. Soc. Rev. 2017, 46, 3302-3321. [CrossRef]

26. Rabbani, M.G.; El-Kaderi, H.M. Template-Free Synthesis of a Highly Porous Benzimidazole-Linked Polymer for $\mathrm{CO}_{2}$ Capture and H2Storage. Chem. Mater. 2011, 23, 1650-1653. [CrossRef]

27. Lu, W.; Yuan, D.; Sculley, J.; Zhao, D.; Krishna, R.; Zhou, H.-C. Sulfonate-Grafted Porous Polymer Networks for Preferential $\mathrm{CO}_{2}$ Adsorption at Low Pressure. J. Am. Chem. Soc. 2011, 133, 18126-18129. [CrossRef]

28. Xie, L.-H.; Suh, M.P.; Xie, L. High $\mathrm{CO}_{2}$-Capture Ability of a Porous Organic Polymer Bifunctionalized with Carboxy and Triazole Groups. Chem. A Eur. J. 2013, 19, 11590-11597. [CrossRef]

29. Mohanty, P.; Kull, L.D.; Landskron, K. Porous covalent electron-rich organonitridic frameworks as highly selective sorbents for methane and carbon dioxide. Nat. Commun. 2011, 2, 401. [CrossRef]

30. Dawson, R.; Cooper, A.I.; Adams, D.J. Chemical functionalization strategies for carbon dioxide capture in microporous organic polymers. Polym. Int. 2013, 62, 345-352. [CrossRef]

31. Haikal, R.R.; Hassan, Y.S.; Emwas, A.-H.; Belmabkhout, Y.; Alkordi, M.H. Poly-functional porous-organic polymers to access functionality- $\mathrm{CO}_{2}$ sorption energetic relationships. J. Mater. Chem. A 2015, 3, 22584-22590.

32. Lu, W.; Sculley, J.P.; Yuan, D.; Krishna, R.; Wei, Z.; Zhou, H.-C. Polyamine-Tethered Porous Polymer Networks for Carbon Dioxide Capture from Flue Gas. Angeww. Chem. Int. Ed. 2012, 51, 7480-7484. [CrossRef]

33. Guillerm, V.; Weselinski, L.J.; Alkordi, M.; Mohideen, M.I.H.; Belmabkhout, Y.; Cairns, A.J.; Eddaoudi, M. Porous organic polymers with anchored aldehydes: A new platform for post-synthetic amine functionalization en route for enhanced $\mathrm{CO}_{2}$ adsorption properties. Chem. Commun. 2014, 50, 1937. [CrossRef]

34. Ratvijitvech, T.; Dawson, R.; Laybourn, A.; Khimyak, Y.Z.; Adams, D.J.; Cooper, A.I. Post-synthetic modification of conjugated microporous polymers. Polymer 2014, 55, 321-325. [CrossRef]

35. Sun, L.-B.; Kang, Y.-H.; Shi, Y.-Q.; Jiang, Y.; Liu, X.-Q. Highly Selective Capture of the Greenhouse Gas $\mathrm{CO}_{2}$ in Polymers. ACS Sustain. Chem. Eng. 2015, 3, 3077-3085. [CrossRef]

36. Puthiaraj, P.; Lee, Y.-R.; Ahn, W.-S. Microporous amine-functionalized aromatic polymers and their carbonized products for $\mathrm{CO}_{2}$ adsorption. Chem. Eng. J. 2017, 319, 65-74. [CrossRef]

37. Xu, C.; Bacsik, Z.; Hedin, N. Adsorption of $\mathrm{CO}_{2}$ on a micro-/mesoporous polyimine modified with tris(2-aminoethyl)amine. J. Mater. Chem. A 2015, 3, 16229-16234. [CrossRef]

38. Sung, S.; Suh, M.P. Highly efficient carbon dioxide capture with a porous organic polymer impregnated with polyethylenimine. J. Mater. Chem. A 2014, 2, 13245-13249. [CrossRef]

39. Lu, W.; Sculley, J.P.; Yuan, D.; Krishna, R.; Zhou, H.-C. Carbon Dioxide Capture from Air Using Amine-Grafted Porous Polymer Networks. J. Phys. Chem. C 2013, 117, 4057-4061. [CrossRef]

40. Hedin, N.; Andersson, L.; Bergström, L.; Yan, J. Adsorbents for the post-combustion capture of $\mathrm{CO}_{2}$ using rapid temperature swing or vacuum swing adsorption. Appl. Energy 2013, 104, 418-433. [CrossRef]

41. Xu, Y.; Jin, S.; Xu, H.; Nagai, A.; Jiang, D. Conjugated microporous polymers: Design, synthesis and application. Chem. Soc. Rev. 2013, 42, 8012. [CrossRef] 
42. Ben, T.; Ren, H.; Ma, S.; Cao, D.; Lan, J.; Jing, X.; Wang, W.; Xu, J.; Deng, F.; Simmons, J.M.; et al. Targeted Synthesis of a Porous Aromatic Framework with High Stability and Exceptionally High Surface Area. Angew. Chem. Int. Ed. 2009, 48, 9457-9460. [CrossRef]

43. Sprick, R.S.; Jiang, J.-X.; Bonillo, B.; Ren, S.; Ratvijitvech, T.; Guiglion, P.; Zwijnenburg, M.A.; Adams, D.J.; Cooper, A.I. Tunable Organic Photocatalysts for Visible-Light-Driven Hydrogen Evolution. J. Am. Chem. Soc. 2015, 137, 3265-3270. [CrossRef]

44. Chen, L.; Honsho, Y.; Seki, S.; Jiang, D. Light-Harvesting Conjugated Microporous Polymers: Rapid and Highly Efficient Flow of Light Energy with a Porous Polyphenylene Framework as Antenna. J. Am. Chem. Soc. 2010, 132, 6742-6748. [CrossRef]

45. Jiang, J.-X.; Su, F.; Niu, H.; Wood, C.D.; Campbell, N.L.; Khimyak, Y.Z.; Cooper, A.I. Conjugated microporous poly(phenylene butadiynylene)s. Chem. Commun. 2008, 486-488. [CrossRef]

46. Jiang, J.-X.; Su, F.; Trewin, A.; Wood, C.D.; Campbell, N.L.; Niu, H.; Dickinson, C.; Ganin, A.Y.; Rosseinsky, M.J.; Khimyak, Y.Z.; et al. Conjugated Microporous Poly(aryleneethynylene) Networks. Angew. Chem. Int. Ed. 2007, 46, 8574-8578. [CrossRef]

47. Choi, J.; Ko, J.H.; Kang, C.W.; Lee, S.M.; Kim, H.J.; Ko, Y.-J.; Yang, M.; Son, S.U. Enhanced redox activity of a hollow conjugated microporous polymer through the generation of carbonyl groups by carbonylative Sonogashira coupling. J. Mater. Chem. A 2018, 6, 6233-6237. [CrossRef]

48. Karabiyikoglu, S.; Kelgokmen, Y.; Zora, M. Facile synthesis of iodopyridines from N-propargylic $\beta$-enaminones via iodine-mediated electrophilic cyclization. Tetrahedron 2015, 71, 4324-4333. [CrossRef]

49. Kelgokmen, Y.; Zora, M. Facile synthesis of heavily-substituted alkynylpyridines via a Sonogashira approach. RSC Adv. 2016, 6, 4608-4621. [CrossRef]

50. Hoven, B.G.V.D.; Alper, H. Innovative Synthesis of 4-Carbaldehydepyrrolin-2-ones by Zwitterionic Rhodium Catalyzed Chemo- and Regioselective Tandem Cyclohydrocarbonylation/CO Insertion of $\alpha$-Imino Alkynes. J. Am. Chem. Soc. 2001, 123, 10214-10220. [CrossRef]

51. Waldo, J.P.; LaRock, R.C. The Synthesis of Highly Substituted Isoxazoles by Electrophilic Cyclization. An Efficient Synthesis of Valdecoxib. J. Org. Chem. 2007, 72, 9643-9647. [CrossRef]

52. Liu, X.; Hong, D.; She, Z.; Hersh, W.H.; Yoo, B.; Chen, Y. Complementary regioselective synthesis of 3,5-disubstituted isoxazoles from ynones. Tetrahedron 2018, 74, 6593-6606. [CrossRef]

53. Socrates, G. Infrared and Raman Characteristic Group Frequencies: Tables and Charts; John Wiley \& Sons: Hoboken, NJ, USA, 2004.

54. $\mathrm{Xu}, \mathrm{C}$; Hedin, N. Synthesis of microporous organic polymers with high $\mathrm{CO}_{2}$-over- $\mathrm{N}_{2}$ selectivity and $\mathrm{CO}_{2}$ adsorption. J. Mater. Chem. A 2013, 1, 3406. [CrossRef]

55. Bacsik, Z.; Atluri, R.; Garcia-Bennett, A.E.; Hedin, N. Temperature-Induced Uptake of $\mathrm{CO}_{2}$ and Formation of Carbamates in Mesocaged Silica Modified with n-Propylamines. Langmuir 2010, 26, 10013-10024. [CrossRef]

56. Knoöfel, C.; Martin, C.; Hornebecq, V.; Llewellyn, P.L. Study of Carbon Dioxide Adsorption on Mesoporous Aminopropylsilane-Functionalized Silica and Titania Combining Microcalorimetry and in Situ Infrared Spectroscopy. J. Phys. Chem. C 2009, 113, 21726-21734.

57. Danon, A.; Stair, P.C.; Weitz, E. FTIR Study of $\mathrm{CO}_{2}$ Adsorption on Amine-Grafted SBA-15: Elucidation of Adsorbed Species. J. Phys. Chem. C 2011, 115, 11540-11549. [CrossRef]

58. Aziz, B.; Hedin, N.; Bacsik, Z. Quantification of chemisorption and physisorption of carbon dioxide on porous silica modified by propylamines: Effect of amine density. Micropor. Mesopor. Mater. 2012, 159, 42-49. [CrossRef]

59. Fu, F.-N.; DeOliveira, D.B.; Trumble, W.R.; Sarkar, H.K.; Singh, B.R. Secondary Structure Estimation of Proteins Using the Amide III Region of Fourier Transform Infrared Spectroscopy: Application to Analyze Calcium-Binding-Induced Structural Changes in Calsequestrin. Appl. Spectrosc. 1994, 48, 1432-1441. [CrossRef]

60. Wang, X.; Schwartz, V.; Clark, J.C.; Ma, X.; Overbury, S.H.; Xu, X.; Song, C. Infrared Study of $\mathrm{CO}_{2}$ Sorption over "Molecular Basket" Sorbent Consisting of Polyethylenimine-Modified Mesoporous Molecular Sieve. J. Phys. Chem. C 2009, 113, 7260-7268. [CrossRef]

61. Hiyoshi, N.; Yogo, K.; Yashima, T. Adsorption characteristics of carbon dioxide on organically functionalized SBA-15. Micropor. Mesopor. Mater. 2005, 84, 357-365. [CrossRef] 
62. Bacsik, Z.; Ahlsten, N.; Ziadi, A.; Zhao, G.; Garcia-Bennett, A.E.; Martín-Matute, B.; Hedin, N. Mechanisms and Kinetics for Sorption of $\mathrm{CO}_{2}$ on Bicontinuous Mesoporous Silica Modified with n-Propylamine. Langmuir 2011, 27, 11118-11128. [CrossRef]

63. Huang, H.Y.; Yang, R.T.; Chinn, D.; Munson, C.L. Amine-Grafted MCM-48 and Silica Xerogel as Superior Sorbents for Acidic Gas Removal from Natural Gas. Ind. Eng. Chem. Res. 2003, 42, 2427-2433. [CrossRef]

64. Myers, A.L.; Prausnitz, J.M. Thermodynamics of mixed-gas adsorption. AIChE J. 1965, 11, 121-127. [CrossRef]

65. Patel, H.H.A.; Byun, J.; Yavuz, C.T. Carbon Dioxide Capture Adsorbents: Chemistry and Methods. ChemSusChem 2017, 10, 1303-1317. [CrossRef] [PubMed]

66. McDonald, T.M.; D'Alessandro, D.M.; Krishna, R.; Long, J.R. Enhanced carbon dioxide capture upon incorporation of $\mathrm{N}, \mathrm{N}^{\prime}$-dimethylethylenediamine in the metal-organic framework CuBTTri. Chem. Sci. 2011, 2, 2022-2028. [CrossRef]

67. Choi, S.; Gray, M.L.; Jones, C.W. Amine-Tethered Solid Adsorbents Coupling High Adsorption Capacity and Regenerability for $\mathrm{CO}_{2}$ Capture from Ambient Air. ChemSusChem 2011, 4, 628-635. [CrossRef] [PubMed]

(C) 2019 by the authors. Licensee MDPI, Basel, Switzerland. This article is an open access article distributed under the terms and conditions of the Creative Commons Attribution (CC BY) license (http://creativecommons.org/licenses/by/4.0/). 

Article

\title{
Near-Infrared Surface-Enhanced Raman Scattering on Silver-Coated Porous Silicon Photonic Crystals
}

\author{
Marko Škrabić ${ }^{1,2}$, Marin Kosović ${ }^{3}$, Marijan Gotić ${ }^{2,4}$, Lara Mikac ${ }^{2,4}$, Mile Ivanda ${ }^{2,4, *(\mathbb{D})}$ and \\ Ozren Gamulin 1,2,* \\ 1 Department of Physics and Biophysics, School of Medicine, University of Zagreb, Šalata 3b, \\ 10000 Zagreb, Croatia; marko.skrabic@mef.hr \\ 2 Research Unit New Functional Materials, Center of Excellence for Advanced Materials and Sensing Devices, \\ Bijenička cesta 54, 10000 Zagreb, Croatia; marijan.gotic@irb.hr (M.G.); lara.mikac@irb.hr (L.M.) \\ 3 Faculty of Science, University of Split, Ruđera Boškovića 33, 21000 Split, Croatia; marin.kosovic@pmfst.hr \\ 4 Laboratory for Molecular Physics, Division of Materials Physics, Ruđer Bošković Institute, Bijenička cesta 54, \\ 10000 Zagreb, Croatia \\ * Correspondence: ivanda@irb.hr (M.I.); ozren@mef.hr (O.G.); \\ Tel.: +385-1-4560928 (M.I.); +385-1-4566761 (O.G.)
}

Received: 25 January 2019; Accepted: 6 March 2019; Published: 12 March 2019

\begin{abstract}
Surface-enhanced Raman scattering (SERS) with near-infrared (NIR) excitation offers a safe way for the detection and study of fragile biomolecules. In this work, we present the possibility of using silver-coated porous silicon photonic crystals as SERS substrates for near-infrared (1064 nm) excitation. Due to the deep penetration of NIR light inside silicon, the fabrication of photonic crystals was necessary to quench the band gap photoluminescence of silicon crystal, which acts as mechanical support for the porous layer. Optimal parameters of the immersion plating process that gave maximum enhancement were found and the activity of SERS substrates was tested using rhodamine 6G and crystal violet dye molecules, yielding significant SERS enhancement for off-resonant conditions. To our knowledge, this is the first time that the $1064 \mathrm{~nm}$ NIR laser excitation is used for obtaining the SERS effect on porous silicon as a substrate.
\end{abstract}

Keywords: SERS; near-infrared; crystal silicon photoluminescence; porous silicon photonic crystals; hot-spots

\section{Introduction}

Surface-enhanced Raman scattering (SERS) is an exceptionally powerful vibrational spectroscopy technique, which finds wide applications in the identification and structural studies of biological materials and chemical substances [1-3]. It has attracted a great deal of scientific interest due to a huge enhancement of the Raman signal from a small number of molecules near or bound to plasmonic surfaces, ultimately reaching single-molecule detection [4]. It is generally accepted that such a signal enhancement is attributed to the superposition of the two effects, the electromagnetic (EM) and the chemical enhancement mechanisms. The EM mechanism is dominant and originates from amplification of the EM fields on or in the immediate vicinity of roughened noble-metal surfaces generated by the excitation of localized surface plasmons, while the chemical mechanism results from charge-transfer between adsorbed molecules and the metal substrate, which increases the polarizability of molecules and thereby their Raman scattering cross-section [5].

Among the various promising SERS-active substrates [6], it has been shown that non-expensive, easy-to-fabricate, stable in air, uniform, reproducible, and highly sensitive SERS-active substrates can be produced using noble-metal nanoparticles deposited or grown on the porous silicon surface [7-13]. 
Recently, a thorough and perspicuous review about SERS on metal-coated porous silicon as a substrate has also been published [14].

Porous silicon (pSi), most commonly obtained on top of a crystalline silicon (cSi) wafer by its anodization in hydrofluoric acid (HF) solution, is a versatile nanostructured material known for its many unique optical, chemical, and physical properties and its corresponding usage [15]. By variation of the anodization parameters, porous layers with tunable pore sizes and thicknesses can be produced [16]. Moreover, the obtained vast active surface area has an inherent property to spontaneously reduce metallic ions, which have positive reduction potentials with respect to hydrogen when immersed in their aqueous solutions [17-19]. Utilizing this feature, immersion plating has become the most common method to coat $\mathrm{pSi}$ with certain metals ( $\mathrm{Ag}, \mathrm{Au}, \mathrm{Cu}$ ) and form SERS-active substrates due to its simplicity, low cost, and, most importantly, control of the substrate morphology by a precise variation of the deposition conditions [20-22].

So far, SERS measurements on pSi were conducted with excitation wavelengths in the visible spectral range, where the strongest Raman enhancement was expected due to the matching of the laser wavelength with the localized surface plasmon resonance of the metal/pSi substrates [23]. Extending the wavelength range to the near-infrared (NIR) at $1064 \mathrm{~nm}$, despite the loss of sensitivity due to the Raman's scattering fourth-power dependence on the excitation frequency, has advantages in the absence of resonance-Raman effects for the majority of molecules, the reduction of fluorescent photobleaching and plasmonic heating, as well as the avoidance of possible photodegradation of biological molecules [24-26].

Although NIR SERS with an excitation at $1064 \mathrm{~nm}$ has been demonstrated to be operative during the past 30 years [24,27-30], hitherto, metal-coated pSi was not used as an SERS-active substrate for NIR excitation. The main reason is probably the deep penetration of NIR light inside cSi or pSi [31,32], hence such an excitation induces the photoluminescence (PL) of the underlying $\mathrm{cSi}[33,34]$ due to the energy matching with the cSi band gap, and consequently the SERS signal is concealed with the broad PL peak. On the other hand, the usage of metal-coated free-standing $\mathrm{pSi}$ as the SERS substrate, obtained by the detachment of the porous layer from the underlying $\mathrm{cSi}$ wafer and subsequent metallization, although possible, does not meet standard SERS requirements for a robust substrate because of its pronouncedly fragile nature.

More than 20 years ago, pSi multilayers were produced [35,36] by the utilization of another of its important properties; the fact that already etched porous layers are not affected during the electrochemical anodization, i.e., cSi dissolution occurs only at the etching front, which is the interface between $\mathrm{pSi}$ and $\mathrm{cSi}$. Thus, by varying the current density applied during the etch process, the porosity can be modulated in the direction perpendicular to the pSi surface and, consequently, almost any refractive index-depth profile can be realized. This allows the fabrication of a variety of $\mathrm{pSi}$ structures with desired optical properties and with a wide range of applications, such as omnidirectional mirrors [37], chemical and biological sensors [38,39], waveguides [40], and biomolecular screening [41]. Among those, periodic structures that can control the propagation of a certain frequency range of light are called porous silicon photonic crystals ( $\mathrm{pSi} \mathrm{PhC}$ ) [42]. They are characterized by a high reflectivity stopband, which can be tuned to appear anywhere in the predetermined spectral region depending on the appropriate selection of fabrication parameters.

The aim of this study is the structural optimization of SERS-active silver-coated pSi substrate for NIR excitation. To obtain the SERS effect, pSi PhC with efficient reflectance in the NIR spectral range $(\sim 1064 \mathrm{~nm})$ that quenches the cSi substrate band gap PL had to be produced. Here, we report a detailed fabrication of porous silicon rugate filters ( $\mathrm{pSi} \mathrm{RFs}$ ) and subsequent synthesis of nanostructured silver (Ag) coating with appropriate morphology by immersion plating of $\mathrm{pSi}$ RFs in Ag salt aqueous solution. The SERS ability of such substrates was evaluated using aqueous/ethanolic solutions of rhodamine 6G (R6G) and crystal violet (CV) dyes at various concentrations. 


\section{Materials and Methods}

The cSi wafers used in this study were p-type, Boron doped, with a resistivity of $0.001-0.002 \mathrm{Ohm} \mathrm{cm}$, (100) crystal face orientation, and $525 \pm 25 \mu \mathrm{m}$ thickness, obtained from Prime Wafers Inc. Prior to anodization, the cSi wafers were cut into $\sim 4 \mathrm{~cm}^{2}$ squares and rinsed in acetone. The etching process was performed in a home-made Teflon electrochemical etch cell with an aluminium foil as a back contact and platinum mesh, suspended on a fixed height above the polished side of the cSi wafer, as a counter electrode. The exposed surface of the cSi wafer electrode was approximately $2.5 \mathrm{~cm}^{2}$, adjusted by an O-ring at the bottom of the cell. All pSi samples were obtained using a LabVIEW-controlled (National Instruments, Austin, TX, USA) current source (2601B SourceMeter, Kiethley Instruments Inc., Solon, OH, USA) in a solution composed of $40 \mathrm{wt} \%$. HF (Sigma Aldrich, Taufkirchen, Germany) and 99\% v/v ethanol in a volume ratio of $3: 1$.

To obtain reproducible surfaces prior to fabricating $\mathrm{pSi} \mathrm{PhC}$, a precleaning procedure on the $\mathrm{pSi}$ wafers was performed using a constant current density of $200 \mathrm{~mA} / \mathrm{cm}^{2}$ for $30 \mathrm{~s}$, followed by dissolving the sacrificial porous layer in $1 \mathrm{M} \mathrm{KOH}$ solution [16]. For pSi RFs, the current density was modulated with a sinusoidal waveform oscillating between 1 and $100 \mathrm{~mA} / \mathrm{cm}^{2}$ and repeated for 40 or 80 cycles. The periods were between 4.6 and $4.9 \mathrm{~s}$ and these conditions yielded a mesoporous structure with $64 \%$ porosity. For ordinary one-layer pSi samples, the anodization process was carried out using a constant current density of $50.5 \mathrm{~mA} / \mathrm{cm}^{2}$ with $200 \mathrm{~s}$ etching duration. After etching, the samples were rinsed twice in ethanol and dried under a gentle stream of nitrogen gas. Table 1 summarizes the characteristics of the samples used in this study. The porosity of the samples was determined gravimetrically by measuring the sample masses on a laboratory balance with a resolution of $10 \mu \mathrm{g}$. The thus prepared pSi and pSi RF samples remained attached to the cSi wafer substrate throughout the rest of the study.

Table 1. Preparation conditions for all used samples.

\begin{tabular}{cccc}
\hline Sample & $\mathbf{J}\left(\mathbf{m A} / \mathbf{c m}^{\mathbf{2}}\right)$ & Period $(\mathbf{s})$ & Cycles \\
\hline pSi S1 & 50.5 & $\mathrm{n} / \mathrm{a}$ & $\mathrm{n} / \mathrm{a}$ \\
RF S1 & $1-100$ & 4.6 & 40 \\
RF S2 & $1-100$ & 4.7 & 40 \\
RF S2a & $1-100$ & 4.7 & 80 \\
RF S3 & $1-100$ & 4.8 & 40 \\
RF S4 & $1-100$ & 4.9 & 40 \\
\hline
\end{tabular}

Just before the immersion plating procedure, the pSi and pSi RF samples were mechanically divided into small rectangles with a surface area of about $1-2 \mathrm{~mm}^{2}$ and dipped for $2 \mathrm{~min}$ in a $2 \mathrm{wt} \%$ HF solution to remove the native oxides from the surface, followed by rinsing with ethanol. Ag nanostructures were deposited on the top surface of a porous layer by immersing the prepared pSi and pSi RF samples into $10^{-2} \mathrm{M} \mathrm{AgNO}_{3}$ aqueous solution for 1 to $35 \mathrm{~min}$. The thus prepared SERS-active substrates were rinsed in water and left to dry in air. When necessary, the Ag-coated pSi and pSi RF samples were immersed into a $10 \mathrm{mM} \mathrm{HCl}$ solution for $10 \mathrm{~s}$ to remove any contaminant adsorption on a high surface area of Ag-coated pSi and pSi RF samples during the specimen preparation and storage.

As testing molecules for SERS R6G and CV were used; the stock $10^{-2} \mathrm{M}$ analyte solutions were prepared by dissolving the solid powder in 1:1 water/ethanol volume ratio. Different concentrations $\left(10^{-3} \mathrm{M}\right.$ to $\left.10^{-8} \mathrm{M}\right)$ were obtained by successive dilution of stock solutions. Ag-coated pSi and pSi RF samples were incubated for $30 \mathrm{~min}$ [43] in $200 \mu \mathrm{L}$ of the analyte solutions to realize molecule adsorption. After incubation, samples were thoroughly rinsed with water and left to dry in air.

Raman and SERS measurements were performed in backscattering geometry using a continuous-wave Nd:YAG $1064 \mathrm{~nm}$ laser $\left(9398 \mathrm{~cm}^{-1}\right)$ as an excitation source with a PerkinElmer GX FT-Raman spectrometer. The spectra were recorded by averaging 10-100 scans in the 3500-200 $\mathrm{cm}^{-1}$ 
range with a spectral resolution of $4 \mathrm{~cm}^{-1}$. The laser power used was between $250-500 \mathrm{~mW}$ to avoid the influence of possible heating while the spot size on the samples was about $0.25 \mathrm{~mm}$ in diameter.

The reflectance spectra of $\mathrm{pSi} \mathrm{PhC}$ were measured by a UV-Vis-NIR spectrophotometer (Shimadzu UV-3600, Shimadzu Corp., Kyoto, Japan) with the integrated sphere in the total reflectance mode over the spectral range of 300-2400 $\mathrm{nm}$ with a resolution of $1 \mathrm{~nm}$ and a normal angle of incidence.

The structural properties of samples were determined using a JEOL JSM-7000F (Jeol Ltd., Tokyo, Japan) thermal field emission scanning electron microscopy (FE-SEM) operating at 3 and $5 \mathrm{kV}$ accelerating voltage and with a working distance of $\sim 10 \mathrm{~mm}$.

All experimental procedures were done at room temperature. Millipore ultrapure water (Milli-Q, 18.2 $\mathrm{M} \Omega / \mathrm{cm}$ ) was exclusively used.

\section{Results and Discussion}

\subsection{Crystal Silicon Photoluminescence}

During the etch process, $\mathrm{pSi}$ is fabricated on top of the underlying cSi wafer, which mainly acts as mechanical support for the porous layer. The penetration depth of the near-infrared $1064 \mathrm{~nm}$ laser excitation used in this work, contrary to the visible lasers commonly used in SERS applications, is rather deep for silicon because of its low absorption coefficient at this wavelength [31], and therefore NIR light penetrates through the pSi into the cSi substrate. Since this excitation has a photon energy of $\sim 1.165 \mathrm{eV}$, which is just slightly above the band gap of cSi ( 1.115 eV at room temperature), strong cSi band gap PL is created due to radiative recombination of photogenerated charge carriers $[44,45]$. The pSi band gap is much wider [15], hence NIR light cannot induce its PL. Figure 1 shows the typical FT-Raman spectrum of pSi on top of the highly doped cSi substrate recorded with the near-infrared $1064 \mathrm{~nm}$ excitation. Superimposed on the broad PL background, only one sharp peak, located at $\sim 520 \mathrm{~cm}^{-1}$ relative to the excitation line and corresponding to the Raman scattering by transverse optical (TO) phonons at the center of the Brillouin zone of cSi is clearly distinguishable. Other visible, much broader peaks and a tailing PL emission have been associated with dislocation effects related to strain, impurities, or ground boundaries in the cSi $[33,45]$. Due to this broad PL band, it is not convenient to use such spectrum as a referent one for SERS measurements.

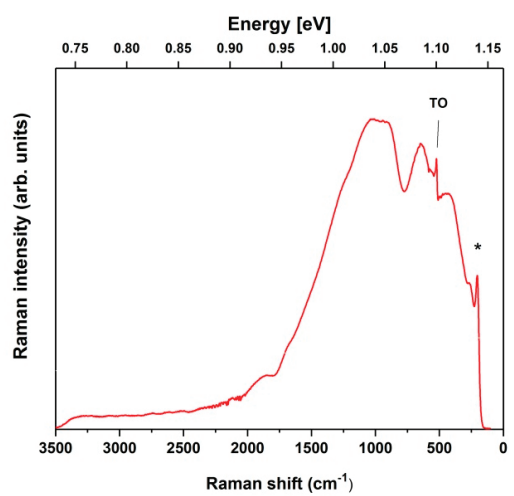

Figure 1. FT-Raman spectrum of pSi on top of highly doped cSi substrate. The band at $\sim 520 \mathrm{~cm}^{-1}$ due to the transverse optical phonons (TO) is shown. The band marked with an asterisk represents instrumental artifact.

To avoid the influence of the cSi substrate band gap PL, the porous layer can be detached from the cSi substrate during the final stages of the electrochemical etching process. Unfortunately, the thin films of free-standing pSi are extremely delicate to handle and are unfavourable for practical applications. Moreover, pSi samples with cSi bases can be easily diced to obtain the desired surface area for certain 
applications. Furthermore, cSi bases are important for possible technological applications, such as the integration of an SERS-active substrate with other elements on a single cSi wafer [15].

On the other hand, an additional possibility to eliminate undesirable cSi PL exists. As already briefly mentioned in the introduction section, the easiest and most common way to deposit Ag on pSi and thereby create SERS-active substrate is the immersion plating method. The spontaneous formation of $\mathrm{Ag}$ nanostructures on the surface of a pSi template during its immersion in $\mathrm{AgNO}_{3}$ solution proceeds in accordance to the Volmer-Weber mechanism and the model proposed by Harraz et al. [18]. The oxidation of the pSi surface occurs simultaneously with the $\mathrm{Ag}^{+}$ion reduction and the whole deposition process continues by Ag island nucleation and growth, resulting in an oxidized pSi layer coated with Ag nanoparticles (Ag NPs). Generally, it is known that the deposition conditions have a determinable effect on the properties of the SERS-active substrates. For instance, Saito et al. [46,47] used the silver mirror reaction to produce silver films on silicon and transparent borosilicate glass. The size of the silver colloidal particles in these films could be tightly controlled by varying the reaction conditions. In the present contribution, the parameters of the immersion procedure, along with the pore diameters, interpore distance, and the thickness of the spongiform pSi surface, have a crucial influence on the morphology (average size, density, and arrangement) of the uniformly deposited Ag NPs and hence on the Raman signal enhancement of the adsorbed molecules [8,20-22,43]. After fixing the parameters, such as the $\mathrm{AgNO}_{3}$ concentration and temperature, increasing the time of deposition leads to an increase of Ag NPs' size, aggregation of the Ag NPs to nanoclusters, and eventually nanocluster coalescence into a uniform layer. However, the deposition of metals is usually accompanied by the quenching of PL due to a fundamental disruption of the luminescence mechanism, increasing with the metal content in the layer [17,48], meaning that Ag crystals attract excited electrons, eliminating the possibility of recombination with holes. Moreover, metals are known for their high reflectivity in the NIR spectral region [49], hence prolonged Ag deposition leads to the formation of layers with efficient reflectance of the incoming $1064 \mathrm{~nm}$ laser excitation, thus preventing the cSi PL emergence.

Considering this, the pSi samples $\mathrm{S} 1$ were immersed in $10^{-2} \mathrm{M} \mathrm{AgNO}_{3}$ for different deposition times (1-35 $\mathrm{min}$ ). With the increase of the deposition time, a gradual color change of the pSi surface from light grey to shiny metallic was observed, indicating the formation of a thick uniform Ag layer. The Raman spectra for this sequence of $\mathrm{Ag} / \mathrm{pSi}$ samples are shown in Figure 2a. It is visible how cSi luminescence quenches with a longer exposure of samples to the Ag salt. To precisely determine the immersion time of the complete cSi PL disappearance, another set of Ag/pSi samples' Raman spectra was recorded and is shown in Figure $2 \mathrm{~b}$ with an expanded vertical axis, revealing that more than 30 min of dipping is needed.
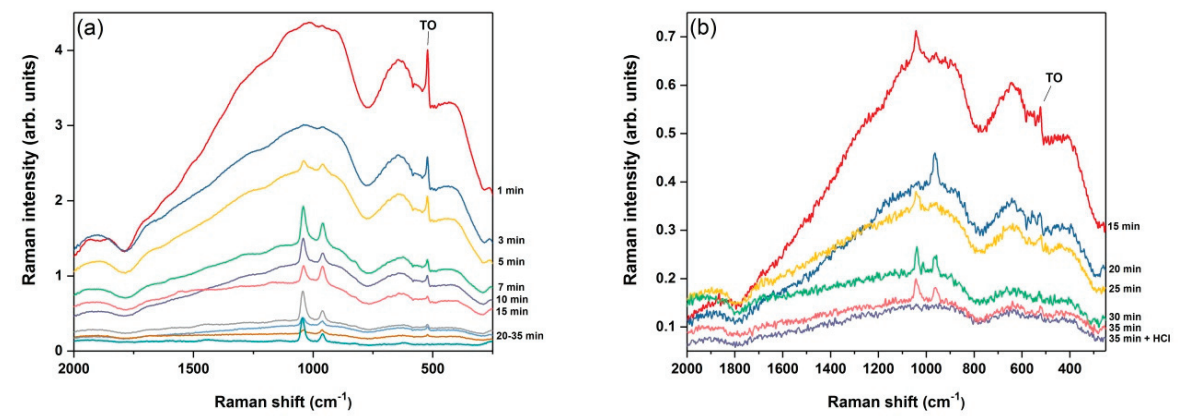

Figure 2. Comparison of FT-Raman spectra of pSi on top of a highly doped cSi substrate immersed in $10^{-2} \mathrm{AgNO}_{3}$ for different deposition times: (a) 1-35 min (50 scans), (b) 15-35 min (10 scans). 
Additionally, it can be seen that the TO cSi peak at $\sim 520 \mathrm{~cm}^{-1}$ decreases at the prolonged immersion times and disappears after $\sim 30 \mathrm{~min}$, which is direct evidence that laser excitation does not penetrate into the cSi substrate. Two sharp peaks (that are possibly unreacted $\mathrm{AgNO}_{3}$ or $\mathrm{Si}-\mathrm{O}$ vibrations) appearing at $\sim 960$ and $\sim 1042 \mathrm{~cm}^{-1}$ after 5 to 7 min of immersion were successfully removed by short dipping in a diluted hydrochloric acid solution. This cleaning process had no influence on the FT-Raman spectrum of Ag-coated pSi, as can also be seen in Figure $2 \mathrm{~b}$.

The morphology of the pSi surface and Ag NPs immobilized on it was examined by FE-SEM. Figure 3 a shows the top view FE-SEM image of pSi before immersion into Ag salt and reveals a dense mesoporous morphology with estimated average pore dimensions of $\sim 10 \mathrm{~nm}$. Figure $3 \mathrm{~b}-\mathrm{d}$ show the same sample after 30-min immersion into $10^{-2} \mathrm{M} \mathrm{AgNO}_{3}$ at different magnifications. It is visible that micrometer-sized Ag dendrites on top of the quasi-continuous Ag film cover the entire porous surface. At higher magnifications, it is evident that film formation consists of almost coalesced particles.
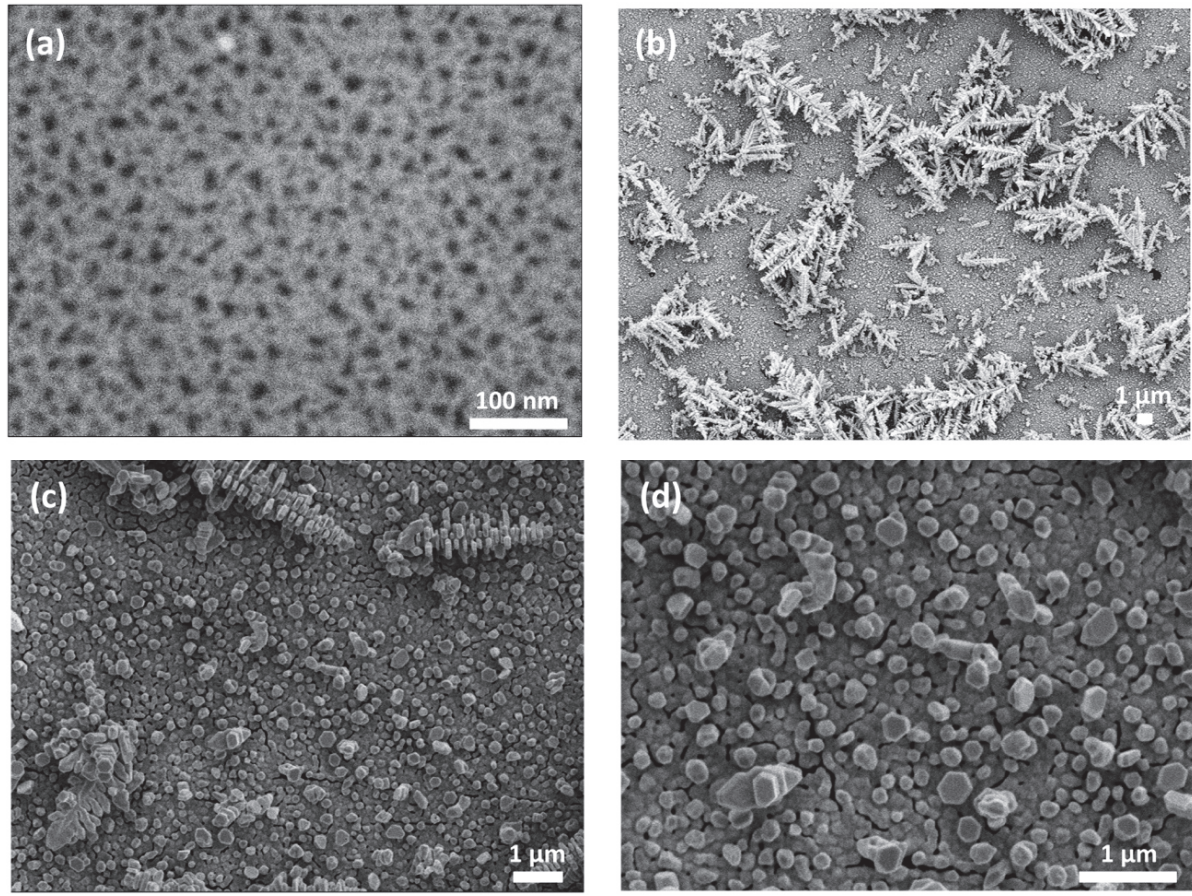

Figure 3. FE-SEM top view images of pSi S1 (a) mesoporous substrate prior to immersion in Ag salt; (b-d) micrographs of Ag particles formed on top of pSi by immersion plating for $30 \mathrm{~min}$ in $10^{-2} \mathrm{M}$ $\mathrm{AgNO}_{3}$ at three magnifications.

\subsection{Porous Silicon Photonic Crystals}

In this work, pSi PhC are utilized to block the penetration of $1064 \mathrm{~nm}$ NIR light into the $\mathrm{cSi}$ and hence inhibit the occurrence of the undesired cSi PL. During the electrochemical etching, the refractive index of $\mathrm{pSi}$, being itself a function of the material's porosity, is determined by the applied current density. A special class of $\mathrm{pSi} \mathrm{PhC}$, which has a continuous sinusoidal refractive index variation in the direction normal to the surface, iscalled pSi rugate filter (pSi RF) [50]. Compared to commonly used Bragg reflectors, which possess a slightly higher and wider reflectivity peak, usually called a stopband, pSi RF's individual layers are not required to be phase-matched, hence they are much simpler to 
fabricate. The spectral position of this reflectivity peak, which arises from the multiple reflections and interference in the periodic internal structure, is described by the equation:

$$
\lambda=2 n_{a v} d
$$

where $n_{a v}$ and $d$ are the average effective refractive index of the porous structure and the period of one sinusoidal oscillation, respectively. Thus, for a fixed difference of anodization currents, the reflectivity peak shifts toward higher wavelengths by increasing the spatial thickness of each layer, which is proportional to the period of an etch cycle [51]. The width of this resonance feature, sometimes also called the photonic band gap (PBG), depends solely on the refractive index contrast and for that reason, we used highly doped $\mathrm{cSi}$, whose porosity of the single layers can be tailored in a broader range compared to the less doped p-type cSi [36].

Figure 4 a shows the reflectance spectra of four pSi RFs prepared with the same etching conditions except slightly different sine periods. For fixed 40 sine cycles, the principal rugate stopband of the samples shifts from 1053 to $1132 \mathrm{~nm}$ as the period increases from 4.6 to $4.9 \mathrm{~s}$. The reflectance is maintained at $\sim 85 \%$ and the full width at half maximum of the reflection peaks vary between 160 and $200 \mathrm{~nm}$. Since we only considered the performance within the stopband, deviations from the ideal pSi RF structure were of no concern. For instance, higher-order harmonics with smaller amplitudes, visible approximately at integer multiples of the energy of the first stopband, can otherwise be suppressed by creating rugate filters with a sinusoidal modulation of the logarithm of the refractive index, $n$, with depth [52] Also, no apodization or index matching functions [53] were applied to the refractive index profiles to reduce interference oscillations (Fabry-Perot fringes) appearing on the higher-wavelength side of the stopband and arising from reflections at the air/pSi and pSi/cSi interfaces. Although increasing the number of sinusoid etch repetitions for a given fixed period reduces the width and increases the reflectivity of a principal band up to a certain limit [54], we observed different behaviour, as seen in Figure $4 \mathrm{~b}$. This is probably because of depth inhomogeneities of the optical thickness of single layers, caused by the conductivity and local changes of the HF concentration [55,56], which smears out the principal band for longer etching times [36].
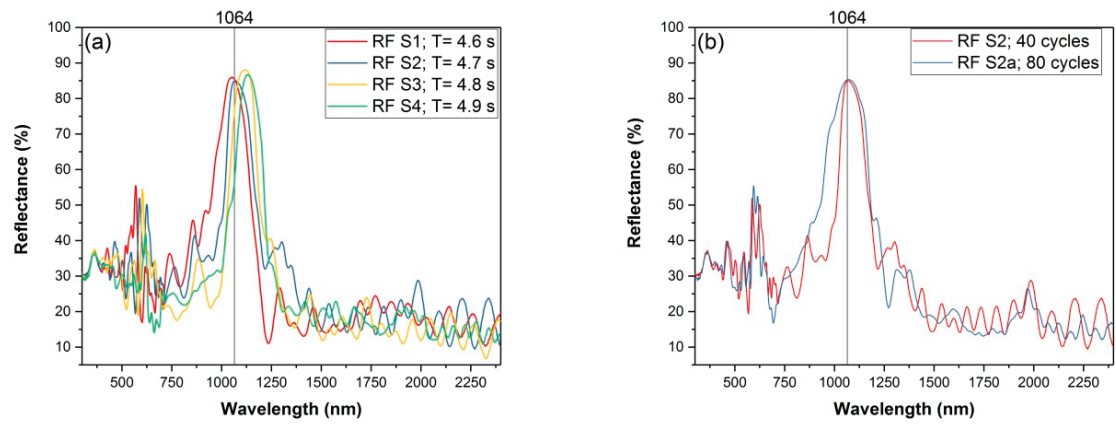

Figure 4. Reflectance spectra of pSi RFs (a) pSi RFs prepared using same sinusoidal current densities and same number of different periods (b) pSi RFs prepared with same period but different number of cycles. The vertical lines represent the wavelength of FT-Raman excitation (1064 nm).

To validate the programmed etch structure of the pSi RFs, cross-sectional FE-SEM images of sample RF S2 were recorded. As shown in Figure 5a,b, the rugate structure consisting of a sinusoidal porosity gradient with smooth interfaces in the direction perpendicular to the plane of the filter is visible. The higher and lower porosities, corresponding to larger and smaller current densities, can be clearly distinguished as darker and brighter zones. A periodic pattern is maintained over the whole layer, which consists of 40 periods with an overall thickness of $\sim 11.5 \mu \mathrm{m}$. It is also important to 
mention that the top surface of the pSi RFs strongly resemble the mesoporous surface of the pSi S1 shown in Figure $3 a$.
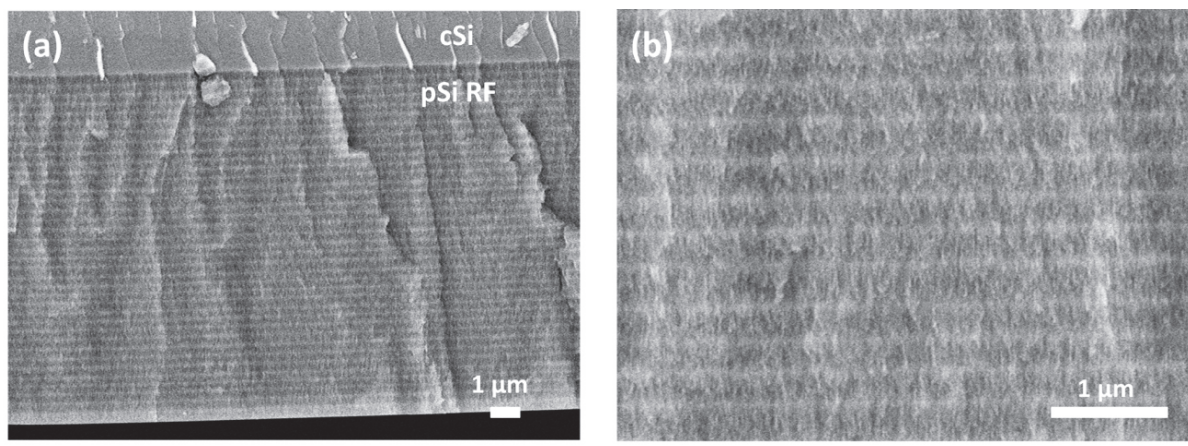

Figure 5. Cross-section FE-SEM images of an RF S2 consisting of 40 cycles recorded with two magnifications. (a) Low magnification image showing the whole rugate filter structure (b) High magnificationimage showing zones of different porosities in more detail.

As displayed in Figure 4, the excitation laser wavelength is aligned with the stopband of samples RF S1, RF S2, and RF S2a, hence the high reflection of the incoming light is expected. It is important to mention that no difference was observed for the Raman or SERS intensities of the probe molecules of all three aforementioned substrates, hence only the spectra obtained from sample RF S2 will be presented. Figure 6 presents a comparison of two FT-Raman spectra: Highly concentrated R6G $\left(10^{-2} \mathrm{M}\right)$ on samples of pSi S1 and RF S2, both on top of a highly doped cSi substrate, prior to Ag deposition. Although both spectra show a Raman TO peak at $520 \mathrm{~cm}^{-1}$, it can be concluded that the $\sim 85 \%$ reflectance on $1064 \mathrm{~nm}$ (visible on Figure 4) of sample RF S2 is enough to successfully quench cSi PL. Also visible are very small peaks corresponding to the most prominent bands of the probe molecule, R6G, exhibiting detection of $10^{-2} \mathrm{M}$ R6G on bare samples of pSi S1 and RF S2, i.e., without Ag coating. The same concentration was also barely detected for CV (not shown). Any Raman signal for concentrations lower than $10^{-2} \mathrm{M}$ of both analytes could not be detected.

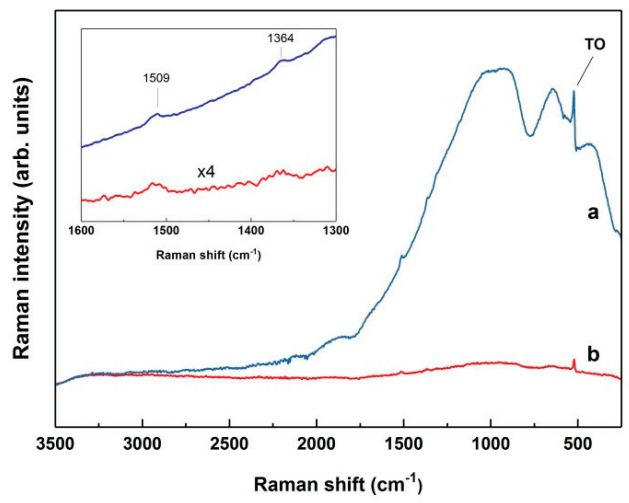

Figure 6. Comparison of FT-Raman spectra of the highest detectable R6G concentration of $\left(10^{-2} \mathrm{M}\right)$ on non-metallized samples: (a) pSi S1, (b) RF S2 (both 100 scans, $500 \mathrm{~mW}$ ). Wavenumber range of $1600-1300 \mathrm{~cm}^{-1}$ is magnified in inset. Two weak peaks at 1509 and $1364 \mathrm{~cm}^{-1}$ corresponding to the most prominent bands of R6G are visible. 


\subsection{SERS on Porous Silicon Photonic Crystals}

To optimize the immersion plating procedure that adjusts the Ag-coated pSi morphology for maximal SERS enhancement, RF S2 samples were immersed into $10^{-2} \mathrm{M} \mathrm{AgNO} 3$ for different deposition times (1-10 min) under a fixed solution temperature. This particular Ag salt concentration, according to previous works $[8,10,12,14,20,22]$, was revealed as optimal for the formation of a reproducible and highly effective SERS-active mesoporous silicon because of the fast yet controllable Ag deposition. Due to their well-characterized Raman features and adsorbability onto Ag NPs, we used commonly investigated dye molecules, R6G and CV, as the probe molecules for SERS detection. Figure 7a,b present the comparison of the SERS spectra obtained from the series of Ag-coated RF S2 samples synthesized with different dipping times using $10^{-4} \mathrm{M}$ R6G and CV, respectively. The strongest peak intensities were for both analytes obtained for an immersion duration of exactly 5 min, although the signal is rather strong in the 4-7 min range. For the other immersion times, a significant decrease in the signal intensities can be seen, which is more pronounced in the CV case probably due to the higher laser power used. Referring to Figure 2, it is also apparent that a deposition time of more than 30 min, which quenches the cSi PL on pSi sample S1, would yield a rather small (or none whatsoever) SERS signal, hence the necessity of pSi PhC utilization is further corroborated.
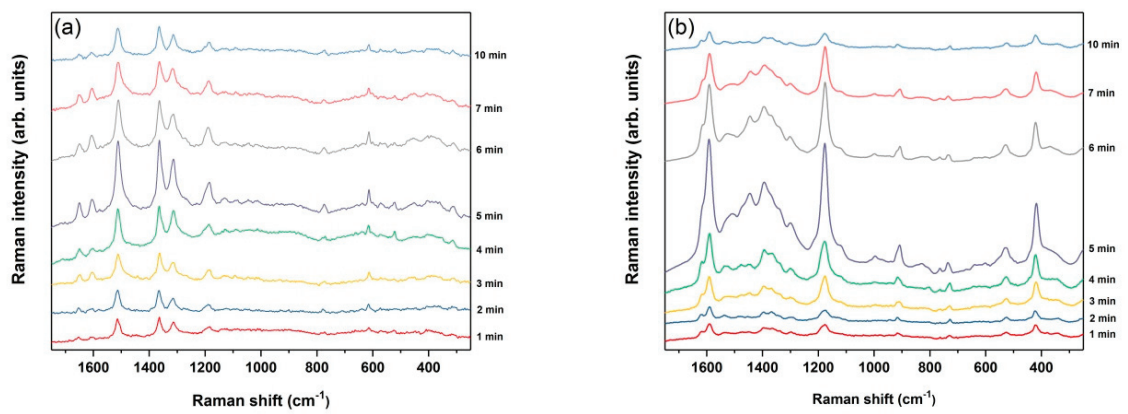

Figure 7. The SERS spectra of $10^{-4} \mathrm{M}$ (a) R6G (25 scans, $250 \mathrm{~mW}$ ) and (b) CV (50 scans, $500 \mathrm{~mW}$ ) molecules deposited on RF S2 samples immersed in $10^{-2} \mathrm{M} \mathrm{AgNO}_{3}$ for different times (1 to $10 \mathrm{~min}$ from bottom to top). Spectra are offset along the $y$-axis for clarity.

Since the SERS effects are related to the shape, size, and aggregation of Ag NPs, FE-SEM images of the sample RF S2 immersed in $10^{-2} \mathrm{M} \mathrm{AgNO}_{3}$ for 5 min were recorded and examined to reveal the optimal morphology of the Ag-coated pSi RF that produced maximal SERS enhancement. Figure 8a-c show the FE-SEM top-view images of the Ag NP-decorated sample, RF S2, and Figure 8d shows the corresponding cross-section image. Although several dendritic structures already formed by agglomeration can be seen, the 5-min immersion process led to the formation of a large number of randomly deposited, densely packed Ag NPs with a wide size distribution. Moreover, it can be inferred from Figure 8c that a new population of smaller NPs within the gaps between larger ones' forms, evidencing not only the presence of new nucleation sites for Ag NPs growth, but also a reduction of the gaps between NPs. These narrow gaps might explain the obtained signal enhancement since their presence is known to be essential in obtaining high SERS activity due to the existence of substantially enhanced local EM fields between them [57]. 

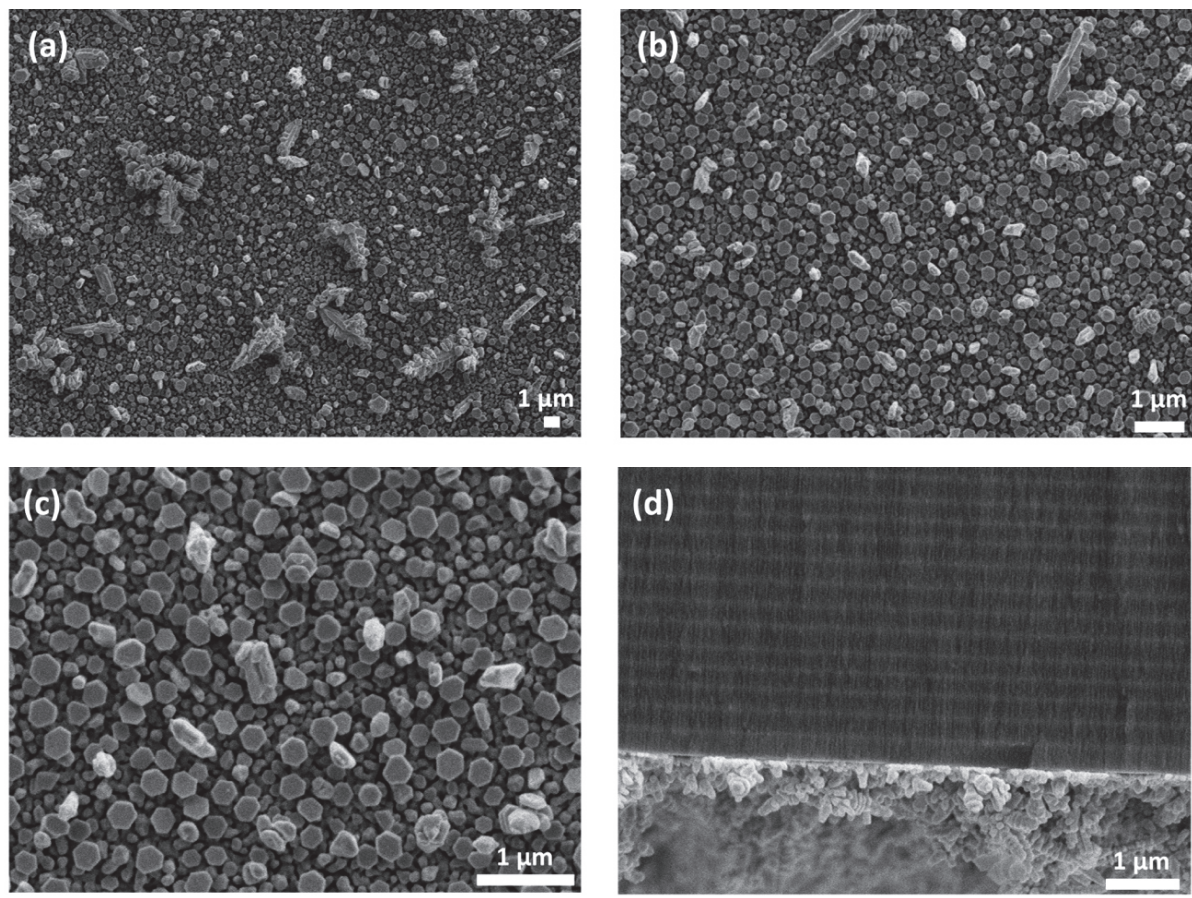

Figure 8. FE-SEM images of Ag NPs, formed on sample RF S2 by immersion plating for 5 min in $10^{-2} \mathrm{M} \mathrm{AgNO}_{3}$. (a-c) Top view micrographs at three magnifications; (d) cross-section view.

After finding the optimal duration of an immersion process that displayed the highest SERS sensitivity, a series of identical Ag-coated pSi samples RF S2 were soaked in different concentrations of R6G and CV in order to obtain the detection limit. The recorded SERS spectra of the probe molecules with decreasing concentrations are shown in Figure 9a,b. It is clearly visible that the minimum detectable concentration for R6G is $10^{-7} \mathrm{M}$ while for $\mathrm{CV}$ we managed to detect a two-times lower concentration of $5 \times 10^{-8} \mathrm{M}$. Although less intensive peaks are not detectable at the lowest concentrations, a few of the most prominent bands of R6G and CV are still well-resolved. They include $614 \mathrm{~cm}^{-1}$ (C-C-C ring), $1188 \mathrm{~cm}^{-1}$ (C-C stretching), $1314 \mathrm{~cm}^{-1}$ (CH deformation), $1364 \mathrm{~cm}^{-1}$ and $1509 \mathrm{~cm}^{-1}$ (both aromatic C-C stretching) for R6G [58,59]. For CV $416 \mathrm{~cm}^{-1}$ (C-C-C out-of-plane bending). $910 \mathrm{~cm}^{-1}$ (phenyl ring breathing mode), $1186 \mathrm{~cm}^{-1}$ (ring C-H in-plane bending), $1391 \mathrm{~cm}^{-1}$ (N-phenyl stretching), $1446 \mathrm{~cm}^{-1}$, and $1592 \mathrm{~cm}^{-1}$ (both ring C-C stretching) were apparent [12,60]. It is apparent that the positions of these most intense vibrations correlate with the reference peaks, although some small shifts are observed. A possible cause for these shifts might be the adsorption of the dyes with different orientations on the Ag NPs. Evident also are changes in the relative intensities of several SERS bands when comparing ours with reference spectra obtained using visible excitation. 

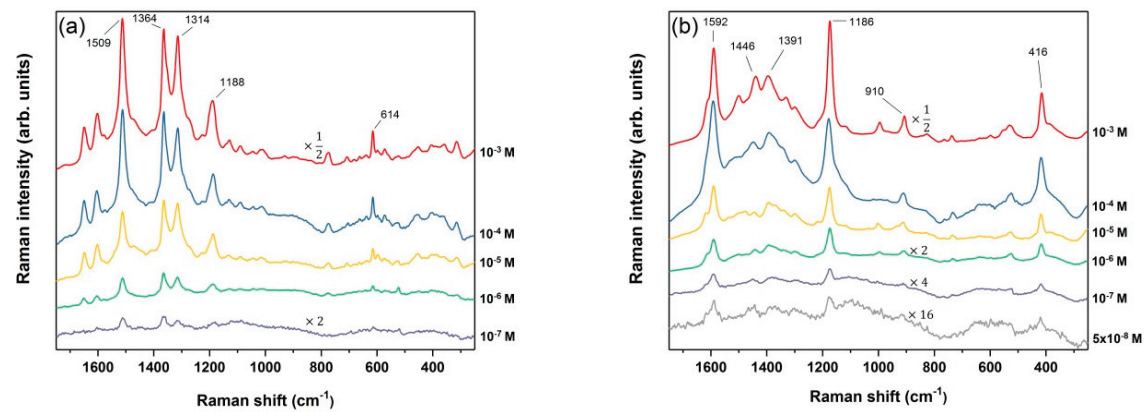

Figure 9. The SERS spectra of (a) R6G and (b) CV (both 100 scans, $500 \mathrm{~mW}$ ), deposited on RF S2 samples at different dilutions (higher to lower concentrations from top to bottom). Spectra are offset along the $y$-axis for clarity.

A typical parameter used for estimation of the SERS substrate performance called the enhancement factor is usually calculated [61]. Due to the complex morphology of Ag-coated pSi and the intrinsic difficulty of precisely determining the scattering volume in FT-Raman measurements, the number of molecules contributing to the SERS signal cannot be reliably determined. By virtue of this, the parameter of choice in our investigation used to estimate SERS enhancement was external amplified Raman efficiency (EARE) [62], defined as the ratio of the minimum detectable concentration of the probe molecules obtained on the bare $\mathrm{pSi}$ and the one obtained on the SERS substrate. For the SERS substrate, RF S2, the calculated EAREs are $10^{5}$ for R6G and $5 \times 10^{5}$ for CV.

The maximum absorptions of R6G and CV are at $\sim 525$ and $\sim 590 \mathrm{~nm}$, respectively, hence our excitation wavelength is off-resonant with the analytes' electronic transitions and no resonance Raman effects, which enhance the SERS signal, are present. Also, the plasmonic resonance of Ag-coated pSi RFs, determined by the size and shape of NPs and their mutual EM interaction, as well as the dielectric function of a pSi substrate, is usually restricted to the visible range $[63,64]$ with only its wings expanding to the NIR region. Therefore, our excitation wavelength is off-resonant with the localized surface plasmon resonance of Ag NPs deposited on pSi RFs. Ergo the obtained SERS enhancement is most likely to be caused by adsorption of molecules onto appropriately structured arrangements of Ag NPs called 'hot spots'. They include narrow junctions between two or more interacting metal particles, where a spatially confined, intense EM field is present, but also sharp tips of the NPs, where the crowding of the electric field lines exist (lightning rod effect) [65]. Our explanation is in agreement with [66], who concluded that the dye molecules, such as R6G and CV, might preferentially adsorb on hot-spots.

Regarding the issue of reproducibility, since our excitation laser beam with a diameter of $\sim 0.25 \mathrm{~mm}$ illuminates a large sample area with randomly adsorbed molecules, which statistically includes many hot spots with different local geometry and hence different enhancement, we did not observe the strong intensity fluctuations notorious for SERS when recording spectra on different spots on samples' surfaces, although the reproducibility standards proposed in [67] were not fully satisfied.

However, an additional possibility for a small contribution to SERS signal enhancement also exists. As already emphasized, the transmission of light through the PBG is prohibited, hence high back-reflection of the excitation light for sample RF S2, where the PBG is aligned with the laser light, is expected. Thus, the back reflected light might contribute to the enhancement of the local EM field around Ag NPs for PSi RFs and therefore also contribute to the overall SERS enhancement. Moreover, if the wavenumber of the Raman-scattered photons falls within the PBG of a periodic multilayered structure, a backward reflection of photons will result in their constructive interference, leading to further enhancement of Raman signals $[68,69]$. This principle was also expanded for SERS measurements [70] and, most recently, Zhong et al. [71] reported an almost 4 fold increase in SERS 
EF by using pSi PhC. Since the primary goal of our PBG was quenching the CSi PL, laser excitation light was aligned with the rather narrow stopband of our pSi RF $(<200 \mathrm{~nm})$, hence only low-frequency Raman modes might be enhanced. Increasing the bandwidth of the pSi RF stopband, attainable either by varying the spatial frequency ('chirping") [53] or by superposition of sine functions [72], in order to quantify the PBG effect contribution to the SERS enhancement, is the scope of our future work.

\section{Conclusions}

In conclusion, silver-coated porous silicon photonic crystals as SERS substrates were developed for near-infrared excitation (1064 nm), which is important for the Raman detection and study of fragile biomolecules. Porous silicon photonic crystals with high reflectance at the excitation wavelength were produced to quench the underlying crystalline silicon substrate band gap photoluminescence. The procedure for the formation of the nanostructured silver deposits with an appropriate morphology on the porous layer was optimized, yielding the most pronounced SERS activity for porous silicon rugate filters immersed for $5 \mathrm{~min}$ in $10^{-2} \mathrm{M} \mathrm{AgNO}_{3}$. The results show high SERS-sensitivity with a concentration detection limit of $10^{-7}$ and $5 \times 10^{-8} \mathrm{M}$ of the typical probe molecules, Rhodamine 6G and Crystal violet, which is a more than 5 orders of magnitude lower concentration than detectable on bare porous silicon. Due to the non-resonant matching of the excitation wavelength with the localized surface plasmon resonance of the silver nanoparticles deposited on the mesoporous silicon, the observed Raman signal enhancement is explained to primarily be the result of the existence of hot-spots on the sample surface.

Author Contributions: M.Š., M.K. and O.G. conceived the study. M.Š. fabricated the samples, performed the measurements, arranged all figures and wrote the draft version of the manuscript. M.K., M.G. and L.M. supervised the proceeding of experiments. All authors interpreted and discussed the results, and edited the draft version of the manuscript. M.S. and O.G. wrote the final version of the manuscript. O.G. and M.I. coordinated the project as a whole and were responsible for funding acquisition. All authors read and approved the final manuscript.

Funding: This work has been partially supported by the Croatian Science Foundation under the project (IP-2014-09-7046) and by the project co-financed by the Croatian Government and the European Union through the European Regional Development Fund-the Competitiveness and Cohesion Operational Programme (KK.01.1.1.01.0001).

Conflicts of Interest: The authors declare no conflict of interest.

\section{References}

1. Moskovits, M. Surface-Enhanced Raman Spectroscopy: A Brief Retrospective. J. Raman Spectrosc. 2005, 36, 485-496. [CrossRef]

2. Cialla, D.; März, A.; Böhme, R.; Theil, F.; Weber, K.; Schmitt, M.; Popp, J. Surface-enhanced Raman spectroscopy (SERS): Progress and trends. Anal. Bioanal. Chem. 2012, 403, 27-54. [CrossRef] [PubMed]

3. Jia, M.; Li, S.; Zang, L.; Lu, X.; Zhang, H. Analysis of Biomolecules Based on the Surface Enhanced Raman Spectroscopy. Nanomaterials 2018, 8, 730. [CrossRef] [PubMed]

4. Etchegoin, P.G.; Le Ru, E.C. A Perspective on Single Molecule SERS: Current Status and Future Challenges. Phys. Chem. Chem. Phys. 2008, 10, 6079-6089. [CrossRef] [PubMed]

5. Lombardi, J.R.; Birke, R.L. A Unified View of Surface-Enhanced Raman Scattering. Acc. Chem. Res. 2009, 42, 734-742. [CrossRef] [PubMed]

6. Mosier-Boss, P. Review of SERS Substrates for Chemical Sensing. Nanomaterials 2017, 7, 142. [CrossRef]

7. Chan, S.; Kwon, S.; Koo, T.W.; Lee, L.P.; Berlin, A.A. Surface-Enhanced Raman Scattering of Small Molecules from Silver-Coated Silicon Nanopores. Adv. Mater. 2003, 15, 1595-1598. [CrossRef]

8. Lin, H.; Mock, J.; Smith, D.; Gao, T.; Sailor, M.J. Surface-Enhanced Raman Scattering from Silver-Plated Porous Silicon. J. Phys. Chem. B 2004, 108, 11654-11659. [CrossRef]

9. Giorgis, F.; Descrovi, E.; Chiodoni, A.; Froner, E.; Scarpa, M.; Venturello, A.; Geobaldo, F. Porous Silicon as Efficient Surface Enhanced Raman Scattering (SERS) Substrate. Appl. Surf. Sci. 2008, 254, 7494-7497. [CrossRef] 
10. Panarin, A.Y.; Terekhov, S.N.; Kholostov, K.I.; Bondarenko, V.P. SERS-Active Substrates Based on n-Type Porous Silicon. Appl. Surf. Sci. 2010, 256, 6969-6976. [CrossRef]

11. Zeiri, L.; Rechav, K.; Porat, Z.; Zeiri, Y. Silver Nanoparticles Deposited on Porous Silicon as a SurfaceEnhanced Raman Scattering (SERS) Active Substrate. Appl. Spectrosc. 2012, 66, 294-299. [CrossRef] [PubMed]

12. Harraz, F.A.; Ismail, A.A.; Bouzid, H.; Al-Sayari, S.A.; Al-Hajry, A.; Al-Assiri, M.S. Surface-Enhanced Raman Scattering (SERS)-Active Substrates from Silver Plated-Porous Silicon for Detection of Crystal Violet. Appl. Surf. Sci. 2015, 331, 241-247. [CrossRef]

13. Kosovic, M.; Balarin, M.; Ivanda, M.; Derek, V.; Marcius, M.; Ristic, M.; Gamulin, O. Porous Silicon Covered with Silver Nanoparticles as Surface-Enhanced Raman Scattering (SERS) Substrate for Ultra-Low Concentration Detection. Appl. Spectrosc. 2015, 69, 1417-1424. [CrossRef] [PubMed]

14. Bandarenka, H.V.; Girel, K.V.; Zavatski, S.A.; Panarin, A.; Terekhov, S.N. Progress in the Development of SERS-Active Substrates Based on Metal-Coated Porous Silicon. Materials 2018, 11, 852. [CrossRef]

15. Canham, L. Handbook of Porous Silicon; Springer International Publishing: Berlin, Germany, 2014.

16. Sailor, M.J. Porous Silicon in Practice: Preparation, Characterization and Applications; Wiley-VCH: Weinheim, Germany, 2011.

17. Andsager, D.; Hilliard, J.; Hetrick, J.M.; Abuhassan, L.H.; Plisch, M.; Nayfeh, M.H. Quenching of Porous Silicon Photoluminescence by Deposition of Metal Adsorbates. J. Appl. Phys. 1993, 74, 4783-4785. [CrossRef]

18. Harraz, F.A.; Tsuboi, T.; Sasano, J.; Sakka, T.; Ogata, Y.H. Metal Deposition onto a Porous Silicon Layer by Immersion Plating from Aqueous and Nonaqueous Solutions. J. Electrochem. Soc. 2002, 149, C456-C463. [CrossRef]

19. Nativ-Roth, E.; Rechav, K.; Porat, Z. Deposition of Gold and Silver on Porous Silicon and Inside the Pores. Thin Solid Films 2016, 603, 88-96. [CrossRef]

20. Chursanova, M.V.; Germash, L.P.; Yukhymchuk, V.O.; Dzhagan, V.M.; Khodasevich, I.A.; Cojoc, D. Optimization of Porous Silicon Preparation Technology for SERS Applications. Appl. Surf. Sci. 2010, 256, 3369-3373. [CrossRef]

21. Bandarenka, H.; Redko, S.; Nenzi, P.; Balucani, M.; Bondarenko, V. Optimization of Chemical Displacement Deposition of Copper on Porous Silicon. J. Nanosci. Nanotechnol. 2012, 12, 8725-8731. [CrossRef]

22. Mikac, L.; Ivanda, M.; Đerek, V.; Gotić, M. Influence of Mesoporous Silicon Preparation Condition on Silver Clustering and SERS Enhancement. J. Raman Spectrosc. 2016, 47, 1036-1041. [CrossRef]

23. Maier, S.A. Plasmonics: Fundamentals and Applications; Springer Science+Business Media LLC: New York, NY, USA, 2007.

24. Kneipp, K.; Roth, E.; Engert, C.; Kiefer, W. Near-Infrared Excited Surface-Enhanced Raman Spectroscopy of Rhodamine 6G on Colloidal Silver. Chem. Phys. Lett. 1993, 207, 450-454. [CrossRef]

25. Muniz-Miranda, F.; Pedone, A.; Muniz-Miranda, M. Raman and Computational Study on the Adsorption of Xanthine on Silver Nanocolloids. ACS Omega 2018, 3, 13530-13537. [CrossRef]

26. DaFonseca, B.G.; Costa, L.A.S.; Sant'Ana, A.C. Insights of Adsorption Mechanisms of Trp-Peptides on Plasmonic Surfaces by SERS. Spectrochim. Acta Part A Mol. Biomol. Spectrosc. 2017, 190, 383-391. [CrossRef] [PubMed]

27. Angel, S.M.; Katz, L.F.; Archibald, D.D.; Lin, L.T.; Honigs, D.E. Near-Infrared Surface-Enhanced Raman Spectroscopy. Part 1: Copper and Gold Electrodes. Appl. Spectrosc. 1988, 42, 1327-1331. [CrossRef]

28. Hildebrandt, P.; Keller, S.; Hoffmann, A.; Vanhecke, F.; Schrader, B. Enhancement Factor of Surface-Enhanced Raman Scattering on Silver and Gold Surfaces Upon Near-Infrared Excitation. Indication of an Unusual Strong Contribution of the Chemical Effect. J. Raman Spectrosc. 1993, 24, 791-796. [CrossRef]

29. Nikoobakht, B.; El-Sayed, M.A. Surface-Enhanced Raman Scattering Studies on Aggregated Gold Nanorods. J. Phys. Chem. A 2003, 107, 3372-3378. [CrossRef]

30. Lai, C.H.; Wang, G.A.; Ling, T.K.; Wang, T.J.; Chiu, P.K.; Chou Chau, Y.F.; Huang, C.C.; Chiang, H.P. Near Infrared Surface-Enhanced Raman Scattering Based on Star-Shaped Gold/Silver Nanoparticles and Hyperbolic Metamaterial. Sci. Rep. 2017, 7, 5446. [CrossRef]

31. Dash, W.C.; Newman, R. Intrinsic Optical Absorption in Single-Crystal Germanium and Silicon at $77^{\circ} \mathrm{K}$ and $300^{\circ}$ K. Phys. Rev. 1955, 99, 1151-1155. [CrossRef]

32. Sagnes, I.; Halimaoui, A.; Vincent, G.; Badoz, P.A. Optical Absorption Evidence of a Quantum Size Effect in Porous Silicon. Appl. Phys. Lett. 1993, 62, 1155-1157. [CrossRef] 
33. Webb, J.D.; Dunlavy, D.J.; Ciszek, T.; Ahrenkiel, R.K.; Wanlass, M.W.; Noufi, R.; Vernon, S.M. Room-Temperature Measurement of Photoluminescence Spectra of Semiconductors Using an FT-Raman Spectrophotometer. Appl. Spectrosc. 1993, 47, 1814-1819. [CrossRef]

34. Kosović, M.; Gamulin, O.; Balarin, M.; Ivanda, M.; Đerek, V.; Ristić, D.; Marciuš, M.; Ristić, M. Phonon Confinement Effects in Raman Spectra of Porous Silicon at Non-Resonant Excitation Condition. J. Raman Spectrosc. 2014, 45, 470-475. [CrossRef]

35. Mazzoleni, C.; Pavesi, L. Application to Optical Components of Dielectric Porous Silicon Multilayers. Appl. Phys. Lett. 1995, 67, 2983. [CrossRef]

36. Berger, M.G.; Arens-Fischer, R.; Thönissen, M.; Krüger, M.; Billat, S.; Lüth, H.; Hilbrich, S.; Theiß, W.; Grosse, P. Dielectric Filters Made of PS: Advanced Performance by Oxidation and New Layer Structures. Thin Solid Films 1997, 297, 237-240. [CrossRef]

37. Agarwal, V.; Del Río, J.A. Tailoring the Photonic Band Gap of a Porous Silicon Dielectric Mirror. Appl. Phys. Lett. 2003, 82, 1512-1514. [CrossRef]

38. Pacholski, C. Photonic Crystal Sensors Based on Porous Silicon. Sensors 2013, 13, 4694-4713. [CrossRef]

39. Harraz, F.A. Porous Silicon Chemical Sensors and Biosensors: A Review. Sens. Actuators B Chem. 2014, 202, 897-912. [CrossRef]

40. Ferrand, P.; Romestain, R.; Vial, J.C. Photonic Band-Gap Properties of a Porous Silicon Periodic Planar Waveguide. Phys. Rev. B Condens. Matter Mater. Phys. 2001, 63, 115106. [CrossRef]

41. Cunin, F.; Schmedake, T.A.; Link, J.R.; Li, Y.Y.; Kom, J.; Bhatia, S.N.; Sailor, M.J. Biomolecular Screening with Encoded Porous-Silicon Photonic Crystals. Nat. Mater. 2002, 1, 39-41. [CrossRef]

42. Pavesi, L.; Cazzanelli, M. Porous Silicon Multilayers and Microcavities. Riv. Nuovo Cim. 1997, $20,1-76$. [CrossRef]

43. Mikac, L.; Ivanda, M.; Gotić, M.; Maksimović, A.; Trusso, S.; Andrea, C.D.; Foti, A.; Irrera, A.; Fazio, B.; Gucciardi, P.G. Metal Nanoparticles Deposited on Porous Silicon Templates as Novel Substrates for SERS. Croat. Chem. Acta 2015, 88, 437-444. [CrossRef]

44. Haynes, J.R.; Westphal, W.C. Radiation Resulting from Recombination of Holes and Electrons in Silicon. Phys. Rev. 1956, 101, 1676-1678. [CrossRef]

45. Pérez-Rodríguez, A.; Cornet, A.; Morante, J.R.; Jiménez, J.; Hemment, P.L.F.; Homewood, K.P. Raman Scattering and Photoluminescence Analysis of Silicon on Insulator Structures Obtained by Single and Multiple Oxygen Implants. J. Appl. Phys. 1991, 70, 1678-1683. [CrossRef]

46. Saito, Y.; Wang, J.J.; Smith, D.A.; Batchelder, D.N. A Simple Chemical Method for the Preparation of Silver Surfaces for Efficient SERS. Langmuir 2002, 18, 2000-2002. [CrossRef]

47. Saito, Y.; Wang, J.J.; Batchelder, D.N.; Smith, D.A. Simple Chemical Method for Forming Silver Surfaces with Controlled Grain Sizes for Surface Plasmon Experiments. Langmuir 2003, 19, 6857-6861. [CrossRef]

48. Jeske, M.; Schultze, J.W.; Thonissen, M.; Munder, H. Electrodeposition of Metals Into Porous Silicon. Thin Solid Films 1995, 255, 63-66. [CrossRef]

49. Fox, M. Optical Properties of Solids, 2nd ed.; Oxford University Press: Oxford, UK, 2010.

50. Lorenzo, E.; Oton, C.J.; Capuj, N.E.; Ghulinyan, M.; Navarro-Urrios, D.; Gaburro, Z.; Pavesi, L. Porous Silicon-Based Rugate Filters. Appl. Opt. 2005, 44, 5415. [CrossRef]

51. Li, S.; Hu, D.; Huang, J.; Cai, L. Optical Sensing Nanostructures for Porous Silicon Rugate Filters. Nanoscale Res. Lett. 2012, 7, 1-8. [CrossRef] [PubMed]

52. Salem, M.S.; Sailor, M.J.; Sakka, T.; Ogata, Y.H. Electrochemical Preparation of a Rugate Filter in Silicon and its Deviation from the Ideal Structure. J. Appl. Phys. 2007, 101. [CrossRef]

53. Imenes, A.G.; McKenzie, D.R. Flat-Topped Broadband Rugate Filters. Appl. Opt. 2006, 45, 7841-7850. [CrossRef] [PubMed]

54. Ilyas, S.; Böcking, T.; Kilian, K.; Reece, P.J.; Gooding, J.; Gaus, K.; Gal, M. Porous Silicon Based Narrow Line-Width Rugate Filters. Opt. Mater. 2007, 29, 619-622. [CrossRef]

55. Thönissen, M.; Berger, M.G.; Billat, S.; Arens-Fischer, R.; Krüger, M.; Lüth, H.; Theiß, W.; Hillbrich, S.; Grosse, P.; Lerondel, G.; et al. Analysis of the Depth Homogeneity of p-PS by Reflectance Measurements. Thin Solid Films 1997, 297, 92-96. [CrossRef]

56. Urata, T.; Fukami, K.; Takeda, N.; Sakka, T.; Ogata, Y.H. Influence of Solvents in HF Solutions on Anodic Formation of Mesoporous Silicon, Revealed by the Characterization of Mesoporous Silicon Rugate Filters. ECS J. Solid State Sci. Technol. 2016, 5, P250-P255. [CrossRef] 
57. Michaels, A.M.; Jiang, J.; Brus, L. Ag Nanocrystal Junctions as the Site for Surface-Enhanced Raman Scattering of Single Rhodamine 6G Molecules. J. Phys. Chem. A 2000, 104, 11965-11971. [CrossRef]

58. Hildebrandt, P.; Stockburger, M. Surface-Enhanced Resonance Raman Spectroscopy of Rhodamine 6G Adsorbed on Colloidal Silver. J. Phys. Chem. 1984, 88, 5935-5944. [CrossRef]

59. Majoube, M.; Henry, M. Fourier Transform Raman and Infrared and Surface-Enhanced Raman Spectra for Rhodamine 6G. Spectrochim. Acta Part A Mol. Biomol. Spectrosc. 1991, 47, 1459-1466. [CrossRef]

60. Liang, E.J.; Ye, X.L.; Kiefer, W. Surface-Enhanced Raman Spectroscopy of Crystal Violet in the Presence of Halide and Halate Ions with Near-Infrared Wavelength Excitation. J. Phys. Chem. 1997, 101, 7330-7335. [CrossRef]

61. Le Ru, E.C.; Etchegoin, P.G. Quantifying SERS Enhancements. MRS Bull. 2013, 38, 631-640. [CrossRef]

62. Virga, A.; Rivolo, P.; Descrovi, E.; Chiolerio, A.; Digregorio, G.; Frascella, F.; Soster, M.; Bussolino, F.; Marchiò, S.; Geobaldo, F.; et al. SERS Active Ag Nanoparticles in Mesoporous Silicon: Detection of Organic Molecules and Peptide-Antibody Assays. J. Raman Spectrosc. 2011, 43, 730-736. [CrossRef]

63. Kelly, K.L.; Coronado, E.; Zhao, L.L.; Schatz, G.C. The Optical Properties of Metal Nanoparticles the Influence of Size, Shape, and Dielectric Environment. J. Phys. Chem. B 2003, 107, 668-677. [CrossRef]

64. Starowicz, Z.; Ozga, P.; Sheregii, E.M. The Tuning of the Plasmon Resonance of the Metal Nanoparticles in Terms of the SERS Effect. Colloid Polym. Sci. 2018, 296, 1029-1037. [CrossRef]

65. Liao, P.F.; Wokaun, A. Lightning Rod Effect in Surface Enhanced Raman Scattering. J. Chem. Phys. 1982, 76, 751-752. [CrossRef]

66. Kudelski, A. Raman Studies of Rhodamine 6G and Crystal Violet Sub-Monolayers on Electrochemically Roughened Silver Substrates: Do Dye Molecules Adsorb Preferentially on Highly SERS-Active Sites? Chem. Phys. Lett. 2005, 414, 271-275. [CrossRef]

67. Natan, M.J. Concluding Remarks - Surface Enhanced Raman Scattering. Faraday Discuss. 2006, 132, 321-328. [CrossRef]

68. Wu, C.Y.; Huang, C.C.; Jhang, J.S.; Liu, A.C.; Chiang, C.; Hsieh, M.-L.; Huang, P.-J.; Tuyen, L.D.; Minh, L.Q.; Yang, S.T.; et al. Hybrid Surface-Enhanced Raman Scattering Substrate from Gold Nanoparticle and Photonic Crystal: Maneuverability and Uniformity of Raman Spectra. Opt. Express 2009, 17, 21522-21529. [CrossRef]

69. Mamichev, D.A.; Gonchar, K.A.; Timoshenko, V.Y.; Mussabek, G.K.; Nikulin, V.E.; Taurbaev, T.I. Enhanced Raman Scattering in Multilayer Structures of Porous Silicon. J. Raman Spectrosc. 2011, 42, 1392-1395. [CrossRef]

70. Tuyen, L.D.; Liu, A.C.; Huang, C.; Tsai, P.; Lin, J.H.; Wu, C.; Chau, L.; Yang, T.S.; Minh, L.Q.; Kan, H.; et al. Doubly Resonant Surface-Enhanced Raman Scattering on Gold Nanorod Decorated Inverse Opal Photonic Crystals. Opt. Express 2012, 20, 29266-29275. [CrossRef] [PubMed]

71. Zhong, F.; Wu, Z.; Guo, J.; Jia, D. Porous Silicon Photonic Crystals Coated with Ag Nanoparticles as Efficient Substrates for Detecting Trace Explosives Using SERS. Nanomaterials 2018, 8, 872. [CrossRef]

72. Ishikura, N.; Fujii, M.; Nishida, K.; Hayashi, S.; Diener, J.; Mizuhata, M.; Deki, S. Broadband Rugate Filters Based on Porous Silicon. Opt. Mater. 2008, 31, 102-105. [CrossRef]

(C) 2019 by the authors. Licensee MDPI, Basel, Switzerland. This article is an open access article distributed under the terms and conditions of the Creative Commons Attribution (CC BY) license (http:/ / creativecommons.org/licenses/by/4.0/). 

Article

\title{
Vibration and Buckling of Shear Deformable Functionally Graded Nanoporous Metal Foam Nanoshells
}

\author{
Yufei Zhang ${ }^{1, *}$ and Fei Zhang ${ }^{2, *}$ \\ 1 College of Aerospace Engineering, Shenyang Aerospace University, Shenyang 110136, China \\ 2 College of Sciences, Northeastern University, Shenyang 110819, China \\ * Correspondence: yufeizhang73@163.com (Y.Z.); feizhangneu@163.com (F.Z.)
}

Received: 22 January 2019; Accepted: 11 February 2019; Published: 15 February 2019

\begin{abstract}
This article aims to investigate free vibration and buckling of functionally graded (FG) nanoporous metal foam (NPMF) nanoshells. The first-order shear deformation (FSD) shell theory is adopted and the theoretical model is formulated by using Mindlin's most general strain gradient theory, which can derive several well-known simplified models. The symmetric and unsymmetric nanoporosity distributions are considered for the structural composition. Hamilton's principle is employed to deduce the governing equations as well as the boundary conditions. Then, via the Navier solution technique, an analytical solution for the free vibration and buckling of FG NPMF nanoshells is presented. Afterwards, a detailed parametric analysis is conducted to highlight the effects of the nanoporosity coefficient, nanoporosity distribution, length scale parameter, and geometrical parameters on the mechanical behaviors of FG NPMF nanoshells.
\end{abstract}

Keywords: nanoporous metal foam; nanoshell; buckling; free vibration; strain gradient theory; first-order shear deformation theory

\section{Introduction}

Functionally graded materials (FGMs) have a continuous and smooth graded distribution of material properties in the spatial field. Due to their superior properties and advantages, FGMs have been successfully extended to various engineering applications and received much attention [1-24]. Recently, a breakthrough made it possible to realize desired structural properties by adjusting the local density of structures, thereby developing novel functionally graded (FG) porous structures composed of metal foams having graded density [25-28]. The application of nanoporous metal foams (NPMFs) has been extended to some advanced engineering fields due to their extremely high specific surface area [29-32]. This kind of material has a combination of properties that is not achievable for ceramics, metals, or dense polymers.

Micro/nanostructures have been successfully used in shape memory alloys [33] and micro- and nano-electro-mechanical systems (MEMS and NEMS) [34,35]. The small-scale effects on the mechanical behaviors of micro/nanostructures have been experimentally observed in their applications [36,37]. It was revealed that the mechanical behaviors of micro/nanostructures were different from their macro counterparts due to the size effect $[38,39]$. Due to the lack of intrinsic material length scale parameters, the classical continuum theory has no ability to predict the mechanical characteristics of micro/nanostructures. Therefore, several size-dependent continuum theories have been proposed to compensate for the drawbacks of the classical continuum theory for micro/nanostructures. One of the size-dependent continuum theories is Mindlin's strain gradient theory (SGT) [40], which is known as the general form of the SGT containing five additional material length scale parameters compared to the classical continuum theory. Later, several special forms of Mindlin's SGT were proposed. For instance, 
one of the most popular forms is the modified strain gradient theory (MSGT) [37]. In fact, this theory is a more useful form of Mindlin's SGT including three material length scale parameters related to symmetric rotation gradients, deviatoric stretch gradients, and dilatation gradients. Several successful applications of the MSGT in dynamic and static analyses of micro/nanobeams [41-44], plates [45-47], and shells [48-50] have been reported. It should be noticed that the modified couple stress theory (MCST) [51] can be achieved by ignoring two of the three material length scale parameters in the MSGT. Moreover, the MSGT can be simplified to the classical theory (CT) by neglecting all of the three material length scale parameters.

Recently, the structural performance of NPMF micro/nanobeams has been investigated by several researchers. Post-buckling analysis for nanobeams made of NPMFs is presented by Barati and Zenkour [52] via the nonlocal elasticity theory (NET). By using the nonlocal strain gradient theory together with the third-order shear deformation beam theory, nonlinear bending of FG NPMF micro/nanobeams reinforced by graphene platelets has been analyzed by Sahmani et al. [53]. Wang et al. [54] utilized the sinusoidal beam theory and the MSGT to study the vibration and bending of NPMF microbeams.

Shell-type structures have excellent mechanical properties [55-61], and thus, nanoshells are important components in various MEMS and NEMS [62-64]. Complete knowledge of the mechanical properties of nanoshells encourages researchers to use them more efficiently. Therefore, some research has been made to illustrate the buckling and vibration characteristics of nanoshells. For example, by using the NET, Hoseinzadeh and Khadem [65] investigated the thermoelastic vibration of double-walled carbon nanotubes (CNTs). By employing the classical shell theory together with the Gurtin-Murdoch elasticity theory, Sahmani et al. [66] analyzed the postbuckling and nonlinear buckling of cylindrical nanoshells subjected to radial and axial compressive loads. Implementing the NET in the first-order shear deformation (FSD) shell theory, Ansari et al. [67] explored the buckling behavior of multi-walled CNTs including the effect of the thermal environment. Wang et al. [68] studied the nonlinear vibration of nanoshells conveying fluid based on the surface stress elasticity theory as well as the classical shell theory.

In the present study, we aim to make an attempt to investigate the vibration and buckling of circular cylindrical nanoshells made from FG NPMFs. In order to accommodate the size dependency of the nanostructure, the general SGT is used to develop the size-dependent first-order shear deformable nanoporous nanoshell model. The governing equations, as well as the related boundary conditions, are obtained simultaneously by utilizing Hamilton's principle. The free vibration and axial buckling of simply supported nanoporous circular cylindrical nanoshells are solved analytically by means of the Navier solution technique. Moreover, the influence of some key parameters on the vibration and buckling properties of the system is shown.

\section{FG NPMF Circular Cylindrical Nanoshells}

An FG NPMF circular cylindrical nanoshell of middle-surface radius $R$, thickness $h$, and length $L$ is shown in Figure 1. Two kinds of nanoporosity distribution in the thickness direction are considered, namely, nanoporosity-1 and nanoporosity-2. Additionally, the nanoshell is subjected to axial loads $N_{x x}^{0}$.

Owing to non-uniform nanoporosity distribution, mass densities $\rho(z)$, Young's modulus $E(z)$, and shear modulus $\mu(z)$ of the nanoshell are functions of position and can be written as [69-74]:

Nanoporosity-1:

$$
\begin{aligned}
& E(z)=E_{1}^{*}\left[1-e_{0} \cos (\pi \zeta)\right] \\
& \rho(z)=\rho_{1}^{*}\left[1-e_{m} \cos (\pi \zeta)\right] \\
& \mu(z)=\mu_{1}^{*}\left[1-e_{0} \cos (\pi \zeta)\right]
\end{aligned}
$$

Nanoporosity-2:

$$
E(z)=E_{1}^{*}\left[1-e_{0} \cos \left(\frac{\pi \zeta}{2}+\frac{\pi}{4}\right)\right]
$$




$$
\begin{aligned}
& \rho(z)=\rho_{1}^{*}\left[1-e_{m} \cos \left(\frac{\pi \zeta}{2}+\frac{\pi}{4}\right)\right] \\
& \mu(z)=\mu_{1}^{*}\left[1-e_{0} \cos \left(\frac{\pi \zeta}{2}+\frac{\pi}{4}\right)\right]
\end{aligned}
$$

where $\zeta=z / h$, the nanoporosity coefficients are $e_{0}=1-E_{0}^{*} / E_{1}^{*}\left(0 \leq e_{0}<1\right)$ and $e_{m}=1-\rho_{0}^{*} / \rho_{1}^{*}(0 \leq$ $\left.e_{m}<1\right), \rho_{0}^{*}$ and $\rho_{1}^{*}$ are the minimum and maximum values of the mass density, respectively. The minimum Young's modulus $E_{0}^{*}$ and the maximum value $E_{1}^{*}$ are related to the minimum shear modulus $\mu_{0}^{*}$ and the maximum value $\mu_{1}^{*}$ according to $\mu_{i}^{*}=E_{i}^{*} /[2(1+v)](i=0,1)$, in which $v$ indicates Poisson's ratio.

For an open-cell metal foam, we have $[75,76]$ :

$$
\frac{E_{0}^{*}}{E_{1}^{*}}=\left(\frac{\rho_{0}^{*}}{\rho_{1}^{*}}\right)^{2}
$$

Thus, the relation between $e_{0}$ and $e_{m}$ is obtained as:

$$
e_{m}=1-\sqrt{1-e_{0}}
$$

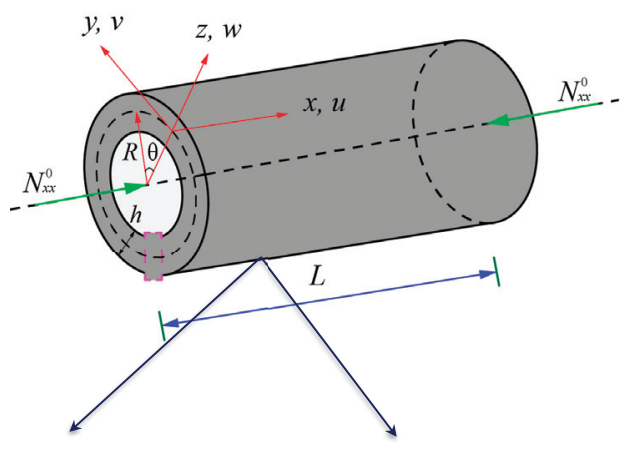

(a)

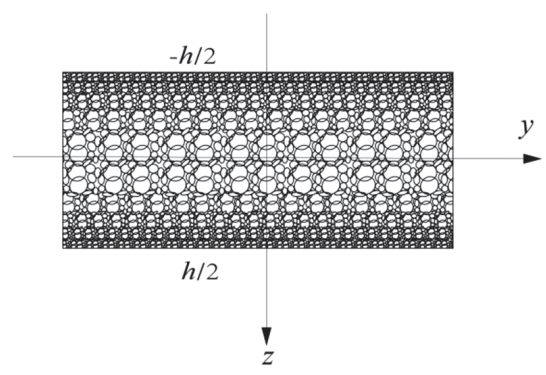

nanoporosity-1

(b)

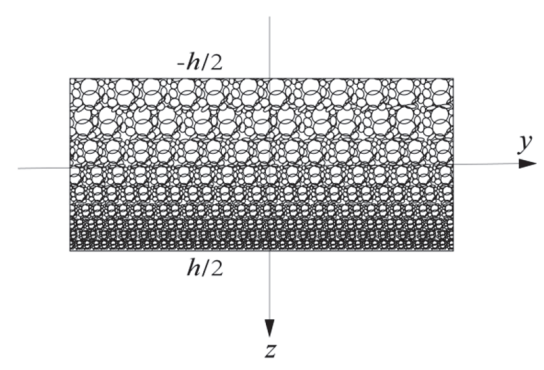

nanoporosity-2

(c)

Figure 1. Schematic of a functionally graded (FG) nanoporous metal foam (NPMF) cylindrical nanoshell.

(a) Coordinate system; (b) nanoporosity-1; (c) nanoporosity-2.

Figures 2 and 3 give the variations of mass density and Young's modulus, respectively, of the FG NPMF nanoshell along the thickness direction. Note that both kinds of nanoporosity distribution have the same minimum and maximum values of mass density and elasticity modulus. For the 
nanoporosity-1 nanoshell, it possesses the minimum values of mass density and Young's modulus on the middle surface $(z=0)$ of the nanoshell; while the maximum values are on the outer $(z=h / 2)$ and inner $(z=-h / 2)$ surfaces which are equal to the values of the nanoshell that consisted of solid metal. For the nanoporosity-2, mass density and elasticity modulus have the minimum values on the inner surface and gradually increase to the maximum values on the outer surface of the shell.

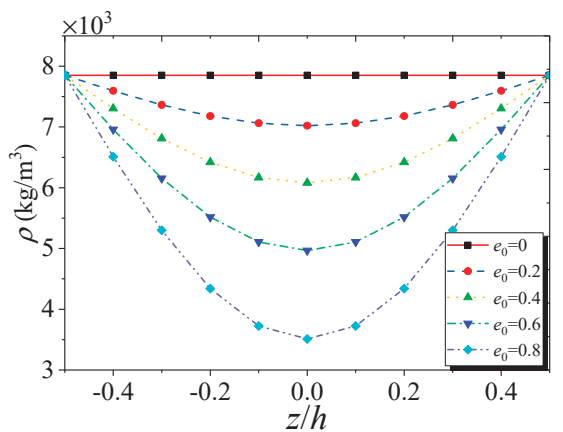

(a)

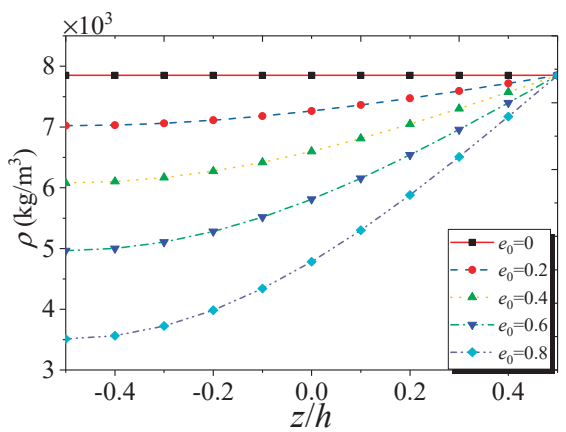

(b)

Figure 2. Variation of mass density of FG NPMF nanoshell: (a) nanoporosity-1; (b) nanoporosity-2.

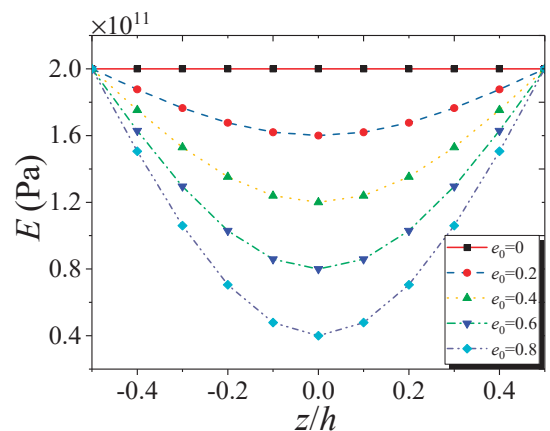

(a)

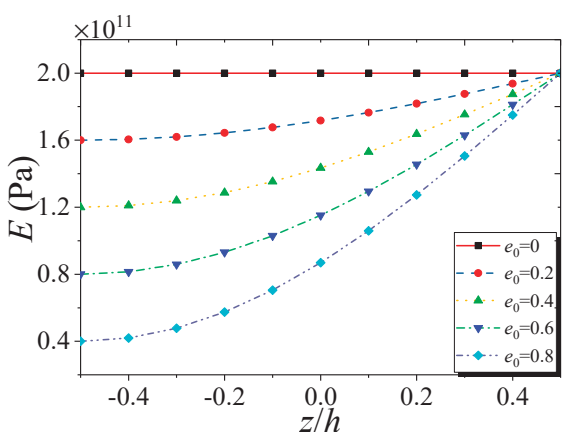

(b)

Figure 3. Variation of Young's modulus of FG NPMF nanoshell: (a) nanoporosity-1; (b) nanoporosity-2.

\section{Theory and Formulation}

\subsection{General SGT}

As we know, the strain energy density in the CT is described as the function of the strain tensor $\varepsilon$. The strain energy density in Mindlin's SGT, however, also incorporates the third-order strain gradient tensor $\xi$. Therefore, the strain energy density $W$ has the most general form $[40,77]$ :

$$
W(\varepsilon, \xi)=\frac{1}{2} \lambda \varepsilon_{i i} \varepsilon_{j j}+\mu \varepsilon_{i j} \varepsilon_{i j}+a_{1} \xi_{i k k} \xi_{i j j}+a_{2} \xi_{k j j} \xi_{i i k}+a_{3} \xi_{j j k} \xi_{i i k}+a_{4} \xi_{i j k} \xi_{i j k}+a_{5} \xi_{k j i} \xi_{i j k}
$$

in which $a_{i}(i=1,2, \ldots, 5)$ are additional constants which can accommodate the small-scale effect of micro/nanostructures, and $\lambda$ is Lame's first parameter defined as [78,79]:

$$
\lambda=\frac{E v}{(1+v)(1-2 v)}
$$


In Equation (9), the third-order strain gradient tensor $\xi$ and infinitesimal strain tensor $\varepsilon$ are defined as [40]:

$$
\begin{gathered}
\varepsilon=\frac{1}{2}\left(\nabla \mathbf{u}+(\nabla \mathbf{u})^{\mathrm{T}}\right), \quad \varepsilon_{i j}=\varepsilon_{j i}=\frac{1}{2}\left(u_{i, j}+u_{j, i}\right) \\
\xi=\nabla \varepsilon, \quad \xi_{i j k}=\xi_{i k j}=\varepsilon_{j k, i}=\frac{1}{2}\left(u_{j, k}+u_{k, j}\right)_{, i}
\end{gathered}
$$

in which $\mathbf{u}$ represents the displacement vector and $\nabla$ is gradient operator.

The double stress tensor $\tau_{i j k}$ and Cauchy stress tensor $\sigma_{i j}$ are written as [80]:

$$
\begin{gathered}
\sigma_{i j}=\sigma_{j i}=\frac{\partial W}{\partial \varepsilon_{i j}}=\lambda \varepsilon_{k k} \delta_{i j}+2 \mu \varepsilon_{i j} \\
\tau_{i j k}=\tau_{i k j}=\frac{\partial W}{\partial \xi_{i j k}}=\frac{a_{1}}{2}\left(\xi_{j p p} \delta_{i k}+2 \xi_{p p i} \delta_{j k}+\xi_{k p p} \delta_{i j}\right)+2 a_{2} \xi_{i p p} \delta_{j k}+a_{3}\left(\xi_{p p j} \delta_{i k}+\xi_{p p k} \delta_{i j}\right) \\
+2 a_{4} \xi_{i j k}+a_{5}\left(\xi_{k j i}+\xi_{j k i}\right)
\end{gathered}
$$

where $\delta_{i j}$ represent the Kronecker delta.

\subsection{Constitutive Relations and Strain Energy}

The displacement field for the FG NPMF cylindrical nanoshell according to the FSD shell theory can be defined as [81-85]:

$$
\left\{\begin{array}{l}
u_{x}(x, y, z, t) \\
u_{y}(x, y, z, t) \\
u_{z}(x, y, z, t)
\end{array}\right\}=\left\{\begin{array}{c}
u(x, y, t) \\
v(x, y, t) \\
w(x, y, t)
\end{array}\right\}+z\left\{\begin{array}{c}
\psi_{x}(x, y, t) \\
\psi_{y}(x, y, t) \\
0
\end{array}\right\}
$$

In Equation (15), $u_{x}, u_{y}$, and $u_{z}$ stand for the displacements of any point in the nanoshell along the $x, y$, and $z$ directions, respectively; $u, v$, and $w$ denote displacement components of a point at the middle surface; $\psi_{x}$ and $\psi_{y}$ are the rotations of the transverse normals about the $y$ and $x$ axes, respectively; and $t$ denotes time.

The nonzero constituents of strain tensor $\varepsilon$ are given by: [86,87]

$$
\left\{\begin{array}{l}
\varepsilon_{x x}=\phi_{0}+z \phi_{1} \\
\varepsilon_{y y}=\varphi_{0}+z \varphi_{1} \\
\varepsilon_{x y}=\varepsilon_{y x}=\left(k_{0}+z k_{1}\right) / 2 \\
\varepsilon_{y z}=\varepsilon_{z y}=\gamma_{2} / 2 \\
\varepsilon_{x z}=\varepsilon_{z x}=\gamma_{1} / 2
\end{array}\right.
$$

where $\phi_{0}, \varphi_{0}$, and $k_{0}$ are the middle surface strains, $\phi_{1}, \varphi_{1}$, and $k_{1}$ are changes in the curvature and torsion of the middle surface, and $\gamma_{1}$ and $\gamma_{2}$ are the transverse shear strains. They are given by:

$$
\left\{\begin{array}{l}
\phi_{0}=\frac{\partial u}{\partial x}, \phi_{1}=\frac{\partial \psi_{x}}{\partial x}, \varphi_{0}=\frac{w}{R}+\frac{\partial v}{\partial y}, \varphi_{1}=\frac{\partial \psi_{y}}{\partial y}, k_{0}=\frac{\partial v}{\partial x}+\frac{\partial u}{\partial y} \\
k_{1}=\frac{\partial \psi_{y}}{\partial x}+\frac{\partial \psi_{x}}{\partial y}, \gamma_{1}=\frac{\partial w}{\partial x}+\psi_{x}, \gamma_{2}=\psi_{y}-\frac{v}{R}+\frac{\partial w}{\partial y}
\end{array}\right.
$$

According to Equation (12), the following nonzero constituents of strain gradient tensor $\xi$ are obtained:

$$
\left\{\begin{array}{l}
\xi_{x x x}=\frac{\partial \phi_{0}}{\partial x}+z \frac{\partial \phi_{1}}{\partial x}, \xi_{y y y}=\frac{\partial \varphi_{0}}{\partial y}+z \frac{\partial \varphi_{1}}{\partial y}, \xi_{x y y}=\frac{\partial \varphi_{0}}{\partial x}+z \frac{\partial \varphi_{1}}{\partial x} \\
\xi_{z y y}=\varphi_{1}, \xi_{y x x}=\frac{\partial \phi_{0}}{\partial y}+z \frac{\partial \phi_{1}}{\partial y}, \xi_{x x y}=\xi_{x y x}=\frac{1}{2}\left(\frac{\partial k_{0}}{\partial x}+z \frac{\partial k_{1}}{\partial x}\right), \xi_{z x x}=\phi_{1}, \\
\xi_{y x y}=\xi_{y y x}=\frac{1}{2}\left(\frac{\partial k_{0}}{\partial y}+z \frac{\partial k_{1}}{\partial y}\right), \xi_{z x y}=\xi_{z y x}=\frac{k_{1}}{2}, \xi_{x x z}=\xi_{x z x}=\frac{1}{2} \frac{\partial \gamma_{1}}{\partial x} \\
\xi_{y x z}=\xi_{y z x}=\frac{1}{2} \frac{\partial \gamma_{1}}{\partial y}, \xi_{x y z}=\xi_{x z y}=\frac{1}{2} \frac{\partial \gamma_{2}}{\partial x}, \xi_{y y z}=\xi_{y z y}=\frac{1}{2} \frac{\partial \gamma_{2}}{\partial y} .
\end{array}\right.
$$


By inserting Equations (16) and (18) into Equations (13) and (14), one can get the nonzero constituents of $\sigma$ and $\tau$ as follows:

$$
\begin{gathered}
\left\{\begin{array}{l}
\sigma_{x x}=(\lambda+2 \mu)\left(\phi_{0}+z \phi_{1}\right)+\lambda\left(\varphi_{0}+z \varphi_{1}\right), \\
\sigma_{y y}=(\lambda+2 \mu)\left(\varphi_{0}+z \varphi_{1}\right)+\lambda\left(\phi_{0}+z \phi_{1}\right), \\
\sigma_{x y}=\sigma_{y x}=\mu\left(k_{0}+z k_{1}\right), \\
\sigma_{x z}=\sigma_{z x}=\mu \gamma_{1}, \\
\sigma_{y z}=\sigma_{z y}=\mu \gamma_{2} .
\end{array}\right. \\
\left\{\begin{array}{l}
\tau_{x x x}=\beta_{1} \xi_{x x x}+\beta_{2} \xi_{x y y}+\beta_{3} \xi_{y x y}, \\
\tau_{y x x}=\beta_{2} \xi_{y y y}+\beta_{5} \xi_{y x x}+\beta_{4} \xi_{x x y}, \\
\tau_{z x x}=\beta_{5} \xi_{z x x}+\beta_{4} \xi_{x x z}+a_{1} \xi_{y y z}+2 a_{2} \xi_{z y y}, \\
\tau_{x y y}=\beta_{4} \xi_{y x y}+\beta_{2} \xi_{x x x}+\beta_{5} \tilde{\xi}_{x y y} \\
\tau_{y y y}=\beta_{2} \xi_{y x x}+\beta_{3} \xi_{x x y}+\beta_{1} \xi_{y y y}, \\
\tau_{z y y}=a_{1} \xi_{x x z}+2 a_{2} \xi_{z x x}+\beta_{5} \xi_{z y y}+\beta_{4} \xi_{y y z}, \\
\tau_{y z z}=a_{1} \xi_{x x y}+2 a_{2} \xi_{y x x}+\beta_{2} \xi_{y y y}, \\
\tau_{x x y}=\tau_{x y x}=\frac{\beta_{3}}{2} \xi_{y y y}+\beta_{6} \xi_{x x y}+\frac{\beta_{4}}{2} \xi_{y x x}, \\
\tau_{y x y}=\tau_{y y x}=\frac{\beta_{4}}{2} \xi_{x y y}+\frac{\beta_{3}}{2} \xi_{x x x}+\beta_{6} \xi_{y x y}, \\
\tau_{z x y}=\tau_{z y x}=2 a_{4} \xi_{z x y}+a_{5}\left(\xi_{x y z}+\xi_{y x z}\right), \\
\tau_{x x z}=\tau_{x z x}=\frac{a_{1}}{2} \xi_{z y y}+a_{3} \xi_{y y z}+\beta_{6} \xi_{x x z}+\frac{\beta_{4}}{2} \xi_{z x x}, \\
\tau_{y x z}=\tau_{y z x}=2 a_{4} \xi_{y x z}+a_{5}\left(\xi_{x y z}+\xi_{z x y}\right), \\
\tau_{x y z}=\tau_{x z y}=2 a_{4} \xi_{x y z}+a_{5}\left(\xi_{y x z}+\xi_{z x y}\right), \\
\tau_{y y z}=\tau_{y z y}=\frac{a_{1}}{2} \xi_{z x x}+a_{3} \xi_{x x z}+\beta_{6} \xi_{y y z}+\frac{\beta_{4}}{2} \xi_{z y y y} .
\end{array}\right.
\end{gathered}
$$

in which

$$
\begin{cases}\beta_{1}=2\left(a_{1}+a_{2}+a_{3}+a_{4}+a_{5}\right), & \beta_{2}=a_{1}+2 a_{2}, \\ \beta_{3}=a_{1}+2 a_{3}, & \beta_{4}=a_{1}+2 a_{5}, \\ \beta_{5}=2\left(a_{2}+a_{4}\right), & \beta_{6}=a_{3}+2 a_{4}+a_{5} .\end{cases}
$$

Based on the general SGT, the stored strain energy, $\Pi_{S}$, in a linear elastic material occupying volume $V$ can be given by [77]:

$$
\Pi_{S}=\frac{1}{2} \int_{V}\left(\sigma_{i j} \varepsilon_{i j}+\tau_{i j k} \xi_{i j k}\right) \mathrm{d} V
$$

If the strain energy is symbolized by classical part $\Pi_{C}$ and non-classical part $\Pi_{N C}$, the total strain energy is expressed as:

$$
\Pi_{S}=\Pi_{N C}+\Pi_{C}
$$

in which,

$$
\begin{aligned}
\Pi_{C}=\frac{1}{2} \int_{A}\left(N_{x x} \phi_{0}\right. & \left.+M_{x x} \phi_{1}+N_{x y} k_{0}+M_{x y} k_{1}+N_{y y} \varphi_{0}+M_{y y} \varphi_{1}+Q_{x} \gamma_{1}+Q_{y} \gamma_{2}\right) \mathrm{d} A \\
\Pi_{N C}= & \frac{1}{2} \int_{A}\left(T_{x x} \frac{\partial \phi_{0}}{\partial x}+M_{x x x} \frac{\partial \phi_{1}}{\partial x}+T_{y x x} \frac{\partial \phi_{0}}{\partial y}+M_{y x x} \frac{\partial \phi_{1}}{\partial y}+T_{z x x} \phi_{1}\right. \\
& +T_{x y y} \frac{\partial \varphi_{0}}{\partial x}+M_{x y y} \frac{\partial \varphi_{1}}{\partial x}+T_{y y y} \frac{\partial \varphi_{0}}{\partial y}+M_{y y y} \frac{\partial \varphi_{1}}{\partial y} \\
& +T_{z y y} \varphi_{1}+T_{x x y} \frac{\partial k_{0}}{\partial x}+M_{x x y} \frac{\partial k_{1}}{\partial x}+T_{y y x} \frac{\partial k_{0}}{\partial y} \\
& +M_{y y x} \frac{\partial k_{1}}{\partial y}+T_{z x y} k_{1}+T_{x x z} \frac{\partial \gamma_{1}}{\partial x}+T_{y x z} \frac{\partial \gamma_{1}}{\partial y} \\
& \left.+T_{x y z} \frac{\partial \gamma_{2}}{\partial x}+T_{y y z} \frac{\partial \gamma_{2}}{\partial y}\right) \mathrm{d} A
\end{aligned}
$$


In Equations (24) and (25), the non-classical and classical resultant moments and forces are expressed as follows:

$$
\begin{aligned}
& N_{i j}=\int_{-\frac{h}{2}}^{\frac{h}{2}} \sigma_{i j} \mathrm{~d} z, \quad M_{i j}=\int_{-\frac{h}{2}}^{\frac{h}{2}} \sigma_{i j} z \mathrm{~d} z, \quad Q_{i}=K_{S} \int_{-\frac{h}{2}}^{\frac{h}{2}} \sigma_{i z} \mathrm{~d} z, \\
& T_{i j k}=\int_{-\frac{h}{2}}^{\frac{h}{2}} \tau_{i j k} \mathrm{~d} z, \quad M_{i j k}=\int_{-\frac{h}{2}}^{\frac{h}{2}} \tau_{i j k} z \mathrm{~d} z .
\end{aligned}
$$

where $K_{S}=5 / 6$ denotes the shear correction factor [88-91]; the non-classical and classical resultant moments and forces are given in Appendix A in detail.

\subsection{Kinetic Energy and External Work}

According to the FSD shell theory, the kinetic energy of the FG NPMF nanoshell, $\Pi_{T}$, is written as:

$$
\begin{gathered}
\Pi_{T}=\frac{1}{2} \int_{A} \int_{-\frac{h}{2}}^{\frac{h}{2}} \rho(z)\left[\left(\frac{\partial u}{\partial t}+z \frac{\partial \psi_{x}}{\partial t}\right)^{2}+\left(\frac{\partial v}{\partial t}+z \frac{\partial \psi_{y}}{\partial t}\right)^{2}+\left(\frac{\partial w}{\partial t}\right)^{2}\right] \mathrm{d} z \mathrm{~d} A \\
=\frac{1}{2} \int_{A}\left[I_{0}\left(\frac{\partial u}{\partial t}\right)^{2}+2 I_{1}\left(\frac{\partial u}{\partial t}\right)\left(\frac{\partial \psi_{x}}{\partial t}\right)+I_{0}\left(\frac{\partial v}{\partial t}\right)^{2}+I_{0}\left(\frac{\partial w}{\partial t}\right)^{2}\right. \\
\left.+2 I_{1}\left(\frac{\partial v}{\partial t}\right)\left(\frac{\partial \psi_{y}}{\partial t}\right)+I_{2}\left(\frac{\partial \psi_{x}}{\partial t}\right)^{2}+I_{2}\left(\frac{\partial \psi_{y}}{\partial t}\right)^{2}\right] \mathrm{d} A
\end{gathered}
$$

in which

$$
I_{0}=\int_{-\frac{h}{2}}^{\frac{h}{2}} \rho(z) \mathrm{d} z, \quad I_{1}=\int_{-\frac{h}{2}}^{\frac{h}{2}} \rho(z) z \mathrm{~d} z, I_{2}=\int_{-\frac{h}{2}}^{\frac{h}{2}} \rho(z) z^{2} \mathrm{~d} z .
$$

Furthermore, the work $\Pi_{P}$ carried out by axial loads $N_{x x}^{0}$ can be written as:

$$
\Pi_{p}=\frac{1}{2} \int_{A}\left[N_{x x}^{0}\left(\frac{\partial w}{\partial x}\right)^{2}\right] \mathrm{d} A
$$

\subsection{Variational Formulation}

Using Hamilton's principle,

$$
\delta \int_{0}^{t}\left(\Pi_{T}-\Pi_{S}-\Pi_{P}\right) \mathrm{d} t=0
$$

Inserting Equations (23), (27) and (29) into Equation (30) yields the following governing equations:

$$
\begin{gathered}
\delta u: \frac{\partial \bar{N}_{x x}}{\partial x}+\frac{\partial \bar{N}_{x y}}{\partial y}=I_{0} \frac{\partial^{2} u}{\partial t^{2}}+I_{1} \frac{\partial^{2} \psi_{x}}{\partial t^{2}} \\
\delta v: \frac{\partial \bar{N}_{x y}}{\partial x}+\frac{\partial \bar{N}_{y y}}{\partial y}+\frac{\bar{Q}_{y}}{R}=I_{0} \frac{\partial^{2} v}{\partial t^{2}}+I_{1} \frac{\partial^{2} \psi_{y}}{\partial t^{2}} \\
\delta w: \frac{\partial \bar{Q}_{x}}{\partial x}+\frac{\partial \bar{Q}_{y}}{\partial y}-\frac{\bar{N}_{y y}}{R}+N_{x x}^{0} \frac{\partial^{2} w}{\partial x^{2}}=I_{0} \frac{\partial^{2} w}{\partial t^{2}} \\
\delta \psi_{x}: \frac{\partial \bar{M}_{x x}}{\partial x}+\frac{\partial \bar{M}_{x y}}{\partial y}-\bar{Q}_{x}=I_{2} \frac{\partial^{2} \psi_{x}}{\partial t^{2}}+I_{1} \frac{\partial^{2} u}{\partial t^{2}} \\
\delta \psi_{y}: \frac{\partial \bar{M}_{x y}}{\partial x}+\frac{\partial \bar{M}_{y y}}{\partial y}-\bar{Q}_{y}=I_{2} \frac{\partial^{2} \psi_{y}}{\partial t^{2}}+I_{1} \frac{\partial^{2} v}{\partial t^{2}}
\end{gathered}
$$


where,

$$
\left\{\begin{array}{l}
\bar{N}_{x x}=N_{x x}-\frac{\partial T_{y x x}}{\partial y}-\frac{\partial T_{x x x}}{\partial x}, \\
\bar{N}_{x y}=N_{x y}-\frac{\partial T_{y y x}}{\partial y}-\frac{\partial T_{x x y}}{\partial x}, \\
\bar{N}_{y y}=N_{y y}-\frac{\partial T_{y y y}}{\partial y}-\frac{\partial T_{x y y}}{\partial x}-\frac{T_{y y z}}{R}, \\
\bar{M}_{x x}=M_{x x}+T_{z x x}-\frac{\partial M_{y x x}}{\partial y}-\frac{\partial M_{x x x}}{\partial x}, \\
\bar{M}_{y y}=M_{y y}+T_{z y y}-\frac{\partial M_{y y y}}{\partial y}-\frac{\partial M_{x y y}}{\partial x}, \\
\bar{M}_{x y}=M_{x y}+T_{z x y}-\frac{\partial M_{y y x}}{\partial y}-\frac{\partial M_{x x y}}{\partial x}, \\
\bar{Q}_{x}=Q_{x}-\frac{\partial T_{y x z}}{\partial y}-\frac{\partial T_{x x z}}{\partial x}, \\
\bar{Q}_{y}=Q_{y}-\frac{\partial T_{y y z}}{\partial y}-\frac{\partial T_{x y z}}{\partial x} .
\end{array}\right.
$$

Simultaneously, boundary conditions are derived as:

$$
\begin{gathered}
\delta u=0 \text { or }\left(\bar{N}_{x x}\right) n_{x}+\left(\bar{N}_{x y}\right) n_{y}=0, \\
\delta u_{, x}=0 \text { or }\left(T_{x x x}\right) n_{x}+\left(T_{y x x}\right) n_{y}=0, \\
\delta u_{, y}=0 \text { or }\left(T_{x x y}\right) n_{x}+\left(T_{y y x}\right) n_{y}=0 . \\
\delta v=0 \text { or }\left(\bar{N}_{x y}-\frac{T_{x y z}}{R}\right) n_{x}+\left(\bar{N}_{y y}-\frac{T_{y y z}}{R}\right) n_{y}=0, \\
\delta v_{, x}=0 \text { or }\left(T_{x x y}\right) n_{x}+\left(T_{y y x}\right) n_{y}=0 \\
\delta v, y=0 \text { or }\left(T_{x y y}\right) n_{x}+\left(T_{y y y}\right) n_{y}=0 . \\
\delta w=0 \text { or }\left(\bar{Q}_{x}+\frac{T_{x y y}}{R}\right) n_{x}+\left(\bar{Q}_{y}+\frac{T_{y y y}}{R}\right) n_{y}=0, \\
\delta w_{, x}=0 \text { or }\left(T_{x x z}\right) n_{x}+\left(T_{y x z}\right) n_{y}=0, \\
\delta w_{, y}=0 \text { or }\left(T_{x y z}\right) n_{x}+\left(T_{y y z}\right) n_{y}=0 . \\
\delta \psi_{x}=0 \text { or }\left(\bar{M}_{x x}+T_{x x z}\right) n_{x}+\left(\bar{M}_{x y}+T_{y x z}\right) n_{y}=0, \\
\delta \psi_{x, x}=0 \text { or }\left(M_{x x x}\right) n_{x}+\left(M_{y x x}\right) n_{y}=0, \\
\delta \psi_{x, y}=0 \text { or }\left(M_{x x y}\right) n_{x}+\left(M_{y y x}\right) n_{y}=0 . \\
\delta \psi_{y}=0 \text { or }\left(\bar{M}_{x y}+T_{x y z}\right) n_{x}+\left(\bar{M}_{y y}+T_{y y z}\right) n_{y}=0, \\
\delta \psi_{y, x}=0 \text { or }\left(M_{x x y}\right) n_{x}+\left(M_{y y x}\right) n_{y}=0, \\
\delta \psi_{y, y}=0 \text { or }\left(M_{x y y}\right) n_{x}+\left(M_{y y y}\right) n_{y}=0 .
\end{gathered}
$$

where $n_{x}$ as well as $n_{y}$ indicate the direction cosines of the outward unit normal to the boundary of the mid-plane.

Substituting Equation (36) into Equations (31)-(35) and considering Equation (17) and Appendix A, it yields the governing equations in terms of $u, v, w, \psi_{x}$, and $\psi_{y}$ :

$$
\begin{aligned}
& A_{11} \frac{\partial^{2} u}{\partial x^{2}}+A_{55}\left(\frac{\partial^{2} u}{\partial y^{2}}+\frac{\partial^{2} v}{\partial x \partial y}\right)-E_{1} \frac{\partial^{4} u}{\partial x^{4}}-\frac{E_{6}}{2} \frac{\partial^{4} u}{\partial y^{4}} \\
& -\left(E_{3}+E_{4}+E_{5}+\frac{E_{6}}{2}\right) \frac{\partial^{4} u}{\partial y^{2} \partial x^{2}}-\frac{\left(2 E_{2}+E_{3}+E_{4}+E_{6}\right)}{2}\left(\frac{\partial^{4} v}{\partial y \partial x^{3}}+\frac{\partial^{4} v}{\partial y^{3} \partial x}\right) \\
& +\left(A_{12}+A_{55}\right) \frac{\partial^{2} v}{\partial \partial x}+\frac{A_{12}}{R} \frac{\partial w}{\partial x}-\frac{2 E_{2}+E_{3}+E_{4}}{2 R} \frac{\partial^{3} w}{\partial y^{2} \partial x} \\
& -\frac{E_{2}}{R} \frac{\partial^{3} w}{\partial x^{3}}+B_{11} \frac{\partial^{2} \psi_{x}}{\partial x^{2}}+B_{55} \frac{\partial^{2} \psi_{x}}{\partial y^{2}}-\left(F_{3}+F_{4}+F_{5}+\frac{F_{6}}{2}\right) \frac{\partial^{4} \psi_{x}}{\partial y^{2} \partial x^{2}}-F_{1} \frac{\partial^{4} \psi_{x}}{\partial x^{4}} \\
& -\frac{F_{6}}{2} \frac{\partial^{4} \psi_{x}}{\partial y^{4}}-\frac{2 F_{2}+F_{3}+F_{4}+F_{6}}{2}\left(\frac{\partial^{4} \psi_{y}}{\partial y \partial x^{3}}+\frac{\partial^{4} \psi_{y}}{\partial y^{3} \partial x}\right) \\
& +\left(B_{12}+B_{55}\right) \frac{\partial^{2} \psi_{y}}{\partial y \partial x}=I_{0} \frac{\partial^{2} u}{\partial t^{2}}+I_{1} \frac{\partial^{2} \psi_{x}}{\partial t^{2}}
\end{aligned}
$$




$$
\begin{aligned}
& -\frac{2 E_{2}+E_{3}+E_{4}+E_{6}}{2}\left(\frac{\partial^{4} u}{\partial y \partial x^{3}}+\frac{\partial^{4} u}{\partial y^{3} \partial x}\right)+\left(A_{12}+A_{55}\right) \frac{\partial^{2} u}{\partial y \partial x} \\
& -\left(E_{3}+E_{4}+E_{5}+\frac{E_{6}}{2}\right) \frac{\partial^{4} v}{\partial y^{2} \partial x^{2}}-\frac{E_{6}}{2} \frac{\partial^{4} v}{\partial x^{4}}-E_{1} \frac{\partial^{4} v}{\partial y^{4}}+A_{55} \frac{\partial^{2} v}{\partial x^{2}}+A_{11} \frac{\partial^{2} v}{\partial y^{2}}-\frac{K_{S} A_{55} v}{R^{2} v} \\
& +\frac{1}{R}\left(A_{11}+K_{S} A_{55}\right) \frac{\partial w}{\partial y}-\frac{1}{R}\left(\frac{E_{3}+E_{4}+2 E_{5}}{2}+A_{3}+A_{4}+\frac{A_{5}}{2}\right) \frac{\partial^{3} w}{\partial y \partial x^{2}} \\
& +\frac{E_{1}+E_{6}}{R} \frac{\partial^{3} w}{\partial y^{3}}-\left[\frac{1}{2 R}\left(2 A_{1}+2 A_{3}+2 A_{5}\right)+B_{12}+B_{55}\right] \frac{\partial^{2} \psi_{x}}{\partial y \partial x} \\
& -\frac{2 F_{2}+F_{3}+F_{4}+F_{6}}{2}\left(\frac{\partial^{4} \psi_{x}}{\partial y^{3} \partial x}+\frac{\partial^{4} \psi_{x}}{\partial y \partial x^{3}}\right)+\left[B_{55}+\frac{1}{2 R}\left(2 A_{4}+A_{5}\right)\right] \frac{\partial^{2} \psi_{y}}{\partial x^{2}} \\
& +\left(B_{11}-\frac{E_{4}+E_{6}}{R}\right) \frac{\partial^{2} \psi_{y}}{\partial y^{2}}-F_{1} \frac{\partial^{4} \psi_{y}}{\partial y^{4}}-\frac{F_{6}}{2} \frac{\partial^{4} \psi_{y}}{\partial x^{4}} \\
& -\left(F_{3}+F_{4}+F_{5}+\frac{F_{6}}{2}\right) \frac{\partial^{4} \psi_{y}}{\partial y^{2} \partial x^{2}}+\frac{K_{S} A_{55}}{R} \psi_{y}=I_{0} \frac{\partial^{2} v}{\partial t^{2}}+I_{1} \frac{\partial^{2} \psi_{y}}{\partial t^{2}} \\
& -\frac{A_{12}}{R} \frac{\partial u}{\partial x}-\frac{1}{2 R}\left(2 E_{2}+E_{3}+E_{4}\right) \frac{\partial^{3} u}{\partial y^{2} \partial x}+\frac{E_{2}}{2 R} \frac{\partial^{3} u}{\partial x^{3}} \\
& -\frac{1}{R}\left(A_{11}+K_{S} A_{55}+\frac{E_{6}}{2 R^{2}}\right) \frac{\partial v}{\partial y}+\frac{1}{R}\left(\frac{E_{3}+E_{4}+2 E_{5}}{2}+\frac{A_{3}+2 A_{4}+A_{5}}{2}\right) \frac{\partial^{3} v}{\partial y \partial x^{2}} \\
& +\frac{1}{R}\left(\frac{2 E_{1}+E_{6}}{2}\right) \frac{\partial^{3} v}{\partial y^{3}}-\left(A_{3}+2 A_{4}+A_{5}\right) \frac{\partial^{4} w}{\partial y^{2} \partial x^{2}} \\
& -\frac{E_{6}}{2}\left(\frac{\partial^{4} w}{\partial x^{4}}+\frac{\partial^{4} w}{\partial y^{4}}\right)+\left(A_{55} K_{S}+\frac{2 E_{5}+A_{3}}{2 R^{2}}\right) \frac{\partial^{2} w}{\partial x^{2}} \\
& +\left(A_{55} K_{S}+\frac{2 E_{1}+E_{6}}{R^{2}}\right) \frac{\partial^{2} w}{\partial y^{2}}-\frac{A_{11}}{R^{2}} w-\left(\frac{A_{1}-A_{3}-2 A_{4}-3 A_{5}}{2}\right) \frac{\partial^{3} \psi_{x}}{\partial y^{2} \partial x} \\
& -\left(\frac{E_{4}+E_{6}}{2}-\frac{F_{2}}{R}\right) \frac{\partial^{3} \psi_{x}}{\partial x^{3}}+\left(K_{S} A_{55}-\frac{B_{12}}{R}+\frac{A_{1}+A_{3}}{R^{2}}\right) \frac{\partial \psi_{x}}{\partial x} \\
& -\left(\frac{A_{1}+A_{3}+2 A_{4}+3 A_{5}}{2}+\frac{F_{3}+F_{4}+2 F_{5}}{R}\right) \frac{\partial^{3} \psi_{y}}{\partial y \partial x^{2}}-\left(\frac{E_{4}+E_{6}}{2}+\frac{-2 F_{1}}{R}\right) \frac{\partial^{3} \psi_{y}}{\partial y^{3}} \\
& +\left(K_{S} A_{55}-\frac{B_{11}}{R}+\frac{E_{4}+E_{6}}{2 R^{2}}\right) \frac{\partial \psi_{y}}{\partial y}+N_{x x}^{0} \frac{\partial^{2} w}{\partial x^{2}}=I_{0} \frac{\partial^{2} w}{\partial t^{2}} \\
& B_{11} \frac{\partial^{2} u}{\partial x^{2}}+B_{55} \frac{\partial^{2} u}{\partial y^{2}}-\left(F_{3}+F_{4}+F_{5}+\frac{F_{6}}{2}\right) \frac{\partial^{4} u}{\partial y^{2} \partial x^{2}} \\
& -F_{1} \frac{\partial^{4} u}{\partial x^{4}}-\frac{F_{6}}{2} \frac{\partial^{4} u}{\partial y^{4}}+\left[B_{12}+B_{55}-\frac{1}{2 R}\left(A_{1}+A_{3}+2 A_{5}\right)\right] \frac{\partial^{2} v}{\partial y \partial x} \\
& -\frac{2 F_{2}+F_{3}+F_{4}+F_{6}}{2}\left(\frac{\partial^{4} v}{\partial y^{3} \partial x}+\frac{\partial^{4} v}{\partial y \partial x^{3}}\right)-\left(K_{S} A_{55}-\frac{B_{12}}{R}\right) \frac{\partial w}{\partial x} \\
& +\left(\frac{A_{1}+A_{3}+2 A_{4}+3 A_{5}}{2}\right) \frac{\partial^{3} w}{\partial y^{2} \partial x}+\left(\frac{E_{4}+E_{6}}{2}-\frac{F_{2}}{R}\right) \frac{\partial^{3} w}{\partial x^{3}} \\
& -G_{1} \frac{\partial^{4} \psi_{x}}{\partial x^{4}}-\frac{G_{6}}{2} \frac{\partial^{4} \psi_{x}}{\partial y^{4}}-\left(G_{3}+G_{4}+G_{5}+G_{6}\right) \frac{\partial^{4} \psi_{x}}{\partial y^{2} \partial x^{2}} \\
& +\left(D_{11}+E_{4}+E_{5}+\frac{E_{6}}{2}\right) \frac{\partial^{2} \psi_{x}}{\partial x^{2}}+\left(D_{55}+2 A_{4}+A_{5}\right) \frac{\partial^{2} \psi_{x}}{\partial y^{2}} \\
& -A_{55} K_{S} \psi_{x}-\frac{G_{2}+G_{3}+G_{4}+G_{6}}{2}\left(\frac{\partial^{4} \psi_{y}}{\partial y \partial x^{3}}+\frac{\partial^{4} \psi_{y}}{\partial y^{3} \partial x}\right) \\
& +\left(D_{12}+D_{55}+A_{1}+2 A_{2}+\frac{A_{3}}{2}+A_{4}+\frac{A_{5}}{2}\right) \frac{\partial^{2} \psi_{y}}{\partial y \partial x}=I_{2} \frac{\partial^{2} \psi_{x}}{\partial t^{2}}+I_{1} \frac{\partial^{2} u}{\partial t^{2}}
\end{aligned}
$$

in which $A_{i j}, B_{i j}, D_{i j}, A_{i}, B_{i}, E_{i}, F_{i}$, and $G_{i}(i, j=1,2, \ldots, 6)$ are given in Appendix B.

It is worth mentioning that the present general strain gradient nanoshell model can reduce to those of MCST, MSGT, and CT. The MSGT model can be achieved if $a_{i}(i=1,2, \ldots, 5)$ are defined by three material length scale parameters as follows:

$$
\begin{array}{ll}
a_{1}=\mu\left(l_{2}^{2}-\frac{4}{15} l_{1}^{2}\right), & a_{2}=\mu\left(l_{0}^{2}-\frac{1}{15} l_{1}^{2}-\frac{1}{2} l_{2}^{2}\right), \\
a_{3}=-\mu\left(\frac{4}{15} l_{1}^{2}+\frac{1}{2} l_{2}^{2}\right), & a_{4}=\mu\left(\frac{1}{3} l_{1}^{2}+l_{2}^{2}\right), \quad a_{5}=\mu\left(\frac{2}{3} l_{1}^{2}-l_{2}^{2}\right) .
\end{array}
$$


where $l_{0}, l_{1}$, and $l_{2}$ are material length scale parameters corresponding to dilatation gradients, deviatoric stretch gradients and symmetric rotation gradients, respectively. In the following discussion, we assume that all the material length scale parameters are the same, namely, $l_{0}=l_{1}=l_{2}=l$. In addition, by setting $a_{1}=a_{2}=a_{3}=a_{4}=a_{5}=0$, the present nanoshell model can be simplified to the CT-based model. Moreover, the MCST model [51] can be achieved if $a_{i}(i=1,2, \ldots, 5)$ are set as:

$$
a_{1}=a_{4}=-2 a_{2}=-2 a_{3}=-a_{5}=\mu l^{2}
$$

\section{Closed-Form Solution}

Herein, we employ the Navier solution technique to analyze the free vibration and axial buckling behaviors of an FG NPMF cylindrical nanoshell. Navier's method can obtain an analytical solution by introducing the double trigonometric series. Note that this method is only applicable to the simply supported boundary condition. For the other boundary conditions which are different from the simply supported boundary condition, other numerical methods such as the finite element method, differential quadrature method, finite difference method, meshless method, and wavelet method can be used. As an example, the boundary condition of the FG NPMF nanoshell considered in our study is simply supported at edges $x=0$ as well as $x=L$, so one obtains:

$$
\left\{\begin{array}{l}
v=w=\psi_{y}=\bar{N}_{x x}=0, \\
\frac{\partial \psi_{y}}{\partial y}=\frac{\partial \psi_{x}}{\partial x}=\frac{\partial w}{\partial y}=\frac{\partial v}{\partial y}=\frac{\partial u}{\partial x}=0, \\
T_{x x y}=T_{x x z}=M_{x x y}=\bar{M}_{x x}+T_{x x z}=0 .
\end{array}\right.
$$

The Navier procedure is used by assuming the displacements as follows:

$$
\left\{\begin{array}{c}
u(x, y, t) \\
v(x, y, t) \\
w(x, y, t) \\
\psi_{x}(x, y, t) \\
\psi_{y}(x, y, t)
\end{array}\right\}=\sum_{n=1}^{\infty} \sum_{m=1}^{\infty}\left\{\begin{array}{c}
u_{m n}(t) \cos \left(\alpha_{m} x\right) \sin \left(\frac{n y}{R}\right) \\
v_{m n}(t) \sin \left(\alpha_{m} x\right) \cos \left(\frac{n y}{R}\right) \\
w_{m n}(t) \sin \left(\alpha_{m} x\right) \sin \left(\frac{n y}{R}\right) \\
\psi_{x m n}(t) \cos \left(\alpha_{m} x\right) \sin \left(\frac{n y}{R}\right) \\
\psi_{y m n}(t) \sin \left(\alpha_{m} x\right) \cos \left(\frac{n y}{R}\right)
\end{array}\right\}
$$

in which $\alpha_{m}=m \pi / L, n$ is the circumferential wave number, and $m$ is the axial half-wave number. Inserting Equation (50) into Equations (42)-(46) and then eliminating the trigonometric functions, the equations can be re-represented in the matrix form as:

$$
\ddot{\mathbf{M d}}+\left(\mathbf{K}+N_{x x}^{0} \mathbf{K}_{\mathbf{g}}\right) \mathbf{d}=0
$$

where the displacement vector $\mathbf{d}$, mass matrix $\mathbf{M}$, geometric stiffness matrix $\mathbf{K}_{\mathbf{g}}$, and stiffness matrix $\mathbf{K}$ are:

$$
\begin{gathered}
\mathbf{d}=\left[u_{m n}, v_{m n}, w_{m n}, \psi_{x m n}, \psi_{y m n}\right]^{\mathrm{T}} \\
\mathbf{K}=\left[\begin{array}{ccccc}
K_{11} & K_{12} & K_{13} & K_{14} & K_{15} \\
K_{21} & K_{22} & K_{23} & K_{24} & K_{25} \\
K_{31} & K_{32} & K_{33} & K_{34} & K_{35} \\
K_{41} & K_{42} & K_{43} & K_{44} & K_{45} \\
K_{51} & K_{52} & K_{53} & K_{54} & K_{55}
\end{array}\right] \\
\mathbf{M}=\left[\begin{array}{ccccc}
M_{11} & 0 & 0 & M_{14} & 0 \\
0 & M_{22} & 0 & 0 & M_{25} \\
0 & 0 & M_{33} & 0 & 0 \\
M_{41} & 0 & 0 & M_{44} & 0 \\
0 & M_{52} & 0 & 0 & M_{55}
\end{array}\right]
\end{gathered}
$$




$$
\mathbf{K}_{g}=\left[\begin{array}{ccccc}
0 & 0 & 0 & 0 & 0 \\
0 & 0 & 0 & 0 & 0 \\
0 & 0 & K_{g 33} & 0 & 0 \\
0 & 0 & 0 & 0 & 0 \\
0 & 0 & 0 & 0 & 0
\end{array}\right]
$$

in which the elements in these matrices are given in Appendix C.

If the dynamic displacement is considered, the form of the displacement vector $\mathbf{d}$ can be written as $\mathbf{d}=\mathbf{d}^{*} \mathrm{e}^{\mathrm{i} \omega t}$. Once we ignore $N_{x x}^{0}$, the eigenvalue problem of free vibrating nanoshells can be obtained as:

$$
\left(\mathbf{K}-\omega^{2} \mathbf{M}\right) \mathbf{d}^{*}=0
$$

where $\omega$ represents the natural frequency of the FG NPMF nanoshell. The non-trivial solution requires vanishing of the determinant of the coefficient matrix in Equation (56) [92-98].

Buckling loads of the FG NPMF nanoshell can be obtained by neglecting the inertia term in Equation (51). Letting $N_{x x}^{0}=-F$, one can get:

$$
\left(\mathbf{K}-F \mathbf{K}_{g}\right) \mathbf{d}=0
$$

where $F$ denotes the buckling load. For different combinations of $m$ and $n$, there exists a minimum value which satisfies Equation (57). This minimum value is termed as the critical buckling load $F_{\text {cr. }}$.

\section{Validation}

Some comparative studies are first undertaken to prove the reliability of the present analysis.

\subsection{Example 1: Homogeneous Cylindrical Nanoshell Based on the MSGT}

In Table 1, the present results for a homogeneous simply supported cylindrical nanoshell are compared with those obtained by Zhang et al. [99]. The parameters used are: $E=1.06 \mathrm{TPa}, v=0.3$, $\rho=2300 \mathrm{~kg} / \mathrm{m}^{3}, R=2.32 \mathrm{~nm}$, and $L / R=5$. The frequency parameter $\bar{\omega}=\omega R \sqrt{\rho / E}$ of the nanoshell is obtained based on the MSGT. One can see that the results from the current study coincide with those reported in Reference [99].

Table 1. Comparison of dimensionless natural frequency $\bar{\omega}$ for a homogeneous nanoscale cylindrical shell.

\begin{tabular}{cccccccc}
\hline \multirow{2}{*}{$(\boldsymbol{m}, \boldsymbol{n})$} & $\boldsymbol{h} / \boldsymbol{R}$ & \multicolumn{3}{c}{$\boldsymbol{l}=\mathbf{0}$} & \multicolumn{3}{c}{$\boldsymbol{l} \boldsymbol{h}$} \\
\cline { 3 - 7 } & & Zhang et al. [99] & Present & Error (\%) & Zhang et al. [99] & Present & Error (\%) \\
\hline$(1,1)$ & 0.02 & 0.19536 & 0.19536 & 0.00 & 0.19595 & 0.19561 & 0.10 \\
& 0.05 & 0.19542 & 0.19542 & 0.00 & 0.19908 & 0.19694 & 0.20 \\
$(2,2)$ & 0.1 & 0.19561 & 0.19564 & 0.01 & 0.20386 & 0.20148 & 1.17 \\
& 0.02 & 0.25285 & 0.25271 & 0.05 & 0.27108 & 0.27004 & 0.30 \\
& 0.05 & 0.25969 & 0.25885 & 0.30 & 0.35606 & 0.34641 & 0.96 \\
$(3,3)$ & 0.1 & 0.28080 & 0.27931 & 0.50 & 0.50626 & 0.50145 & 0.90 \\
& 0.02 & 0.27627 & 0.27580 & 0.16 & 0.37783 & 0.37382 & 1.39 \\
& 0.05 & 0.31667 & 0.31413 & 0.80 & 0.71543 & 0.69918 & 2.27 \\
& 0.1 & 0.40671 & 0.41916 & 2.97 & 1.08810 & 1.07892 & 0.84 \\
\hline
\end{tabular}

\subsection{Example 2: Homogeneous Cylindrical Nanoshells Based on the MCST}

In Table 2, the comparison study is conducted for natural frequency $\Omega=\omega R \sqrt{\rho / E}$ of a homogeneous nanoscale cylindrical shell with a simply supported boundary condition by using the MCST. The adopted material properties are: $E=1.06 \mathrm{TPa}, v=0.3, \rho=2300 \mathrm{~kg} / \mathrm{m}^{3}$. It is observed that the obtained results have a reasonable accordance with those reported [100]. 
Table 2. Comparison of dimensionless natural frequency $\Omega$ for a homogeneous cylindrical nanoshell $(R=2.32 \mathrm{~nm}$ and $L / R=5)$.

\begin{tabular}{cccccccc}
\hline \multirow{2}{*}{$h / R$} & $(m, n)$ & \multicolumn{3}{c}{$l=\mathbf{0}$} & \multicolumn{2}{c}{$l=h$} \\
\cline { 3 - 7 } & & Ghadiri et al. [100] & Present & Error (\%) & Ghadiri et al. [100] & Present & Error (\%) \\
\hline \multirow{2}{*}{0.02} & $m=n=1$ & 0.19536215 & 0.19536215 & 0.00 & 0.19543206 & 0.19548050 & 0.01 \\
& $m=n=2$ & 0.25271274 & 0.25271274 & 0.00 & 0.25731258 & 0.25785715 & 0.09 \\
& $m=n=3$ & 0.27580092 & 0.27580092 & 0.00 & 0.30621690 & 0.30717244 & 0.10 \\
& $m=5$ & 0.19542305 & 0.19542305 & 0.00 & 0.19585782 & 0.19618570 & 0.16 \\
& $m=n=1$ & 0.25884786 & 0.25884786 & 0.00 & 0.28543902 & 0.28780026 & 0.80 \\
& $m=n=2$ & 0.31407326 & 0.31407326 & 0.00 & 0.45457555 & 0.46000081 & 1.10 \\
\hline
\end{tabular}

\subsection{Example 3: FG Cylindrical Shell}

Herein, a comparison study is conducted for a simply supported FG cylindrical shell without considering the size effect, as given in Table 3. The FG shell is made of the mixture of Stainless Steel (SS) and Nickel (Ni) with the following material parameters: $E_{\mathrm{SS}}=207.788 \mathrm{GPa}, \rho_{\mathrm{SS}}=8166 \mathrm{~kg} / \mathrm{m}^{3}$ and $v_{\mathrm{SS}}=0.317756$ for SS, and $E_{\mathrm{Ni}}=205.098 \mathrm{GPa}, \rho_{\mathrm{Ni}}=8900 \mathrm{~kg} / \mathrm{m}^{3}$ and $\nu_{\mathrm{NI}}=0.31$ for Ni. Our study yields an excellent agreement with Reference [101], bespeaking the correctness of the current research.

Table 3. Comparison of natural frequencies $(\mathrm{Hz})$ for a simply supported FG cylindrical shell $(n=1$, $R=1 \mathrm{~m}$ and $L / R=20$ )

\begin{tabular}{cccccccc}
\hline \multirow{2}{*}{$h / \boldsymbol{R}$} & $\boldsymbol{N}$ & \multicolumn{3}{c}{ Loy et al. [101] } & \multicolumn{3}{c}{ Present } \\
\cline { 3 - 7 } & & $\boldsymbol{m = 1}$ & $\boldsymbol{m = 2}$ & $\boldsymbol{m = 3}$ & $\boldsymbol{m = 1}$ & $\boldsymbol{m = \mathbf { 2 }}$ & $\boldsymbol{m}=\mathbf{3}$ \\
\hline 0.002 & 0 & 13.548 & 4.5920 & 4.2633 & 13.548 & 4.5920 & 4.2633 \\
& 0.5 & 13.321 & 4.5168 & 4.1911 & 13.321 & 4.5168 & 4.1911 \\
& 1 & 13.211 & 4.4800 & 4.1569 & 13.211 & 4.4800 & 4.1569 \\
& 2 & 13.103 & 4.4435 & 4.1235 & 13.103 & 4.4434 & 4.1234 \\
0.05 & 5 & 12.998 & 4.4068 & 4.0891 & 12.998 & 4.4068 & 4.0891 \\
& 0 & 13.572 & 33.296 & 93.001 & 13.572 & 33.242 & 92.634 \\
& 0.5 & 13.345 & 32.702 & 91.319 & 13.345 & 32.645 & 90.943 \\
& 1 & 13.235 & 32.430 & 90.553 & 13.235 & 32.370 & 90.172 \\
& 2 & 13.127 & 32.170 & 89.828 & 13.127 & 32.111 & 89.451 \\
& 5 & 13.021 & 31.910 & 89.109 & 13.021 & 31.854 & 88.743 \\
\hline
\end{tabular}

\section{Results and Discussion}

In this section, size-dependent free vibration and axial buckling of an FG NPMF nanoshell simply supported at both ends are studied. The material properties of the nanoshell are $E_{1}^{*}=200 \mathrm{GPa}$, $\rho_{1}^{*}=7850 \mathrm{~kg} / \mathrm{m}^{3}$, and $\nu=1 / 3$. The dimensionless natural frequency is defined as $\Omega=\omega R \sqrt{\rho_{1}^{*} / E_{1}^{*}}$ and the dimensionless buckling load is $\bar{F}=F / A_{110}$, where $A_{110}$ is the specific value of $A_{11}$ for the homogeneous nanoshell made of solid metal.

\subsection{Free Vibration Analysis}

Table 4 shows the variation of dimensionless natural frequency with the circumferential wave number for various length scale parameters. It is found that by increasing the dimensionless length scale parameter, the natural frequencies of the system decrease. Moreover, the fundamental natural frequency occurs at $n=2$, independent of the length scale parameter. In the following studies, the mode $(1,2)$ is chosen as a representative mode.

Table 4. Effect of length scale parameter on dimensionless natural frequencies $\Omega$ based on the MSGT (nanoporosity-1, $m=1, h=10 \mathrm{~nm}, R=20 h, L / R=4, e_{0}=0.5$ ).

\begin{tabular}{cccccccc}
\hline & $h / l=\mathbf{1}$ & $h / l=\mathbf{1 . 5}$ & $h / l=\mathbf{2}$ & $h / l=\mathbf{3}$ & $h / l=4$ & $h / l=\mathbf{5}$ & $h / l=\mathbf{1 0}$ \\
\hline$n=1$ & 0.25824 & 0.25723 & 0.25687 & 0.25662 & 0.25653 & 0.25649 & 0.25643 \\
$n=2$ & 0.20493 & 0.16730 & 0.15125 & 0.13840 & 0.13356 & 0.13125 & 0.12809 \\
$n=3$ & 0.42938 & 0.31512 & 0.25919 & 0.20833 & 0.18683 & 0.17591 & 0.16009 \\
$n=4$ & 0.76650 & 0.56684 & 0.46542 & 0.37079 & 0.32994 & 0.30894 & 0.27818 \\
$n=5$ & 1.17537 & 0.88269 & 0.72927 & 0.58336 & 0.51961 & 0.48665 & 0.43816 \\
$n=6$ & 1.64107 & 1.25206 & 1.04209 & 0.83851 & 0.74844 & 0.70162 & 0.63245 \\
\hline
\end{tabular}


The dimensionless natural frequency versus nanoporosity coefficient for different theories and nanoporosity distributions is illustrated in Figure 4. Results show that the natural frequency decreases by increasing the nanoporosity coefficient, indicating that the nano-pores decrease the effective stiffness of the nanoshell. Furthermore, the nanoporosity-2 nanoshell has a lower natural frequency than its nanoporosity-1 counterpart. It is observed that the natural frequencies predicted by the MCST and MSGT are greater than the natural frequency predicted by the CT. In other words, the additional length scale parameter makes the FG NPMF nanoshell stiffer. This is due to the extra stiffness introduced in the MCST and MSGT.

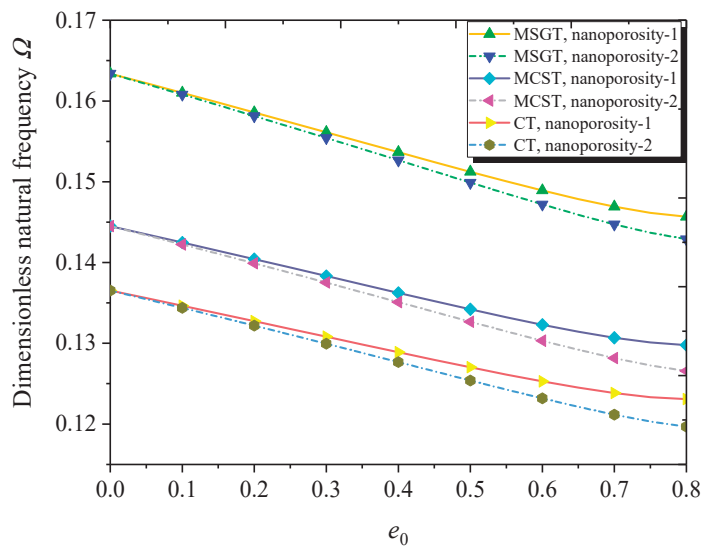

Figure 4. Dimensionless natural frequency versus nanoporosity coefficient with different theories and nanoporosity distributions ( $m=1, n=2, h=10 \mathrm{~nm}, R=20 h, h=2 l, L=4 R$ ).

Depicted in Figure 5 is the variation of the dimensionless natural frequency against the dimensionless length scale parameter. It is seen that the size effect on natural frequency is more pronounced when the thickness of the nanoshell is comparable to the length scale parameter. The dimensionless natural frequencies from the MCST and MSGT converge to the results from the CT for a large value of the dimensionless length scale parameter, indicating that the larger dimensionless length scale parameter diminishes the size effect on the natural frequency of the FG NPMF nanoshell.

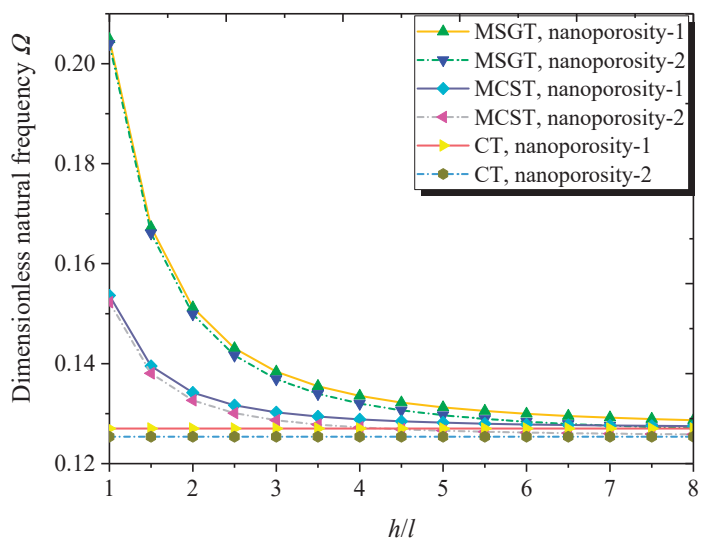

Figure 5. Dimensionless natural frequency versus dimensionless length scale parameter with different theories and nanoporosity distributions ( $m=1, n=2, h=10 \mathrm{~nm}, R=20 h, L=4 R, e_{0}=0.5$ ). 
Figure 6 plots the dimensionless natural frequency versus length-to-radius ratio with different theories and nanoporosity distributions. One can see that as the length-to-radius ratio increases, the dimensionless natural frequency decreases gradually. Compared to the MCST, the MSGT leads to more reasonable results due to the introduction of an additional deviatoric stretch gradient tensor and the dilatation gradient tensor in addition to the symmetric rotation gradient tensor.

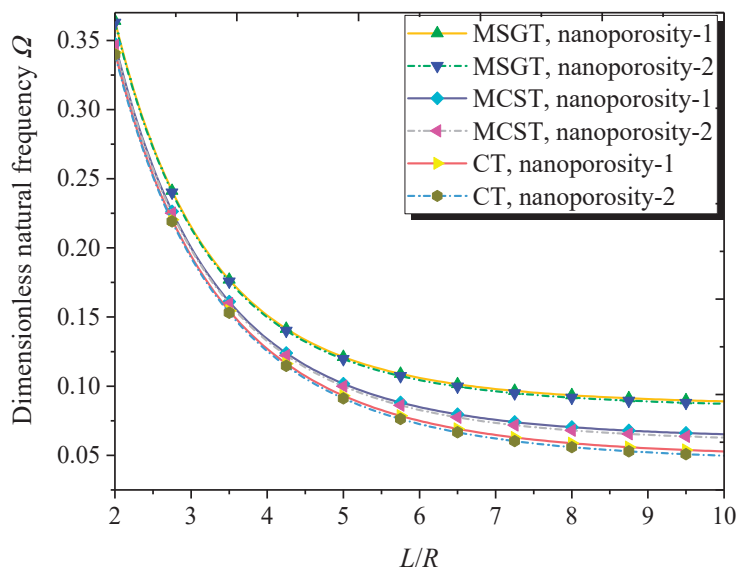

Figure 6. Dimensionless natural frequency versus length-to-radius ratio with different theories and nanoporosity distributions ( $m=1, n=2, h=10 \mathrm{~nm}, R=20 h, h=2 l, e_{0}=0.5$ ).

Figure 7 illustrates the effect of the thickness-to-radius ratio on the dimensionless natural frequency of the FG NPMF nanoshell. As expected, the natural frequency of the FG NPMF nanoshell increases with the rise of thickness-to-radius. This is because the larger thickness-to-radius ratio results in the enhancement of the nanoshell stiffness. Moreover, the difference among the results obtained from the MCST, MSGT, and CT becomes more and more notable as the ratio of thickness-to-radius increases, indicating that the size effect is more significant at the larger thickness-to-radius ratio.

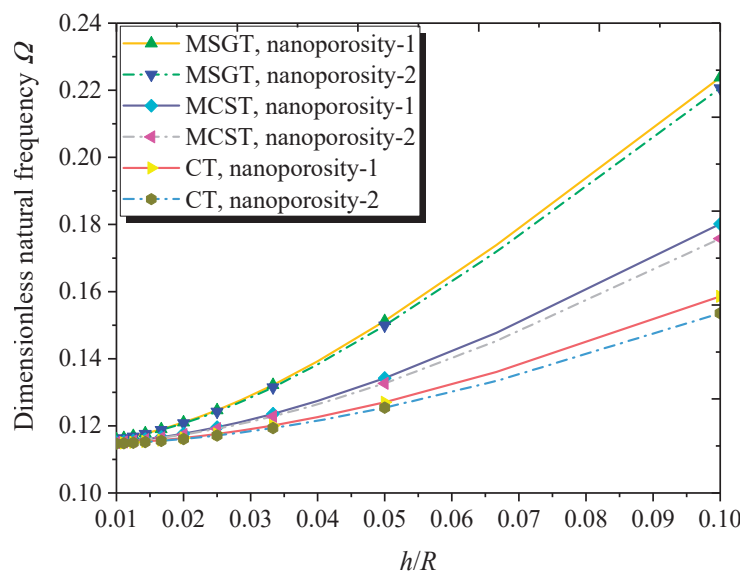

Figure 7. Dimensionless natural frequency versus thickness-to-radius ratio with different theories and nanoporosity distributions ( $m=1, n=2, h=10 \mathrm{~nm}, L=4 R, h=2 l, e_{0}=0.5$ ). 


\subsection{Buckling Analysis}

The effect of the length scale parameter on the dimensionless buckling load is shown in Table 5 . It is revealed that by increasing the dimensionless length scale parameter, the buckling load of the system decreases. Additionally, with the increase of circumferential wave number, the buckling load first decreases and then increases. It is noted that the critical buckling load occurs at $n=2$.

Table 5. Effect of the length scale parameter on dimensionless buckling load $\bar{F}$ based on the MSGT (nanoporosity-1, $m=1, h=10 \mathrm{~nm}, R=20 h, L / R=4, e_{0}=0.5$ ).

\begin{tabular}{cccccccc}
\hline & $h / l=\mathbf{1}$ & $h / l=\mathbf{1 . 5}$ & $h / l=\mathbf{2}$ & $h / l=\mathbf{3}$ & $h / l=4$ & $h / l=5$ & $h / l=\mathbf{1 0}$ \\
\hline$n=1$ & 0.12274 & 0.12167 & 0.12129 & 0.12101 & 0.12092 & 0.12087 & 0.12081 \\
$n=2$ & 0.04801 & 0.03188 & 0.02603 & 0.02177 & 0.02027 & 0.01957 & 0.01864 \\
$n=3$ & 0.18358 & 0.09853 & 0.06657 & 0.04297 & 0.03455 & 0.03062 & 0.02536 \\
$n=4$ & 0.55614 & 0.30326 & 0.20422 & 0.12951 & 0.10252 & 0.08987 & 0.07285 \\
$n=5$ & 1.27769 & 0.71906 & 0.49043 & 0.31364 & 0.24878 & 0.21820 & 0.17686 \\
$n=6$ & 2.45989 & 1.43011 & 0.99029 & 0.64101 & 0.51065 & 0.44875 & 0.36462 \\
\hline
\end{tabular}

Figure 8 plots the dimensionless critical buckling load versus nanoporosity coefficient for both nanoporosity distributions based on the MCST, MSGT, and CT. As can be observed, the larger nanoporosity coefficient results in a lower dimensionless critical buckling load. Moreover, the nanoporosity-1 nanoshell has a higher critical buckling load than its nanoporosity-2 counterpart. The difference between them tends to be significant with the increase of the nanoporosity coefficient. Furthermore, compared to the MCST, the MSGT leads to a more reasonable buckling load due to the introduction of an additional deviatoric stretch gradient tensor and dilatation gradient tensor in addition to the symmetric rotation gradient tensor.

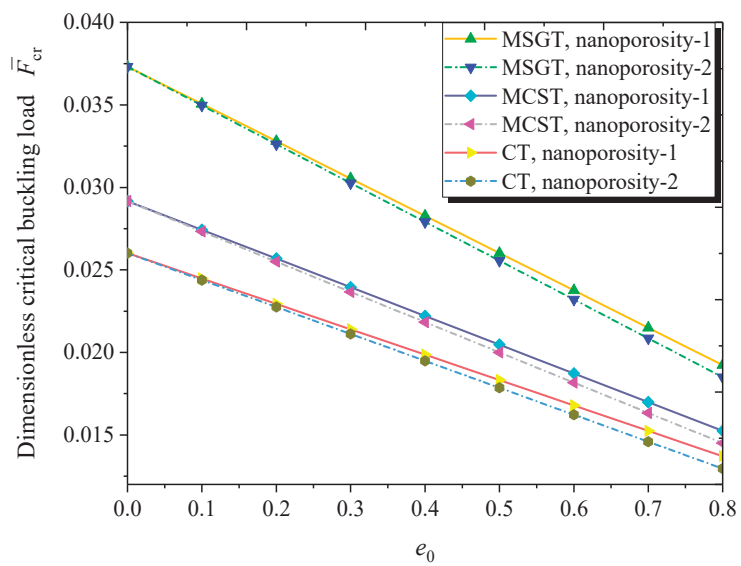

Figure 8. Dimensionless critical buckling load versus nanoporosity coefficient $(m=1, n=2, h=10 \mathrm{~nm}$, $R=20 h, L=4 R, h=2 l)$.

Figure 9 compares the variation of the dimensionless critical buckling load with the dimensionless length scale parameter based on classical and non-classical shell models. It is noted that the critical buckling load decreases with the increasing dimensionless length scale parameter. In addition, the difference among the results from the three models (MCST, MSGT, and CT) is diminishing when the dimensionless length scale parameter tends to large, indicating that the size effect is only significant when the thickness of the nanoshell is comparable to the length scale parameter. This phenomenon was also found in microplates and microbeams [41,47,102]. 


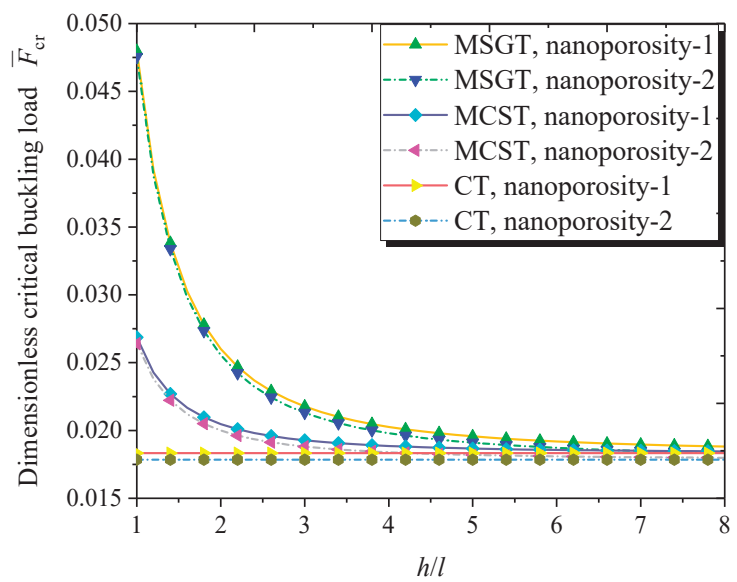

Figure 9. Dimensionless critical buckling load versus dimensionless length scale parameter $(m=1$, $\left.n=2, h=10 \mathrm{~nm}, R=20 h, L=4 R, e_{0}=0.5\right)$.

Depicted in Figure 10 is the variation of the dimensionless buckling load with the length-to-radius ratio for both kinds of nanoporosity distribution. It can be seen that with the increase of the length-to-radius ratio, the dimensionless buckling load first decreases and then increases. Moreover, the dimensionless buckling load obtained through the MSGT is greater than those predicted via the CT and MCST. The difference between the results obtained by the MCST, MSGT, and CT becomes more and more significant as the length-to-radius ratio rises.

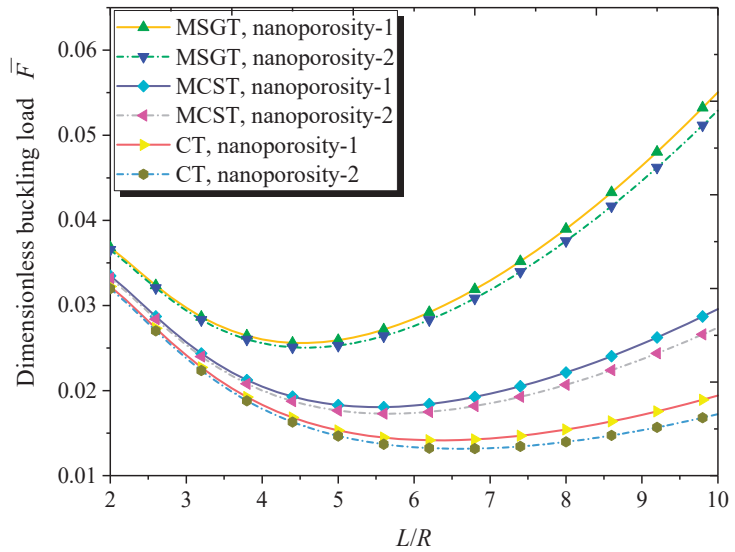

Figure 10. Dimensionless buckling load versus length-to-radius ratio $(m=1, n=2, h=10 \mathrm{~nm}, R=20 h$, $\left.h=2 l, e_{0}=0.5\right)$.

Figure 11 plots the dimensionless buckling load with respect to the thickness-to-radius ratio for both kinds of nanoporosity distribution. As can be seen, the increase in the thickness-to-radius ratio contributes to the higher buckling load of the FG NPMF nanoshell. This is due to the fact that the larger thickness-to-radius ratio enhances the stiffness of the FG NPMF nanoshell. 


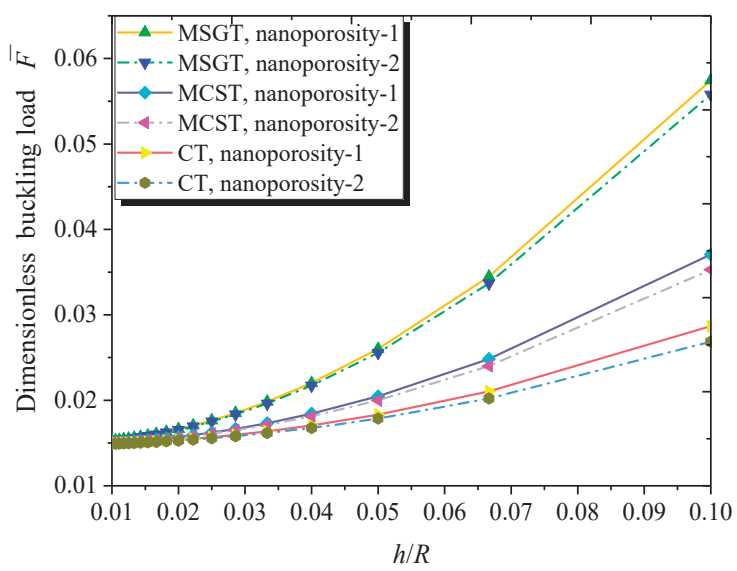

Figure 11. Dimensionless buckling load versus thickness-to-radius ratio ( $m=1, n=2, h=10 \mathrm{~nm}, L=4 R$, $\left.h=2 l, e_{0}=0.5\right)$.

\section{Conclusions}

In this paper, size-dependent free vibration and buckling of FG NPMF cylindrical nanoshells are investigated based upon the FSD shell theory and general SGT. The symmetric and unsymmetric nanoporosity distributions are considered for the structural composition. Governing equations, as well as corresponding boundary conditions, are derived via Hamilton's principle. Moreover, the Navier solution technique is employed to derive the analytical solutions for FG NPMF nanoshells with a simply supported boundary condition. The conclusions can be summarized as follows:

(1) Nanoporosity distribution has a significant influence on the vibration and buckling characteristics of FG NPMF nanoshells. Natural frequencies and buckling loads of the nanoporosity-2 nanoshell are lower than those of the nanoporosity- 1 nanoshell. As the nanoporosity coefficient increases, natural frequencies and buckling loads of the nanoshell decrease.

(2) Natural frequencies of the FG NPMF nanoshells decrease with the increasing length-to-radius ratio. Additionally, the larger thickness-to-radius ratio leads to the higher natural frequency of the FG NPMF nanoshell.

(3) Buckling loads decrease first and then increase with the increase of the length-to-radius ratio. Furthermore, buckling loads increase with the increasing thickness-to-radius ratio of the nanoshell.

(4) When the nanoshell thickness is approximately equal to the length scale parameter, the MSGT is more appropriate than the CT and MCST for free vibration and buckling analysis of FG NPMF nanoshells.

Author Contributions: Conceptualization, Y.Z. and F.Z.; Methodology, F.Z.; Software, F.Z.; Validation, F.Z.; Formal Analysis, F.Z.; Investigation, F.Z.; Resources, Y.Z.; Data Curation, F.Z.; Writing-Original Draft Preparation, F.Z.; Writing-Review \& Editing, Y.Z.; Visualization, F.Z.; Supervision, Y.Z.; Project Administration, Y.Z.; Funding Acquisition, Y.Z.

Funding: This research was funded by the National Natural Science Foundation of China (Grant no. 11672188).

Conflicts of Interest: The authors declare no conflict of interest.

\section{Appendix A}

The non-classical and classical resultant moments and forces in Equation (26) are:

$$
N_{x x}=B_{11} \phi_{1}+A_{11} \phi_{0}+B_{12} \varphi_{1}+A_{12} \varphi_{0}
$$




$$
\begin{aligned}
& N_{y y}=B_{11} \varphi_{1}+A_{11} \varphi_{0}+B_{12} \phi_{1}+A_{12} \phi_{0} \\
& N_{x y}=B_{55} k_{1}+A_{55} k_{0} \\
& Q_{x}=K_{S} A_{55} \gamma_{1}, Q_{y}=K_{S} A_{55} \gamma_{2} \\
& M_{x x}=D_{11} \phi_{1}+B_{11} \phi_{0}+D_{12} \varphi_{1}+B_{12} \varphi_{0} \\
& M_{y y}=D_{11} \varphi_{1}+B_{11} \varphi_{0}+D_{12} \phi_{1}+B_{12} \phi_{0} \\
& M_{x y}=D_{55} k_{1}+B_{55} k_{0} \\
& T_{x x x}=E_{1} \frac{\partial \phi_{0}}{\partial x}+E_{2} \frac{\partial \varphi_{0}}{\partial x}+\frac{E_{3}}{2} \frac{\partial k_{0}}{\partial y}+F_{1} \frac{\partial \phi_{1}}{\partial x}+F_{2} \frac{\partial \varphi_{1}}{\partial x}+\frac{F_{3}}{2} \frac{\partial k_{1}}{\partial y} \\
& T_{y x x}=E_{2} \frac{\partial \varphi_{0}}{\partial y}+\frac{1}{2}\left(E_{4} \frac{\partial k_{0}}{\partial x}+F_{4} \frac{\partial k_{1}}{\partial x}\right)+E_{5} \frac{\partial \phi_{0}}{\partial y}+F_{2} \frac{\partial \varphi_{1}}{\partial y}+F_{5} \frac{\partial \phi_{1}}{\partial y} \\
& T_{z x x}=E_{5} \phi_{1}+\frac{E_{4}}{2} \frac{\partial \gamma_{1}}{\partial x}+\frac{A_{1}}{2} \frac{\partial \gamma_{2}}{\partial y}+2 A_{2} \varphi_{1} \\
& T_{x y y}=\frac{E_{4}}{2} \frac{\partial k_{0}}{\partial y}+E_{2} \frac{\partial \phi_{0}}{\partial x}+E_{5} \frac{\partial \varphi_{0}}{\partial x}+\frac{F_{4}}{2} \frac{\partial k_{1}}{\partial y}+F_{2} \frac{\partial \phi_{1}}{\partial x}+F_{5} \frac{\partial \varphi_{1}}{\partial x} \\
& T_{y y y}=E_{2} \frac{\partial \phi_{0}}{\partial y}+\frac{E_{3}}{2} \frac{\partial k_{0}}{\partial x}+E_{1} \frac{\partial \varphi_{0}}{\partial y}+F_{2} \frac{\partial \phi_{1}}{\partial y}+\frac{F_{3}}{2} \frac{\partial k_{1}}{\partial x}+F_{1} \frac{\partial \varphi_{1}}{\partial y} \\
& T_{z y y}=\frac{A_{1}}{2} \frac{\partial \gamma_{1}}{\partial x}+2 A_{2} \phi_{1}+E_{5} \varphi_{1}+\frac{E_{4}}{2} \frac{\partial \gamma_{2}}{\partial y} \\
& T_{x x y}=\frac{E_{3}}{2} \frac{\partial \varphi_{0}}{\partial y}+\frac{E_{6}}{2} \frac{\partial k_{0}}{\partial x}+\frac{E_{4}}{2} \frac{\partial \phi_{0}}{\partial y}+\frac{F_{3}}{2} \frac{\partial \varphi_{1}}{\partial y}+\frac{F_{6}}{2} \frac{\partial k_{1}}{\partial x}+\frac{F_{4}}{2} \frac{\partial \phi_{1}}{\partial y} \\
& T_{y y x}=\frac{E_{4}}{2} \frac{\partial \varphi_{0}}{\partial x}+\frac{E_{3}}{2} \frac{\partial \phi_{0}}{\partial x}+\frac{E_{6}}{2} \frac{\partial k_{0}}{\partial y}+\frac{F_{4}}{2} \frac{\partial \varphi_{1}}{\partial x}+\frac{F_{3}}{2} \frac{\partial \phi_{1}}{\partial x}+\frac{F_{6}}{2} \frac{\partial k_{1}}{\partial y} \\
& T_{z x y}=A_{4} k_{1}+\frac{A_{5}}{2}\left(\frac{\partial \gamma_{2}}{\partial x}+\frac{\partial \gamma_{1}}{\partial y}\right) \\
& T_{x x z}=\frac{A_{1}}{2} \varphi_{1}+\frac{A_{3}}{2} \frac{\partial \gamma_{2}}{\partial y}+\frac{E_{6}}{2} \frac{\partial \gamma_{1}}{\partial x}+\frac{E_{4}}{2} \phi_{1} \\
& T_{y x z}=A_{4} \frac{\partial \gamma_{1}}{\partial y}+\frac{A_{5}}{2}\left(\frac{\partial \gamma_{2}}{\partial x}+k_{1}\right) \\
& T_{x y z}=A_{4} \frac{\partial \gamma_{2}}{\partial x}+\frac{A_{5}}{2}\left(\frac{\partial \gamma_{1}}{\partial y}+k_{1}\right) \\
& T_{y y z}=\frac{A_{1}}{2} \phi_{1}+\frac{A_{3}}{2} \frac{\partial \gamma_{1}}{\partial x}+\frac{E_{6}}{2} \frac{\partial \gamma_{2}}{\partial y}+\frac{E_{4}}{2} \varphi_{1} \\
& M_{x x x}=F_{1} \frac{\partial \phi_{0}}{\partial x}+F_{2} \frac{\partial \varphi_{0}}{\partial x}+\frac{F_{3}}{2} \frac{\partial k_{0}}{\partial y}+G_{1} \frac{\partial \phi_{1}}{\partial x}+G_{2} \frac{\partial \varphi_{1}}{\partial x}+\frac{G_{3}}{2} \frac{\partial k_{1}}{\partial y} \\
& M_{y x x}=F_{2} \frac{\partial \varphi_{0}}{\partial y}+F_{5} \frac{\partial \phi_{0}}{\partial y}+\frac{F_{4}}{2} \frac{\partial k_{0}}{\partial x}+G_{2} \frac{\partial \varphi_{1}}{\partial y}+G_{5} \frac{\partial \phi_{1}}{\partial y}+\frac{G_{4}}{2} \frac{\partial k_{1}}{\partial x} \\
& M_{x y y}=\frac{F_{4}}{2} \frac{\partial k_{0}}{\partial y}+F_{2} \frac{\partial \phi_{0}}{\partial x}+F_{5} \frac{\partial \varphi_{0}}{\partial x}+\frac{G_{4}}{2} \frac{\partial k_{1}}{\partial y}+G_{2} \frac{\partial \phi_{1}}{\partial x}+G_{5} \frac{\partial \varphi_{1}}{\partial x} \\
& M_{y y y}=F_{2} \frac{\partial \phi_{0}}{\partial y}+\frac{F_{3}}{2} \frac{\partial k_{0}}{\partial x}+F_{1} \frac{\partial \varphi_{0}}{\partial y}+G_{2} \frac{\partial \phi_{1}}{\partial y}+\frac{G_{3}}{2} \frac{\partial k_{1}}{\partial x}+G_{1} \frac{\partial \varphi_{1}}{\partial y} \\
& M_{x x y}=\frac{F_{3}}{2} \frac{\partial \varphi_{0}}{\partial y}+\frac{F_{6}}{2} \frac{\partial k_{0}}{\partial x}+\frac{F_{4}}{2} \frac{\partial \phi_{0}}{\partial y}+\frac{G_{3}}{2} \frac{\partial \varphi_{1}}{\partial y}+\frac{G_{6}}{2} \frac{\partial k_{1}}{\partial x}+\frac{G_{4}}{2} \frac{\partial \phi_{1}}{\partial y}
\end{aligned}
$$




$$
M_{y y x}=\frac{F_{4}}{2} \frac{\partial \varphi_{0}}{\partial x}+\frac{F_{3}}{2} \frac{\partial \phi_{0}}{\partial x}+\frac{F_{6}}{2} \frac{\partial k_{0}}{\partial y}+\frac{G_{4}}{2} \frac{\partial \varphi_{1}}{\partial x}+\frac{G_{3}}{2} \frac{\partial \phi_{1}}{\partial x}+\frac{G_{6}}{2} \frac{\partial k_{1}}{\partial y}
$$

\section{Appendix B}

The parameters in Equations (42)-(46) are given by:

$$
\begin{gathered}
A_{11}=\int_{-\frac{h}{2}}^{\frac{h}{2}}(\lambda+2 \mu) \mathrm{d} z, B_{11}=\int_{-\frac{h}{2}}^{\frac{h}{2}}(\lambda+2 \mu) z \mathrm{~d} z, D_{11}=\int_{-\frac{h}{2}}^{\frac{h}{2}}(\lambda+2 \mu) z^{2} \mathrm{~d} z \\
A_{12}=\int_{-\frac{h}{2}}^{\frac{h}{2}} \lambda \mathrm{d} z, B_{12}=\int_{-\frac{h}{2}}^{\frac{h}{2}} \lambda z \mathrm{~d} z, D_{12}=\int_{-\frac{h}{2}}^{\frac{h}{2}} \lambda z^{2} \mathrm{~d} z \\
A_{55}=\int_{-\frac{h}{2}}^{\frac{h}{2}} \mu \mathrm{d} z, B_{55}=\int_{-\frac{h}{2}}^{\frac{h}{2}} \mu z \mathrm{~d} z, D_{55}=\int_{-\frac{h}{2}}^{\frac{h}{2}} \mu z^{2} \mathrm{~d} z \\
A_{1}=\int_{-\frac{h}{2}}^{\frac{h}{2}} a_{1} \mathrm{~d} z, A_{2}=\int_{-\frac{h}{2}}^{\frac{h}{2}} a_{2} \mathrm{~d} z, A_{3}=\int_{-\frac{h}{2}}^{\frac{h}{2}} a_{3} \mathrm{~d} z \\
A_{4}=\int_{-\frac{h}{2}}^{\frac{h}{2}} a_{4} \mathrm{~d} z, A_{5}=\int_{-\frac{h}{2}}^{\frac{h}{2}} a_{5} \mathrm{~d} z, B_{1}=\int_{-\frac{h}{2}}^{\frac{h}{2}} a_{1} z \mathrm{~d} z \\
B_{2}=\int_{-\frac{h}{2}}^{\frac{h}{2}} a_{2} z \mathrm{~d} z, B_{3}=\int_{-\frac{h}{2}}^{\frac{h}{2}} a_{3} z \mathrm{~d} z, B_{4}=\int_{-\frac{h}{2}}^{\frac{h}{2}} a_{4} z \mathrm{~d} z \\
E_{1}=\int_{-\frac{h}{2}}^{\frac{h}{2}} \beta_{1} \mathrm{~d} z, E_{2}=\int_{-\frac{h}{2}}^{\frac{h}{2}} \beta_{2} \mathrm{~d} z, E_{3}=\int_{-\frac{h}{2}}^{\frac{h}{2}} \beta_{3} \mathrm{~d} z \\
E_{4}=\int_{-\frac{h}{2}}^{\frac{h}{2}} \beta_{4} \mathrm{~d} z, E_{5}=\int_{-\frac{h}{2}}^{\frac{h}{2}} \beta_{5} \mathrm{~d} z, E_{6}=\int_{-\frac{h}{2}}^{\frac{h}{2}} \beta_{6} \mathrm{~d} z \\
G_{4}=\int_{-\frac{h}{2}}^{\frac{h}{2}} \beta_{4} z^{2} \mathrm{~d} z, G_{5}=\int_{-\frac{h}{2}}^{\frac{h}{2}} \beta_{5} z^{2} \mathrm{~d} z, G_{6}=\int_{-\frac{h}{2}}^{\frac{h}{2}} \beta_{6} z^{2} \mathrm{~d} z \\
F_{1}=\int_{-\frac{h}{2}}^{\frac{h}{2}} \beta_{1} z \mathrm{~d} z, F_{2}=\int_{-\frac{h}{2}}^{\frac{h}{2}} \beta_{2} z \mathrm{~d} z, F_{3}=\int_{-\frac{h}{2}}^{\frac{h}{2}} \beta_{3} z \mathrm{~d} z \\
F_{4}=\int_{-\frac{h}{2}}^{\frac{h}{2}} \beta_{4} z \mathrm{~d} z, F_{5}=\int_{-\frac{h}{2}}^{\frac{h}{2}} \beta_{5} z \mathrm{~d} z, F_{6}=\int_{-\frac{h}{2}}^{\frac{h}{2}} \beta_{6} z \mathrm{~d} z \\
\beta_{1} z^{2} \mathrm{~d} z, G_{2}=\int_{-\frac{h}{2}}^{\frac{h}{2}} \beta_{2} z^{2} \mathrm{~d} z, G_{3}=\int_{3}^{\frac{h}{2}} \beta_{3} z^{2} \mathrm{~d} z \\
\end{gathered}
$$

\section{Appendix C}

The nonzero components in Equations (53)-(55) are:

$$
\begin{gathered}
K_{11}=A_{11} \alpha_{m}^{2}+E_{1} \alpha_{m}^{4}+\left[A_{55}+\left(E_{3}+E_{4}+E_{5}+E_{6}\right) \alpha_{m}^{2}\right] \frac{n^{2}}{R^{2}}+\frac{E_{6} n^{4}}{2 R^{4}} \\
K_{12}=K_{21}=\frac{\alpha_{m} n}{R}\left[A_{12}+A_{55}+\left(\frac{2 E_{2}+E_{3}+E_{4}+E_{6}}{2}\right)\left(\alpha_{m}^{2}+\frac{n^{2}}{R^{2}}\right)\right] \\
K_{13}=K_{31}=-\frac{\left(E_{3}+E_{4}\right) \alpha_{m} n^{2}}{2 R^{3}}-\frac{E_{2} \alpha_{m}\left(\alpha_{m}^{2}+\frac{n^{2}}{R^{2}}\right)}{R}-\frac{A_{12} \alpha_{m}}{R} \\
K_{14}=K_{41}=F_{1} \alpha_{m}^{4}+\frac{F_{6}}{2} \frac{n^{4}}{R^{4}}+\left(\frac{2 F_{3}+2 F_{4}+2 F_{5}+F_{6}}{2}\right) \frac{\alpha_{m}^{2} n^{2}}{R^{2}}+B_{11} \alpha_{m}^{2}+\frac{B_{55} n^{2}}{R^{2}}
\end{gathered}
$$




$$
\begin{aligned}
& K_{15}=K_{51}=\left(\frac{2 F_{2}+F_{3}+F_{4}+F_{6}}{2}\right)\left(\frac{\alpha_{m}^{3} n}{R}+\frac{\alpha_{m} n^{3}}{R^{3}}\right)+\left(B_{12}+B_{55}\right) \frac{\alpha_{m} n}{R} \\
& K_{22}=\frac{E_{6} \alpha_{m}^{4}}{2}+\left(\frac{E_{6}+2 E_{3}+2 E_{4}+2 E_{5}}{2}\right) \frac{\alpha_{m}^{2} n^{2}}{R^{2}}+\frac{E_{1} n^{4}}{R^{4}} \\
& +\left(A_{11}+\frac{E_{6}}{R^{2}}\right) \frac{n^{2}}{R^{2}}+\alpha_{m}^{2}\left(A_{55}+\frac{A_{4}}{R^{2}}\right)+\frac{K_{S} A_{55}}{R^{2}} \\
& K_{23}=K_{32}=-\frac{\left(2 A_{3}+2 A_{4}+A_{5}+E_{3}+E_{4}+2 E_{5}\right) \alpha_{m}^{2} n}{2 R^{2}} \\
& -\frac{\left(E_{1}+E_{6}\right) n^{3}}{R^{4}}-\frac{n}{R^{2}}\left(A_{11}+K_{S} A_{55}\right) \\
& K_{24}=K_{42}=-\frac{\alpha_{m} n}{R^{2}}\left(A_{1}+A_{3}+A_{5}\right) \\
& +\left[\left(\frac{2 F_{2}+F_{3}+F_{4}+F_{6}}{2}\right)\left(\frac{\alpha_{m}^{3} n}{R}+\frac{\alpha_{m} n^{3}}{R^{3}}\right)+\left(B_{12}+B_{55}\right) \frac{\alpha_{m} n}{R}\right] \\
& K_{25}=K_{52}=-\frac{1}{2 R}\left[\left(2 A_{4}+A_{5}\right) \alpha_{m}^{2}+\left(E_{4}+E_{6}\right) \frac{n^{2}}{R^{2}}\right]-\frac{K_{S} A_{55}}{R} \\
& +\left[\frac{F_{6} \alpha_{m}^{4}}{2}+\frac{F_{1} n^{4}}{R^{4}}+\left(\frac{2 F_{3}+2 F_{4}+2 F_{5}+F_{6}}{2}\right) \frac{\alpha_{m}^{2} n^{2}}{R^{2}}\right]+B_{55} \alpha_{m}^{2}+\frac{B_{11} n^{2}}{R^{2}} \\
& K_{33}=\left(A_{3}+2 A_{4}+A_{5}\right) \frac{\alpha_{m}^{2} n^{2}}{R^{2}}+\frac{\left(2 E_{1}+E_{6}\right) n^{2}}{2 R^{4}}+\frac{\left(2 E_{5}+A_{3}\right) \alpha_{m}^{2}}{2 R^{2}} \\
& +K_{S} A_{55}\left(\alpha_{m}^{2}+\frac{n^{2}}{R^{2}}\right)+\frac{E_{6}}{2}\left(\alpha_{m}^{4}+\frac{n^{4}}{R^{4}}\right)+\frac{A_{11}}{R^{2}} \\
& K_{34}=K_{43}=\frac{\alpha_{m}\left(A_{1}+A_{3}\right)}{2 R^{2}}+\alpha_{m}\left(K_{S} A_{55}-\frac{2 F_{2}+F_{3}+F_{4}}{2 R} \frac{n^{2}}{R^{2}}+\frac{E_{6}+E_{4}}{2} \alpha_{m}^{2}\right) \\
& +\frac{1}{2}\left(A_{1}+A_{3}+2 A_{4}+3 A_{5}\right) \frac{\alpha_{m} n^{2}}{R^{2}}+\frac{\alpha_{m}^{3} F_{2}}{R}-\frac{B_{12} \alpha_{m}}{R} \\
& K_{35}=K_{53}=\frac{1}{2}\left[\left(A_{1}+A_{3}+2 A_{4}+3 A_{5}\right) \alpha_{m}^{2}+\left(E_{4}+E_{6}\right) \frac{n^{2}}{R^{2}}\right] \frac{n}{R} \\
& -\frac{F_{3}-F_{4}-2 F_{5}}{2 R} \frac{\alpha_{m}^{2} n}{R}-\frac{F_{1}}{R} \frac{n^{3}}{R^{3}}-\left(\frac{B_{11}}{R}-K_{S} A_{55}\right) \frac{n}{R} \\
& K_{44}=G_{1} \alpha_{m}^{4}+\left[\left(\frac{2 G_{3}+2 G_{4}+2 G_{5}+G_{6}}{2}\right) \frac{n^{2}}{R^{2}}+D_{11}+\frac{2 E_{4}+2 E_{5}+E_{6}}{2}\right] \alpha_{m}^{2} \\
& +\frac{G_{6} n^{4}}{2 R^{4}}+\frac{n^{2}}{R^{2}}\left(D_{55}+2 A_{4}+A_{5}\right)+K_{S} A_{55} \\
& K_{45}=K_{54}=\frac{\alpha_{m}}{R}\left[\frac{2 G_{2}+G_{3}+G_{4}+G_{6}}{2}\left(\alpha_{m}^{2}+\frac{n^{2}}{R^{2}}\right)\right] \\
& +\frac{\alpha_{m}}{R}\left(D_{12}+D_{55}+\frac{2 A_{1}+4 A_{2}+A_{3}+2 A_{4}+3 A_{5}}{2}\right) \\
& K_{55}=\frac{G_{1} n^{4}}{R^{4}}+\frac{\alpha_{m}^{4} G_{6}}{2}+\left(\frac{2 G_{3}+2 G_{4}+2 G_{5}+G_{6}}{2}\right) \frac{\alpha_{m}^{2} n^{2}}{R^{2}} \\
& +\frac{n^{2}}{R^{2}}\left(D_{11}+\frac{2 E_{4}+2 E_{5}+E_{6}}{2}\right)+\alpha_{m}^{2}\left(D_{55}+2 A_{4}+A_{5}\right)+K_{S} A_{55} \\
& K_{g_{33}}=-\frac{m^{2} \pi^{2}}{L^{2}} \\
& M_{11}=M_{22}=M_{33}=I_{0}, M_{44}=M_{55}=I_{2}, M_{14}=M_{25}=M_{41}=M_{52}=I_{1}
\end{aligned}
$$

\section{References}

1. Wang, Y.; Ye, C.; Zu, J. Identifying the temperature effect on the vibrations of functionally graded cylindrical shells with porosities. Appl. Math. Mech. 2018, 39, 1587-1604. [CrossRef]

2. Wang, Y.Q.; Zu, J.W. Nonlinear dynamics of a translational FGM plate with strong mode interaction. Int. J. Struct. Stab. Dyn. 2018, 18, 1850031. [CrossRef]

3. Wang, Y.Q.; Wan, Y.H.; Zhang, Y.F. Vibrations of longitudinally traveling functionally graded material plates with porosities. Eur. J. Mech.-A/Solids 2017, 66, 55-68. [CrossRef]

4. Wang, Y.Q.; Yang, Z. Nonlinear vibrations of moving functionally graded plates containing porosities and contacting with liquid: Internal resonance. Nonlinear Dyn. 2017, 90, 1461-1480. [CrossRef]

5. Nejati, M.; Asanjarani, A.; Dimitri, R.; Tornabene, F. Static and free vibration analysis of functionally graded conical shells reinforced by carbon nanotubes. Int. J. Mech. Sci. 2017, 130, 383-398. [CrossRef] 
6. Wang, Y.Q.; Zu, J.W. Nonlinear dynamic thermoelastic response of rectangular FGM plates with longitudinal velocity. Compos. Part B Eng. 2017, 117, 74-88. [CrossRef]

7. Wang, Y.Q.; Zu, J.W. Large-amplitude vibration of sigmoid functionally graded thin plates with porosities. Thin-Walled Struct. 2017, 119, 911-924. [CrossRef]

8. Wang, Y.Q.; Zu, J.W. Porosity-dependent nonlinear forced vibration analysis of functionally graded piezoelectric smart material plates. Smart Mater. Struct. 2017, 26, 105014. [CrossRef]

9. Wang, Y.; $\mathrm{Zu}$, J. Nonlinear oscillations of sigmoid functionally graded material plates moving in longitudinal direction. Appl. Math. Mech. 2017, 38, 1533-1550. [CrossRef]

10. Trinh, M.-C.; Kim, S.-E. Nonlinear thermomechanical behaviors of thin functionally graded sandwich shells with double curvature. Compos. Struct. 2018, 195, 335-348. [CrossRef]

11. Wang, Y.Q.; Zu, J.W. Nonlinear dynamics of functionally graded material plates under dynamic liquid load and with longitudinal speed. Int. J. Appl. Mech. 2017, 9, 1750054. [CrossRef]

12. Wang, Y.Q.; Zu, J.W. Speed-dependent nonlinear broadband vibrations of smart functionally graded piezoelectric material plates. J. Intell. Mater. Syst. Struct. 2018, 29, 1764-1776. [CrossRef]

13. Wang, Y.Q.; Zu, J.W. Vibration characteristics of moving sigmoid functionally graded plates containing porosities. Int. J. Mech. Mater. Des. 2018, 14, 473-489. [CrossRef]

14. Tornabene, F.; Fantuzzi, N.; Bacciocchi, M.; Viola, E. Effect of agglomeration on the natural frequencies of functionally graded carbon nanotube-reinforced laminated composite doubly-curved shells. Compos. Part B Eng. 2016, 89, 187-218. [CrossRef]

15. Wang, Y.; Zu, J.W. Nonlinear dynamic behavior of inhomogeneous functional plates composed of sigmoid graded metal-ceramic materials. Sci. China Technol. Sci. 2018, 61, 1654-1665. [CrossRef]

16. Fantuzzi, N.; Tornabene, F.; Bacciocchi, M.; Dimitri, R. Free vibration analysis of arbitrarily shaped Functionally Graded Carbon Nanotube-reinforced plates. Compos. Part B Eng. 2017, 115, 384-408. [CrossRef]

17. Zhang, W.; Yang, J.; Hao, Y. Chaotic vibrations of an orthotropic FGM rectangular plate based on third-order shear deformation theory. Nonlinear Dyn. 2010, 59, 619-660. [CrossRef]

18. Hao, Y.; Zhang, W.; Yang, J. Nonlinear dynamics of a FGM plate with two clamped opposite edges and two free edges. Acta Mech. Solida Sin. 2014, 27, 394-406. [CrossRef]

19. Wang, Y.Q.; Zu, J.W. Nonlinear steady-state responses of longitudinally traveling functionally graded material plates in contact with liquid. Compos. Struct. 2017, 164, 130-144. [CrossRef]

20. Zhang, W.; Hao, Y.; Guo, X.; Chen, L. Complicated nonlinear responses of a simply supported FGM rectangular plate under combined parametric and external excitations. Meccanica 2012, 47, 985-1014. [CrossRef]

21. Wang, Y.Q.; Zu, J.W. Vibration behaviors of functionally graded rectangular plates with porosities and moving in thermal environment. Aerosp. Sci. Technol. 2017, 69, 550-562. [CrossRef]

22. Zhang, W.; Hao, Y.; Yang, J. Nonlinear dynamics of FGM circular cylindrical shell with clamped-clamped edges. Compos. Struct. 2012, 94, 1075-1086. [CrossRef]

23. Wang, Y.Q. Electro-mechanical vibration analysis of functionally graded piezoelectric porous plates in the translation state. Acta Astronaut. 2018, 143, 263-271. [CrossRef]

24. Wang, Y.Q.; Wan, Y.H.; Zu, J.W. Nonlinear dynamic characteristics of functionally graded sandwich thin nanoshells conveying fluid incorporating surface stress influence. Thin-Walled Struct. 2019, 135, 537-547. [CrossRef]

25. Hassani, A.; Habibolahzadeh, A.; Bafti, H. Production of graded aluminum foams via powder space holder technique. Mater. Des. 2012, 40, 510-515. [CrossRef]

26. He, S.Y.; Zhang, Y.; Dai, G.; Jiang, J.Q. Preparation of density-graded aluminum foam. Mater. Sci. Eng. A 2014, 618, 496-499. [CrossRef]

27. Hangai, Y.; Takahashi, K.; Utsunomiya, T.; Kitahara, S.; Kuwazuru, O.; Yoshikawa, N. Fabrication of functionally graded aluminum foam using aluminum alloy die castings by friction stir processing. Mater. Sci. Eng. A 2012, 534, 716-719. [CrossRef]

28. Hangai, Y.; Saito, K.; Utsunomiya, T.; Kitahara, S.; Kuwazuru, O.; Yoshikawa, N. Compression properties of $\mathrm{Al} / \mathrm{Al}-\mathrm{Si}-\mathrm{Cu}$ alloy functionally graded aluminum foam fabricated by friction stir processing route. Mater. Trans. 2013, 54, 405-408. [CrossRef]

29. Pia, G.; Delogu, F. On the elastic deformation behavior of nanoporous metal foams. Scr. Mater. 2013, 69, 781-784. [CrossRef] 
30. Park, H.; Ahn, C.; Jo, H.; Choi, M.; Kim, D.S.; Kim, D.K.; Jeon, S.; Choe, H. Large-area metal foams with highly ordered sub-micrometer-scale pores for potential applications in energy areas. Mater. Lett. 2014, 129, 174-177. [CrossRef]

31. Heydari, H.; Moosavifard, S.E.; Shahraki, M.; Elyasi, S. Facile synthesis of nanoporous CuS nanospheres for high-performance supercapacitor electrodes. J. Energy Chem. 2017, 26, 762-767. [CrossRef]

32. Li, J.; Wang, S.; Xiao, T.; Tan, X.; Xiang, P.; Jiang, L.; Deng, C.; Li, W.; Li, M. Controllable preparation of nanoporous $\mathrm{Ni}_{3} \mathrm{~S}_{2}$ films by sulfuration of nickel foam as promising asymmetric supercapacitor electrodes. Appl. Surf. Sci. 2017, 420, 919-926. [CrossRef]

33. Fu, Y.; Du, H.; Zhang, S. Functionally graded TiN/TiNi shape memory alloy films. Mater. Lett. 2003, 57, 2995-2999. [CrossRef]

34. Li, X.; Bhushan, B.; Takashima, K.; Baek, C.-W.; Kim, Y.-K. Mechanical characterization of micro/nanoscale structures for MEMS/NEMS applications using nanoindentation techniques. Ultramicroscopy 2003, 97, 481-494. [CrossRef]

35. Moser, Y.; Gijs, M.A. Miniaturized flexible temperature sensor. J. Microelectromech. Syst. 2007, 16, 1349-1354. [CrossRef]

36. Fleck, N.; Muller, G.; Ashby, M.; Hutchinson, J. Strain gradient plasticity: Theory and experiment. Acta Metall. Mater. 1994, 42, 475-487. [CrossRef]

37. Lam, D.C.; Yang, F.; Chong, A.; Wang, J.; Tong, P. Experiments and theory in strain gradient elasticity. J. Mech. Phys. Solids 2003, 51, 1477-1508. [CrossRef]

38. Miller, R.E.; Shenoy, V.B. Size-dependent elastic properties of nanosized structural elements. Nanotechnology 2000, 11, 139. [CrossRef]

39. Xu, F.; Qin, Q.; Mishra, A.; Gu, Y.; Zhu, Y. Mechanical properties of ZnO nanowires under different loading modes. Nano Res. 2010, 3, 271-280. [CrossRef]

40. Mindlin, R.D.; Eshel, N. On first strain-gradient theories in linear elasticity. Int. J. Solids Struct. 1968, 4, 109-124. [CrossRef]

41. Wang, B.; Zhao, J.; Zhou, S. A micro scale Timoshenko beam model based on strain gradient elasticity theory. Eur. J. Mech.-A/Solids 2010, 29, 591-599. [CrossRef]

42. Ansari, R.; Gholami, R.; Faghih Shojaei, M.; Mohammadi, V.; Sahmani, S. Size-dependent bending, buckling and free vibration of functionally graded Timoshenko microbeams based on the most general strain gradient theory. Compos. Struct. 2013, 100, 385-397. [CrossRef]

43. Kong, S.; Zhou, S.; Nie, Z.; Wang, K. Static and dynamic analysis of micro beams based on strain gradient elasticity theory. Int. J. Eng. Sci. 2009, 47, 487-498. [CrossRef]

44. Akgöz, B.; Civalek, Ö. Analysis of micro-sized beams for various boundary conditions based on the strain gradient elasticity theory. Arch. Appl. Mech. 2012, 82, 423-443. [CrossRef]

45. Wang, B.; Zhou, S.; Zhao, J.; Chen, X. A size-dependent Kirchhoff micro-plate model based on strain gradient elasticity theory. Eur. J. Mech.-A/Solids 2011, 30, 517-524. [CrossRef]

46. Movassagh, A.A.; Mahmoodi, M. A micro-scale modeling of Kirchhoff plate based on modified strain-gradient elasticity theory. Eur. J. Mech.-A/Solids 2013, 40, 50-59. [CrossRef]

47. Akgöz, B.; Civalek, Ö. A microstructure-dependent sinusoidal plate model based on the strain gradient elasticity theory. Acta Mech. 2015, 226, 2277-2294. [CrossRef]

48. Zeighampour, H.; Beni, Y.T. Cylindrical thin-shell model based on modified strain gradient theory. Int. J. Eng. Sci. 2014, 78, 27-47. [CrossRef]

49. Ansari, R.; Gholami, R.; Norouzzadeh, A. Size-dependent thermo-mechanical vibration and instability of conveying fluid functionally graded nanoshells based on Mindlin's strain gradient theory. Thin-Walled Struct. 2016, 105, 172-184. [CrossRef]

50. Zeighampour, H.; Beni, Y.T.; Karimipour, I. Torsional vibration and static analysis of the cylindrical shell based on strain gradient theory. Arabian J. Sci. Eng. 2016, 41, 1713-1722. [CrossRef]

51. Yang, F.; Chong, A.; Lam, D.C.C.; Tong, P. Couple stress based strain gradient theory for elasticity. Int. J. Solids Struct. 2002, 39, 2731-2743. [CrossRef]

52. Barati, M.R.; Zenkour, A.M. Investigating post-buckling of geometrically imperfect metal foam nanobeams with symmetric and asymmetric porosity distributions. Compos. Struct. 2017, 182, 91-98. [CrossRef] 
53. Sahmani, S.; Aghdam, M.M.; Rabczuk, T. Nonlinear bending of functionally graded porous micro/nano-beams reinforced with graphene platelets based upon nonlocal strain gradient theory. Compos. Struct. 2018, 186, 68-78. [CrossRef]

54. Wang, Y.Q.; Zhao, H.L.; Ye, C.; Zu, J.W. A Porous Microbeam Model for Bending and Vibration Analysis Based on the Sinusoidal Beam Theory and Modified Strain Gradient Theory. Int. J. Appl. Mech. 2018, 10, 1850059. [CrossRef]

55. Wang, Y.; Guo, X.; Chang, H.; Li, H. Nonlinear dynamic response of rotating circular cylindrical shells with precession of vibrating shape-Part I: Numerical solution. Int. J. Mech. Sci. 2010, 52, 1217-1224. [CrossRef]

56. Wang, Y.; Guo, X.; Chang, H.; Li, H. Nonlinear dynamic response of rotating circular cylindrical shells with precession of vibrating shape-Part II: Approximate analytical solution. Int. J. Mech. Sci. 2010, 52, 1208-1216. [CrossRef]

57. Wang, Y.Q.; Liang, L.; Guo, X.H. Internal resonance of axially moving laminated circular cylindrical shells. J. Sound Vib. 2013, 332, 6434-6450. [CrossRef]

58. Wang, Y.Q. Nonlinear vibration of a rotating laminated composite circular cylindrical shell: Traveling wave vibration. Nonlinear Dyn. 2014, 77, 1693-1707. [CrossRef]

59. Wang, Y.; Guo, X.; Li, Y.; Li, J. Nonlinear traveling wave vibration of a circular cylindrical shell subjected to a moving concentrated harmonic force. J. Sound Vib. 2010, 329, 338-352. [CrossRef]

60. Wang, Y.; Liang, L.; Guo, X.; Li, J.; Liu, J.; Liu, P. Nonlinear vibration response and bifurcation of circular cylindrical shells under traveling concentrated harmonic excitation. Acta Mech. Solida Sin. 2013, 26, 277-291. [CrossRef]

61. Nejati, M.; Dimitri, R.; Tornabene, F.; Hossein Yas, M. Thermal buckling of nanocomposite stiffened cylindrical shells reinforced by functionally graded wavy carbon nanotubes with temperature-dependent properties. Appl. Sci. 2017, 7, 1223. [CrossRef]

62. Baughman, R.H.; Cui, C.; Zakhidov, A.A.; Iqbal, Z.; Barisci, J.N.; Spinks, G.M.; Wallace, G.G.; Mazzoldi, A.; De Rossi, D.; Rinzler, A.G. Carbon nanotube actuators. Science 1999, 284, 1340-1344. [CrossRef] [PubMed]

63. Wu, G.; Hu, Y.; Zhao, J.; Lan, T.; Wang, D.; Liu, Y.; Chen, W. Ordered and Active Nanochannel Electrode Design for High-Performance Electrochemical Actuator. Small 2016, 12, 4986-4992. [CrossRef] [PubMed]

64. Raschke, G.; Brogl, S.; Susha, A.; Rogach, A.; Klar, T.; Feldmann, J.; Fieres, B.; Petkov, N.; Bein, T.; Nichtl, A. Gold nanoshells improve single nanoparticle molecular sensors. Nano Lett. 2004, 4, 1853-1857. [CrossRef]

65. Hoseinzadeh, M.; Khadem, S. A nonlocal shell theory model for evaluation of thermoelastic damping in the vibration of a double-walled carbon nanotube. Phys. E Low-Dimens. Syst. Nanostruct. 2014, 57, 6-11. [CrossRef]

66. Sahmani, S.; Aghdam, M.; Bahrami, M. Nonlinear buckling and postbuckling behavior of cylindrical nanoshells subjected to combined axial and radial compressions incorporating surface stress effects. Compos. Part B Eng. 2015, 79, 676-691. [CrossRef]

67. Ansari, R.; Rouhi, H.; Sahmani, S. Thermal effect on axial buckling behavior of multi-walled carbon nanotubes based on nonlocal shell model. Phys. E Low-Dimens. Syst. Nanostruct. 2011, 44, 373-378. [CrossRef]

68. Wang, Y.Q.; Li, H.; Zhang, Y.; Zu, J.W. A nonlinear surface-stress-dependent model for vibration analysis of cylindrical nanoscale shells conveying fluid. Appl. Math. Model. 2018, 64, 55-70. [CrossRef]

69. Magnucki, K.; Stasiewicz, P. Elastic buckling of a porous beam. J. Theor. Appl. Mech. 2004, 42, 859-868.

70. Jabbari, M.; Mojahedin, A.; Khorshidvand, A.; Eslami, M. Buckling analysis of a functionally graded thin circular plate made of saturated porous materials. J. Eng. Mech. 2013, 140, 287-295. [CrossRef]

71. Wang, Y.Q.; Liang, C. Wave propagation characteristics in nanoporous metal foam nanobeams. Results Phys. 2019, 12, 287-297. [CrossRef]

72. Wang, Y.Q.; Liang, C.; Zu, J.W. Examining wave propagation characteristics in metal foam beams: Euler-Bernoulli and Timoshenko models. J. Braz. Soc. Mech. Sci. Eng. 2018, 40, 565. [CrossRef]

73. Wang, Y.; Zhang, Z. Non-local buckling analysis of functionally graded nanoporous metal foam nanoplates. Coatings 2018, 8, 389. [CrossRef]

74. Wang, Y.Q.; Ye, C.; Zu, J.W. Nonlinear vibration of metal foam cylindrical shells reinforced with graphene platelets. Aerosp. Sci. Technol. 2019, 85, 359-370. [CrossRef]

75. Chen, D.; Yang, J.; Kitipornchai, S. Elastic buckling and static bending of shear deformable functionally graded porous beam. Compos. Struct. 2015, 133, 54-61. [CrossRef] 
76. Chen, D.; Yang, J.; Kitipornchai, S. Free and forced vibrations of shear deformable functionally graded porous beams. Int. J. Mech. Sci. 2016, 108, 14-22. [CrossRef]

77. Fleck, N.; Hutchinson, J. Strain gradient plasticity. Adv. Appl. Mech. 1997, 33, 296-361.

78. Rahim, M.Z.; Ding, S.; Hu, B.; Mo, J. Crater size prediction in electrical discharge grinding (EDG) of polycrystalline diamond (PCD). Nonconv. Technol. Rev./Revista de Tehnologii Neconventionale 2014, 18, 92-97.

79. Rezaiee-Pajand, M.; Pourhekmat, D.; Arabi, E. Thermo-mechanical stability analysis of functionally graded shells. Eng. Struct. 2019, 178, 1-11. [CrossRef]

80. Mindlin, R.D. Micro-structure in linear elasticity. Arch. Ration. Mech. Anal. 1964, 16, 51-78. [CrossRef]

81. Amabili, M. Nonlinear Vibrations and Stability of Shells and Plates; Cambridge University Press: Cambridge, UK, 2008.

82. Leissa, A.W. Vibration of Shells; Scientific and Technical Information Office, National Aeronautics and Space Administration: Washington, DC, USA, 1973.

83. Kamarian, S.; Salim, M.; Dimitri, R.; Tornabene, F. Free vibration analysis of conical shells reinforced with agglomerated Carbon Nanotubes. Int. J. Mech. Sci. 2016, 108, 157-165. [CrossRef]

84. Kiani, Y.; Dimitri, R.; Tornabene, F. Free vibration study of composite conical panels reinforced with FG-CNTs. Polym. Compos. 2018, 172, 472-482. [CrossRef]

85. Tornabene, F.; Bacciocchi, M.; Fantuzzi, N.; Reddy, J. Multiscale approach for three-phase CNT/polymer/fiber laminated nanocomposite structures. Polym. Compos. 2017. [CrossRef]

86. Reddy, J.N. Mechanics of Laminated Composite Plates and Shells: Theory and Analysis; CRC Press: Boca Raton, FL, USA, 2004.

87. Christoforou, A.; Swanson, S. Analysis of simply-supported orthotropic cylindrical shells subject to lateral impact loads. J. Appl. Mech. 1990, 57, 376-382. [CrossRef]

88. Thai, H.-T.; Choi, D.-H. A simple first-order shear deformation theory for the bending and free vibration analysis of functionally graded plates. Compos. Struct. 2013, 101, 332-340. [CrossRef]

89. Whitney, J.; Pagano, N. Shear deformation in heterogeneous anisotropic plates. J. Appl. Mech. 1970, 37, 1031-1036. [CrossRef]

90. Kiani, Y.; Shakeri, M.; Eslami, M. Thermoelastic free vibration and dynamic behaviour of an FGM doubly curved panel via the analytical hybrid Laplace-Fourier transformation. Acta Mech. 2012, 223, 1199-1218. [CrossRef]

91. Ke, L.-L.; Wang, Y.-S.; Yang, J.; Kitipornchai, S. Nonlinear free vibration of size-dependent functionally graded microbeams. Int. J. Eng. Sci. 2012, 50, 256-267. [CrossRef]

92. Wang, Y.Q.; Huang, X.B.; Li, J. Hydroelastic dynamic analysis of axially moving plates in continuous hot-dip galvanizing process. Int. J. Mech. Sci. 2016, 110, 201-216. [CrossRef]

93. Wang, Y.Q.; Liu, Y.F.; Zu, J.W. Analytical treatment of nonlocal vibration of multilayer functionally graded piezoelectric nanoscale shells incorporating thermal and electrical effect. Eur. Phys. J. Plus 2019, 134, 54. [CrossRef]

94. Wang, Y.; Zu, J. Analytical analysis for vibration of longitudinally moving plate submerged in infinite liquid domain. Appl. Math. Mech. 2017, 38, 625-646. [CrossRef]

95. Wang, Y.Q.; Zu, J.W. Instability of viscoelastic plates with longitudinally variable speed and immersed in ideal liquid. Int. J. Appl. Mech. 2017, 9, 1750005. [CrossRef]

96. Wang, Y.; Du, W.; Huang, X.; Xue, S. Study on the dynamic behavior of axially moving rectangular plates partially submersed in fluid. Acta Mech. Solida Sin. 2015, 28, 706-721. [CrossRef]

97. Wang, Y.Q.; Xue, S.W.; Huang, X.B.; Du, W. Vibrations of axially moving vertical rectangular plates in contact with fluid. Int. J. Struct. Stab. Dyn. 2016, 16, 1450092. [CrossRef]

98. Wang, Y.Q.; Guo, X.H.; Sun, Z.; Li, J. Stability and dynamics of axially moving unidirectional plates partially immersed in a liquid. Int. J. Struct. Stab. Dyn. 2014, 14, 1450010. [CrossRef]

99. Zhang, B.; He, Y.; Liu, D.; Shen, L.; Lei, J. Free vibration analysis of four-unknown shear deformable functionally graded cylindrical microshells based on the strain gradient elasticity theory. Compos. Struct. 2015, 119, 578-597. [CrossRef]

100. Ghadiri, M.; SafarPour, H. Free vibration analysis of size-dependent functionally graded porous cylindrical microshells in thermal environment. J. Therm. Stress. 2017, 40, 55-71. [CrossRef] 
101. Loy, C.; Lam, K.; Reddy, J. Vibration of functionally graded cylindrical shells. Int. J. Mech. Sci. 1999, 41, 309-324. [CrossRef]

102. Sahmani, S.; Ansari, R. On the free vibration response of functionally graded higher-order shear deformable microplates based on the strain gradient elasticity theory. Compos. Struct. 2013, 95, 430-442. [CrossRef]

(c) (2)

(C) 2019 by the authors. Licensee MDPI, Basel, Switzerland. This article is an open access article distributed under the terms and conditions of the Creative Commons Attribution (CC BY) license (http:/ / creativecommons.org/licenses/by/4.0/). 

Article

\title{
Structural and Electrical Studies for Birnessite-Type Materials Synthesized by Solid-State Reactions
}

\author{
Nayda P. Arias ${ }^{1,2}$, María E. Becerra ${ }^{1,3,4,5,6}$ and Oscar Giraldo 1,3,5,* \\ 1 Grupo de Investigación en Procesos Químicos, Catalíticos y Biotecnológicos, Universidad Nacional de \\ Colombia-Sede Manizales, Kilometro 9 vía al aeropuerto, La Nubia, Manizales 170003, Colombia

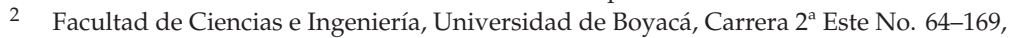 \\ Tunja 15001, Boyacá, Colombia \\ 3 Laboratorio de Materiales Nanoestructurados y Funcionales, Facultad de Ciencias Exactas y Naturales, \\ Universidad Nacional de Colombia-Sede Manizales, Kilometro 9 vía al aeropuerto, La Nubia, \\ Manizales 170003, Colombia \\ 4 Departamento de Ingeniería Química, Facultad de Ingeniería y Arquitectura, Universidad Nacional de \\ Colombia-Sede Manizales, Kilometro 9 vía al aeropuerto, La Nubia, Manizales 170003, Colombia \\ 5 Departamento de Física y Química, Facultad de Ciencias Exactas y Naturales, Universidad Nacional de \\ Colombia-Sede Manizales, Kilometro 9 vía al aeropuerto, La Nubia, Manizales 170003, Colombia \\ 6 Departamento de Química, Universidad de Caldas, Calle 65 No 26-10, Manizales 17001, Colombia \\ * Correspondence: ohgiraldoo@unal.edu.co
}

Received: 14 July 2019; Accepted: 8 August 2019; Published: 12 August 2019

\begin{abstract}
The focus of this paper is centered on the thermal reduction of $\mathrm{KMnO}_{4}$ at controlled temperatures of 400 and $800{ }^{\circ} \mathrm{C}$. The materials under study were characterized by atomic absorption spectroscopy, thermogravimetric analysis, average oxidation state of manganese, nitrogen adsorption-desorption, and impedance spectroscopy. The structural formulas, found as a result of these analyses, were $\mathrm{K}_{0.29}^{+}\left(\mathrm{Mn}_{0.84}^{4+} \mathrm{Mn}_{0.16}^{3+}\right) \mathrm{O}_{2.07} \cdot 0.61 \mathrm{H}_{2} \mathrm{O}$ and $\mathrm{K}_{0.48}^{+}\left(\mathrm{Mn}_{0.64}^{4+} \mathrm{Mn}_{0.36}^{3+}\right) \mathrm{O}_{2.06} \cdot 0.50 \mathrm{H}_{2} \mathrm{O}$. The $\mathrm{N}_{2}$ adsorption-desorption isotherms show the microporous and mesoporous nature of the structure. Structural analysis showed that synthesis temperature affects the crystal size and symmetry, varying their electrical properties. Impedance spectroscopy (IS) was used to measure the electrical properties of these materials. The measurements attained, as a result of IS, show that these materials have both electronic and ionic conductivity. The conductivity values obtained at $10 \mathrm{~Hz}$ were $4.1250 \times 10^{-6}$ and $1.6870 \times 10^{-4} \Omega^{-1} \mathrm{~cm}^{-1}$ for Mn 4 at 298 and $423 \mathrm{~K}$ respectively. For Mn8, the conductivity values at this frequency were $3.7074 \times 10^{-7}(298)$ and $3.9866 \times 10^{-5} \Omega^{-1} \mathrm{~cm}^{-1}(423 \mathrm{~K})$. The electrical behavior was associated with electron hopping at high frequencies, and protonic conduction and ionic movement of the $\mathrm{K}^{+}$species, in the interlayer region at low frequencies.
\end{abstract}

Keywords: Birnessite; nanoporous metal oxides; impedance spectroscopy

\section{Introduction}

From the 1960s, works of Wolkestein [1] state the importance of electron theory to elucidate the relation between the catalytic and electronic properties of a catalyst and also the semiconductor nature of this type of material. Swaminathan [2] produced research about the opportunities and ways to improve catalyst technology, specifically in their development, cost reduction, and field applications [2]. Among the catalysts, semiconductors such as $\mathrm{TiO}_{2}, \mathrm{ZnO}$, and $\mathrm{SnO}_{2}$ play a pivotal role, as they can use the electromagnetic spectra to degrade contaminants [3,4]. It has been reported that these semiconductor oxides also have acidic and basic natures [2]. Therefore, they are useful as both solid acid and base catalysts. For this reason, efforts to develop new, cheaper, active, and selective catalysts are ongoing. Manganese oxides are among the most extensively studied raw, supported, or doped 
catalysts [5-11]; however, their electrical properties have been less studied [12-14]. The family of the manganese oxide type of materials have variations in their structure depending on the way the $\mathrm{Mn}-\mathrm{O}$ is linked together [15]. Therefore, layer, tunnel, spinel, and compact structures can be found. Manganese oxides have also been used as a cathode in secondary batteries [16,17]. Manganese, as a central atom in the octahedral coordination in these structures, mainly has the $4+$ and $3+$ oxidation states. However, average oxidations states of 3.5 and 3.8 are commonly found because of the presence of $\mathrm{Mn}^{4+}$ and $\mathrm{Mn}^{3+}$ in the same building blocks [18]. Birnessite is a special structure of this manganese oxide family. It is composed of $\mathrm{Mn}-\mathrm{O}$ octahedra forming octahedral layers as clays, and it has monovalent or divalent ions surrounded by water molecules to compensate the electrical charge of its layers. Therefore, these monovalent or divalent cations are located in the region called the interlayer $[9,12]$. The cations in the interlayer region can be displaced by other species because of their mobile nature. Birnessite has been used in previous works as a catalyst in soot combustion processes and in methylene blue degradation, showing appreciable catalytic activity compared to traditional catalysts $[9,11,19]$. For this reason, the present work focuses on the charge transport mechanism for two birnessite material types, $\mathrm{Mn} 4$ and $\mathrm{Mn} 8$, synthesized at 400 and $800{ }^{\circ} \mathrm{C}$, respectively, with the intention for a deeper understanding of the nature of this type of material for advanced applications.

\section{Results and Discussion}

\subsection{Chemical Composition, Thermogravimetric Analysis (TGA), and Average Oxidation State (AOS)}

The thermal reduction of $\mathrm{KMnO}_{4}$ has been reported by Kappestein [20] and Herbstein [21]. In the study conducted by Herbstein et al. [21] on the thermal decomposition of $\mathrm{KMnO}_{4}$ in a temperature range of 25 to $900{ }^{\circ} \mathrm{C}$, in an atmosphere of air and nitrogen, it was found that the idealized equation for the decomposition of $\mathrm{KMnO}_{4}$ in air at $250{ }^{\circ} \mathrm{C}$ results in a soluble phase, the $\mathrm{K}_{2} \mathrm{MnO}_{4}$, and another phase that is insoluble, like this:

$$
10 \mathrm{KMnO}_{4} \rightarrow 2.65 \mathrm{~K}_{2} \mathrm{MnO}_{4}+\left[2.35 \mathrm{~K}_{2} \mathrm{O} 7.75 \mathrm{MnO}_{2.05}\right]+6 \mathrm{O}_{2} .
$$

Decomposition in air or nitrogen at higher temperatures (up to $540{ }^{\circ} \mathrm{C}$ ) results in more considerable amounts of $\mathrm{O}_{2}$, corresponding to the change in the composition of the nonsoluble phase. At temperatures above $540{ }^{\circ} \mathrm{C}$ in both air and nitrogen, $\mathrm{K}_{2} \mathrm{MnO}_{4}$ decomposes into:

$$
10 \mathrm{~K}_{2} \mathrm{MnO}_{4} \rightarrow 5.7 \mathrm{~K}_{3} \mathrm{MnO}_{4}+0.5\left[2.9 \mathrm{~K}_{2} \mathrm{O} 8.6 \mathrm{MnO}_{2.1}\right]+3.4 \mathrm{O}_{2} .
$$

These potassium manganates are stable within the temperature range of 25 to $900{ }^{\circ} \mathrm{C}$, but they react quickly with water vapor. The thermal decomposition of $\mathrm{KMnO}_{4}$ is a redox reaction in which the oxoanion oxygen is oxidized to molecular oxygen, while the oxidation number of manganese in the oxoanion is reduced from $\mathrm{Mn}$ (VII) to $\mathrm{Mn}(\mathrm{VI})$, from $\mathrm{MnO}_{4}^{-}$and $\mathrm{MnO}_{4}^{2-}$. It has been reported that in the thermal decomposition of $\mathrm{KMnO}_{4}$ at $250{ }^{\circ} \mathrm{C}$, an average of $1.6 \mathrm{Mn}-\mathrm{O}$ bonds are broken in $73 \%$ of the permanganate ions. The electrons are then transferred to the remaining $27 \%$ of permanganate ions, which are reduced to $\mathrm{MnO}_{4}^{2-}$ without presenting a significant change in its tetrahedral form. In the $\mathrm{K}_{2} \mathrm{MnO}_{4}$ at $600{ }^{\circ} \mathrm{C}, 1.6 \mathrm{Mn}-\mathrm{O}$ bonds are broken on average in $43 \%$ of $\mathrm{MnO}_{4}^{2-}$ ions, and the electrons are transferred to the remaining $57 \%$ of manganate ions, which are reduced to $\mathrm{MnO}_{4}^{3-}$.

The manganates formed by this reaction are soluble salts. For this reason, the preparation of birnessite-type materials for this synthesis route involves a washing procedure after the calcination process to provide birnessite as the only crystallographic phase.

The K/Mn ratio, obtained by atomic absorption (AA) results (Table 1), shows a variation in the potassium and manganese content of the materials as the synthesis temperature increases [9]. 
Table 1. Structural formulas for birnessite-type materials.

\begin{tabular}{|c|c|c|c|c|c|c|c|}
\hline Material & Structural Formula & $\mathrm{K} / \mathrm{Mn}$ & $\begin{array}{c}\text { Average } \\
\text { Oxidation } \\
\text { State (AOS) }\end{array}$ & $\begin{array}{l}\mathrm{d}_{001} \\
(\AA)\end{array}$ & $\begin{array}{l}\text { Crystal } \\
\text { Size * } \\
(\mathrm{nm})\end{array}$ & $\begin{array}{c}\text { Specific } \\
\text { Surface Area } \\
\left(\mathrm{m}^{2} / \mathrm{g}\right)\end{array}$ & $\begin{array}{c}\text { Bulk } \\
\text { Conductivity } \\
\left(\Omega^{-1} \mathrm{~cm}^{-1}\right) \times 10^{-5}\end{array}$ \\
\hline Mn4 & $\mathrm{K}_{0.29}^{+}\left(\mathrm{Mn}_{0.84}^{4+} \mathrm{Mn}_{0.16}^{3+}\right) \mathrm{O}_{2.07} \cdot 0.61 \mathrm{H}_{2} \mathrm{O}$ & 0.29 & 3.84 & 7.12 & 25 & $16.26 \pm 0.17$ & 2.106 \\
\hline Mn8 & $\mathrm{K}_{0.48}^{+}\left(\mathrm{Mn}_{0.64}^{4+} \mathrm{Mn}_{0.36}^{3+}\right) \mathrm{O}_{2.06} \cdot 0.50 \mathrm{H}_{2} \mathrm{O}$ & 0.48 & 3.64 & 7.11 & 61 & $4.56 \pm 0.04$ & 2.135 \\
\hline
\end{tabular}

${ }^{*}$ By Debye-Scherrer Equation, ${ }^{* *} 21^{\circ} \mathrm{C}$.

Similarly, a decrease in the average oxidation state (AOS) (Table 1) indicates the presence of manganese in the $4+$ and $3+$ oxidation states. The percentage of $\mathrm{Mn}^{3+}$ in these materials was $16 \%$, and $36 \%$ for Mn4 and Mn8, respectively. The results of the AOS, for Mn4 and Mn8, are close to those reported in the literature $[9,22]$ for birnessite produced by solid-state reactions at 400 and $800{ }^{\circ} \mathrm{C}$. Thermal analysis in nitrogen and air atmospheres (Figure 1) showed thermal events typical of these layer materials $[9,22,23]$. Weight loss, up to $250^{\circ} \mathrm{C}$, is attributed to the evaporation of physiosorbed water and interlayer water. From 250 to about $800{ }^{\circ} \mathrm{C}$, the materials lose oxygen because of the phase transformation from a layer to a tunnel structure [9]. When heated to temperatures above $250{ }^{\circ} \mathrm{C}$, the Mn4 material loses $2.48 \%$ of its original mass in nitrogen atmosphere. Similarly, Mn8 experienced a weight loss of $1.69 \%$. These results indicate that the materials synthesized at higher temperatures lose less oxygen, and show a greater thermal stability, compared to the ones synthesized by chemical routes [24]. The materials were more stable in nitrogen than in air, as it can be seen in Figure 1. The difference in weight losses at temperatures higher than $250^{\circ} \mathrm{C}$ between both atmospheres indicates a release of oxygen from the framework, as it was reported by Suib et al. [25]. For Mn4, this difference was $0.53 \%$, and it was $0.16 \%$ for Mn 8 . The combined results of atomic absorption, thermogravimetric analysis (TGA), and AOS were used to formulate the structural formula shown in Table 1.

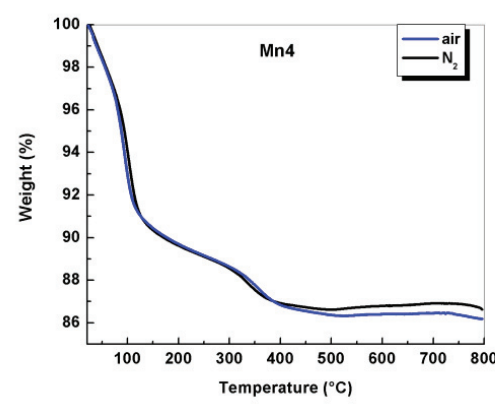

(a)

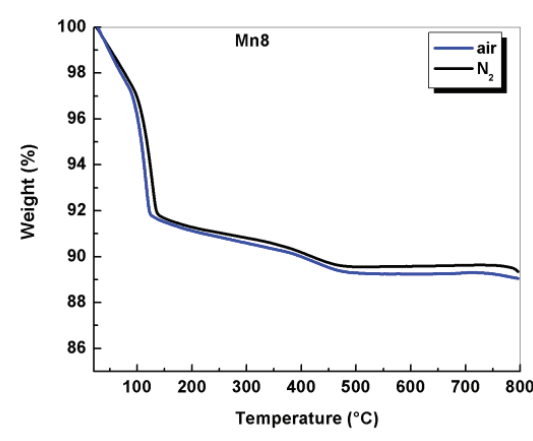

(b)

Figure 1. Thermograms in air and $\mathrm{N}_{2}$ for synthesized birnessite-type materials. (a) birnessite type of material synthezised at $400^{\circ} \mathrm{C},(\mathbf{b})$ birnessite type of material synthezised at $800^{\circ} \mathrm{C}$.

\subsection{Structural Analysis and Rietveld Refinement}

The synthesis method produced a typical layered manganese oxide (birnessite) structure, as confirmed by X-ray diffraction (XRD) (Figure 2a). The d (001) basal spacing and estimated crystal size are shown in Table 1 . The basal spacing of these layer materials is in accordance with the published works $[18,22,26,27]$. 


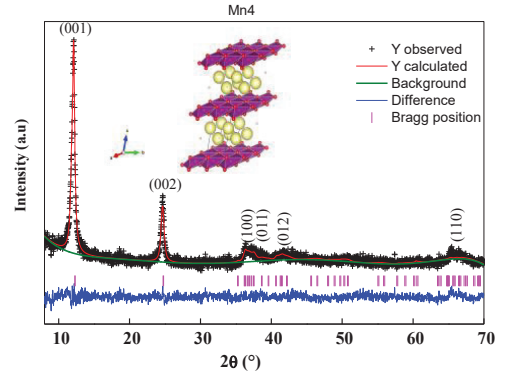

(a)

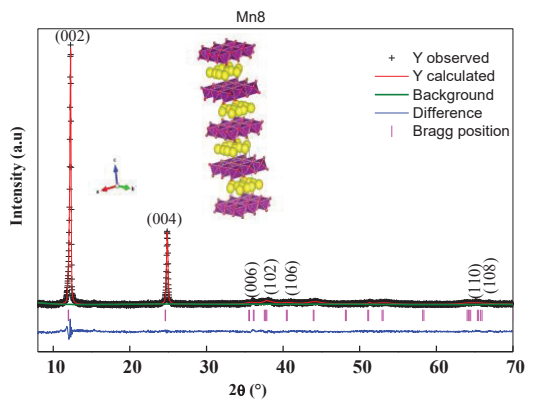

(b)

Figure 2. Rietveld refinement results for (a) Mn4, and (b) Mn8. The insert shows the polyhedral structure of the triclinic and hexagonal birnessite for (a) Mn4, and (b) Mn8 respectively.

Analysis between $30^{\circ}$ and $70^{\circ}$ in $2 \theta$ showed the presence of structural disorders associated with the rotation and translational stacking faults of the layers, as demonstrated in phyllosilicate minerals [28]. The synthesis temperature and structural disorder ratio was also noted by Gaillot et al. [22,29]. The Mn4 material (Figure 2a), in the range mentioned above, had diffraction peaks located at 2.91, 2.47, 2.40, 2.29, $2.17,1.81,1.43,1.39$, and $1.35 \AA$, which are in agreement with those reported for triclinic birnessite $[29,30]$. For Mn8 it was observed that X-rays diffracted at angles of $12.42^{\circ}, 25.06^{\circ}, 36.48^{\circ}, 38.54^{\circ}, 41.36^{\circ}, 44.48^{\circ}$, $44.80^{\circ}$, and $53.46^{\circ} 2 \theta$, which correspond to interplanar spacing of $7.12,3.55,2.46,2.33,2.18,2.03,2.02$, and $1.71 \AA$, respectively. These are characteristic of a hexagonal birnessite $[29,30]$, an observation that also appears in Kim et al. [31].

The atomic position (fractional coordinates) can be shown in Appendix A, Table A1.

The structural symmetry of birnessite was confirmed by the Rietveld method. The structural parameters have been summarized in Table 2, and comparisons between the experimental and theoretical patterns are shown in Figure 2. The refined parameters confirm the triclinic structure for Mn4 and the hexagonal structure for Mn8 (Table 2). For Mn8 material, the crystallographic density value was higher than Mn4 (Table 2). The change in the crystallographic density for Mn8 was related to the variation in the crystal symmetry from triclinic to hexagonal. The c-cell parameter increased because of the rearrangement of the atoms in the interlayer region and the densification that resulted from temperature increase.

A typical Mn-O1 bond distance, in the layer of the analyzed materials, falls between 1.088-2.352 $\AA$ and 1.860 Å for Mn4 and Mn8 materials, respectively. The presence of $\mathrm{Mn}^{3+}$, in both the high- and low-spin states, as was evidenced by AOS (Table 1), was confirmed by the four short and two long $\mathrm{Mn}-\mathrm{O}$ distances, which resulted from Jahn-Teller distortion. The Jahn-Teller distortion has important implications for the electrical conductivity of these materials. The $\mathrm{Mn}-\mathrm{O}$ bond distances are in close agreement with those reported by Drits et al. [32], Gaillot et al. [22], Lopano et al. [33], and Post and Veblen et al. [34]. The crystal broadening, for Mn4, is isotropic, as can be seen in the aspect ratio index (Table 2), whereas it was anisotropic for Mn8. The crystal anisotropy affects the electrical properties, as will be discussed later. 
Table 2. Summary of Rietveld refinement results for Mn4 and Mn8 materials.

\begin{tabular}{|c|c|c|c|}
\hline \multicolumn{2}{|c|}{ Sample Parameter } & $\operatorname{Mn} 4$ & Mn8 \\
\hline \multicolumn{2}{|l|}{ Space group } & P-1 & $\mathrm{P} 63 / \mathrm{mmc}$ \\
\hline \multicolumn{2}{|l|}{ Data/Parameters } & $3074 / 26$ & $3249 / 26$ \\
\hline \multicolumn{2}{|l|}{ Mn1 (Occ) } & 1 & 1 \\
\hline \multicolumn{2}{|l|}{ K1 (Occ) } & 0.29 & 0.09 \\
\hline \multicolumn{2}{|l|}{$\mathrm{O} 1$ (Occ) } & 1.02 & 0.95 \\
\hline \multicolumn{2}{|l|}{$\mathrm{O} 2(\mathrm{Occ})$} & 0.27 & 0.56 \\
\hline \multicolumn{2}{|l|}{ Mn1(Uiso) } & 0.005800 & 0.012370 \\
\hline \multicolumn{2}{|l|}{ K1 (Uiso) } & 0.067300 & 0.094000 \\
\hline \multicolumn{2}{|l|}{ O1 (Uiso) } & 0.031800 & 0.017300 \\
\hline \multicolumn{2}{|l|}{ O2 (Uiso) } & 0.067300 & 0.080000 \\
\hline \multirow{6}{*}{ Lattice parameters } & a $(\AA)$ & $2.91846 \pm 0.005645$ & $2.874708 \pm 0.002132$ \\
\hline & $\mathrm{b}(\AA)$ & $2.93104 \pm 0.005117$ & $2.874708 \pm 0.002132$ \\
\hline & $c(\AA)$ & $7.43240 \pm 0.006679$ & $14.168819 \pm 0.000357$ \\
\hline & $\alpha\left(^{\circ}\right)$ & $78.2025 \pm 0.184$ & 90 \\
\hline & $\beta\left({ }^{\circ}\right)$ & $103.5718 \pm 0.166$ & 90 \\
\hline & $\gamma\left({ }^{\circ}\right)$ & $121.7815 \pm 0.093$ & 120 \\
\hline \multicolumn{2}{|l|}{ Volume $\left(\AA^{3}\right)$} & $52.284 \pm 0.140$ & $101.403 \pm 0.123$ \\
\hline \multicolumn{2}{|c|}{ Calculated Unit Cell Molecular Weight } & 108.114 & 214.884 \\
\hline \multicolumn{2}{|c|}{ Crystallographic density $\left(\mathrm{g} / \mathrm{cm}^{3}\right)$} & 3.434 & 3.531 \\
\hline \multicolumn{2}{|c|}{ Perpendicular crystal size (nm) } & 18 & 53 \\
\hline \multicolumn{2}{|c|}{ Parallel crystal size (nm) } & 15 & 198 \\
\hline \multicolumn{2}{|c|}{ Aspect ratio } & 0.83 & 3.74 \\
\hline \multicolumn{2}{|l|}{$\chi^{2}$} & 0.9317 & 1.460 \\
\hline \multicolumn{2}{|l|}{$\hat{\mathrm{R}}_{\mathrm{p}}$} & 0.0209 & 0.0224 \\
\hline \multicolumn{2}{|l|}{$\mathrm{R}_{\mathrm{wp}}$} & 0.0266 & 0.0293 \\
\hline \multicolumn{2}{|l|}{$\mathrm{R}_{\mathrm{f}}$} & 0.4121 & 0.0315 \\
\hline \multicolumn{2}{|l|}{$R_{\exp }$} & 0.0276 & 0.0242 \\
\hline
\end{tabular}

Mn1: Mn layer, O1: O layer, and O2: O from interlayer water.

\subsection{Morphological Analysis}

Scanning electron microscopy analysis (Figure 3) shows that Mn4 (Figure 3a) was formed by particle aggregates small in size compared to Mn8 (Figure 3b). When subjected to calcination at $800{ }^{\circ} \mathrm{C}(\mathrm{Mn} 8)$, these agglomerates grew uniformly. These agglomerates tended to have a hexagonal plate morphology and had smoother surfaces, which is characteristic of these types of materials. These observations are consistent with the crystal size/temperature increment relation showed by XRD (Figure 2, Table 1) and Rietveld refinement (Table 2).
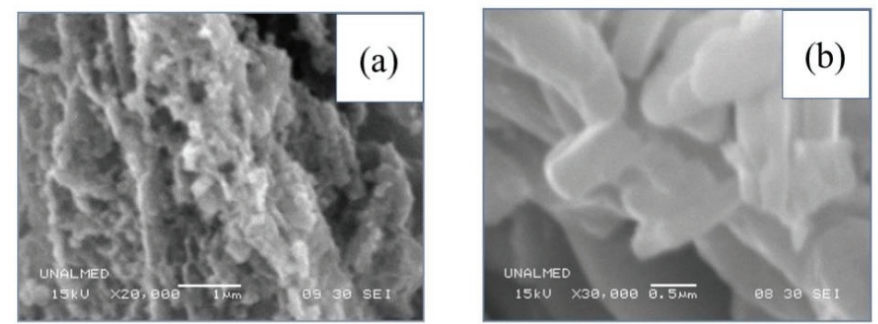

Figure 3. SEM images for Birnessite-type materials (a) Mn4 and (b) Mn8.

\section{4. $\mathrm{N}_{2}$ Adsorption-Desorption Analysis}

The $\mathrm{N}_{2}$ adsorption-desorption isotherms of the materials (Figure 4a) showed the existence of a type II isotherm, according to the International Union of Pure and Applied Chemistry (IUPAC) 
classification [35] and H3 hysteresis, characteristic of materials with slit-shaped and large pores [36]. The surface area, found by using the Brunauer-Emmet-Teller (BET) method (Table 1), decreased as the synthesis temperature increased. This trend is consistent with the crystal growth-smoothness relation, as evidenced by XRD (Figure 2) and SEM (Figure 3). The mesopore size distribution (Figure 4b) showed peaks centered at around 399.3 and $414.7 \AA$ for Mn4 and Mn8, respectively, with a pore volume that decreased as the synthesis temperature increased. This observation is in accordance with the aggregate size increment of the birnessite particles. All materials showed microporosity, as observed in Figure 4c, and the data show that the microporosity changes with increasing synthesis temperature. The interaction energy of the porous solid surface with the $\mathrm{N}_{2}$, obtained by nonlocal density functional theory (NLDFT) [37], varied with the synthesis temperature for the birnessite-type material. The data presented in Figure $4 \mathrm{~d}$ show values for the interaction energy around 48, 56, 60, 72, and $100 \mathrm{~K}$, with a greater contribution at $72 \mathrm{~K}$ for the Mn4 material. The main contribution for Mn8 occurred at $28 \mathrm{~K}$ followed by interaction energies of 38, 70, and $100 \mathrm{~K}$. Maddox et al. [38] reported that in mesoporous materials, like MCM41, values below $75 \mathrm{~K}$ correspond to the usual range of values reported for $\mathrm{O}-\mathrm{N}_{2}$ interactions. Values between 125 and $75 \mathrm{~K}$ correspond to theoretical $\varepsilon s f / k$ values for the $\mathrm{O}-\mathrm{O}$ interaction [38]. Therefore, the information presented asserts that the surfaces of the birnessite-type material are energetically heterogeneous, which probably contributes, in a positive manner, to its electrical processes.
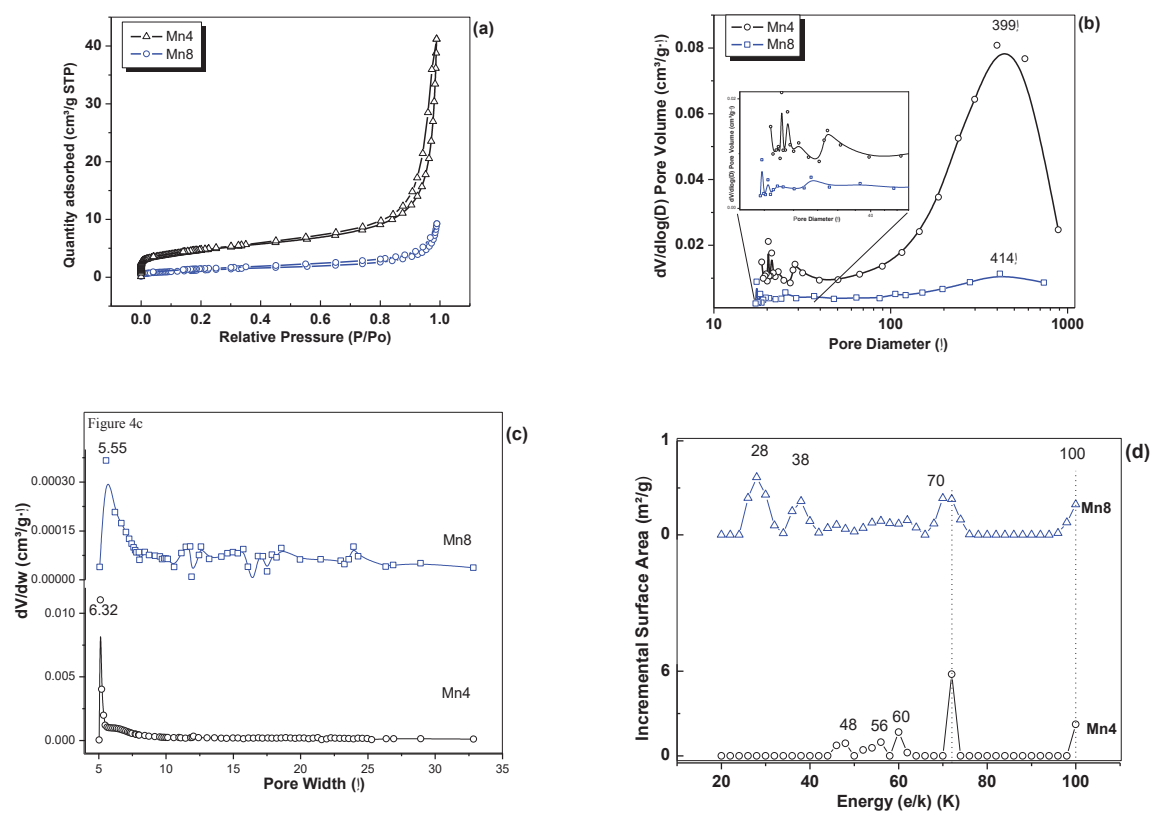

Figure 4. $\mathrm{N}_{2}$ adsorption-desorption results: (a) $\mathrm{N}_{2}$ isotherms, (b) mesopore size distribution by Barret-Joyner-Halenda (BJH), (c) micropore size distribution by Hovarth-Kawazoe (HK), and (d) interaction energy by nonlocal density functional theory (NLDFT). 


\subsection{Electrical Analysis of Nyquist Plots}

Nyquist plots from the impedance experimental data were conducted with the aim of studying the effect of temperature on the electrical response of the synthetized materials; the results are shown in Figure 5. The Nyquist plot exhibits a semicircle and a straight line at low frequency, but the magnitude of the diameter of the semicircle reduced as the temperature increased in both studied materials. This experimental evidence suggests an impedance reduction of the "bulk" and grain boundary processes. The presence of the semicircle in the Nyquist plot was associated with the electron transport processes on the "bulk", in which there are a contribution of inter-crystalline and intra-crystalline charge transport processes. Also, in this region, a possible additional contribution to the electrical response came from protonic conduction $\left(\mathrm{H}_{3} \mathrm{O}^{+}\right)$because of the interlayer water in the birnessite structure. The observations corresponding to the electron transport process are concurrent with the results of previous research [12,13]. However, the preparation methods reported here produced materials with less impedance compared to previous work [12]. Therefore, is possible to tune the electrical properties of manganese oxides. The straight line at low frequency was associated with the ionic diffusion of $\mathrm{K}^{+}$ions located in the interlayer region, which follow a Warburg diffusion process. The straight lines observed in Figure 5a,b indicated that the ionic diffusion was preserved up to $373 \mathrm{~K}$, due to the satisfactory thermal stability of these materials (Figure 1), as opposed to soft synthesis routes [12,23].

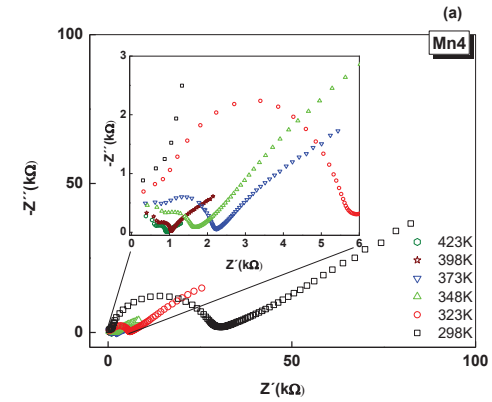

(a)

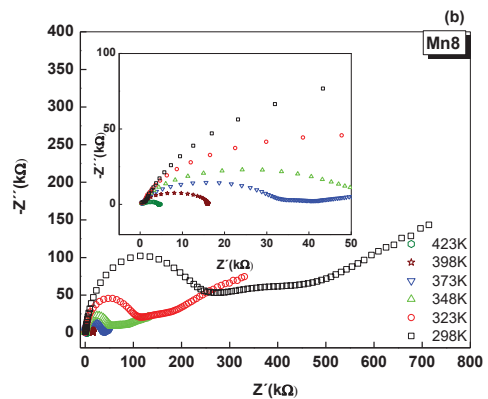

(b)
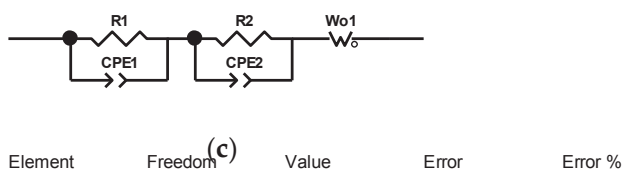

Figure 5. Nyquist Plot as a function of temperature for (a) Mn4 and (b) Mn8. (c) equivalent circuit. R1 and R2: resistances; CPE-1 and CPE-2: constant phase element; and Wo1: Warburg open element. The insert in (a) corresponds to an increase in the scale between 0 to $8 \mathrm{k} \Omega$, The insert in (b) corresponds to an increase in the scale between 0 to $50 \mathrm{k} \Omega$.

The equivalent circuit, shown in Figure 5, that represents the experimental results, was constructed considering the morphology and structural issues for the studied materials, and it also takes into account the reports of the literature for the electrical behavior of porous materials [12,13,39-42]. In this circuit, each circuital element is composed of a constant phase element (CPE) connected in parallel with one resistor (R). CPE1 and R1 reflect the intra-/inter-crystalline electrical process, while CPE2 and $\mathrm{R} 2$ were assigned to fit the results concerning the charge transport in the grain boundary or aggregate boundary. These two circuital elements were put in series because it was the better circuit that better adjust the experimental results. Also, each of the circuital elements were connected in series because 
the Nyquist plot described consecutive processes [43], as reported in previous work [12]. The circuit was finally completed with a Warburg open element (W1). In these equivalent circuits, the constant phase elements (CPE1, CPE2) were selected based on SEM (Figure 3) and textural analysis (Figure 4). CPE describes a nonideal capacitive process, [12,44] which, for the purposes of this study, was used to model the porous structure of the material and its heterogeneous surface (Figure $4 a-d)[45,46]$. The numerical results of the equivalent circuits are summarized in Appendix A (Tables A2 and A3).

In the circuital model, R1 and R2 are the inter-/intra-crystalline resistance and grain boundary resistance, respectively; CPE1-T is the capacitance of inter-/intra-crystalline processes; CPE2-T corresponds to the capacitance of the grain boundary process; and CPE1-P and CPE2-P are the exponents of the impedance for CPE (Equation (1)) for the inter-/intra-crystalline and grain boundary processes.

$$
Z_{C P E}=\frac{1}{\left(T(I \times \omega)^{P}\right)}
$$

where $Z_{C P E}$ is the impedance of the CPE element, $T$ corresponds to CPE-T, $P$ corresponds to CPE-P, $\omega=$ angular frequency of alternating current signal, and $I=\sqrt{-1}$.

In the same model, Wo-R is the resistance to the ionic diffusion, and Wo-T and Wo-P are the coefficients according to the Warburg impedance equation (Equation (2)):

$$
Z_{W o}=\frac{R\left(\operatorname{ctgh}(I \times T \times \omega)^{P}\right)}{(I \times T \times \omega)^{P}},
$$

where $Z w_{0}$ is the impedance for the Warburg open element, $R$ describes the diffusion resistance $(\Omega)$, $P$ is the exponential coefficient, and $T$ is described through Equation (3):

$$
W_{0}-T=\frac{L^{2}}{D}
$$

where $W_{0}-T$ is the Warburg $T$ coefficient, $L$ is the effective diffusion thickness $\left(\mathrm{m}^{2}\right)$, and $D\left(\mathrm{~m}^{2} \mathrm{~s}^{-1}\right)$ is the effective diffusion coefficient of the charge carrier. The contribution of the charge transport processes, and their accumulation at the grain boundaries of the Birnessite particle's aggregates, overlap with the "bulk" contribution because of the proximity of the particles, which was produced by the sample preparation for the electrical experiments (Figure 3). Because of this reason, the CPE2 and R2 elements were introduced into the circuital model.

The increase of the resistance of the "bulk" process (intra-crystalline and inter-crystalline), in the order Mn4 < Mn8 (Tables A2 and A3, Appendix A), suggests an interplay between the crystal size, the average oxidation state of manganese, and the crystal symmetry (Tables 1 and 2). Therefore, the smaller the crystal size is, the higher the micropore and surface area. For instance, Mn4, compared to the other cases, allows the electrons to travel through the crystal more freely because of the shorter Mn-O bond distances, as discussed above.

The values for the relaxation time are presented in Figure 6. The increase in relaxation time with temperature is consistent with the decrease of the resistance at "bulk process", most likely due to higher $\mathrm{K}-\mathrm{O}$ bond distances in $\mathrm{Mn} 8$, as was observed by the Rietveld refinement (Table 2). This relaxation time was almost linear with respect to the temperature for Mn8, but it decreased nearly exponentially for Mn4. This suggests that the relaxation time in the "bulk" is thermally activated and is lower for Mn4, indicating a fast electron mobility correlated to a high surface area and low crystal size (Table 1). 


\subsection{Alternant Current $(A C)$ conductivity}

AC conductivity measurements (Figure 7) unraveled a power law behavior at high frequencies [47], which suggests electron hopping $[48,49]$ and short-range conductivity [50]. The power law was first reported by Jonscher [47] and referred to as the universal dynamic response. It is described as

$$
\sigma_{a c}=\sigma_{0}+A \omega^{n},
$$

where $\sigma_{a c}$ is the AC conductivity, $\sigma_{0}$ is the DC conductivity, $\omega$ is the angular frequency of the applied electric field, $\omega=2 \pi \mathrm{f}$, and $A$ and $n$ are the fitting parameters. $n$ generally falls between zero and unity.

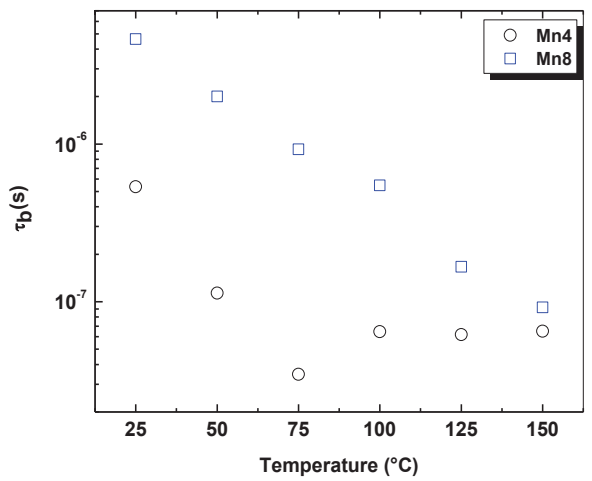

Figure 6. Effect of temperature on bulk relaxation time $\left(\tau_{\mathrm{b}}\right)$ for the synthesized birnessite-type material.

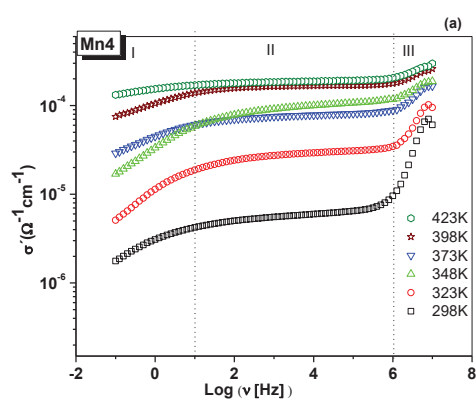

(a)

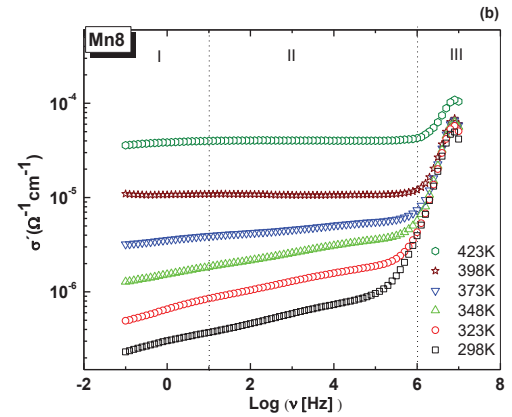

(b)

Figure 7. Real component of the complex conductivity as a function of temperature. (a) Mn4, birnessite type of material synthesized at $400^{\circ} \mathrm{C}$, (b) Mn8, birnessite type of material synthesized at $400^{\circ} \mathrm{C}$.

Such behavior has been observed in layered manganese oxides [12] and perovskite-type materials [51]. The sudden increment in the conductivity, above $10 \mathrm{~Hz}$ for Mn8 material (Figure 7), most likely is due to the high quantity of $\mathrm{Mn}^{3+}$ (Table 1) compared to Mn4. However, Mn4 had the highest conductivity (Figure 7) because of its smaller crystal size and higher surface area (Table 1). The conductivity values obtained at $10 \mathrm{~Hz}$ were $4.1250 \times 10^{-6}$ and $1.6870 \times 10^{-4} \Omega^{-1} \mathrm{~cm}^{-1}$ for Mn4 at 298 and $423 \mathrm{~K}$, respectively. For Mn8, the conductivity values at this frequency were $3.7074 \times 10^{-7}$ $(298 \mathrm{~K})$ and $3.9866 \times 10^{-5} \Omega^{-1} \mathrm{~cm}^{-1}(423 \mathrm{~K})$. 
It is probable that the stacking faults in Mn4 provide crystallographic active sites for the movement of the charge carrier, as was evidenced in the surface energy plots (Figure 4c,d). Hence, it is probable that, at low frequencies, the ionic conduction process is the most favorable for Mn4, as represented by the appearance of the straight line in Figure 5a. Also, in this material, the $\mathrm{K}-\mathrm{O}$ bond distances, the crystallographic position of $\mathrm{K}^{+}$, and the $\mathrm{H}_{2} \mathrm{O}$ interlayer allows the continuity in the channels for ionic conduction. Differences in the amount of potassium and water, and its position in the crystal cell of the studied materials, influence the electrical behavior in the low-frequency region. At higher contents of $\mathrm{K}^{+}$ions, the two positions in the crystal cell, for the water molecules in Mn8, and the proper alignment of the material's layers limit the ionic conduction routes, such that this contributes to a diminished ionic conductivity at low frequency (Figure 7). These types of materials are ionic exchangers [52]; therefore, the ions in the interlayer space are mobile. Water is an important key for the mobility of the ions in the interlayer space [12,53]. A low amount of water in the interlayer region can diminish the ionic mobility of the ions [53]. Furthermore, the water's ability to facilitate ion conduction is dependent on the charge density of these ion [12,53,54]. Another reason for the enhanced conductivity is that the stacking faults alter the electrical conduction pathways. It is probable that this heterogeneous surface creates interactions between the electric field and the charge carrier. The variations in surface energies (Figure 4c,d) support the heterogeneity of the material surfaces.

Figure 7 shows the AC conductivity for each material, by around two orders of magnitude, along with the induced temperature of the experiment. In Figure 7a, a low-frequency dispersion (LFD) can be seen for all temperatures. The region II (between $10 \mathrm{~Hz}$ up to $1 \mathrm{MHz}$ ) is dominated by DC conductivity, and region III (after $1 \mathrm{MHz}$ ) is characterized by the "universal Jonscher law" [47]. The results suggest that the charge transport mechanism is temperature-activated. Figure 8 shows the activation energy of each material. It is evident that, for Mn4 material (Figure 8a), the conductivity depends on the frequency and temperature. However, for Mn8 (Figure 8b), at temperatures higher than $348 \mathrm{~K}$ and frequencies below $10 \mathrm{MHz}$, the dependence is mainly associated with the temperature. The conductivity results suggest that the process is dominated by thermally activated "electron hopping" in the range of analyzed temperatures. When the electrons move forward between Mn sites, there is a change in the local structure caused by the change in the oxidation state of the $\mathrm{MnO}_{6}$ units that form the layer. These changes generate lattice vibrations. This phenomenon should be understood as a strong electron-phonon interaction or polaron mechanism [55], which is the other one present in the electrical conductivity process. The activation energies of each material (Figure 8) were lower than those reported for similar materials [12]. This is because of the higher average oxidation state of manganese (Table 1), which means a higher amount of $\mathrm{Mn}^{4+}$, as is reported for manganites obtained from a nickel permanganate precursor [56]. The lower activation energy of Mn4 compared to Mn6 and Mn8 could be associated with the difference in the quantity of $\mathrm{Mn}^{3+}$ between the synthesized materials, the variation of the $\mathrm{Mn}-\mathrm{O}-\mathrm{Mn}$ bond lengths resulting from crystal symmetry (Table 2), the changes of the surface area that can lead to a redistribution of electron charge [57], "polaron hopping" [58], and the Jahn-Teller distortion of $\mathrm{Mn}^{3+}$ ions [12]; thus, there are different electric behaviors with respect to the frequency of the applied electric field. Presumably, the increase of the conductivity involved in the transition zone, between Region I and Region II (Figure 8), was due to the release of physiosorbed water on the material's surface [12]. 


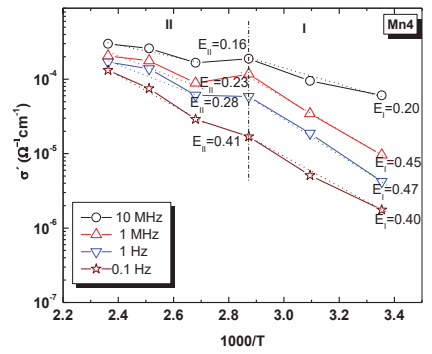

(a)

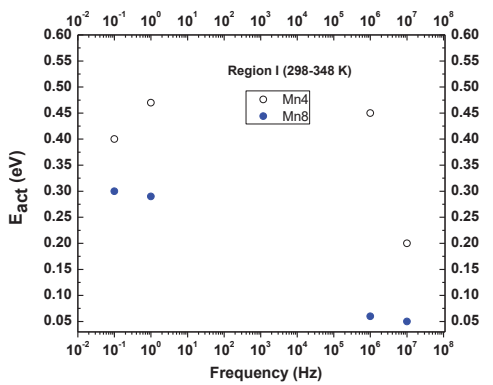

(c)

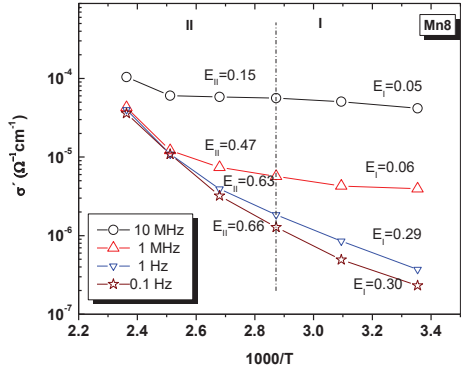

(b)

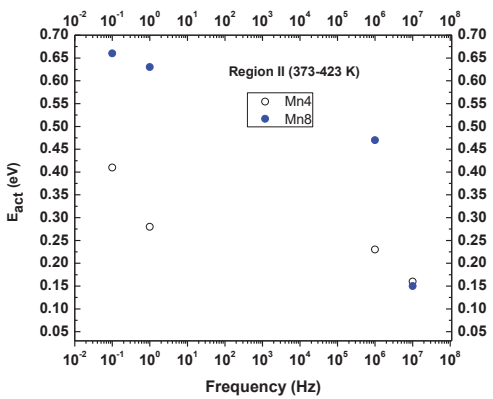

(d)

Figure 8. Arrhenius plot of the real component of the complex conductivity.(a) Mn4, (b) Mn8, (c) comparison of the activation energy between 298 to $348 \mathrm{~K}$, (d) comparison of the activation energy between 373-423 K.

The comparison of conductivity values for manganese oxides and birnessites synthesized in this work is shown in the Table 3.

Table 3. Conductivity values for different manganese oxides.

\begin{tabular}{lccc}
\hline \multicolumn{1}{c}{ Phase } & Conditions & Conductivity & Reference \\
\hline $\mathrm{MnO}$ & Room temperature & $10^{-9} \Omega^{-1} \mathrm{~cm}^{-1}$ & {$[59]$} \\
birnessite & $298 \mathrm{~K}$ & $10^{-5}$ to $10^{-6} \Omega^{-1} \mathrm{~cm}^{-1}$ & {$[60]$} \\
Todorokite & $298 \mathrm{~K}$ & $2.083 \times 10^{-6} \Omega^{-1} \mathrm{~cm}^{-1}\left(4.8 \times 10^{5} \Omega \mathrm{cm}\right)$ & {$[60]$} \\
\hline $\mathrm{MnO}_{2}$ & Room temperature & Resistivity $0.5 \mathrm{ohm}-\mathrm{cm}\left(2 \Omega^{-1} \mathrm{~cm}^{-1}\right)$ & {$[61]$} \\
$\mathrm{Mn}_{2} \mathrm{O}_{3}$ & Room temperature & Resistivity $0.0028 \mathrm{ohm}-\mathrm{cm}$ & \\
\hline $\mathrm{Mn}_{2} \mathrm{O}_{3}$ & Room temperature & $\sim 10^{-3} \Omega^{-1} \mathrm{~m}^{-1}$ & {$[62]$} \\
$\mathrm{MnO}_{2}$ & Under pressure 43 GPa & Resistivity $6.8 \times 10^{-7} \Omega \mathrm{m}$ & {$[63]$} \\
$\mathrm{B}_{-} \mathrm{MnO}_{2}$ & Room temperature & $1.27 \times 10^{-4} \Omega^{-1} \mathrm{~cm}^{-1}$ & {$[64]$} \\
$\mathrm{Mn}_{3} \mathrm{O}_{4}$ & Room temperature & $3.18 \times 10^{-5} \Omega^{-1} \mathrm{~cm}^{-1}$ & {$[65]$} \\
$\mathrm{Mn}_{3} \mathrm{O}_{4}$ & $323 \mathrm{~K}$ & $(3.68 \pm 0.03) \times 10^{-8} \Omega^{-1} \mathrm{~m}^{-1}$ & {$[65]$} \\
$\mathrm{MnO}_{2}$ todorokite & $423 \mathrm{~K}$ & $(2.04 \pm 0.001) \times 10^{-5} \Omega^{-1} \mathrm{~m}^{-1}$ & {$[66]$} \\
\hline
\end{tabular}


Table 3. Cont.

\begin{tabular}{|c|c|c|c|}
\hline Phase & Conditions & Conductivity & Reference \\
\hline $\mathrm{MnO}_{2}$ criptomelane & & $10^{-3}$ to $10^{-4} \Omega^{-1} \mathrm{~cm}^{-1}$ & [15] \\
\hline $\mathrm{MnO}_{2}$ criptomelane & & $10^{-6} \Omega^{-1} \mathrm{~cm}^{-1}$ & [52] \\
\hline K-birnessite & & $10^{-6} \Omega^{-1} \mathrm{~cm}^{-1}$ & \\
\hline Na Birnessite & $298 \mathrm{~K}, 1 \mathrm{MHz}$ & $8.39 \times 10^{-6} \Omega^{-1} \mathrm{~cm}^{-1}$ & [12] \\
\hline \multirow{4}{*}{ K-birnessite } & $298 \mathrm{~K}, 10 \mathrm{~Hz}$ & $\begin{array}{l}\text { Mn4: } 4.1250 \times 10^{-6} \Omega^{-1} \mathrm{~cm}^{-1} \\
\text { Mn8: } 3.7074 \times 10^{-7} \Omega^{-1} \mathrm{~cm}^{-1}\end{array}$ & This Work \\
\hline & $298 \mathrm{~K}, 1 \mathrm{MHz}$ & $\begin{array}{l}\text { Mn4: } 6.555 \times 10^{-5} \Omega^{-1} \mathrm{~cm}^{-1} \\
\text { Mn8: } 3.944 \times 10^{-6} \Omega^{-1} \mathrm{~cm}^{-1}\end{array}$ & This Work \\
\hline & $423 \mathrm{~K}, 10 \mathrm{~Hz}$ & $\begin{array}{c}\text { Mn4: } 1.6870 \times 10^{-4} \Omega^{-1} \mathrm{~cm}^{-1} \\
\text { Mn8: } 3.85 \times 10^{-5} \Omega^{-1} \mathrm{~cm}^{-1}\end{array}$ & This Work \\
\hline & $423 \mathrm{~K}, 1 \mathrm{MHz}$ & $\begin{array}{l}\text { Mn4: } 2.050 \times 10^{-4} \Omega^{-1} \mathrm{~cm}^{-1} \\
\text { Mn8: } 4.270 \times 10^{-5} \Omega^{-1} \mathrm{~cm}^{-1}\end{array}$ & This Work \\
\hline
\end{tabular}

\section{Materials and Methods}

\subsection{Synthesis}

Manganese oxides with birnessite-type structures (K-birnessite) were synthesized by the thermal reduction of a manganese salt, $\mathrm{KMnO}_{4}$ (Merck, Darmstand-Germany, 99\%), as detailed in previous studies $[9,22,31,67]$. The procedure was as follows; the $\mathrm{KMnO}_{4}$ in powder form was homogeneously dispersed in a porcelain dish and exposed to calcination in a muffle furnace at temperatures of 400 and $800{ }^{\circ} \mathrm{C}$ for $6 \mathrm{~h}$ at $10^{\circ} \mathrm{C} / \mathrm{min}$, to induce the thermal reduction, then they were cooled to room temperature. After calcination, each material was washed with deionized and distilled water to remove any soluble salts (potassium manganates) formed during the process and to reduce the $\mathrm{pH}$ from 12 to 9.5. The materials were dried at $60^{\circ} \mathrm{C}$ for $24 \mathrm{~h}$ for further characterization. The materials were named as Mn4 and Mn8 (from thermal reduction at 400 and $800^{\circ} \mathrm{C}$, respectively).

\subsection{Elemental Analysis and Average Oxidation State of Manganese}

An elemental chemical analysis for the determination of $\mathrm{K}$ and $\mathrm{Mn}$ was performed by atomic absorption spectroscopy (AAS) in an atomic absorption spectrophotometer, PERKIN ELMER, model 3110, (Perkin Elmer Corporation, Waltham, MA, USA) and by using a standard procedure for sample digestion. The sample digestion process consisted of dissolving $100.0 \mathrm{mg}$ of sample powder in $2.0 \mathrm{~mL}$ of $37 \% \mathrm{HCl}$ and $1.0 \mathrm{~mL}$ of distilled and deionized water (DDW). The sample was then heated up to $100{ }^{\circ} \mathrm{C}$, for about $30 \mathrm{~min}$, until the solution became transparent and there were no undissolved solid particles. The Mn and K contents were determined at wavelengths of 279.5 and $766.5 \mathrm{~nm}$, respectively. The average oxidation states (AOSs) of the manganese in the samples were determined by potentiometric and colorimetric titration [68]. In the first step, $40.0 \mathrm{mg}$ of the sample was dissolved by heating in $18.5 \% \mathrm{v} / \mathrm{v} \mathrm{HCl}$ solution, with the final volume being adjusted to $100 \mathrm{~mL}$. After that, $10 \mathrm{~mL}$ of this solution was added to $100 \mathrm{~mL}$ of a saturated solution of $\mathrm{Na}_{2} \mathrm{P}_{2} \mathrm{O}_{7}$, the $\mathrm{pH}$ of the solution was adjusted to between 6.5-7.0, and then it was titrated with $\mathrm{KMnO}_{4}$ standard (around $1 \times 10^{-3} \mathrm{M}$ ). The final point for this titration was taken when the potential increased to more than 100-150 mV. In the second step, about $40 \mathrm{mg}$ of sample was dissolved in $10.0 \mathrm{~mL}$ of ferrous ammonium sulfate (FAS) solution under constant nitrogen flow, and the volume was adjusted up to $100 \mathrm{~mL}$ with DDW in order to reduce $\mathrm{Mn}^{4+}$ and $\mathrm{Mn}^{3+}$ to $\mathrm{Mn}^{2+}$. For the final step, $10.0 \mathrm{~mL}$ of this solution was back titrated, with a permanganate standard, until a color change occurred. All measurements were repeated three times in order to obtain the standard deviation. 


\subsection{X-ray Diffraction (XRD) Data Collection and Structural Refinement}

All X-Ray Diffraction (XRD) patterns of the powder samples were performed at room temperature with a Brag-Brentano focusing geometry in a RIGAKU MINIFLEX II diffractometer, (Rigaku Company, Tokyo Japan), using $\mathrm{CuK} \alpha$ radiation at $30 \mathrm{kV}$ and $15 \mathrm{~mA}$ with a scan rate of $2^{\circ}\left(2 \theta \mathrm{min}^{-1}\right.$, sampling width of $0.01^{\circ}(2 \theta)$, and between $3^{\circ}$ and $70^{\circ}(2 \theta)$. Rietveld refinement [69], for the obtained birnessite-type materials, was performed with a General Structure Analysis System (GSAS) [70] using the EXPGUI interface [71]. An experimental XRD pattern of a silicon powder was refined in order to obtain the instrumental parameter file. Because of the differences in the layer arrangements between each material, the initial structural parameters, triclinic [33] and hexagonal [22] symmetries, were used. The crystallographic information file (CIF) was obtained from Crystallography Open Database [72,73]. All polyhedral crystal structure drawings were made by using Vesta software.

\subsection{Thermal Analysis}

The thermal stability of the materials was studied by thermogravimetric analysis (TGA) on a TA instruments, model TGA Q500 thermogravimetric analyzer (TA Instrument, Delawere, DE, USA). Measurements were made on $10.0 \mathrm{mg}$ of sample, using a high-resolution algorithm (sensitivity: 1, resolution: 5) with $\mathrm{N}_{2}$ flow $\left(100 \mathrm{~mL} \mathrm{~min}^{-1}\right)$ at a heating rate of $10^{\circ} \mathrm{C} \mathrm{min}^{-1}$. The measurement range was from 21 up to $800{ }^{\circ} \mathrm{C}$.

\subsection{Surface Area and Porosity}

$\mathrm{N}_{2}$ adsorption-desorption isotherms were conducted to study the surface area, pore volume, and pore size distribution of the materials. The samples $(100.0 \mathrm{mg})$ were degassed under vacuum at $120^{\circ} \mathrm{C}$ for $24 \mathrm{~h}$, and the adsorption-desorption isotherms were taken in a MICROMERITICS equipment model ASAP 2020, (Micromeritics, Norcross (Atlanta), Georgia, GA, USA), at $77 \mathrm{~K}$ with a pressure range from $1 \times 10^{-7} \mathrm{P} / \mathrm{Po}$ to $0.99 \mathrm{P} / \mathrm{Po}$. The specific area was calculated by the Brunauer-Emmett-Teller (BET) method. The Barret-Joyner-Halenda (BJH) method for mesopores and the Hovarth-Kawazoe (HK) method for micropores were used to determine the pore size distribution. To predict the surface energy of the synthesized materials, nonlocal density functional theory (NLDFT) was applied.

\subsection{Scanning Electron Microscopy (SEM)}

Micrographs were obtained in a JEOL JSM 5910LV microscope, (JEOL company Akishima, Tokyo, Japan), equipped with a secondary electron (SEI) detector operated at $15 \mathrm{kV}$ in high-vacuum mode. For this analysis, around $3.0 \mathrm{mg}$ of the synthesized material was placed onto a carbon ribbon, and then a thin layer of gold was deposited onto the surface of the sample by a sputter coating technique.

\subsection{Impedance Spectroscopy Analysis}

For impedance spectroscopy analysis, expressed as a function of temperature, the powder samples were uniaxially pressed at about $51 \mathrm{MPa}$ to obtain pellets approximately $1.37 \mathrm{~mm}$ thick and $10 \mathrm{~mm}$ in diameter $[12,14]$. The pellets were kept between two platinum electrodes (the effective diameter for the working electrode was $10 \mathrm{~mm}$ ) under spring-loaded pressure. The setup was put inside a furnace with temperature control from 298 to $423 \mathrm{~K}$ in steps of $25 \mathrm{~K}$, and, in this case, measurements were taken using a dielectric interface SOLARTRON 1296 coupled to SOLARTRON 1260 analyzer (Solartron Analytical, Farnborough, UK). The cell was allowed to reach thermal stability for about $20 \mathrm{~min}$ before each measurement. Data were recorded in a frequency range of $10 \mathrm{MHz}$ to $0.1 \mathrm{~Hz}$ with a voltage amplitude of $100 \mathrm{mVrms}$ and $0 \mathrm{DC}$ bias. The fitting circuit simulation of AC impedance data was performed with ZView ${ }^{\circledR}$ (Scribner Association, Southern Pines, North Carolina, NC, USA) software. 


\section{Conclusions}

Changes in symmetry and microstructure of synthesized birnessite-type materials produced variations in their electrical properties and relaxation times for the electrical transport mechanism. Mn4 exhibited the highest conductivity, which was associated with turbostratic disorder, shorter Mn-O bond length, lower crystal size, higher $\mathrm{Mn}^{4+}$ content, and higher surface area. For Mn8, the crystal size increment might have diminished the contact area between the particle agglomerates, making electron transport more difficult than in the Mn4 material. The enhanced conductivity with temperature suggests a thermally activated electron "hopping" and semiconductor behaviour for the synthesized materials. It is concluded that conductivity and other electronic-related phenomena can be tuned by varying the synthesis conditions.

Author Contributions: Synthesis conceptualization, O.G.; methodology, O.G., N.P.A., and M.E.B.; validation M.E.B.; formal analysis, N.P.A. and O.G.; investigation and data curation N.P.A. and M.E.B.; writing N.P.A. and O.G.; all authors reviewed and approved the manuscript.

Funding: This research received no external funding.

Acknowledgments: The authors wish to thank the Dirección de Laboratorios de Sede, Laboratorio de Química (Atomic Absorption Analysis) and Laboratorio de Magnetismo y Materiales Avanzados (Thermal Analysis) at the Universidad Nacional de Colombia, Sede Manizales. The authors also thank the Laboratorio de Microscopia Avanzada (SEM) at the Universidad Nacional de Colombia, Sede Medellín. N.P.A acknowledge to Davián Martinez Buitrago for his advice in the Rietveld Refinement.

Conflicts of Interest: The authors declare no conflict of interest.

\section{Appendix A}

Table A1. Fractional coordinates for atom positions in Mn4 and Mn8.

\begin{tabular}{lccc}
\hline & & Mn4 & Mn8 \\
\hline \multirow{2}{*}{ Fractional Coordinates Mn1 } & $\mathrm{x}$ & 0 & 0 \\
& $\mathrm{y}$ & 0 & 0 \\
& $\mathrm{z}$ & 0 & 0 \\
\hline \multirow{2}{*}{ Fractional Coordinates K1 } & $\mathrm{x}$ & 1.625160 & 0.127491 \\
& $\mathrm{y}$ & 0.835220 & 0.872509 \\
& $\mathrm{z}$ & 0.407410 & 0.250000 \\
\hline \multirow{2}{*}{ Fractional Coordinates O1 } & $\mathrm{x}$ & 0.223160 & 0.666700 \\
& $\mathrm{y}$ & 0.821360 & 0.333300 \\
& $\mathrm{z}$ & 0.094050 & 0.059257 \\
\hline \multirow{2}{*}{ Fractional Coordinates O2 } & $\mathrm{x}$ & 0.032800 & 0.333300 \\
& $\mathrm{y}$ & -0.059160 & 0.666700 \\
& $\mathrm{z}$ & 0.554910 & 0.250000 \\
\hline
\end{tabular}

Table A2. Circuital element values from equivalent circuit fitting of the experimental results for Mn4.

\begin{tabular}{cccccccccc}
\hline T (K) & CPE1-T (F) & CPE1-P & Rg $(\boldsymbol{\Omega})$ & CPE2-T (F) & CPE2-P & Rgb $(\boldsymbol{\Omega})$ & Wo-R & Wo-T & WoP \\
\hline 298 & $1.40 \times 10^{-11}$ & 1.04 & $1.67 \times 10^{5}$ & $3.18 \times 10^{-10}$ & 0.94 & $8.95 \times 10^{3}$ & $3.05 \times 10^{4}$ & $3.45 \times 10^{-1}$ & 0.22 \\
323 & $5.54 \times 10^{-11}$ & 0.95 & $4.85 \times 10^{4}$ & $6.23 \times 10^{-12}$ & 0.12 & $3.02 \times 10^{2}$ & $3.98 \times 10^{3}$ & $2.86 \times 10^{-2}$ & 0.22 \\
348 & $1.58 \times 10^{-9}$ & 0.76 & $1.30 \times 10^{3}$ & $6.18 \times 10^{-19}$ & 0.94 & $157 \times 10^{2}$ & $8.63 \times 10^{2}$ & $5.41 \times 10^{-3}$ & 0.20 \\
373 & $3.06 \times 10^{-9}$ & 0.70 & $2.13 \times 10^{3}$ & $2.09 \times 10^{-17}$ & 2.00 & $1.11 \times 10^{1}$ & $1.22 \times 10^{2}$ & $8.23 \times 10^{-5}$ & 0.17 \\
398 & $9.65 \times 10^{-10}$ & 0.78 & $8.84 \times 10^{2}$ & $1.00 \times 10^{-20}$ & 2.91 & $1.28 \times 10^{2}$ & $1.04 \times 10^{-1}$ & $1.49 \times 10^{-12}$ & 0.17 \\
423 & $2.08 \times 10^{-9}$ & 0.77 & $6.74 \times 10^{2}$ & $1.00 \times 10^{-20}$ & 2.92 & $1.03 \times 10^{2}$ & $8.45 \times 10^{-2}$ & $5.15 \times 10^{-14}$ & 0.12 \\
\hline
\end{tabular}

CPE1-T and CPE1-P are the coefficients of the constant phase element in Equation (1); Wo-R, Wo-T, and WoP are the coefficients for Warburg open element in Equation (2); and Rg and Rgb are the resistances in grain and grain boundary, respectively. 
Table A3. Circuital element values from equivalent circuit fitting of the experimental results for Mn8.

\begin{tabular}{cccccccccc}
\hline T $(K)$ & CPE1-T (F) & CPE1-P & $\operatorname{Rg}(\Omega)$ & CPE2-T (F) & CPE2-P & Rgb $(\Omega)$ & Wo-R $(\Omega)$ & Wo-T $(s)$ & WoP \\
\hline 298 & $2.51 \times 10^{-11}$ & 0.98 & $2.08 \times 10^{5}$ & $4.61 \times 10^{-8}$ & 0.634 & $1.98 \times 10^{5}$ & $1.07 \times 10^{6}$ & 39.38 & 0.34 \\
323 & $1.67 \times 10^{-11}$ & 1.00 & $8.87 \times 10^{4}$ & $8.56 \times 10^{-8}$ & 0.618 & $6.75 \times 10^{4}$ & $6.13 \times 10^{5}$ & 45.61 & 0.32 \\
348 & $1.37 \times 10^{-11}$ & 1.02 & $4.34 \times 10^{4}$ & $2.01 \times 10^{-7}$ & 0.572 & $3.09 \times 10^{4}$ & $2.10 \times 10^{5}$ & 126.6 & 0.26 \\
373 & $1.13 \times 10^{-11}$ & 1.04 & $2.68 \times 10^{4}$ & $6.93 \times 10^{-8}$ & 0.680 & $8.53 \times 10^{3}$ & $4.37 \times 10^{4}$ & 91.41 & 0.19 \\
398 & $2.10 \times 10^{-11}$ & 1.00 & $8.29 \times 10^{3}$ & $6.24 \times 10^{-4}$ & 0.068 & $1.50 \times 10^{17}$ & N.A & N.A & N.A \\
423 & $4.36 \times 10^{-11}$ & 0.97 & $3.69 \times 10^{3}$ & $1.19 \times 10^{-3}$ & 0.042 & $5.00 \times 10^{7}$ & N.A & N.A & N.A \\
\hline
\end{tabular}

CPE1-T and CPE1-P are the coefficients of the constant phase element in Equation (1); Wo-R, Wo-T, and WoP are the coefficients for Warburg open element in Equation (2); and $\mathrm{Rg}$ and $\mathrm{Rgb}$ are the resistances in grain and grain boundary, respectively.

\section{References}

1. Wolkenstein, T. The electron theory of catalysis on semiconductors. In Advances in Catalysis; Eley, D.D., Selwood, P.W., Weisz, P.B., Eds.; Academic Press: Cambridge, MA, USA, 1960; Volume 12, pp. 189-264.

2. Swaminathan, M. Chapter 10-Semiconductor oxide nanomaterials as catalysts for multiple applications. In Handbook of Nanomaterials for Industrial Applications; Mustansar Hussain, C., Ed.; Elsevier: Amsterdam, The Netherlands, 2018; pp. 197-207. [CrossRef]

3. Venkatanarayanan, A.; Spain, E. 13.03-Review of recent developments in sensing materials. In Comprehensive Materials Processing; Hashmi, S., Batalha, G.F., Van Tyne, C.J., Yilbas, B., Eds.; Elsevier: Amsterdam, The Netherlands, 2014; pp. 47-101. [CrossRef]

4. Grabowska, E.; Marchelek, M.; Paszkiewicz-Gawron, M.; Zaleska-Medynska, A. 3-Metal oxide photocatalysts. In Metal Oxide-Based Photocatalysis; Zaleska-Medynska, A., Ed.; Elsevier: Amsterdam, The Netherlands, 2018; pp. 51-209. [CrossRef]

5. Liu, C.; Shi, J.W.; Gao, C.; Niu, C. Manganese oxide-based catalysts for low-temperature selective catalytic reduction of NOx with $\mathrm{NH}_{3}$ : A review. Appl. Catal. A Gen. 2016, 522, 54-69. [CrossRef]

6. Dutta, B.; Clarke, R.; Raman, S.; Shaffer, T.D.; Achola, L.; Nandi, P.; Suib, S.L. Lithium promoted mesoporous manganese oxide catalyzed oxidation of allyl ethers. Nat. Commun. 2019, 10, 655. [CrossRef] [PubMed]

7. Luo, M.; Cheng, Y.; Peng, X.; Pan, W. Copper modified manganese oxide with tunnel structure as efficient catalyst for low-temperature catalytic combustion of toluene. Chem. Eng. J. 2019, 369, 758-765. [CrossRef]

8. Liu, G.; Wang, H.; Feng, N.; Chen, L.; Yu, J.; Meng, J.; Fang, F.; Wang, L.; Wan, H.; Guan, G. Construction of substrate-dependent 3D structured $\mathrm{MnO}_{2}$ catalysts for diesel soot elimination. Appl. Surf. Sci. 2019, 484, 197-208. [CrossRef]

9. Becerra, M.E.; Arias, N.P.; Giraldo, O.H.; López Suárez, F.E.; Illán Gómez, M.J.; Bueno López, A. Soot combustion manganese catalysts prepared by thermal decomposition of $\mathrm{KMnO}_{4}$. Appl. Catal. B Environ. 2011, 102, 260-266. [CrossRef]

10. Becerra, M.E.; Arias, N.P.; Giraldo, O.H.; López-Suárez, F.E.; Illán-Gómez, M.J.; Bueno-López, A. Alumina-supported manganese catalysts for soot combustion prepared by thermal decomposition of $\mathrm{KMnO}_{4}$. Catalysts 2012, 2, 352-367. [CrossRef]

11. Becerra, M.E.; Suarez, A.M.; Arias, N.P.; Giraldo, O. Decomposition of the methylene blue dye using layered manganese oxide materials synthesized by solid state reactions. Int. J. Chem. Eng. 2018, 2018, 11. [CrossRef]

12. Arias, N.P.; Dávila, M.T.; Giraldo, O. Electrical behavior of an octahedral layered OL-1-type manganese oxide material. Ionics 2013, 19, 201-214. [CrossRef]

13. Arias, N.P.; Becerra, M.E.; Giraldo, O. Caracterización eléctrica de un oxido de manganeso laminar tipo birnesita. Revista Mexicana de Física 2015, 61, 380-387.

14. Giraldo, O.; Arias, N.P.; Becerra, M.E. Electrical properties of $\mathrm{TiO}_{2}$-pillared bidimensional manganese oxides. Appl. Clay Sci. 2017, 141, 157-170. [CrossRef]

15. Suib, S.L. Porous manganese oxide octahedral molecular sieves and octahedral layered materials. Acc. Chem. Res. 2008, 41, 479-487. [CrossRef] [PubMed]

16. Minakshi, M.; Singh, P.; Carter, M.; Prince, $\mathrm{K}$. The $\mathrm{Zn}-\mathrm{MnO}_{2}$ battery: The influence of aqueous $\mathrm{LiOH}$ and $\mathrm{KOH}$ electrolytes on the intercalation mechanism. Electrochem. Solid State Lett. 2008, 11, A145-A149. [CrossRef] 
17. Minakshi, M.; Singh, P.; Issa, T.B.; Thurgate, S.; Marco, R.D. Lithium insertion into manganese dioxide electrode in $\mathrm{MnO}_{2} / \mathrm{Zn}$ aqueous battery: Part II. Comparison of the behavior of EMD and battery grade $\mathrm{MnO}_{2}$ in $\mathrm{Zn} \mid \mathrm{MnO}_{2}$ |aqueous LiOH electrolyte. J. Power Sources 2004, 138, 319-322. [CrossRef]

18. Brock, S.L.; Duan, N.; Tian, Z.R.; Giraldo, O.; Zhou, H.; Suib, S.L. A review of porous manganese oxide materials. Chem. Mater. 1998, 10, 2619-2628. [CrossRef]

19. Atribak, I.; Bueno-López, A.; García-García, A.; Navarro, P.; Frías, D.; Montes, M. Catalytic activity for soot combustion of birnessite and cryptomelane. Appl. Catal. B Environ. 2010, 93, 267-273. [CrossRef]

20. Kappenstein, C.; Pirault-Roy, L.; Guérin, M.; Wahdan, T.; Ali, A.A.; Al-Sagheer, F.A.; Zaki, M.I. Monopropellant decomposition catalysts: V. Thermal decomposition and reduction of permanganates as models for the preparation of supported MnOx catalysts. Appl. Catal. A Gen. 2002, 234, 145-153. [CrossRef]

21. Herbstein, F.H.; Ron, G.; Weissman, A. The thermal decomposition of potassium permanganate and related substances. Part, I. Chemical aspects. J. Chem. Soc. Inorg. Phys. Theor. 1971, 1821-1826. [CrossRef]

22. Gaillot, A.C.; Flot, D.; Drits, V.A.; Manceau, A.; Burghammer, M.; Lanson, B. Structure of synthetic K-rich birnessite obtained by high-temperature decomposition of $\mathrm{KMnO}_{4}$. I. Two-layer polytype from $800{ }^{\circ} \mathrm{C}$ experiment. Chem. Mater. 2003, 15, 4666-4678. [CrossRef]

23. Cai, J.; Liu, J.; Suib, S.L. Preparative parameters and framework dopant effects in the synthesis of layer-structure birnessite by air oxidation. Chem. Mater. 2002, 14, 2071-2077. [CrossRef]

24. Luo, J.; Zhang, Q.; Huang, A.; Giraldo, O.; Suib, S.L. Double-aging method for preparation of stabilized Na-buserite and transformations to todorokites incorporated with various metals. Inorg. Chem. 1999, 38, 6106-6113. [CrossRef]

25. Shen, Y.F.; Suib, S.L.; O'Young, C.L. Effects of inorganic cation templates on octahedral molecular sieves of manganese oxide. J. Am. Chem. Soc. 1994, 116, 11020-11029. [CrossRef]

26. Yang, D.S.; Wang, M.K. Syntheses and Characterization of Well-Crystallized Birnessite. Chem. Mater. 2001, 13, 2589-2594. [CrossRef]

27. Julien, C.M.M.; Baddour-Hadjean, R.; Frager, S.; Bach, S.; Pereira-Ramos, J.P. Raman spectra of birnessite manganese dioxides. Solid State Ion. 2003, 159, 345-356. [CrossRef]

28. Drits, V.A.; Tchoubar, C. X-ray Diffraction by Disordered Lamellar Structures: Theory and Applications to Microdivided Silicates and Carbons; Springer Verlag: Berlin/Heidelberg, Germany, 1990; p. 371.

29. Ching, S.W.E.; Hughes, S.; Bahadoor, A.; Suib, S.L. Nonaqueous Sol-Gel Syntheses of Microporous Manganese Oxides. Chem. Mater. 2002, 14, 1292-1299. [CrossRef]

30. Victor, A.; Drits, E.S.; Anatoli, I.; Gorshkov, A.; Alain, M. Structure of monoclinic Na-rich birnessite and hexagonal birnessite: I. results from X-ray diffraction and selected-area electron diffraction. Am. Mineral. 1997, 82, 946-961.

31. Kim, S.H.; Kim, S.J.; Oh, S.M. Preparation of layered $\mathrm{MnO}_{2}$ via thermal decomposition of $\mathrm{KMnO}_{4}$ and its electrochemical characterizations. Chem. Mater. 1999, 11, 557-563. [CrossRef]

32. Drits Victor, A.; Lanson, B.; Gaillot, A.C. Birnessite polytype systematics and identiP cation by powder X-ray diffraction. Am. Mineral. 2007, 92, 771-788. [CrossRef]

33. Lopano, C.L.; Heaney, P.J.; Post, J.E.; Hanson, J.; Komarneni, S. Time-resolved structural analysis of K-and Ba-exchange reactions with synthetic Na-birnessite using synchrotron X-ray diffraction. Am. Mineral. 2007, 92, 380-387. [CrossRef]

34. Post, J.E.; Veblen, D.R. Crystal structure determinations of synthetic sodium, magnesium, and potassium birnessite using TEM and the Rietveld method. Am. Mineral. 1990, 75, 477-489.

35. Nandy, S.; Mallick, S.; Ghosh, P.K.; Das, G.C.; Mukherjee, S.; Mitra, M.K.; Chattopadhyay, K.K. Impedance spectroscopic studies of nickel nanocluster in silica matrix synthesized by sol-gel method. J. Alloys Compd. 2008, 453, 1-6. [CrossRef]

36. Klobes, P.; Klaus, M.; Munro, G.M. Porosity and Specific Surface Area Mearuments for Solid Materials; NIST, Ed.; NIST: Gaithersburg, MD, USA, 2006.

37. Jagiello, J.; Olivier, J.P. A simple two-dimensional NLDFT model of gas adsorption in finite carbon pores. Application to pore structure analysis. J. Phys. Chem. C 2009, 113, 19382-19385. [CrossRef]

38. Maddox, M.W.; Olivier, J.P.; Gubbins, K.E. Characterization of MCM-41 using molecular simulation: Heterogeneity effects. Langmuir 1997, 13, 1737-1745. [CrossRef] 
39. Minakshi Sundaram, M.; Biswal, A.; Mitchell, D.; Jones, R.; Fernandez, C. Correlation among physical and electrochemical behaviour of nanostructured electrolytic manganese dioxide from leach liquor and synthetic for aqueous asymmetric capacitor. Phys. Chem. Chem. Phys. 2016, 18, 4711-4720. [CrossRef] [PubMed]

40. Kidner, N.J.; Perry, N.H.; Mason, T.O.; Garboczi, E.J. The brick layer model revisited: Introducing the nano-grain composite model. J. Am. Ceram. Soc. 2008, 91, 1733-1746. [CrossRef]

41. Swider, K.E.; Merzbacher, C.I.; Hagans, P.L.; Rolison, D.R. Synthesis of ruthenium dioxide-titanium dioxide aerogels: Redistribution of electrical properties on the nanoscale. Chem. Mater. 1997, 9, 1248-1255. [CrossRef]

42. Korotcenkov, G. The role of morphology and crystallographic structure of metal oxides in response of conductometric-type gas sensors. Mater. Sci. Eng. R Rep. 2008, 61,1-39. [CrossRef]

43. Andrew, K.J. Dielectric relaxation in solids. J. Phys. D Appl. Phys. 1999, 32, R57.

44. McNealy, B.E.; Hertz, J.L. On the use of the constant phase element to understand variation in grain boundary properties. Solid State Ion. 2014, 256, 52-60. [CrossRef]

45. Córdoba-Torres, P.; Mesquita, T.J.; Nogueira, R.P. Influence of geometry-induced current and potential distributions on the characterization of constant-phase element behavior. Electrochim. Acta 2013, 87, 676-685. [CrossRef]

46. Shoar Abouzari, M.R.; Berkemeier, F.; Schmitz, G.; Wilmer, D. On the physical interpretation of constant phase elements. Solid State Ion. 2009, 180, 922-927. [CrossRef]

47. Jonscher, A.K. Relaxation in low-loss dielectrics. J. Mol. Liq. 2000, 86, 259-268. [CrossRef]

48. Jonscher, A.K. Dielectric characterisation of semiconductors. Solid State Electron. 1990, 33, 737-742. [CrossRef]

49. Jonscher, A.K. Frequency-dependence of conductivity in hopping systems. J. Non Cryst. Solids 1972, 8, 293-315. [CrossRef]

50. Hill, R.M.; Jonscher, A.K. DC and AC conductivity in hopping electronic systems. J. Non Cryst. Solids 1979, 32, 53-69. [CrossRef]

51. Bucheli, W.; Jiménez, R.; Sanz, J.; Várez, A. The $\log (\sigma)$ vs. $\log (\omega)$ derivative plot used to analyze the ac conductivity. Application to fast $\mathrm{Li}^{+}$ion conductors with perovskite structure. Solid State Ion. 2012, 227, 113-118. [CrossRef]

52. Giraldo, O.; Marquez, M.; Brock, S.L.; Suib, S.L.; Hillhouse, H.; Tsapatsis, M. Spontaneous formation of inorganic helical fibers and rings. J. Am. Chem. Soc. 2000, 122, 12158-12163. [CrossRef]

53. Henn, F.; Durand, C.; Cerepi, A.; Brosse, E.; Giuntini, J.C. DC conductivity, cationic exchange capacity, and specific surface area related to chemical composition of pore lining chlorites. J. Colloid Interface Sci. 2007, 311, 571-578. [CrossRef]

54. Le Caër, S.; Lima, M.; Gosset, D.; Simeone, D.; Bergaya, F.; Pommeret, S.; Renault, J.P.; Righini, R. Dynamics of water confined in clay minerals. J. Phys. Chem. C 2012, 116, 12916-12925. [CrossRef]

55. Madelung, O. Introduction to Solid-State Theory; Springer: Berlin/Heidelberg, Germany, 1978; Volume 2, p. 490.

56. Díez, A.; Schmidt, R.; Sagua, A.E.; Frechero, M.A.; Matesanz, E.; Leon, C.; Morán, E. Structure and physical properties of nickel manganite $\mathrm{NiMn}_{2} \mathrm{O}_{4}$ obtained from nickel permanganate precursor. J. Eur. Ceram. Soc. 2010, 30, 2617-2624. [CrossRef]

57. Ngala, J.K.; Alia, S.; Dobley, A.; Crisostomo, V.M.B.; Suib, S.L. Characterization and electrocatalytic behavior of layered $\mathrm{Li}_{2} \mathrm{MnO}_{3}$ and its acid-treated form. Chem. Mater. 2007, 19, 229-234. [CrossRef]

58. Ghosh, R.; Shen, X.; Villegas, J.C.; Ding, Y.; Malinger, K.; Suib, S.L. Role of manganese oxide octahedral molecular sieves in styrene epoxidation. J. Phys. Chem. B 2006, 110, 7592-7599. [CrossRef]

59. Bhide, V.G.; Dani, R.H. Electrical conductivity in oxides of manganese and related compounds. Physica 1961, 27, 821-826. [CrossRef]

60. De Guzman, R.N.; Awaluddin, A.; Shen, Y.F.; Tian, Z.R.; Suib, S.L.; Ching, S.; O'Young, C.L. Electrical resistivity measurements on manganese oxides with layer and tunnel structures: Birnessites, todorokites, and cryptomelanes. Chem. Mater. 1995, 7, 1286-1292. [CrossRef]

61. Klose, P.H. Electrical properties of manganese dioxide and manganese sesquioxide. J. Electrochem. Soc. 1970, 117, 854-858. [CrossRef]

62. Hong, F.; Yue, B.; Hirao, N.; Liu, Z.; Chen, B. Significant improvement in $\mathrm{Mn}_{2} \mathrm{O}_{3}$ transition metal oxide electrical conductivity via high pressure. Sci. Rep. 2017, 7, 44078. [CrossRef]

63. Tan, F.K.; Hassan, J.; Wahab, Z.A.; Azis, R.A.S. Electrical conductivity and dielectric behaviour of manganese and vanadium mixed oxide prepared by conventional solid state method. Eng. Sci. Technol. Int. J. 2016, 19, 2081-2087. [CrossRef] 
64. Hedden, M.; Francis, N.; Haraldsen, J.T.; Ahmed, T.; Constantin, C. Thermoelectric properties of nano-meso-micro $\beta-\mathrm{MnO}_{2}$ powders as a function of electrical resistance. Nanoscale Res. Lett. 2015, 10, 292. [CrossRef]

65. Bose, V.C.; Maniammal, K.; Madhu, G.; Veenas, C.L.; Raj, A.S.A.; Biju, V. DC electrical conductivity of nanocrystalline $\mathrm{Mn}_{3} \mathrm{O}_{4}$ synthesized through a novel sol-gel route. Iop Conf. Ser. Mater. Sci. Eng. 2015, 73, 012084. [CrossRef]

66. Byles, B.W.; Palapati, N.K.R.; Subramanian, A.; Pomerantseva, E. The role of electronic and ionic conductivities in the rate performance of tunnel structured manganese oxides in Li-ion batteries. APL Mater. 2016, 4, 046108. [CrossRef]

67. Gaillot, A.C.; Drits, V.A.; Manceau, A.; Lanson, B. Structure of the synthetic K-rich phyllomanganate birnessite obtained by high-temperature decomposition of $\mathrm{KMnO}_{4}$ : Substructures of K-rich birnessite from $1000{ }^{\circ} \mathrm{C}$ experiment. Microporous Mesoporous Mater. 2007, 98, 267-282. [CrossRef]

68. Xia, G.G.; Tong, W.; Tolentino, E.N.; Duan, N.G.; Brock, S.L.; Wang, J.Y.; Suib, S.L.; Ressler, T. Synthesis and characterization of nanofibrous sodium manganese oxide with a $2 \times 4$ tunnel structure. Chem. Mater. 2001, 13, 1585-1592. [CrossRef]

69. Rietveld, H. A profile refinement method for nuclear and magnetic structures. J. Appl. Crystallogr. 1969, 2, 65-71. [CrossRef]

70. Larson, A.C.; Von Dreele, R.B. General Structure Analysis System (GSAS); Los Alamos National Laboratory: Santa Fe, NM, USA, 2004; pp. 86-748.

71. Toby, B. EXPGUI, a graphical user interface for GSAS. J. Appl. Crystallogr. 2001, 34, 210-213. [CrossRef]

72. Gražulis, S.; Chateigner, D.; Downs, R.T.; Yokochi, A.F.T.; Quirós, M.; Lutterotti, L.; Le Bail, A. crystallography open database-An open-access collection of crystal structures. J. Appl. Crystallogr. 2009, 42, 726-729. [CrossRef]

73. Gražulis, S.; Daškevič, A.; Merkys, A.; Chateigner, D.; Lutterotti, L.; Quiros, M.; Le Bail, A. Crystallography open database (COD): An open-access collection of crystal structures and platform for world-wide collaboration. Nucleic Acids Res. 2012, 40, D420-D427. [CrossRef]

Sample Availability: Samples of the compounds Mn4 and Mn8 are available from the authors.

(C) 2019 by the authors. Licensee MDPI, Basel, Switzerland. This article is an open access article distributed under the terms and conditions of the Creative Commons Attribution (CC BY) license (http://creativecommons.org/licenses/by/4.0/). 
Article

\title{
Investigation of Well-Defined Pinholes in $\mathrm{TiO}_{2}$ Electron Selective Layers Used in Planar Heterojunction Perovskite Solar Cells
}

\author{
Muhammad Talha Masood ${ }^{1,2}$, Syeda Qudsia ${ }^{1}$, Mahboubeh Hadadian ${ }^{1}$, Christian Weinberger ${ }^{1,3}$, \\ Mathias Nyman ${ }^{4}$, Christian Ahläng ${ }^{4}$, Staffan Dahlström ${ }^{4}$, Maning Liu ${ }^{5}$, Paola Vivo ${ }^{5}$, \\ Ronald Österbacka ${ }^{4}$ and Jan-Henrik Smått ${ }^{1, *}$ \\ 1 Laboratory of Molecular Science and Engineering, Åbo Akademi University, Porthansgatan 3-5, \\ 20500 Turku, Finland; mmasood@abo.fi or talha.masood@scme.nust.edu.pk (M.T.M.); squdsia@abo.fi (S.Q.); \\ mhadadia@abo.fi (M.H.); christian.weinberger@upb.de (C.W.) \\ 2 Department of Materials Engineering, School of Chemical \& Materials Engineering, National University of \\ Science \& Technology (NUST), Sector H-12, Islamabad 44100, Pakistan \\ 3 Department of Chemistry—Inorganic Functional Materials, Paderborn University, \\ 33098 Paderborn, Germany \\ 4 Physics, Faculty of Science and Engineering, Åbo Akademi University, Porthansgatan 3-5, \\ 20500 Turku, Finland; mathias.nyman@abo.fi (M.N.); cahlang@abo.fi (C.A.); staffan.dahlstrom@abo.fi (S.D.); \\ rosterba@abo.fi (R.Ö.) \\ 5 Faculty of Engineering and Natural Sciences, Tampere University, P.O. Box 541, FI-33014 Tampere, Finland; \\ maning.liu@tuni.fi (M.L.); paola.vivo@tuni.fi (P.V.) \\ * Correspondence: jsmatt@abo.fi; Tel.: +358-40-5223318
}

Received: 17 December 2019; Accepted: 16 January 2020; Published: 20 January 2020

\begin{abstract}
The recently introduced perovskite solar cell (PSC) technology is a promising candidate for providing low-cost energy for future demands. However, one major concern with the technology can be traced back to morphological defects in the electron selective layer (ESL), which deteriorates the solar cell performance. Pinholes in the ESL may lead to an increased surface recombination rate for holes, if the perovskite absorber layer is in contact with the fluorine-doped tin oxide (FTO) substrate via the pinholes. In this work, we used sol-gel-derived mesoporous $\mathrm{TiO}_{2}$ thin films prepared by block co-polymer templating in combination with dip coating as a model system for investigating the effect of ESL pinholes on the photovoltaic performance of planar heterojunction PSCs. We studied $\mathrm{TiO}_{2}$ films with different porosities and film thicknesses, and observed that the induced pinholes only had a minor impact on the device performance. This suggests that having narrow pinholes with a diameter of about $10 \mathrm{~nm}$ in the ESL is in fact not detrimental for the device performance and can even, to some extent improve their performance. A probable reason for this is that the narrow pores in the ordered structure do not allow the perovskite crystals to form interconnected pathways to the underlying FTO substrate. However, for ultrathin $(\sim 20 \mathrm{~nm})$ porous layers, an incomplete ESL surface coverage of the FTO layer will further deteriorate the device performance.
\end{abstract}

Keywords: perovskite solar cell; electron selective layer; pinhole; mesoporous $\mathrm{TiO}_{2}$; evaporation-induced self-assembly; dip coating

\section{Introduction}

Organic-inorganic lead halide perovskite solar cells (PSCs) have gained substantial attention in the last decade, and soon they are expected to be able to compete with conventional silicon-based solar cells due to their outstanding device performance. PSCs offer low-cost solar energy conversion due to the ease in fabrication and the possibility to make devices on top of glass or flexible substrates [1]. 
The first PSC was reported by Kojima et al. in 2009 [2] with 3.8\% power conversion efficiency (PCE). Within the next seven years, a PCE above $20 \%$ was reached [3], while the current certified record efficiency is, amazingly, above $25 \%$ [4]. However, there are still some challenges to be addressed before the technology can reach market penetration, including device reproducibility [5], scalability [6], and stability [7].

A PSC consists of a perovskite light-absorbing layer sandwiched between an electron selective layer (ESL) and a hole selective layer (HSL). Electron-hole pairs are generated in the perovskite layer upon illumination. Electrons are selectively extracted by the ESL and transported to an external circuit via a transparent conductive substrate, such as fluorine-doped tin oxide (FTO), while holes are extracted by the HSL, most commonly lithium-doped Spiro-OMeTAD. n-Type metal oxide semiconductors, including $\mathrm{TiO}_{2}, \mathrm{ZnO}$ and $\mathrm{SnO}_{2}[8,9]$, are the most commonly used ESLs in PSCs, although conductive polymers have also been used [10-12]. The highest efficiency reported for $\mathrm{TiO}_{2}$ as the ESL reaches above $20 \%$ when using cesium containing triple-cation mixed-halide perovskite as the light absorber [3]. This involves the use of a thin mesoscopic scaffold layer consisting of $\mathrm{TiO}_{2}$ nanoparticles coated on top of a compact $\mathrm{TiO}_{2}$ layer. The perovskite is thought to be embedded in the mesoporous scaffold along with a thick capping layer on top, which isolates the $\mathrm{TiO}_{2}$ scaffold from the HSL [13]. Together with the perovskite in the mesoporous $\mathrm{TiO}_{2}$, the capping layer absorbs enough light to obtain good photocurrent. The mesoscopic scaffold plays an important role in supporting electron injection into $\mathrm{TiO}_{2}$ because it tends to establish a high $\mathrm{TiO}_{2}$ /perovskite interfacial area. Without the scaffold layer, it is difficult to achieve highly efficient solar cells with $\mathrm{TiO}_{2}$, because the low contact area between the perovskite and the $\mathrm{TiO}_{2}$ results in charge build-up at the interface $[8,14]$. This is due to the relatively low inherent electron mobility in $\mathrm{TiO}_{2}$ and the misalignment of its work function with respect to the conduction band energy level of the perovskite. This further becomes an important source of hysteresis in planar heterojunction $\mathrm{TiO}_{2}$-based PSCs [8,9].

Morphological defects such as pinholes [15] (either in the form of larger bare patches or as porosity on the nanoscale [16]) in the ESL can result in increased surface recombination as well as charge injection barriers due to improper alignment in the energy levels between the perovskite and the ESL. Pinholes in ESLs are predominantly reported as incomplete surface coverage of the ESL film on top of the conductive FTO, which results in FTO crystals protruding through the metal oxide films creating a direct contact with the perovskite $[17,18]$. This degrades the device performance due to a poor hole-blocking ability or high current leakage at the ESL/perovskite interfaces [9]. These types of pinholes are formed due to poor substrate wettability or microbubble formation during the film deposition or drying stages and are most prominent in ultrathin metal oxide films. Thermally or mechanically induced cracks might also expose the underlying FTO in relatively thick ESLs $[1,19]$. Furthermore, the choice of deposition technique and film deposition rate are important factors that affect the surface coverage and the denseness of the produced ESL layer [16]. Atomic layer deposition (ALD) is currently considered the best deposition method for producing homogeneous and dense metal oxide thin films with well-defined morphology and crystallinity $[16,20]$. Whereas the atomic layer-by-layer structure buildup in ALD creates very dense metal oxide layers, the more commonly used solution-processable nanoparticle- or sol-gel-based methods typically produce layers with a lower density, as they contain some porosity at the nanoscale [16]. The increased porosity and grain boundaries in the ESLs are thought to increase the number of trap states where charge recombination can take place [21]. Nonetheless, due to expensive ALD equipment costs, sol-gel-based spray pyrolysis and spin coating are still the most popular methods for producing the compact metal oxide layers used in PSCs [22]. Moreover, some of the possible trap state defects can be alleviated by surface passivation strategies [18].

As the nature of the possible defect morphologies in ESLs can vary substantially (in the literature irregular and randomly occurring defect structures are often encountered), it is difficult to study their possible effects in the performance of PSCs systematically. In this study, we deliberately introduce well-defined morphological defects to model nanoscale pinholes evenly distributed throughout $\sim 70 \mathrm{~nm}$ 
thick $\mathrm{TiO}_{2}$ films. The sol-gel-derived films are prepared using an inexpensive, well-controlled, and scalable dip-coating method [23] in combination with evaporation-induced self-assembly (EISA) of block co-polymers to generate an ordered pore structure in the final films with a pore size of $\sim 10 \mathrm{~nm}$ in diameter [24]. Such porous films have previously been utilized in PSCs, but only in combination with an additional compact $\mathrm{TiO}_{2}$ layer underneath [25]. In our study, however, the porosity in the $\mathrm{TiO}_{2}$ films is tuned to simulate a large number of uniform pinholes in a single $\mathrm{TiO}_{2}$ layer. The $\mathrm{TiO}_{2}$ layers are characterized using grazing incidence $\mathrm{X}$-ray diffraction (GI-XRD), X-ray reflectometry (XRR), field emission scanning electron microscopy (FE-SEM) and charge extraction (of injected carriers) by linearly increasing voltage in metal-insulator-semiconductor structures (MIS-CELIV) measurements, confirming that the pore system is achieved through the entire $\mathrm{TiO}_{2}$ layer and thus forms narrow pinholes down to the underlying FTO contact. Unexpectedly, devices based on $\mathrm{TiO}_{2}$ layers with high porosity still work very well. This indicates that narrow pinholes similar to the ones described by our model system do not have a significant negative impact on the device performance. This further implies that variations in the density of the $\mathrm{TiO}_{2}$ layer when using different deposition methods or deposition rates are less important as long as the ESL fully covers the FTO substrate.

\section{Materials and Methods}

To prepare the ordered mesoporous $\mathrm{TiO}_{2}$ films, a modified protocol of the one described by Ortel et al. [26] was used. However, instead of using triblock-based co-polymers, we used the commercially available poly(butadiene(1,4 addition)-b-ethylene oxide diblock co-polymer (P2952_BdEO, MW = 13,000 g/mol, Polymer Source Inc., Dorval, QC, Canada) in our study. Two independent parameters were studied: (1) block co-polymer content (i.e., change in porosity), and (2) layer thickness (while keeping the porosity constant).

The $\mathrm{TiO}_{2}$ dip coating sols were prepared accordingly: Titanium (IV) chloride $\left(\mathrm{TiCl}_{4}>99 \%\right.$, Fluka, Seelze, Germany) was initially diluted in ethanol (EtOH, $>99.5 \%$, ALTIA Plc, Helsinki, Finland) while stirring in an ice bath to give a 1:16 molar ratio $\mathrm{TiCl}_{4}: \mathrm{EtOH}$ stock solution. Mixtures of $\mathrm{EtOH}$, Millipore water, and P2952_BdEO were also prepared. Subsequently, the $\mathrm{TiCl}_{4}$ stock solution was added dropwise to the other solutions to produce dipping sols with the final molar ratios, as listed in Table 1.

Table 1. Molar compositions for the dip coating sols used in this study.

\begin{tabular}{cccccc}
\hline & Sol/Sample $^{\mathbf{1}}$ & $\mathrm{TiCl}_{\mathbf{4}}$ & EtOH & $\mathbf{H}_{\mathbf{2}} \mathbf{O}$ & P2952_BdEO \\
\hline Porosity series & & & & & \\
& Ti-0 & 1 & 32.5 & 8.4 & 0 \\
& Ti-6 & 1 & 36.6 & 9.5 & $5.88 \times 10^{-6}$ \\
& Ti-12 & 1 & 48.5 & 12.6 & $11.8 \times 10^{-6}$ \\
& Ti-21 & 1 & 67.9 & 17.6 & $21.2 \times 10^{-6}$ \\
\hline Thickness series & & & & & \\
& Ti-21-0.8 & 1 & 56.2 & 14.6 & $21.2 \times 10^{-6}$ \\
& Ti-21-1 & 1 & 67.9 & 17.6 & $21.2 \times 10^{-6}$ \\
& Ti-21-2.5 & 1 & 169 & 43.7 & $21.2 \times 10^{-6}$ \\
\hline
\end{tabular}

${ }^{1}$ The sample names in the porosity series (Ti- $x$ ) are derived according to the P2952_BdEO/TiCl ${ }_{4}$ molar ratios, where $x$ indicates the molar ratio $\times 10^{6}$. In the sample names in the thickness series (Ti-21-y), the $y$ parameter indicates the relative solvent amount $\left(\mathrm{H}_{2} \mathrm{O}+\mathrm{EtOH}\right)$ in comparison to the original Ti-21 sample.

Fluorine-doped tin oxide substrates (FTO, TCO22-15, Solaronix, Aubonne, Switzerland) with dimensions $4 \times 2 \mathrm{~cm}^{2}$ were sonicated in water, acetone, and 2-propanol for $10 \mathrm{~min}$ each. The samples were subsequently dried in nitrogen flow and plasma-treated for $5 \mathrm{~min}$ before $\mathrm{TiO}_{2}$ film deposition. The same cleaning protocol was used when microscope glass substrates (VWR international, cut into $2.5 \times 2 \mathrm{~cm}^{2}$ pieces) were used. The substrates were then dip-coated with the sols described in Table 1 to produce two different series (i.e., change in porosity and change in film thickness, respectively). 
The dip coating was performed using a withdrawal speed of $85 \mathrm{~mm} / \mathrm{min}$ at a relative humidity below $20 \%$. The substrates were then kept at the same relative humidity in the dipping chamber for at least 5-10 min before they were transferred to the oven for calcination. The films were initially kept at $80^{\circ} \mathrm{C}$ for $4 \mathrm{~h}$ and then heated to $475^{\circ} \mathrm{C}$ at a heating rate of $1{ }^{\circ} \mathrm{C} / \mathrm{min}$. The samples were held at $475^{\circ} \mathrm{C}$ for $15 \mathrm{~min}$ and then allowed to naturally cool to $150{ }^{\circ} \mathrm{C}$.

GI-XRD was performed on $\mathrm{TiO}_{2}$ films coated on top of FTO substrates using a Bruker AXS D8 Discover instrument. The measurements were performed between $24^{\circ}$ and $40^{\circ}$ using a step size of $0.04^{\circ}$ and a grazing incidence angle of $0.3^{\circ}$. The TOPAS P software (v. 4.2) was used to calculate the $\mathrm{TiO}_{2}$ crystallite size using the Scherrer equation [27]. The same instrument was used for XRR analysis of $\mathrm{TiO}_{2}$ films deposited on microscope glass slides instead of FTO substrates, as the high

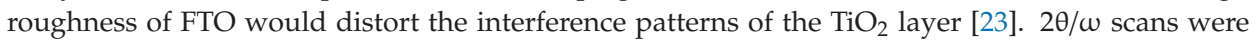
performed with an increment of $0.002^{\circ}$. The experimental data was fitted using the LEPTOS software (v.7.03). FE-SEM was used to determine the morphology of the $\mathrm{TiO}_{2}$ films with different porosity using a magnification of $100 \mathrm{kX}$, electron high tension of $2.70 \mathrm{kV}$, and an aperture size of $10 \mu \mathrm{m}$ on a Zeiss Leo Gemini 1530 instrument. MIS-CELIV measurements using poly(3-hexylthiophene) (P3HT, Sigma-Aldrich, St. Louis, MO, USA) as charge injector layer were carried out to obtain information about the interconnectivity of the porous structure. The measurement setup and sample preparation are described in the Supplementary Information.

PSCs using the porous $\mathrm{TiO}_{2}$ ESLs were prepared accordingly: A $1.5 \times 2 \mathrm{~cm}^{2}$ area from one side of the $4 \times 2 \mathrm{~cm}^{2}$ FTO substrates was selectively etched using Zn powder (Sigma Aldrich) and $4 \mathrm{M} \mathrm{HCl}$ solution in water. The etched FTO substrates were subsequently sonicated in $2 \%$ aqueous solution of Hellmanex III detergent, water, acetone and 2-propanol for $10 \mathrm{~min}$ each at room temperature. The deposition of ordered porous $\mathrm{TiO}_{2}$ was performed by dip coating followed by calcination using the protocol described above. Kapton tape was used to mask the back side and the anode region of FTO substrate to avoid film deposition in those regions. Since there was a risk that the porous $\mathrm{TiO}_{2}$ films might absorb water from the moist environment, the samples were immediately transferred to a nitrogen glovebox once the samples had cooled down to $150{ }^{\circ} \mathrm{C}$ after calcination. The cesium-containing triple-cation mixed-halide perovskite light absorber layer was deposited by spin coating in combination with the anti-solvent method $[3,28]$. The mixed ion perovskite precursor solution contains a mixture of formamidium iodide (FAI, Greatcell Solar, Queanbeyan, Australia, $1 \mathrm{M}$ ), methylammonium bromide (MABr, Greatcell Solar, $0.2 \mathrm{M})$, lead iodide $\left(\mathrm{PbI}_{2}, 99.99 \%\right.$, TCI Europe, Zwijndrecht, Belgium, $1.1 \mathrm{M}$ ), and lead bromide ( $\mathrm{PbBr}_{2}, 99.99 \%$, TCI Europe, $\left.0.2 \mathrm{M}\right)$ dissolved in a 4:1 mixture of $N, N$-dimethylformamide (DMF, 99.8\%, Sigma-Aldrich) and dimethyl sulfoxide (DMSO, 99.9\%, Sigma-Aldrich). A 1.5 M solution of cesium iodide (CsI, 99.999\%, ABCR, Karlsruhe, Germany) in DMSO was added to the above solution in a 1:19 volume ratio. This triple cation perovskite solution was spin-coated using a two-step program at 1000 and $6000 \mathrm{rpm}$ for 10 and $20 \mathrm{~s}$, respectively. During the second step, $200 \mu \mathrm{L}$ of chlorobenzene $(99.8 \%$, TCI Europe) was pipetted onto the spinning substrate $5 \mathrm{~s}$ prior to the end of the program. The color of the films turned dark orange upon addition of chlorobenzene. Upon placing the samples on a hot plate at $100{ }^{\circ} \mathrm{C}$, they turned dark brown within $10 \mathrm{~s}$. Films were then annealed at the same temperature for $30 \mathrm{~min}$. After annealing, the samples were allowed to cool down to room temperature. Subsequently the HSL solution was spin-coated on top of the perovskite layer at $4000 \mathrm{rpm}$ for $30 \mathrm{~s}$. The HSL solution composition was based on spiro-OMeTAD (Luminescence Technology Corporation, New Taipei, Taiwan) as the main component. Spiro-OMeTAD and 4-tert-butylpyridine (Sigma-Aldrich) were dissolved in chlorobenzene. The required amount of stock solutions of lithium bis(trifluromethylsulfonyl)imide (Li-TFSI, Sigma-Aldrich) and cobalt (III) tri[bis-(trifluromethane) sulfonamide] salt (FK209 Co (III), Greatcell Solar) in acetonitrile (99.8\%, Sigma-Aldrich) were added into the first solution to obtain a molar composition of 1.0:0.5:2.5 × 10 2 :3.3:131.5:7.2 (spiro-OMeTAD:Li-TFSI:FK209 Co (III):4-tert-butylpyridine:chlorobenzene:acetonitrile). Finally, an 80-nm-thick gold layer was deposited on top of the spiro-OMeTAD layer to form the back metal contact via evaporation at $2.5 \times 10^{-5}$ bar. 
An evaporation rate of $0.1 \AA / \mathrm{s}$ was used for the first $10 \mathrm{~nm}$, after which it increased to $0.2 \AA / \mathrm{s}$ until $20 \mathrm{~nm}$. The rate of $0.8 \AA / \mathrm{s}$ was then used to evaporate further up to $80 \mathrm{~nm}$. The shape of the gold contacts was circular with a diameter of $0.6 \mathrm{~cm}$, i.e., the contact area was $0.28 \mathrm{~cm}^{2}$.

The devices were characterized by measuring current density against voltage (J-V) scans using a 2636 Series Source Meter (Keithley Instruments, Cleveland, OH, USA) under simulated AM 1.5 sunlight close to $100 \mathrm{~mW} / \mathrm{cm}^{2}$ irradiance from an Oriel Class ABB solar simulator $\left(150 \mathrm{~W}, 2^{\prime \prime} \times 22^{\prime \prime}\right)$. The devices were masked using a black metal mask with an aperture size of $0.126 \mathrm{~cm}^{2}$. The J-V scans were performed between $-0.3 \mathrm{~V}$ and $1.1 \mathrm{~V}$ at a scan speed of $10 \mathrm{mV} / \mathrm{s}$, both in forward and reverse sweep. Time-dependent measurements of the devices were also performed for $5 \mathrm{~min}$ to determine the current densities close to their respective maximum power points (MPPs) under illumination at 1 Sun. Furthermore, for UV-Vis spectroscopy and photoluminescence (PL) measurements, $\mathrm{TiO}_{2}$ films deposited on glass substrates were coated with perovskite using the same deposition protocol as described above. The UV-Vis measurements were performed using a Perkin Elmer Lambda 900 UV-Vis/near infrared spectrometer. The samples were scanned in the $\lambda$ range $500-900 \mathrm{~nm}$ and the measurements were performed in the presence of standard reflectance standards. The slit size was $2 \mathrm{~mm}$. PL spectra were obtained with a FLS1000 spectrofluorometer (Edinburgh Instruments, Livingston, UK). Time-resolved photoluminescence (TR-PL) decays were determined using a time-correlated single photon counting (TCSPC) apparatus equipped with a Picoharp 300 controller and a PDL 800-B driver for excitation and a Hamamatsu R3809U-50 microchannel plate photomultiplier for detection in a $90^{\circ}$ configuration. All samples were measured using a $648 \mathrm{~nm}$ excitation wavelength with an excitation energy intensity of $40 \mu \mathrm{J} / \mathrm{cm}^{2}$ while exciting from the perovskite film side. The PL decays were monitored at $765 \mathrm{~nm}$ and well fitted with a bi-exponential function $I(t)=A_{1} \cdot e^{\left(-t / \tau_{1}\right)}+A_{2} \cdot e^{\left(-t / \tau_{2}\right)}$, where $I(t)$ is the PL intensity at time $t, A_{\mathrm{x}}$ is the initial amplitude of component $x(x=1$ or 2$)$, and $\tau$ is the exponential lifetime of component $x[29,30]$.

\section{Results and Discussion}

\subsection{Structural Properties of the $\mathrm{TiO}_{2}$ Thin Films}

The $\mathrm{TiO}_{2}$ thin films dip-coated on top of FTO substrates were characterized using GI-XRD to investigate the effect of block co-polymer content (i.e., film porosity) on the crystal structure. The diffractograms shown in Figure 1 reveal that all the films consist of the anatase crystal structure regardless of the amount of added block co-polymer. However, the declining peak intensity and Scherrer analysis of the full-width half maximum of the (101) reflection indicate that the anatase crystallite size decreases when higher block co-polymer amounts are used (see Table 2). The reflections at $34.0^{\circ}$ and $38.1^{\circ} 2 \theta$ originate from the underlying FTO substrate. 


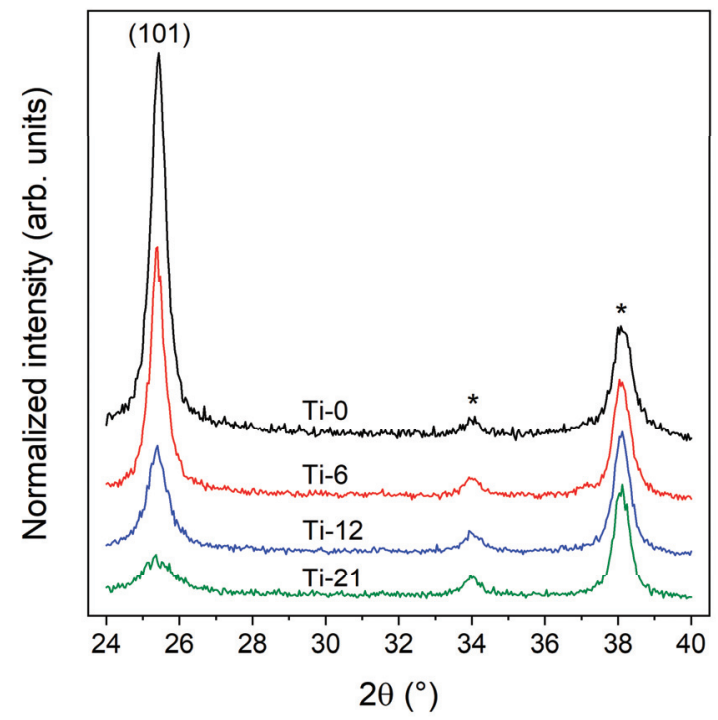

Figure 1. XRD diffractograms of $\mathrm{TiO}_{2}$ films with different block co-polymer content deposited on FTO substrates. The (101) reflection of the anatase phase is indicated in the figure. The asterisks $\left({ }^{*}\right)$ indicate reflections from the underlying FTO substrate. The diffractograms have been normalized to the intensity of the FTO reflection at $38.1^{\circ} 2 \theta$ as well as offset for clarity.

$\mathrm{TiO}_{2}$ films dip-coated on top of planar glass substrates were studied by X-ray reflectometry (XRR) to estimate the porosity and the film thickness. Figure S1 in the Supplementary Information shows the XRR interference patterns of $\mathrm{TiO}_{2}$ films with different porosities. The trends in the film density and thickness as a function of block co-polymer concentration are listed in Table 2. The density of the Ti-0 reference sample is lower than the literature value for a completely crystalline anatase material $\left(3.79 \mathrm{~g} / \mathrm{cm}^{3}\right)$. However, it is expected that nanocrystalline thin films have lower densities. With an increase in block co-polymer concentration, the density of the films decreases, meaning that the porosity originating from the block co-polymer template increases (up to $47 \%$ for the Ti-21 sample). We aimed at keeping the film thickness constant at $\sim 5 \mathrm{~nm}$ regardless of the block co-polymer content to be able to directly relate the device performance to the porosity of the films. However, initial tests simply by increasing the block co-polymer amount resulted in a rapidly increasing film thickness due to the increasing viscosity of the dip coating sol. To compensate for this, a higher dilution in water and $\mathrm{EtOH}$ was used for higher block co-polymer to $\mathrm{TiCl}_{4}$ ratios (see details in Table 1). Despite this adjustment, a slight variation in film thickness was observed for the samples, ranging from $75 \mathrm{~nm}$ for the Ti-0 sample to $50 \mathrm{~nm}$ for the Ti-21 sample. Thus, in order to investigate the influence of the film thickness, we made another series based on a fixed porosity. To produce the thinnest sample, 2.5 times more solvent (EtOH and water) compared to the Ti-21 sample was used in the dipping sol (sample Ti-21-2.5), while in order to produce the thickest sample, $80 \%$ of the original solvent amount was used (Ti-21-0.8). The XRR measurements shown in Figures S1 and S2 in the Supplementary Information reveal that the film thickness of the Ti-21-2.5 sample is $20 \mathrm{~nm}$, while the Ti-21-0.8 dipping sol produces a 75-nm-thick $\mathrm{TiO}_{2}$ film. However, both films have a density of $\sim 1.7 \mathrm{~g} / \mathrm{cm}^{3}$, which is the same as for the original 50 nm-thick film (Ti-21-1.0). 
Table 2. Summary of the $\mathrm{TiO}_{2}$ film characteristics derived from XRD and XRR data.

\begin{tabular}{ccccc}
\hline Sample & Crystallite Size $(\mathbf{n m})$ & Thickness $(\mathbf{n m})$ & Density $\left(\mathrm{g} / \mathbf{c m}^{\mathbf{3}}\right)$ & Porosity $^{(\%)} \mathbf{~}^{\mathbf{1}}$ \\
\hline Ti-0 & 20 & 75 & 3.21 & 0 \\
Ti-6 & 21 & 71 & 2.76 & 14.0 \\
Ti-12 & 14 & 61 & 2.39 & 25.5 \\
Ti-21 & 7 & 50 & 1.70 & 47.0 \\
\hline
\end{tabular}

${ }^{1}$ The porosity values for the block co-polymer-templated samples are calculated by relating their densities to the non-porous Ti-0 reference sample.

The films deposited on FTO substrates were further characterized using top-view SEM imaging, as shown in Figure 2. The Ti-0 sample shows a smooth granular surface with a grain size in the range of 10-20 nm, which is expected from the crystallite size obtained from XRD analysis. However, for the block co-polymer-templated films, pseudo-ordered mesoporous structures can be observed. The SEM images show a reduction in pore wall thickness from $\sim 27 \mathrm{~nm}$ to $\sim 15 \mathrm{~nm}$ with the increase in block co-polymer concentration, while the diameters of the pore openings remain roughly constant between 13 to $15 \mathrm{~nm}$. At the bottom of some of the pores (highlighted in the dashed area in Figure 2c), spots with comparably darker contrast can be seen. These spots indicate the second row of pores deeper inside the $\mathrm{TiO}_{2}$ thin film. In the EISA process, the arrangement and interconnection of the spherical block co-polymer micellar templates determine the final pore structure [24]. In our case, it is expected that the mesopores have a body-centered-cubic (bcc) arrangement with pore shrinkage perpendicular to the substrate [26]. The ellipsoidal pores are connected via narrow channels, through which the combusted block co-polymer template escaped during the calcination process. This creates a tortuous pathway down to the underlying substrate. Based on the information obtained from XRR, XRD, and AFM, a schematic 2-D representation of the porous films can be constructed, as shown in Figure 3a.

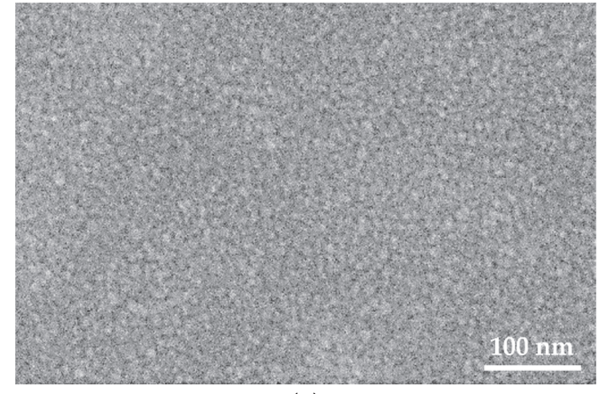

(a)

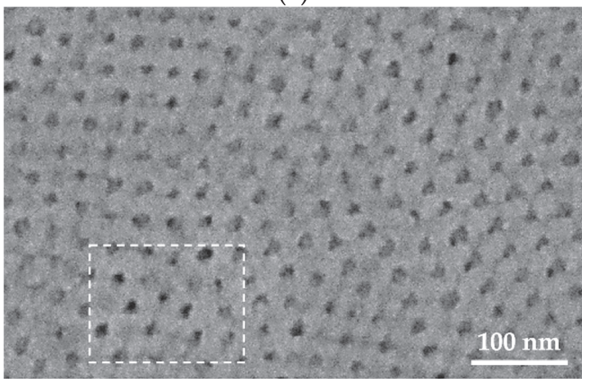

(c)

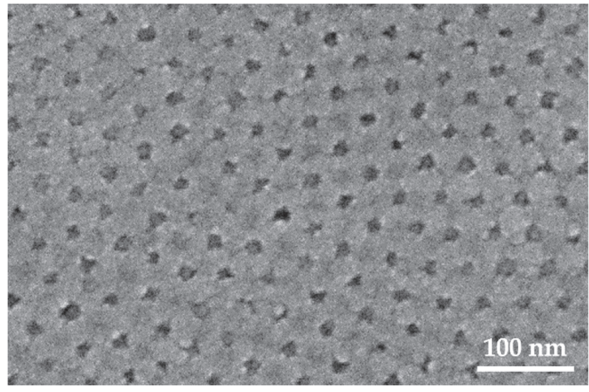

(b)

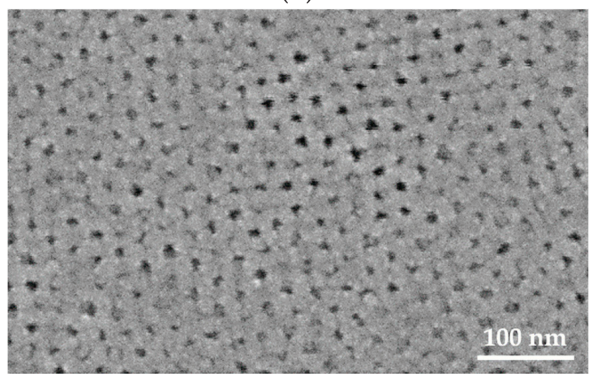

(d)

Figure 2. Top-view SEM images of the (a) Ti-0, (b) Ti-6, (c) Ti-12, and (d) Ti-21 thin films made on FTO substrates. The dark spherical features indicate pore openings, while the brighter areas represent the surrounding $\mathrm{TiO}_{2}$ wall structure (see text for further details). 


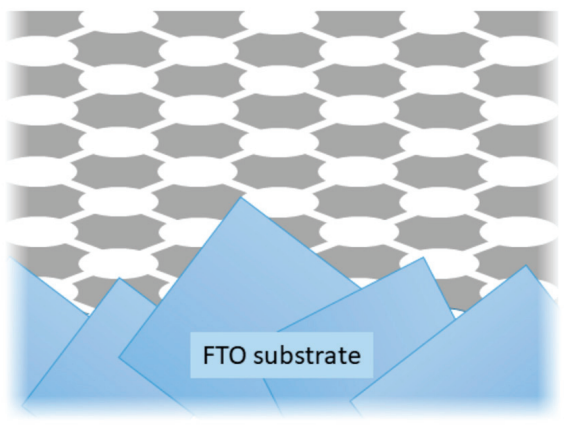

(a)

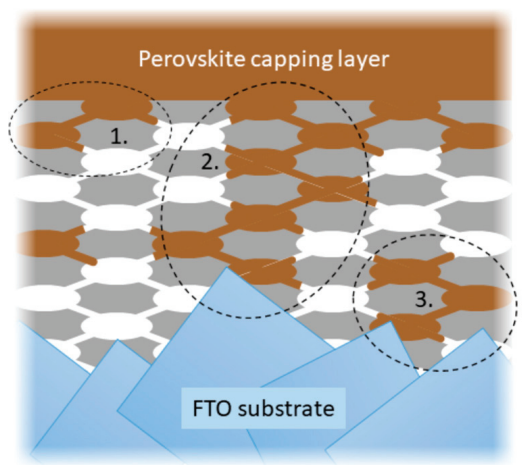

(b)

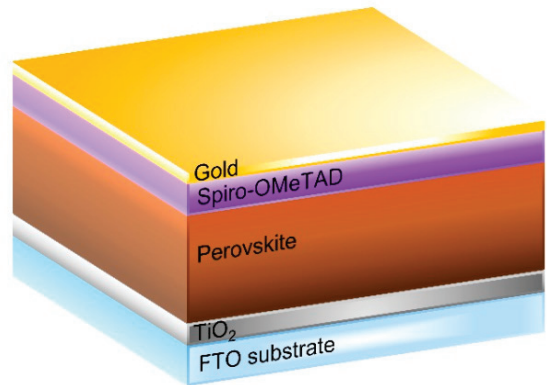

(c)

Figure 3. (a) A schematic 2-D representation of a porous $\mathrm{TiO}_{2}$ thin film deposited on top of a rough FTO substrate (note that the dimensions are not to scale); (b) suggested pore filling behavior of perovskite inside the porous $\mathrm{TiO}_{2}$ matrix: 1. Perovskite in contact with the perovskite capping layer, 2. direct perovskite pathway from the capping layer to FTO, and 3. isolated perovskite inside the porous matrix; (c) schematic illustration of the investigated device structures, where the $\mathrm{TiO}_{2}$ ESL is either dense or porous.

To verify whether the underlying FTO substrate is accessible via the pores from the top, the surface recombination velocity of holes at the $\mathrm{FTO} / \mathrm{TiO}_{2}$ contact was determined in model devices where the semiconducting polymer P3HT was coated on top of the different $\mathrm{TiO}_{2}$ films and the gold contact was evaporated on top of the P3HT. Gold forms a hole-Ohmic contact to P3HT, whereas it is well known that $\mathrm{TiO}_{2}$ is hole blocking. It is expected that the P3HT can fill the porous structures more easily than the perovskite, and the more P3HT that is in direct contact with FTO the higher the surface recombination would be, since FTO does not block holes [31-33]. The surface recombination velocity at the $\mathrm{TiO}_{2} / \mathrm{P} 3 \mathrm{HT}$ interfaces was determined using the MIS-CELIV technique [34]. The current transients and calculated surface recombination rates for holes, $\mathrm{S}_{\mathrm{R}}$, for compact and porous $\mathrm{TiO}_{2}$ films are shown in Figures S3 and S4 in the Supplementary Information, respectively. For the Ti-0 sample, we obtained $S_{R} \approx 10^{-5} \mathrm{~cm} / \mathrm{s}$, which is slightly higher than previously reported values [34]. We also found that $S_{R}$ increases with increasing porosity. The Ti- 6 sample has a $S_{R}$ value one order of magnitude larger than the Ti-0 sample, and when increasing the porosity to that of the Ti- 21 sample, $S_{R}$ increases by another order of magnitude. We attribute this sharp increase to $\mathrm{P} 3 \mathrm{HT}$ reaching all the way through the porous $\mathrm{TiO}_{2}$ films, down to the FTO, where holes will recombine much faster than at the $\mathrm{TiO}_{2} / \mathrm{P} 3 \mathrm{HT}$ interface. The sharp increase in $\mathrm{S}_{\mathrm{R}}$ even at low porosity would correspond to P3HT pathways forming down to the FTO, and as the porosity increases, these pathways become more accessible and/or more numerous, seen as a further increase in $S_{R}$. This leaves us with the conclusion that the porous channels in the 
$\mathrm{TiO}_{2}$ films reaches all the way down to the FTO substrate. However, since these $S_{R}$ measurements are limited to hole-only devices and low-mobility materials, this method cannot be used to further clarify whether these porous channels are accessible to the perovskite layer. Earlier, it has been shown that the substrate is readily accessible through thinner block co-polymer-templated $\mathrm{TiO}_{2}$ porous films $[35,36]$. Thus, we believe that the ordered mesoporous $\mathrm{TiO}_{2}$ films can be used as a model system for $\mathrm{TiO}_{2} \mathrm{ESLs}$ with narrow and well-defined pinholes.

\subsection{Device Performance}

In the next step, the non-porous reference sample (Ti-0) and the ordered mesoporous $\mathrm{TiO}_{2}$ films with different porosities were used as ESLs in PSCs. The overall device configuration is schematically illustrated in Figure 3c. In Figure 4a, representative J-V curves of devices made with $\mathrm{TiO}_{2} \mathrm{ESLs}_{\text {with }}$ different porosities show that there are no large deviations in device performance as a function of porosity. The corresponding dark curves are shown in Figure S5 in the Supplementary Information. Furthermore, the PCE values of the devices (measured in the reverse sweep) are plotted in Figure 4b and summarized in Table 3. The devices with a dense $\mathrm{TiO}_{2}$ layer (Ti-0) have a mean PCE of $13.1 \pm 0.7 \%$. The reason for the lower PCE compared to previously reported values for planar PSCs based on mixed perovskites [37] is mainly attributed to the relatively large active area $\left(\sim 0.13 \mathrm{~cm}^{2}\right)$ and substrate size, which creates a large series resistance in the device. However, the reproducibility of the device performance is still very good, which is a prerequisite for this study.

Upon increasing the porosity in the $\mathrm{TiO}_{2}$ layer, the device efficiencies remain almost unchanged. The highest average efficiency $(13.8 \pm 0.7 \%)$ can actually be achieved for the samples with the most porous $\mathrm{TiO}_{2}$ layers (Ti-21). This is rather surprising, as the ordered pore structure percolates all the way through the $\mathrm{TiO}_{2}$ films and reaches down to the underlying FTO layer. If the perovskite were to be in direct contact with the FTO layer, one would expect shunt pathways and a considerable loss in device performance [9]. However, it seems like these narrow pore channels prevent the formation of detrimental perovskite pathways through the porous $\mathrm{TiO}_{2}$ to the FTO. After the high-temperature calcination of the $\mathrm{TiO}_{2}$ films, they were immediately transferred to the glove box in order to avoid contamination of the surface with volatile organics. Thus, the $\mathrm{TiO}_{2}$ pore surface is very energetic due to surface hydroxyl groups and should be readily wetted by polar solvents like the ones used in the perovskite precursor solution (DMF and DMSO). However, it is well known that the addition of the anti-solvent (chlorobenzene) brings the perovskite precursor solution into supersaturation after which a rapid perovskite crystallization commences. Our hypothesis is that the crystallization starts from the top of the porous $\mathrm{TiO}_{2}$ structure. The initially formed perovskite will then obstruct the pore entrances so that further precursor solution is not able to enter the pores upon solvent evaporation, but instead contributes to the perovskite capping layer. Nonetheless, the precursor solution that initially occupies the pores will be converted to perovskite upon annealing. However, as the resulting perovskite material is estimated to only occupy $15-20 \mathrm{vol} \%$ in relation to the volume of the starting precursor solution (the solvents occupy the rest of the volume); this is scarcely enough to form percolating networks throughout the pore system. Instead, due to limited adhesion of the formed perovskite on the $\mathrm{TiO}_{2}$ surface, isolated islands of perovskite will be created inside the pore system. The suggested pore filling behavior is schematically illustrated in Figure $3 \mathrm{~b}$. Relating these results to the perovskite filling of nanoparticle-based mesoscopic $\mathrm{TiO}_{2}$ layers, the more accessible pores of those structures would allow for a considerably higher pore filling degree. In that case, an additional compact $\mathrm{TiO}_{2}$ layer is needed to avoid direct shunt pathways between the perovskite and FTO [23,38]. This further suggests that also the pore size could affect the pore filling degree as one would expect less pore entrance obstruction by the perovskite when the pore size is larger. 


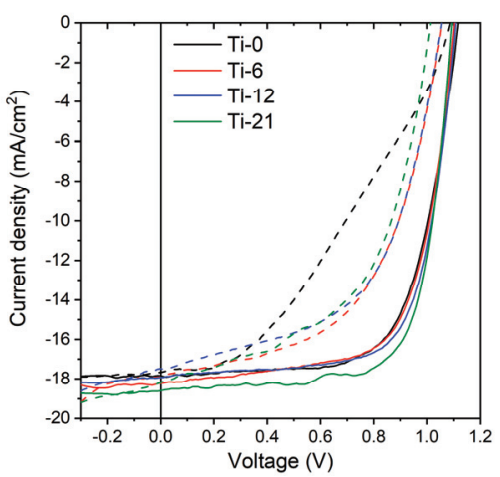

(a)

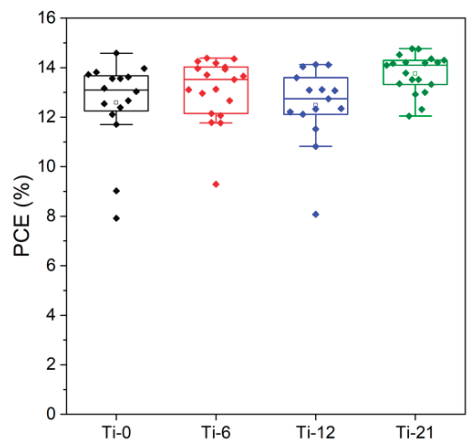

(b)

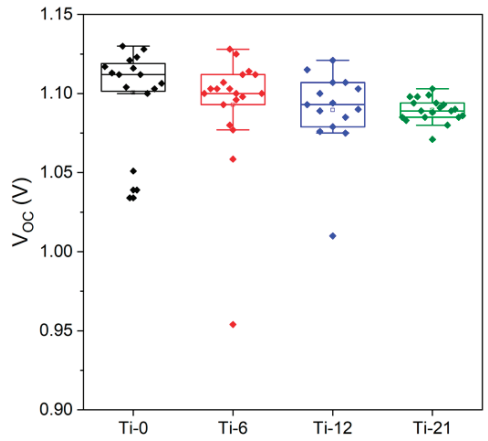

(d)

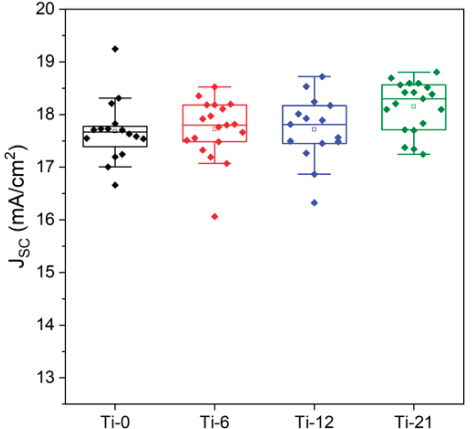

(c)

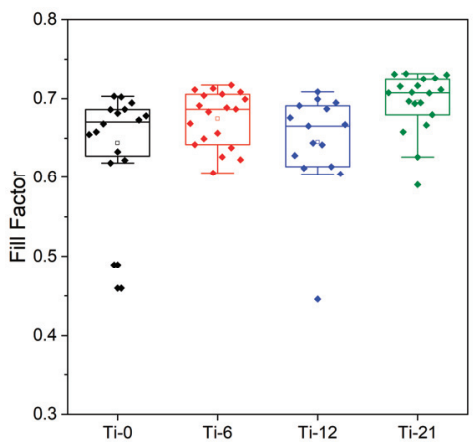

(e)

Figure 4. (a) Representative J-V curves in forward (dashed lines) and reverse (solid lines) sweep for devices with increasing porosity in the $\mathrm{TiO}_{2}$ layer. The solar cells were measured at a scan rate of $10 \mathrm{mV} / \mathrm{s}$ and AM $1.5 \mathrm{G}$ illumination with light intensity of $100 \mathrm{~mW} / \mathrm{cm}^{2}$; Changes in (b) device efficiencies, (c) $J_{S C}$, (d) $V_{O C}$, and (e) FF for devices measured in reverse sweep with increase in porosity in the $\mathrm{TiO}_{2}$ layer.

In the reverse sweep, it can be observed that the short circuit current $\left(J_{S C}\right)$ slightly increases with porosity (from $17.5 \mathrm{~mA} / \mathrm{cm}^{2}$ to $18.5 \mathrm{~mA} / \mathrm{cm}^{2}$ for the Ti- 0 and Ti-21 samples, respectively). On the other hand, the open circuit voltage $\left(V_{O C}\right)$ marginally drops from $1.11 \mathrm{~V}$ to $1.09 \mathrm{~V}$ for the same set of samples. The opposing trends in $J_{S C}$ and $V_{O C}$ explain the rather constant PCE values regardless of porosity in 
the $\mathrm{TiO}_{2}$ ESL layer. When comparing UV-Vis absorption data of $\mathrm{TiO}_{2}$ films coated with perovskite (see Figure $\mathrm{S} 6$ in the Supplementary Information), the absorption of the perovskite in the 500-750 nm wavelength range is virtually the same for all samples with a standard deviation of $\sim 1 \%$ at $\lambda=700 \mathrm{~nm}$. Due to the thinness of the $\mathrm{TiO}_{2}$ films, we expect optical effects like increased reflectance or optical interference to be small $[39,40]$. Thus, the UV-Vis results further support that the perovskite located in the pore systems is proportionally low. The slight increase in JSC with porosity could, however, be a result of more continuous perovskite pathways inside the pores at higher porosities, as illustrated in Figure $3 b$ (case 1). Charges generated in isolated perovskite crystals inside the pores would normally recombine (case 3), but if more continuous pathways were to form, these charges could be extracted, and thus increase $J_{S C}$. This could also explain the drop in $V_{O C}$, as there will be a greater possibility that direct (shunt) pathways are formed between the perovskite capping layer and the FTO as the continuity in the perovskite pathways increase (case 2). As schematically illustrated in Figure 3b, we believe that such perovskite pathways can be formed in thinner regions of the $\mathrm{TiO}_{2}$ layer caused by the high surface roughness of FTO.

To evaluate the $\mathrm{TiO}_{2}$ porosity-influenced electron-injection process from the perovskite conduction band (CB) to the $\mathrm{CB}$ of the $\mathrm{TiO}_{2}$ layer, steady-state photoluminescence (PL) experiments on glass/perovskite and glass/ $\mathrm{TiO}_{2} /$ perovskite samples with different porosities of the $\mathrm{TiO}_{2}$ layer were conducted. Figure S7 shows a clear PL quenching effect for all perovskite coated $\mathrm{TiO}_{2}$ films. The calculated PL quenching efficiency (PLQE), or in other words, the electron-injection yield, is increasing with decreasing porosity, suggesting that a lower porosity of the $\mathrm{TiO}_{2}$ layer is more favorable for an efficient electron injection process. We now turn to assess the influence of the porosity of the $\mathrm{TiO}_{2}$ films on the charge transfer dynamics at the perovskite/ $\mathrm{TiO}_{2}$ interface. Figure S8 shows TR-PL decays (obtained via TCSPC measurements) of the perovskite with and without coated $\mathrm{TiO}_{2}$ films with different porosities together with the extracted bi-exponential fitted data of the PL decays. All PL decays of the perovskite-coated $\mathrm{TiO}_{2}$ films show acceleration compared to that of the pristine perovskite on glass reference, suggesting that the interfacial electron injection has occurred for all cases of perovskite/ $\mathrm{TiO}_{2}$ films, which is also consistent with previous PL quenching data. A clear deceleration of the decay profiles is observed with increasing porosity, although the decay lifetimes for the samples with the highest porosities (Ti-12 and Ti-21) are virtually identical. Based on the reported global analysis methods [41-43], we attribute the first component $\left(\mathrm{A}_{1}, \tau_{1}\right)$ to the trap-state-mediated recombination, while assigning the second component $\left(\mathrm{A}_{2}, \tau_{2}\right)$ to the nongeminate free carrier (electron and hole) recombination and electron injection process from the $\mathrm{CB}$ of the excited perovskite to that of the $\mathrm{TiO}_{2}$ film. It is evident that the second component dominates the overall decay process, suggesting that a low porosity is more favorable for suppressing charge recombination, which in turn results in the enhanced $V_{O C}$ [44]. Another possibility for the change in $V_{O C}$ is that the increased porosity can generate more traps on the $\mathrm{TiO}_{2}$ structure, leading to a deepening of the $\mathrm{TiO}_{2} \mathrm{CB}$, which could intrinsically lower the $V_{O C}[30,45]$.

Table 3. Mean values and standard deviations of photovoltaic parameters measured in reverse sweep of all type of devices.

\begin{tabular}{ccccccc}
\hline Sample & Thickness $(\mathbf{n m})$ & No of Devices & $J_{S C}\left(\mathbf{m A} / \mathbf{c m}^{2}\right)$ & $V_{O C}(\mathbf{V})$ & FF & PCE (\%) \\
\hline Ti-0 & 75 & 13 & $17.6 \pm 0.4$ & $1.11 \pm 0.02$ & $0.67 \pm 0.03$ & $13.1 \pm 0.7$ \\
Ti-6 & 71 & 18 & $17.8 \pm 0.4$ & $1.10 \pm 0.02$ & $0.68 \pm 0.03$ & $13.3 \pm 0.9$ \\
Ti-12 & 61 & 13 & $17.8 \pm 0.5$ & $1.10 \pm 0.01$ & $0.66 \pm 0.03$ & $13.0 \pm 0.8$ \\
Ti-21 & 50 & 19 & $18.1 \pm 0.5$ & $1.09 \pm 0.01$ & $0.70 \pm 0.03$ & $13.8 \pm 0.7$ \\
Ti-21-0.8 & 75 & 8 & $17.8 \pm 0.3$ & $1.05 \pm 0.01$ & $0.69 \pm 0.02$ & $12.9 \pm 0.4$ \\
Ti-21-1.0 & 50 & 6 & $18.1 \pm 0.1$ & $1.08 \pm 0.01$ & $0.72 \pm 0.004$ & $14.1 \pm 0.2$ \\
Ti-21-2.5 & 20 & 7 & $17.2 \pm 2.0$ & $1.01 \pm 0.09$ & $0.63 \pm 0.11$ & $11.0 \pm 2.9$ \\
\hline
\end{tabular}

Furthermore, the fill factors (FF) in reverse sweep (Figure 4e) show quite similar values for all porosities in the range of $0.67-0.70$. However, when comparing the device hysteresis, larger differences 
are observed. As seen in Figure 4a, the device based on the dense reference $\mathrm{TiO}_{2}$ layer (Ti-0) displays an s-shaped feature in the forward sweep, which is not observed in the reverse sweep. This results in a high hysteresis index for the device $(\sim 12 \%)$. S-shapes and high hysteresis are commonly observed for planar $\mathrm{TiO}_{2}$-based devices [8,9]. The s-shape is indicative of an unstabilized power output and caused by polarization of the device (most likely due to diffusion of ionic species) [46]. Upon inducing pores in the ESL, the s-shape in the forward sweep disappears, which has also been observed when shifting from planar to mesoscopic $\mathrm{TiO}_{2}$-based devices [46]. The hysteresis between the forward and reverse sweeps remains high (in the range of $8-10 \%$ ), but the FF in the forward sweep is significantly improved upon inducing porosity in $\mathrm{TiO}_{2}$ films. This is also evident from the time-dependent current density measurements performed close to the maximum power point (MPP) under illumination, shown in Figure S9 in the Supplementary Information. The device based on a dense $\mathrm{TiO}_{2}$ film requires more time to stabilize close to the MPP than the devices based on porous $\mathrm{TiO}_{2}$ films. With further increase in porosity, stabilization of the current at MPP is even faster, while the magnitude of current density at the MPP is also slightly enhanced. This correlates well with the J-V curves, as an improvement in JSC was observed in Figure 4a,c.

As mentioned earlier, the thickness of the $\mathrm{TiO}_{2}$ films decreases slightly when more block co-polymer amounts were used, i.e., from $75 \mathrm{~nm}$ for the Ti-0 sample to $50 \mathrm{~nm}$ for the Ti-21 sample. We are aware that the device performance could be affected when the thickness of the $\mathrm{TiO}_{2}$ layer is altered, due to small changes in the charge transport properties or optical effects. Nonetheless, we consider the samples in porosity series to be "thick enough", as they are all equal to or thicker than $50 \mathrm{~nm}$. This is important, as it rules out the possibility that there are bare patches of FTO exposed in our devices [23]. To verify that the observed device change is an effect of the porosity rather than a change in thickness, we also made a series where the thickness of the $\mathrm{TiO}_{2}$ ESL was varied, while keeping the block co-polymer to $\mathrm{TiCl}_{4}$ ratio the same as in the Ti-21 sample. When comparing the J-V characteristics and the efficiencies in the box chart diagram in Figure 5, all thicknesses of the porous ESL display good average device performances. The devices prepared using the $75 \mathrm{~nm}$-thick porous $\mathrm{TiO}_{2}$ films (Ti-21-0.8) perform slightly worse (PCE $=12.9 \%$ ) than those prepared using the $50 \mathrm{~nm}$ porous $\mathrm{TiO}_{2} \mathrm{ESL}(\mathrm{PCE}=14.1 \%)$. This suggests that small thickness variations can indeed also be important for optimized performance for this device structure; however, the reduced $\mathrm{V}_{\mathrm{OC}}$ trend can still be observed when comparing this Ti-21 batch to the devices with less porous $\mathrm{TiO}_{2}$ layers in Table 3. For instance, the non-porous Ti-0 sample and the highly porous Ti-21-0.8 sample have the same film thickness $(75 \mathrm{~nm})$ and devices made from these samples possess roughly the same efficiency $(\sim 13 \%)$. However, when comparing the $\mathrm{V}_{\mathrm{OC}}$ values for these two samples, it is clear that the $\mathrm{V}_{\mathrm{OC}}$ is substantially lower for devices based on the porous $\mathrm{TiO}_{2}$ layer (1.05 V compared to $1.11 \mathrm{~V})$. This is most likely attributed to increased charge recombination as suggested by the TR-PL data. It is noteworthy that even the devices based on a $\sim 20$ nm-thick porous $\mathrm{TiO}_{2}$ layer (Ti-21-2.5) display a decent average device efficiency (PCE $=11.0 \%$ ). However, as seen from the scattered PCE data points in the box diagram as well as the larger standard deviations in Table 3, the thinnest sample clearly suffers from poor reproducibility (see also Figure S10 for the statistics of the photovoltaic parameters). As the porosity is roughly the same for the different thicknesses, a similar interconnectivity of the perovskite inside the pores is to be expected. Thus, the main difference between the $75 \mathrm{~nm}$ (Ti-21-0.8) and $50 \mathrm{~nm}$ (Ti-21-1.0) samples is more likely that the thicker ESL is not able to extract electrons as well as the thinner layer, which is seen as a slightly lower PCE [9]. Furthermore, an ESL layer that is too thick can also reduce the light transmittance due to stronger light scattering and greater absorption of photons with energies higher than that of the ESL band gap, and this reduces the photon absorption by the active layer $[47,48]$. However, when the porous layer becomes thin enough, as in the Ti-21-2.5 sample, more direct shunt pathways are to be expected as the pore channels become shallower perpendicular to the FTO substrate. The large scattering of data points suggests that in some $\mathrm{TiO}_{2}$ layers, very few such pathways can be achieved, while others suffer severely from direct shunt pathways. In ultrathin $\mathrm{TiO}_{2}$ layers, shunt pathways can also arise from direct contacts between the perovskite and bare patches of FTO due to incomplete surface coverage of 
the ESL. We previously reported that compact $\mathrm{TiO}_{2}$ layers prepared by the dip-coating method need to have a thickness of at least $\sim 30 \mathrm{~nm}$ to work optimally in mesoscopic PSCs [23]. However, in the planar configuration, the $\mathrm{TiO}_{2}$ layer probably needs to be somewhat thicker $(\sim 50 \mathrm{~nm})$ to avoid this kind of pinholes in the devices.

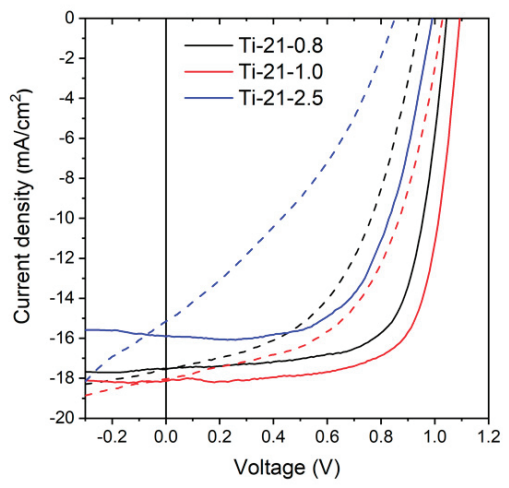

(a)

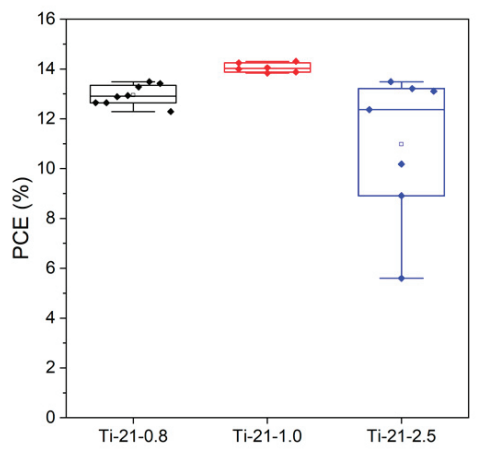

(b)

Figure 5. (a) J-V curves for representative devices based on $\mathrm{TiO}_{2}$ ESLs with the highest porosity with different thicknesses. Dashed lines indicate forward sweep and solid lines reverse sweep; (b) box chart for the efficiencies in reverse sweep.

\section{Conclusions}

We introduced a model system for pinholes in $\mathrm{TiO}_{2}$-based ESL layers using block co-polymer-templated thin films with well-defined pore structures. We believe that the investigated system predicts morphological defects, such as narrow pinholes, well. We observed that such pinholes have a very small effect on the overall device performance most likely due to the fact that very few direct pathways of perovskite reach the FTO substrate through the ordered pore system. We saw a slight improvement in $J_{S C}$ for layers at large porosities as well as a drop in $V_{O C}$ with increasing porosity. A more interconnected pathway of perovskite forming in the pores when the porosity is high can explain both effects. Larger effects on the device performance are expected if the pore size were to be larger or if the pore structure were to be more open, and we plan to investigate these parameters in a follow-up study. Furthermore, for ultrathin $(\sim 20 \mathrm{~nm})$ porous layers, additional direct shunt pathways due to an incomplete ESL surface coverage of the FTO layer further deteriorates the device performance.

Supplementary Materials: The following are available online at http://www.mdpi.com/2079-4991/10/1/181/s1, Figure S1: XRR interference patterns of various $\mathrm{TiO}_{2}$ thin films, Figure S2: Film thickness and density dependence when varying the solvent amount, Figure S3: MIS-CELIV data, Figure S4: Calculated surface recombination velocities, Figure S5: J-V scans under dark conditions, Figure S6: UV-vis absorption measurements, Figure S7: Steady-state PL measurements, Figure S8: TR-PL measurements, Figure S9: Time-dependent current density measurements, Figure S10: Box charts for photovoltaic parameters of devices where the ESL thickness has been varied.

Author Contributions: Conceptualization, M.T.M., M.H., C.W., M.N., C.A., S.D., R.Ö. and J.-H.S.; methodology, S.Q., M.N., C.A. and S.D.; validation, M.H., C.W. and S.D.; formal analysis, M.N., C.A., S.D., M.L. and P.V.; investigation, M.T.M., S.Q. and M.L.; resources, P.V.; writing—original draft preparation, M.T.M.; writing—review and editing, all authors; visualization, M.T.M. and J.-H.S.; supervision, M.H., M.N., P.V., R.Ö. and J.-H.S.; project administration, P.V., R.Ö. and J.H.S.; funding acquisition, P.V., R.Ö. and J.-H.S. All authors have read and agree to the published version of the manuscript. 
Funding: This research was funded by Academy of Finland, grant numbers 308307 and 326000 as well as Jane \& Aatos Erkko Foundation (project "ASPIRE"). This work is also part of the Academy of Finland Flagship Programme, Photonics Research and Innovation (PREIN) (decision No 320165). C.W. thanks the Deutsche Forschungsgemeinschaft (DFG, WE 6127/1-1) for a postdoctoral fellowship.

Conflicts of Interest: The authors declare no conflict of interest. The funders had no role in the design of the study; in the collection, analyses, or interpretation of data; in the writing of the manuscript, or in the decision to publish the results.

\section{References}

1. Mahmood, K.; Sarwar, S.; Mehran, M.T. Current status of electron transport layers in perovskite solar cells: Materials and properties. RSC Adv. 2017, 7, 1744-1762. [CrossRef]

2. Kojima, A.; Teshima, K.; Shirai, Y.; Miyasaka, T. Organometal Halide Perovskites as Visible-Light Sensitizers for Photovoltaic Cells. J. Am. Chem. Soc. 2009, 131, 6050-6051. [CrossRef] [PubMed]

3. Saliba, M.; Matsui, T.; Seo, J.; Domanski, K.; Correa-Baena, J.; Nazeeruddin, M.K.; Zakeeruddin, S.M.; Tress, W.; Abate, A.; Hagfeldt, A.; et al. Cesium-containing triple cation perovskite solar cells: Improved stability, reproducibility and high efficiency. Energy Environ. Sci. 2016, 9, 1989-1997. [CrossRef]

4. Best Research Cell-Efficiencies. Available online: https://www.nrel.gov/pv/assets/pdfs/best-research-cellefficiencies.20190802.pdf (accessed on 15 December 2019).

5. Shen, H.; Wu, Y.; Peng, J.; Duong, T.; Fu, X.; Barugkin, C.; White, T.P.; Weber, K.; Catchpole, K.R. Improved Reproducibility for Perovskite Solar Cells with $1 \mathrm{~cm}^{2}$ Active Area by a Modified Two-Step Process. ACS Appl. Mater. Interfaces 2017, 9, 5974-5981. [CrossRef]

6. Ramirez, D.; Velilla, E.; Montoya, J.F.; Jaramillo, F. Mitigating scalability issues of perovskite photovoltaic technology through a p-i-n meso-superstructured solar cell architecture. Sol. Energy Mater. Sol. Cells 2019, 195, 191-197. [CrossRef]

7. Meng, L.; You, J.; Yang, Y. Addressing the stability issue of perovskite solar cells for commercial applications. Nat. Commun. 2018, 9, 5265. [CrossRef] [PubMed]

8. Correa Baena, J.P.; Steier, L.; Tress, W.; Saliba, M.; Neutzner, S.; Matsui, T.; Giordano, F.; Jacobsson, T.J.; Srimath Kandada, A.R.; Zakeeruddin, S.M.; et al. Highly efficient planar perovskite solar cells through band alignment engineering. Energy Environ. Sci. 2015, 8, 2928-2934. [CrossRef]

9. Mohamad Noh, M.F.; Teh, C.H.; Daik, R.; Lim, E.L.; Yap, C.C.; Ibrahim, M.A.; Ahmad Ludin, N.; bin Mohd Yusoff, A.R.; Jang, J.; Mat Teridi, M.A. The architecture of the electron transport layer for a perovskite solar cell. J. Mater. Chem. C 2018, 6, 682-712. [CrossRef]

10. Guo, Y.; Sato, W.; Inoue, K.; Zhang, W.; Yu, G.; Nakamura, E. n-Type doping for efficient polymeric electron-transporting layers in perovskite solar cells. J. Mater. Chem. A 2016, 4, 18852-18856. [CrossRef]

11. Yang, D.; Sano, T.; Yaguchi, Y.; Sun, H.; Sasabe, H.; Kido, J. Achieving 20\% Efficiency for Low-Temperature-Processed Inverted Perovskite Solar Cells. Adv. Funct. Mater. 2019, 29, 1807556. [CrossRef]

12. Yang, D.; Zhang, X.; Wang, K.; Wu, C.; Yang, R.; Hou, Y.; Jiang, Y.; Liu, S.; Priya, S. Stable Efficiency Exceeding 20.6\% for Inverted Perovskite Solar Cells through Polymer-Optimized PCBM Electron-Transport Layers. Nano Lett. 2019, 19, 3313-3320. [CrossRef] [PubMed]

13. Fu, K.; Nelson, C.T.; Scott, M.C.; Minor, A.; Mathews, N.; Wong, L.H. Influence of void-free perovskite capping layer on the charge recombination process in high performance $\mathrm{CH}_{3} \mathrm{NH}_{3} \mathrm{PbI}_{3}$ perovskite solar cells. Nanoscale 2016, 8, 4181. [CrossRef] [PubMed]

14. Jiang, E.; Yan, J.; Ai, Y.; Li, N.; Yan, B.; Zeng, Y.; Sheng, J.; Ye, J. Defect engineering of oxygen vacancies in SnOx electron transporting layer for perovskite solar cells. Mater. Today Energy 2019, 12, 389-397. [CrossRef]

15. Yang, G.; Tao, H.; Qin, P.; Ke, W.; Fang, G. Recent progress in electron selective layers for efficient perovskite solar cells. J. Mater. Chem. A 2016, 4, 3970-3990. [CrossRef]

16. Wu, Y.; Yang, X.; Chen, H.; Zhang, K.; Qin, C.; Liu, J.; Peng, W.; Islam, A.; Bi, E.; Ye, F.; et al. Highly compact $\mathrm{TiO}_{2}$ layer for efficient hole-blocking in perovskite solar cells. Appl. Phys. Express 2014, 7, 052301. [CrossRef]

17. Jeong, E.; Bae, S.; Park, J.B.; Yu, S.M.; Kim, D.; Lee, H.; Rha, J.; Cho, Y.; Yun, J. Pinhole-free TiO $2 / \mathrm{Ag}(\mathrm{O}) / \mathrm{ZnO}$ configuration for flexible perovskite solar cells with ultralow optoelectrical loss. RSC Adv. 2019, 9, 9160-9170. [CrossRef] 
18. Lan, F.; Jiang, M.; Li, G. The characterization of defects states and charge injection barriers in perovskite solar cells. In Proceedings of the 2017 IEEE 17th International Conference on Nanotechnology, Pittsburg, PA, USA, 25-28 July 2017; pp. 379-382. [CrossRef]

19. Ren, H.; Zou, X.; Cheng, J.; Ling, T.; Bai, X.; Chen, D. Facile Solution Spin-Coating $\mathrm{SnO}_{2}$ Thin Film Covering Cracks of $\mathrm{TiO}_{2}$ Hole Blocking Layer for Perovskite Solar Cells. Coatings 2018, 8, 314. [CrossRef]

20. Lv, Y.; Xu, P.; Ren, G.; Chen, F.; Nan, H.; Liu, R.; Wang, D.; Tan, X.; Liu, X.; Zhang, H.; et al. Low-Temperature Atomic Layer Deposition of Metal Oxide Layers for Perovskite Solar Cells with High Efficiency and Stability under Harsh Environmental Conditions. ACS Appl. Mater. Interfaces 2018, 10, 23928-23937. [CrossRef]

21. Jiménez, J.M.; Bourret, G.R.; Berger, T.; McKenna, K.P. Modification of Charge Trapping at Particle/Particle Interfaces by Electrochemical Hydrogen Doping of Nanocrystalline $\mathrm{TiO}_{2}$. J. Am. Chem. Soc. 2016, 138, 15956-15964. [CrossRef]

22. Hu, Q.; Wu, J.; Jiang, C.; Liu, T.; Que, X.; Zhu, R.; Gong, Q. Engineering of Electron-Selective Contact for Perovskite Solar Cells with Efficiency Exceeding 15\%. ACS Nano 2014, 8, 10161-10167. [CrossRef]

23. Masood, M.T.; Weinberger, C.; Sarfraz, J.; Rosqvist, E.; Sandén, S.; Sandberg, O.J.; Vivo, P.; Hashmi, G.; Lund, P.D.; Österbacka, R.; et al. Impact of Film Thickness of Ultrathin Dip-Coated Compact $\mathrm{TiO}_{2}$ Layers on the Performance of Mesoscopic Perovskite Solar Cells. ACS Appl. Mater. Interfaces 2017, 9, 17906-17913. [CrossRef] [PubMed]

24. Grosso, D.; Cagnol, F.; Soler-Illia, G.; Crepaldi, E.; Amenitsch, H.; Brunet-Bruneau, A.; Bourgeois, A.; Sanchez, C. Fundamentals of Mesostructuring Through Evaporation-Induced Self-Assembly. Adv. Funct. Mater. 2004, 14, 309-322. [CrossRef]

25. Sarkar, A.; Jeon, N.J.; Noh, J.H.; Seok, S.I. Well-Organized Mesoporous $\mathrm{TiO}_{2}$ Photoelectrodes by Block Copolymer-Induced Sol-Gel Assembly for Inorganic-Organic Hybrid Perovskite Solar Cells. J. Phys. Chem. C 2014, 118, 16688-16693. [CrossRef]

26. Ortel, E.; Fischer, A.; Chuenchom, L.; Polte, J.; Emmerling, F.; Smarsly, B.; Kraehnert, R. New Triblock Copolymer Templates, PEO-PB-PEO, for the Synthesis of Titania Films with Controlled Mesopore Size, Wall Thickness, and Bimodal Porosity. Small 2012, 8, 298-309. [CrossRef]

27. Weidenthaler, C. Pitfalls in the characterization of nanoporous and nanosized materials. Nanoscale 2011, 3, 792. [CrossRef]

28. Saliba, M.; Correa-Baena, J.; Wolff, C.M.; Stolterfoht, M.; Phung, N.; Albrecht, S.; Neher, D.; Abate, A. How to Make over 20\% Efficient Perovskite Solar Cells in Regular (n-i-p) and Inverted (p-i-n) Architectures. Chem. Mater. 2018, 30, 4193-4201. [CrossRef]

29. Manser, J.S.; Kamat, P.V. Band filling with free charge carriers in organometal halide perovskites. Nat. Photonics 2014, 8, 737-743. [CrossRef]

30. Liu, M.; Endo, M.; Shimazaki, A.; Wakamiya, A.; Tachibana, Y. Identifying an Optimum Perovskite Solar Cell Structure by Kinetic Analysis: Planar, Mesoporous Based, or Extremely Thin Absorber Structure. ACS Appl. Energy Mater. 2018, 1, 3722-3732. [CrossRef]

31. Coakley, K.M.; Liu, Y.; McGehee, M.D.; Frindell, K.L.; Stucky, G.D. Infiltrating semiconducting polymers into self-assembled mesoporous titania films for photostatic application. Adv. Funct. Mater. 2003, 13, 301-306. [CrossRef]

32. Abrusci, A.; Ding, I.; Al-Hashimi, M.; Segal-Peretz, T.; McGehee, M.D.; Heeney, M.; Frey, G.L.; Snaith, H.J. Facile infiltration of semiconducting polymer into mesoporous electrodes for hybrid solar cells. Energy Environ. Sci. 2011, 4, 3051. [CrossRef]

33. Rawolle, M.; Sarkar, K.; Niedermeier, M.A.; Schindler, M.; Lellig, P.; Gutmann, J.S.; Moulin, J.; Haese-Seiller, M.; Wochnik, A.S.; Scheu, C.; et al. Infiltration of Polymer Hole-Conductor into Mesoporous Titania Structures for Solid-State Dye-Sensitized Solar Cells. ACS Appl. Mater. Interfaces 2013, 5, 719-729. [CrossRef] [PubMed]

34. Sandberg, O.J.; Sandén, S.; Sundqvist, A.; Smått, J.H.; Österbacka, R. Determination of Surface Recombination Velocities at Contacts in Organic Semiconductor Devices Using Injected Carrier Reservoirs. Phys. Rev. Lett. 2017, 118, 076601. [CrossRef] [PubMed]

35. Lantiat, D.; Vivier, V.; Laberty-Robert, C.; Grosso, D.; Sanchez, C. Gold Nanoelectrode Arrays and their Evaluation by Impedance Spectroscopy and Cyclic Voltammetry. ChemPhysChem 2010, 11, 1971-1977. [CrossRef] [PubMed] 
36. Fisher, A.; Kuemmel, M.; Järn, M.; Linden, M.; Boissière, C.; Nicole, L.; Sanchez, C.; Grosso, D. Surface Nanopatterning by Organic/Inorganic Self-Assembly and Selective Local Functionalization. Small 2006, 2, 587. [CrossRef]

37. Kaewprajak, A.; Kumnorkaew, P.; Sagawa, T. Improved photovoltaic performance and device stability of planar heterojunction perovskite solar cells using $\mathrm{TiO}_{2}$ and $\mathrm{TiO}_{2}$ mixed with $\mathrm{AgInS}$. quantum dots as dual electron transport layers. Org. Electron. 2019, 69, 26-33. [CrossRef]

38. Jeong, I.; Park, Y.H.; Bae, S.; Park, M.; Jeong, H.; Lee, P.; Ko, M.J. Solution-Processed Ultrathin $\mathrm{TiO}_{2}$ Compact Layer Hybridized with Mesoporous $\mathrm{TiO}_{2}$ for High-Performance Perovskite Solar Cells. ACS Appl. Mater. Interfaces 2017, 9, 36865-36874. [CrossRef]

39. Macdonald, T.J.; Batmunkh, M.; Lin, C.T.; Kim, J.; Tune, D.D.; Ambroz, F.; Li, X.; Xu, S.; Sol, C.; Papakonstantinou, I.; et al. Origin of Performance Enhancement in $\mathrm{TiO}_{2}$-Carbon Nanotube Composite Perovskite Solar Cells. Small Methods 2019, 3, 1900164. [CrossRef]

40. Du, T.; Kim, J.; Ngiam, J.; Xu, S.; Barnes, P.R.F.; Durrant, J.R.; McLachlan, M.A. Elucidating the Origins of Subgap Tail States and Open-Circuit Voltage in Methylammonium Lead Triiodide Perovskite Solar Cells. Adv. Funct. Mater. 2018, 28, 1801808. [CrossRef]

41. Kim, J.; Godin, R.; Dimitrov, S.D.; Du, T.; Bryant, D.; McLachlan, M.A.; Durrant, J.R. Excitation Density Dependent Photoluminescence Quenching and Charge Transfer Efficiencies in Hybrid Perovskite/Organic Semiconductor Bilayers. Adv. Energy Mater. 2018, 8, 1802474. [CrossRef]

42. Makuta, S.; Liu, M.; Endo, M.; Nishimura, H.; Wakamiya, A.; Tachibana, Y. Photo-excitation intensity dependent electron and hole injections from lead iodide perovskite to nanocrystalline $\mathrm{TiO}_{2}$ and spiro-OMeTAD. Chem. Commun. 2016, 52, 673-676. [CrossRef]

43. Zhang, H.; Liu, M.; Yang, W.; Judin, L.; Hukka, T.I.; Priimagi, A.; Deng, Z.; Vivo, P. Thionation Enhances the Performance of Polymeric Dopant-Free Hole-Transporting Materials for Perovskite Solar Cells. Adv. Mater. Interfaces 2019, 6, 1901036. [CrossRef]

44. Tress, W.; Yavari, M.; Domanski, K.; Yadav, P.; Niesen, B.; Correa Baena, J.P.; Hagfeldt, A.; Graetzel, M. Interpretation and evolution of open-circuit voltage, recombination, ideality factor and subgap defect states during reversible light-soaking and irreversible degradation of perovskite solar cells. Energy Environ. Sci. 2018, 11, 151-165. [CrossRef]

45. Saliba, M.; Orlandi, S.; Matsui, T.; Aghazada, S.; Cavazzini, M.; Correa-Baena, J.P.; Gao, P.; Scopelliti, R.; Masconi, E.; Dahmen, K.; et al. A molecularly engineered hole-transporting material for efficient perovskite solar cells. Nat. Energy 2016, 1, 15017. [CrossRef]

46. Unger, E.L.; Hoke, E.T.; Bailie, C.D.; Nguyen, W.H.; Bowring, A.R.; Heumüller, T.; Christoforo, M.G.; McGehee, M.D. Hysteresis and transient behavior in current-voltage measurements of hybrid-perovskite absorber solar cells. Energy Environ. Sci. 2014, 7, 3690. [CrossRef]

47. Lu, H.; Ma, Y.; Gu, B.; Tian, W.; Li, L. Identifying the optimum thickness of electron transport layers for highly efficient perovskite planar solar cells. J. Mater. Chem. A 2015, 3, 16445-16452. [CrossRef]

48. Li, C.; Li, Y.; Xing, Y.; Zhang, Z.; Zhang, X.; Li, Z.; Shi, Y.; Ma, T.; Ma, R.; Wang, K.; et al. Perovskite Solar Cell Using a Two-Dimensional Titania Nanosheet Thin Film as the Compact Layer. ACS Appl. Mater. Interfaces 2015, 7, 15117-15122. [CrossRef]

(C) 2020 by the authors. Licensee MDPI, Basel, Switzerland. This article is an open access article distributed under the terms and conditions of the Creative Commons Attribution (CC BY) license (http://creativecommons.org/licenses/by/4.0/). 
Article

\title{
Growth and Functionalization of Particle-Based Mesoporous Silica Films and Their Usage in Catalysis
}

\author{
Pei-Hsuan Wu ${ }^{1}$, Peter Mäkie ${ }^{1}$, Magnus Odén ${ }^{1}$ and Emma M. Björk ${ }^{1,2, *}$ \\ 1 Nanostructured Materials, Department of Physics, Chemistry and Biology (IFM), Linköping University, \\ 58183 Linköping, Sweden; peiwu389@student.liu.se (P.-H.W.); p_makie@hotmail.com (P.M.); \\ magnus.oden@liu.se (M.O.) \\ 2 Institute of Inorganic Chemistry II, University of Ulm, Albert-Einstein-Allee 11, 89081 Ulm, Germany \\ * Correspondence: emma.bjork@liu.se; Tel.: +46-13-28-25-43
}

Received: 1 March 2019; Accepted: 2 April 2019; Published: 6 April 2019

\begin{abstract}
We report the formation of mesoporous films consisting of SBA-15 particles grown directly onto substrates and their usage as catalysts in esterification of acetic acid and ethanol. The film thickness was altered between $80 \mathrm{~nm}$ and $750 \mathrm{~nm}$ by adding $\mathrm{NH}_{4} \mathrm{~F}$ to the synthesis solution. The salt also affects the formation rate of the particles, and substrates must be added during the formation of the siliceous network in the solution. Various substrate functionalizations were tested and hydrophobic substrates are required for a successful film growth. We show that large surfaces $\left(>75 \mathrm{~cm}^{2}\right)$, as well as 3D substrates, can be homogenously coated. Further, the films were functionalized, either with acetic acid through co-condensation, or by coating the films with a thin carbon layer through exposure to furfuryl alcohol fumes followed by carbonization and sulfonation with $\mathrm{H}_{2} \mathrm{SO}_{4}$. The carbon-coated film was shown to be an efficient catalyst in the esterification reaction with acetic acid and ethanol. Due to the short, accessible mesopores, chemical variability, and possibility to homogenously cover large, rough surfaces. the films have a large potential for usage in various applications such as catalysis, sensing, and drug delivery.
\end{abstract}

Keywords: mesoporous silica; mesoporous films; direct growth; esterification; material formation

\section{Introduction}

Mesoporous silica films are of large interest in applications such as sensing, catalysis, and drug delivery [1-6]. Their large surface area, tunable pore characteristics, and versatile surface functionality are attractive features. For some applications, ordered cylindrical pores are preferable over spherical [7] or wormlike [8] pores. SBA-15 is a type of mesoporous silica with hexagonally ordered, cylindrical pores [9]. By alterations in the synthesis conditions, e.g. addition of swelling agents or altered reaction temperature, the pores can be increased from the regular $\sim 8 \mathrm{~nm}$ to $>18 \mathrm{~nm}[10,11]$, and the particle morphology changed from fibers to rods or platelets [11,12]. This makes the material attractive in, e.g., catalysis [13,14], enzyme immobilization [15], and sensing [16]. However, the synthesis of mesoporous films using SBA- 15 structures most often results in long pores that are aligned parallel to the substrate [17], making them inaccessible.

The most common method for synthesizing SBA-15 films is evaporation-induced self-assembly (EISA) [18], where an ethanol-containing solution is deposited onto a substrate using spin- or dip-coating. The method can be used on large substrates with various compositions, but is limited, as the dipping angle is crucial for the film thickness [19], resulting in non-homogenous coatings on non-flat substrates, and pores larger than $10 \mathrm{~nm}$ are rare [20]. Recently, methods have been developed for depositing thin layers of pre-synthesized mesoporous silica particles on substrates, e.g., by spinning them onto a substrate [21], or using Langmuir-Blodgett deposition [22], making also cylindrical pores easily accessible. However, these films consist of separated particles located on the substrate, which 
results in poor mechanical integrity. In addition, the method requires flat substrates, which makes it less attractive for many applications. It is possible to bind the particles to a substrate through covalent linking [5], but this is a time-consuming procedure, with functionalization of both particles and substrates. A different direct growth (DiG) method, to form a monolayer of SBA-15 particles adhered to a substrate using a simple one-pot synthesis method, was recently reported [23]. This method yields densely packed, separate particles with short, accessible pores for gases and liquids, despite having the pores running parallel to the substrate surface.

In the present study, we show that mesoporous films with controlled thickness can be synthesized by growing monodispersed SBA-15 particles onto substrates. The effect of substrate functionalization, as well as the formation of the films, are investigated, and we show that it is possible to form mechanically stable films on large and rough surfaces. Functionalization of the films using co-condensation and the possibility to coat the films with a carbon layer through exposure of furfuryl alcohol vapor, forming CMK-5 [24], are investigated to study the variability of the films. To explore the accessibility of the pores, the film is tested as a catalyst for esterification of acetic acid and ethanol. The DiG-technique can be suitable for synthesizing mesoporous coatings for, e.g., catalysts, sensors, or medical implants.

\section{Materials and Methods}

\subsection{Reagents}

Hydrochloric acid ( $\geq 37 \%$, puriss. p.a., Fluka, ACS Reagent, fuming), triblock copolymer EO20PO70EO20 (P123) (Mn 5800, Aldrich, ammonium fluoride ( $\geq 98.0 \%$, puriss. p.a., ACS reagent, Fluka), tetraethyl orthosilicate (TEOS)(reagent grade, 98\%, Aldrich), heptane $(99 \%$, ReagentPlus ${ }^{\circledR}$, Sigma-Aldrich), (3-Mercaptopropyl)trimethoxysilane (MPTMS) (Aldrich), hydrogen peroxide ( $\geq 35 \%$ at RT, purum p.a., Sigma-Aldrich), octadecyltrichlorosilane (OTS) ( $\geq 90 \%$, Aldrich), chlorotrimethylsilane (TMCS) ( $\geq 99 \%$, Aldrich), (3-Aminopropyl)trimethoxysilane (APTMS) $(97 \%$, Aldrich), toluene ( $\geq 99.5 \%$, Sigma-Aldrich), nitric acid ( $\geq 64-66 \%$, Sigma-Aldrich), sulphuric acid (95.0-98.0\%, ACS Reagent, Sigma-Aldrich), glycerol ( $\geq 99.0 \%$, Sigma-Aldrich), acetone $(\geq 99.9 \%$, Sigma-Aldrich), 1,6-diisocynanatohexane (98\%, Aldrich), ethanol (95\%, Kemetyl), ethanol (99.5\%, Solveco), furfuryl alcohol (98\%, Aldrich), methanol (99.8\%, Sigma-Aldrich), and benzene (purity $\geq$ 99.7\%, Sigma-Aldrich)) were purchased from Sigma-Aldrich, Stockholm, Sweden, and used as received.

\subsection{Syntheses}

\subsubsection{Functionalization of Substrates}

OTS-functionalized Si wafers were used as substrates for the DiG films [23]. Prior to functionalization, organic contaminants on the substrates were removed from the surface with standard Radio Corporation of America (RCA) cleaning fluid $\left(\mathrm{H}_{2} \mathrm{O}: \mathrm{H}_{2} \mathrm{O}_{2}: \mathrm{NH}_{3}\right.$ in a volume ratio of 5:1:1 at $85^{\circ} \mathrm{C}$ for $10 \mathrm{~min}$ ), washed with water, and then treated with nitric acid at room temperature for $5 \mathrm{~min}$. The substrates were then washed with large amounts of water and dried with compressed $\mathrm{N}_{2}$ gas. The OTS was grafted onto the substrates by immersing them in a heptane solution with $1 \mathrm{mM}$ OTS at $18{ }^{\circ} \mathrm{C}$ for $15 \mathrm{~min}$. After the OTS treatment, the substrates were rinsed with heptane, dried at $200{ }^{\circ} \mathrm{C}$ for $2 \mathrm{~h}$, and stored in heptane until usage.

Details of the additional functionalization methods used are presented in the Supplementary Materials.

\subsubsection{Film Synthesis}

The films were grown following a modified protocol from Björk et al. [23]. In a typical synthesis, $2.4 \mathrm{~g}$ of $\mathrm{P} 123$ and a specific amount $(0-28 \mathrm{mg})$ of $\mathrm{NH}_{4} \mathrm{~F}$ were dissolved in $80 \mathrm{~mL}$ of $1.84 \mathrm{M} \mathrm{HCl}$ solution at $20^{\circ} \mathrm{C}$. The mixture was stirred in a round bottom flask until the reagents were dissolved. $5.5 \mathrm{~mL}$ of TEOS and $1 \mathrm{~mL}$ heptane were premixed and added to the micellar solution under stirring for $4 \mathrm{~min}$, followed by static conditions overnight. During this static time, substrates were immersed in the 
solution at specific time intervals, depending on the amount of $\mathrm{NH}_{4} \mathrm{~F}$ used. The substrates were transferred to a sealed polytetrafluorethylene (PTFE) flask, while still being submersed in the solution, and placed in an oven at $100{ }^{\circ} \mathrm{C}$ for $24 \mathrm{~h}$ for hydrothermal treatment. The products were collected by filtration, rinsed with deionized water, and dried at ambient temperature overnight. For template removal, both the films and powder were calcined in air at $550{ }^{\circ} \mathrm{C}$ for $5 \mathrm{~h}$ with a $2{ }^{\circ} \mathrm{C} / \mathrm{min}$ ramp rate. The materials are labelled SBA-15_X, where $X$ is the $\mathrm{NH}_{4} \mathrm{~F} / \mathrm{P} 123$ molar ratio.

\subsubsection{Direct Sulfonation (SBA-15-DS)}

Films with sulfonic acid groups were synthesized by adding MPTMS and $\mathrm{H}_{2} \mathrm{O}_{2}$ during the particle formation, following the protocol by Margolese et al. [25]. A double batch of SBA-15_0.0 was synthesized, and when the stirring was turned off, the solution was divided into six beakers. In five beakers, $0.17 \mathrm{~mL}$ of MPTMS and $0.27 \mathrm{~mL}$ of $\mathrm{H}_{2} \mathrm{O}_{2}$ were added to the synthesis solution at different times $(1-20 \mathrm{~h})$ after the TEOS addition. These materials are labelled SBA-15_0.0_YDS, where $Y$ corresponds to the hours between the addition of TEOS and MPTMS $+\mathrm{H}_{2} \mathrm{O}_{2}$. For these materials, the P123 was removed by ethanol extraction, as described in the Supplementary Materials.

\subsubsection{Carbon Infiltration and Sulfonation (SBA-15-CMK-5)}

To get an even distribution of carbon species in the films, the carbon infiltration was performed by exposing the silica films to furfuryl alcohol vapor. Calcined SBA-15_0.0 was exposed to alcohol vapor from furfuryl alcohol $(5 \mathrm{~mL})$ in a closed atmosphere at $40{ }^{\circ} \mathrm{C}$ overnight. The composites were then kept in a furnace at $100^{\circ} \mathrm{C}$ overnight to ensure an even distribution of furfuryl alcohol into the mesopores, and to polymerize the alcohol. The material was then transferred to a nitrogen purged tube furnace at $800^{\circ} \mathrm{C}$ for $1 \mathrm{~h}$. Pyrolysis of the polymer during the heat treatment resulted in a thin carbon layer on the mesoporous silica walls.

The carbon infiltrated SBA-15 was sulfonated according to previous reports [13,26]. Briefly, $0.5 \mathrm{~g}$ of SBA-15-CMK-5 was mixed with $25 \mathrm{~mL}$ of $\mathrm{H}_{2} \mathrm{SO}_{4}$ and heated to $80{ }^{\circ} \mathrm{C}$ under reflux overnight. After the reaction, the solution was cooled down to room temperature, rinsed with large amounts of deionized water, and collected by filtration. The SBA-15-CMK-5-SO3H was finally dried at $80{ }^{\circ} \mathrm{C}$ overnight.

\subsection{Characterization}

The material morphology was observed by scanning electron microscopy (SEM), using a Leo 1550 Gemini Scanning Electron Microscope (Zeiss) operated at $3 \mathrm{kV}$ and a working distance of 3-5 $\mathrm{mm}$. The pore characteristics were determined for all powders using $\mathrm{N}_{2}$ sorption with an ASAP2020 (Micromeritics) at $-196{ }^{\circ} \mathrm{C}$. The specific surface area was determined with the BET method at $P / P_{0}=0.8-0.18$, and the total pore volume was calculated at $P / P_{0}=0.98$. The pore size was calculated using the KJS method at the adsorption isotherms. Small angle x-ray diffraction (SAXRD) was used to identify the pore order. Diffractograms were recorded with an Empyrean diffractometer from, in transmission mode using $\mathrm{Cu}$ $\mathrm{K}_{\alpha}$ radiation (Malvern Panalytical). The pore structure was further visualized by transmission electron microscopy (TEM) performed with a Tecnai G2 TF 20 UT microscope operated at $200 \mathrm{kV}$ (FEI). TEM samples were prepared by dispersing the product in acetone and depositing it on hollow carbon grids.

The contact angle of the functionalized substrates was determined by contact angle measurements using a CAM 200 Optical Contact Angle Meter (KSV Instruments). The measurements were performed using a $2 \mu \mathrm{L}$ droplet of distilled water, which was placed in the middle of the substrate. Three independent measurements were conducted for each substrate.

Determination of sulfonic acid groups was performed using acid-base titration. For the silica-based samples, $0.10 \mathrm{~g}$ of the material was mixed with deionized water, followed by direct acid-base titration with a $0.005 \mathrm{M} \mathrm{NaOH}$ solution. For the SBA-15-CMK-5-SO3H, the catalyst was mixed with $30 \mathrm{~mL} 0.1 \mathrm{M} \mathrm{Na}_{2} \mathrm{SO}_{4}$ to react with the sulfonic groups, forming bisulfate, $4 \mathrm{~h}$ prior to the acid-base titration. The bisulfate reacted with the $\mathrm{NaOH}$, giving rise to the total amount of sulfonic 
acid groups. Other acid groups (carboxylic, phenolic, lactonic) are less acidic than sulphate, and do not create bisulfate upon exposure to sulphate ions [27]. The number of acidic groups was calculated as

$$
n_{\mathrm{ac}}=V_{\mathrm{NaOH}} \times[\mathrm{NaOH}]
$$

\subsection{Esterification Reaction}

The catalytic activity of an SBA-15-CMK-5-SO3H DiG film is shown in an esterification reaction with acetic acid and ethanol. In the reaction, $25 \mathrm{~mL}$ of ethanol and $10 \mathrm{~mL}$ of acetic acid was mixed and heated to $80^{\circ} \mathrm{C}$ under stirring in a closed beaker. A 4-inch silicon wafer coated with SBA-15_CMK-5_SO3H cut in pieces was added to the mixture. $1 \mathrm{~mL}$ aliquots were removed from the solution at specific time points and mixed with deionized water to terminate the reaction. The conversion of acetic acid was determined by titration with a $1 \mathrm{M} \mathrm{NaOH}$ solution, and the equivalence point was found using a pH electrode. The conversion was calculated using

$$
X(\%)=(\text { molHAcinitial }- \text { molHAcend }) / \text { molHAcinitial } \times 100
$$

As a reference, the reaction was also performed without the presence of a catalyst.

\section{Results}

\subsection{Film Growth}

Films were synthesized with various $\mathrm{NH}_{4} \mathrm{~F}$ concentrations in the solution. The particle sizes, both on the substrates and in the solution, as well as film thickness, were affected by the salt concentration, as seen in Figure 1. It was clear that densely packed films could be grown independent of the $\mathrm{NH}_{4} \mathrm{~F}$ concentration. The particle size, both on the substrate and in powder form, was affected by the salt concentration. The particles became narrower, from platelets (Figure 1e,f) to rods (Figure 1g,h), with an increasing $\mathrm{NH}_{4} \mathrm{~F}$ to $\mathrm{P} 123$ molar ratio. The particle narrowing was consistent with the results from Björk et al. [12], and was a result of the decreased solubility of the polyethylene oxide (PEO) chains of $\mathrm{P} 123$ when the $\mathrm{NH}_{4} \mathrm{~F}$ concentration increases. The TEM micrographs show cylindrical pores, ordered in a hexagonal structure, for all $\mathrm{NH}_{4} \mathrm{~F}$ concentration. The pore orientation supported that side-by-side attachment of the micelles causes the particle broadening.

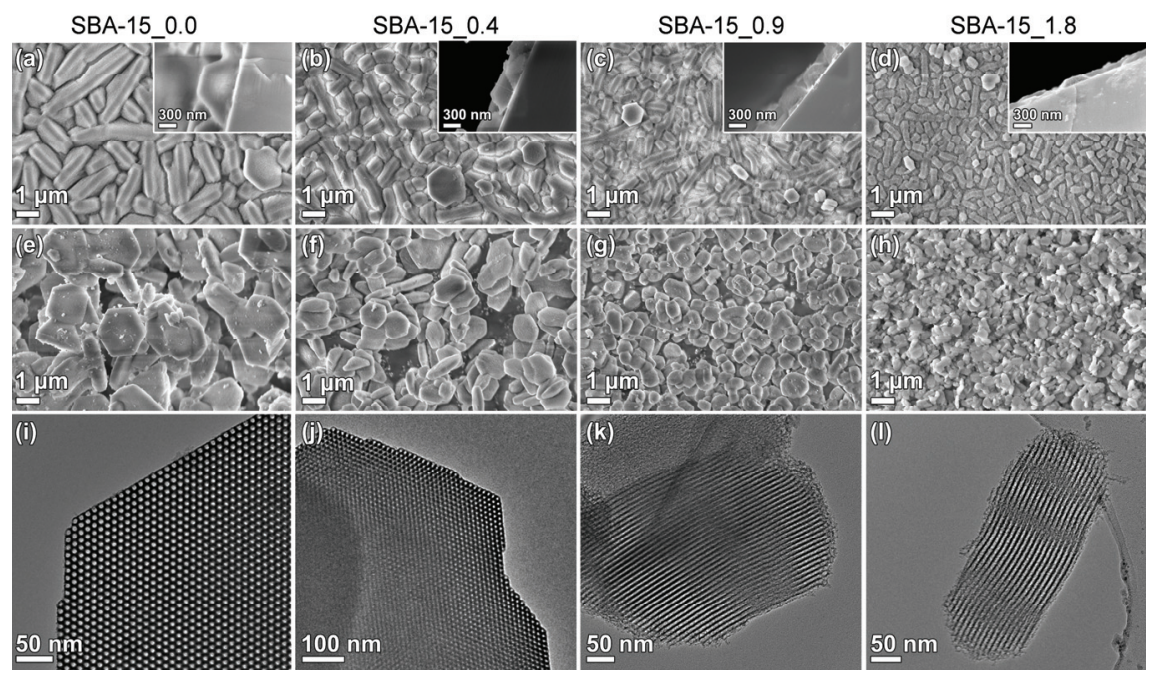

Figure 1. SEM micrographs of films (first row) and particles (second row), and TEM micrographs of particles (third row) synthesized with a $\mathrm{NH}_{4} \mathrm{~F}$ to P123 molar ratio of $(\mathbf{a}, \mathbf{e}, \mathbf{i})$ 0.0, (b,f,j) 0.4, (c, $\left.\mathbf{g}, \mathbf{k}\right)$ 0.9, and $(\mathbf{d}, \mathbf{h}, \mathbf{l}) 1.8$. 
The relation between the width of the film particles and the film thickness is presented in Figure 2. It is apparent that the film thickness and particle width follow the same trend, even though the film thickness is a factor of 2-3 times smaller than the particle width. Nitrogen sorption isotherms, SAXRD diffractograms, and the corresponding physicochemical properties of the SBA-15 powders from the film syntheses are available in the Supplementary Materials (Figure S1 and Table S1). These results show that the pores were cylindrical and $\sim 10 \mathrm{~nm}$ in diameter. The $\mathrm{x}$-ray diffractograms show three well-resolved peaks for all materials, confirming the hexagonal ordering of the pores.

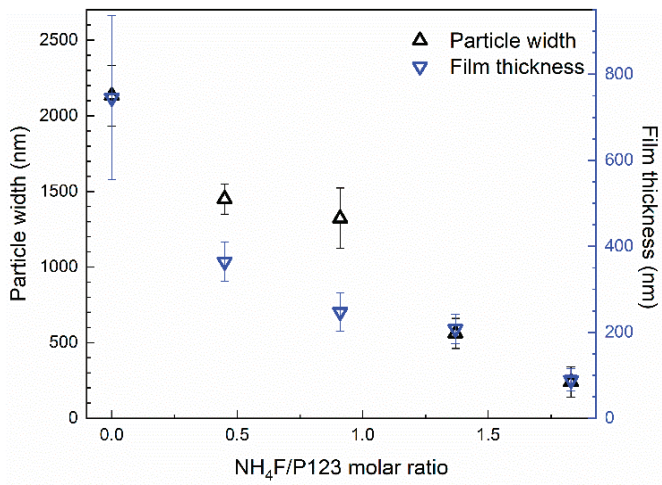

Figure 2. The relation between film thickness and particle width for different direct growth (DiG) films synthesized with various $\mathrm{NH}_{4} \mathrm{~F}$ to $\mathrm{P} 123$ molar ratios.

To study the mechanism for a successful film growth, substrates were added at different times, depending on the formation rate. It is well known that the formation rate of SBA-15 is affected by addition of $\mathrm{NH}_{4} \mathrm{~F}$, where higher concentrations of salt give a faster formation rate [12,28]. The substrate addition times yielding the desired film morphology and its correlation to the formation stages of the material are presented in Figure 3. The films were evaluated by SEM, and successful film growth is here defined as a homogenous layer of densely packed particles on the substrate, see the first row in Figure 1.

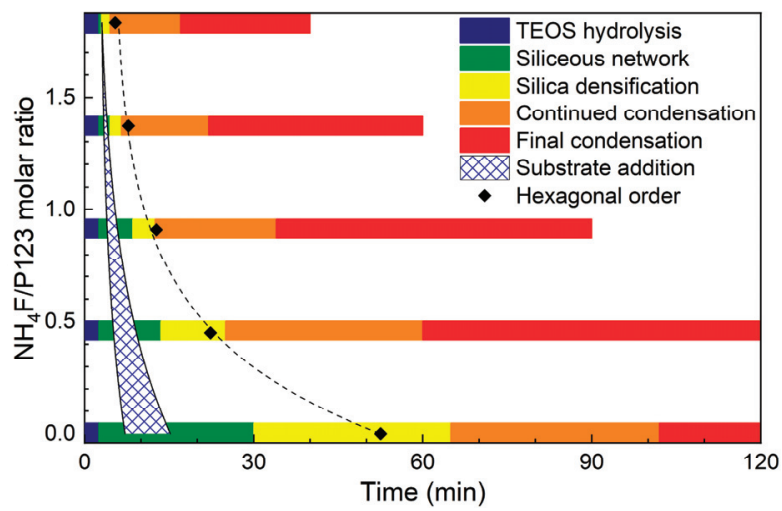

Figure 3. The window for substrate addition for a dense film growth and its correlation for material formation stages (Adapted from [28]).

\subsection{Surfactant Removal}

The choice of micelle removal technique can be used to tailor the material characteristics, e.g., pore size, silanol group concentration, or survival of co-condensed functional groups. Figure 4 . shows 
SBA-15_0.4 films where the surfactant was removed with various methods: calcination, ethanol extraction [9], $\mathrm{H}_{2} \mathrm{O}_{2}$ oxidation [11], and methanol sonication [29]. The removal techniques are presented in the Supplementary Materials. It is clear from Figure 4a,b,d that surfactant removal by calcination, ethanol extraction, and methanol sonication did not affect the film morphology. However, $\mathrm{H}_{2} \mathrm{O}_{2}$ oxidation (Figure $4 \mathrm{c}$ ) removed the particles from the substrate, resulting in a nearly naked substrate surface.
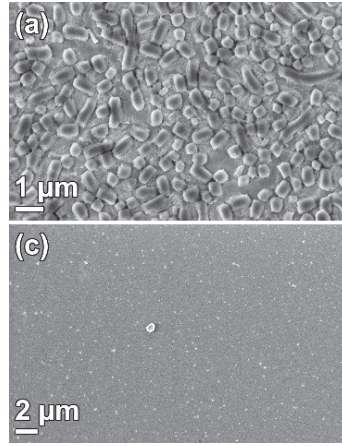
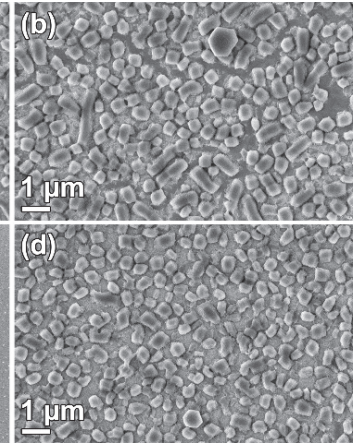

Figure 4. SEM micrographs of DiG_0.4 films where the surfactant was removed by (a) calcination, (b) ethanol extraction, (c) $\mathrm{H}_{2} \mathrm{O}_{2}$ oxidation, and (d) methanol sonication.

\subsection{Substrate Effects}

Several types of substrate functionalizations were used here to study the requirements for film growth. The methods for functionalization of silicon wafers with P123, sulfonic acid, thiol groups, amino groups, octadecyl groups, and methyl groups are presented in the Supplementary Materials. The contact angles for the films and SEM micrographs of the grown films are presented in Figure 5. No contact angle value is presented for the clean wafer with silanol groups, since it was so hydrophilic that no angle could be determined. As can be seen, dense DiG films (SBA-15_0.0) could only be grown on substrates functionalized with octadecyl or methyl groups (Figure $5 \mathrm{f}, \mathrm{g}$ ), which are the most hydrophobic substrates. The silanol and P123 functionalized substrates also held a number of small SBA-15 particles (Figure 5a,b), while the substrate with sulfonic acid, thiol, and amino groups mainly consisted of a tissue phase and some particles (Figure $5 c-e$ ).

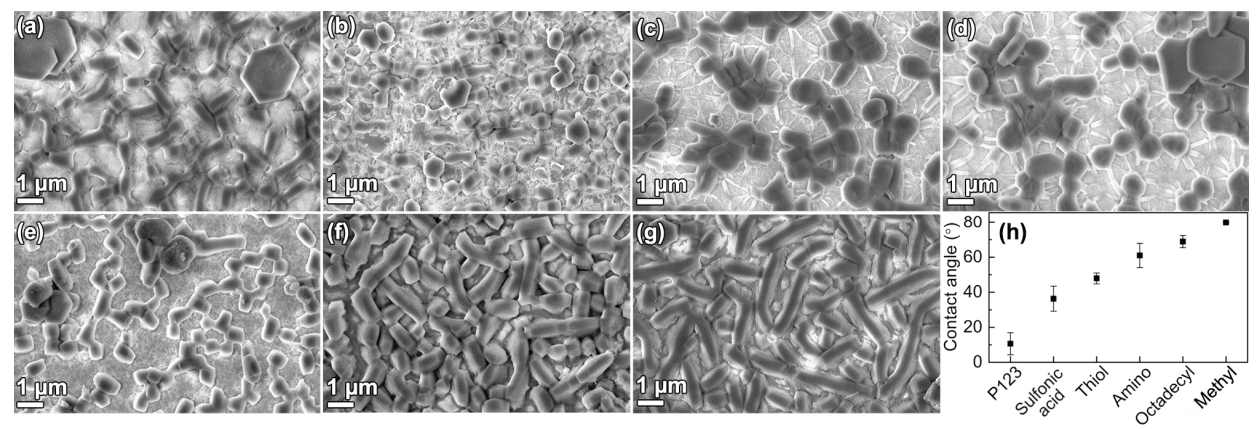

Figure 5. SEM micrographs of DiG_0.0 films grown onto substrates functionalized with (a) silanol groups (b) P123, (c) sulfonic acid, (d) thiol groups, (e) amino groups, (f) octadecyl groups, (g) methyl groups, and (h) the contact angle for the corresponding substrates.

Figure 6 shows that it was possible to grow films with the $\mathrm{DiG}$ method on rough and large area substrates. An SBA-15_0.0 film was grown on a silicon wafer that was blasted with alumina sand, 
creating a rough surface, prior to the OTS functionalization. Figure 6a shows a dense film coverage of the rough substrate surface, where particles are grown on all surfaces, independent of incline. Also, a full 4-inch silicon wafer was coated with SBA-15_0.0, resulting in a homogenous film across the substrate (Figure $6 \mathrm{~b}$ ). The substrate addition time for both syntheses was $16 \mathrm{~min}$ after TEOS addition.

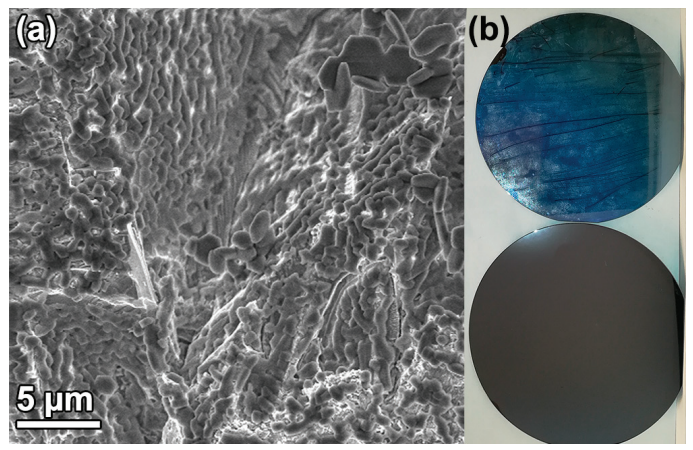

Figure 6. (a) SEM micrograph of a SBA-15_0.0 DiG film grown on a blasted substrate, and (b) a photograph of (top) a SBA-15_0.0coated and (bottom) clean 4 inch silicon wafer.

\subsection{Functionalization}

SBA-15_0.0 films were functionalized with sulfonic acid using MPTMS and $\mathrm{H}_{2} \mathrm{O}_{2}$ during a co-condensation process during the material formation. The SBA-15_0.0 synthesis was chosen since it has the lowest formation rate, and a mixture of MPTMS and $\mathrm{H}_{2} \mathrm{O}_{2}$ was added to the synthesis mixture after 1, 2, 4, and $20 \mathrm{~h}$ into the reaction. The morphology of the functionalized particles and films are shown in Figure 7 and it can be observed that the addition time affected the material characteristics. When the MPTMS $/ \mathrm{H}_{2} \mathrm{O}_{2}$ was added $1 \mathrm{~h}$ into the synthesis, the particles were small and aggregated resulting in inhomogeneous coverage of the substrate surface. The film consists of a tissue phase with sparsely attached particles (Figure $7 \mathrm{~b}$ ). When the reagents were added after $2 \mathrm{~h}$, the platelet morphology had started to form (Figure 7c), but the particles were narrower compared to the original SBA-15_0.0, and in addition, small spherical features coexisted. The corresponding films consisted of particles, but it was apparent that these were smaller and not as developed as the unfunctionalized films in Figure $1 \mathrm{a}$. When the MPTMS $/ \mathrm{H}_{2} \mathrm{O}_{2}$ was added after $4 \mathrm{~h}$, both the particle and film morphologies (Figure 7e,f) resembled the unfunctionalized materials. Finally, when the functionality was added after $20 \mathrm{~h}$, i.e., directly prior to the hydrothermal treatment, the particle morphology was unaffected, but the appearance of the films was fuzzy, as if the particles had been covered with an additional layer (Figure $7 \mathrm{~g}, \mathrm{~h}$ ).

The acidity and physicochemical properties of the materials are presented in Table 1 . Nitrogen sorption isotherms and small angle x-ray diffractograms are provided in the Supplementary Materials (Figure S2). The small angle x-ray diffractograms show three peaks, confirming a hexagonal order of the pores, also for the sulfonated materials. The less intense 110 and 200 peaks of SBA-15_1DS indicate a lower degree of order compared to when functionalization was performed later in the synthesis. The highest numbers of acidic groups were found in the materials functionalized after 1 and $4 \mathrm{~h}$ after the TEOS addition with $0.024 \mathrm{mmol} / \mathrm{g}$ and $0.020 \mathrm{mmol} / \mathrm{g}$, respectively, compared to $0.003 \mathrm{mmol} / \mathrm{g}$ without functionalization. The addition of the reagents after $2 \mathrm{~h}$ and prior to the hydrothermal treatment had a negligible effect on the acidity of the materials compared to unfunctionalized SBA-15_0.0. It should be noted that the acidity was only measured on the powder materials, due to the small material amount on the substrates. 

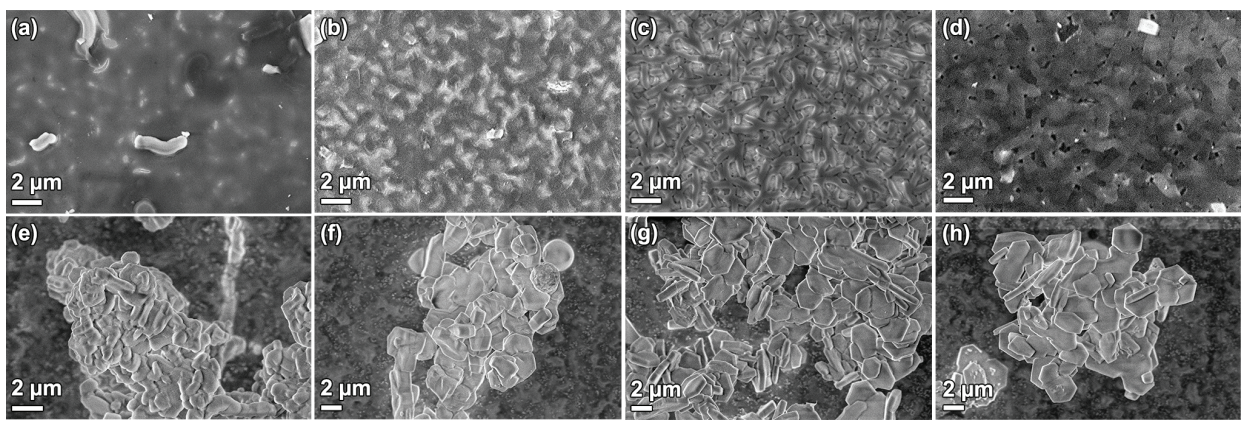

Figure 7. SEM micrographs of SBA-15_0.0 films (first row) and particles (second row) functionalized by co-condensation (a,e) 1 h, (b,f) 2 h, (c,g) 4 h, and (d,h) $20 \mathrm{~h}$ after the addition of TEOS.

Table 1. Physiochemical properties and acidity of the functionalized materials.

\begin{tabular}{|c|c|c|c|c|c|}
\hline Material & $\begin{array}{c}\text { Specific } \\
\text { Surface Area } \\
\left(\mathrm{m}^{2} / \mathrm{g}\right)\end{array}$ & $\begin{array}{l}\text { Pore Size } \\
\text { (nm) }\end{array}$ & $\begin{array}{c}\text { Pore } \\
\text { Volume } \\
\left(\mathrm{cm}^{3} / \mathrm{g}\right)\end{array}$ & $\begin{array}{c}\text { Unit Cell } \\
\text { Parameter } \\
\text { (nm) }\end{array}$ & $\begin{array}{c}\text { Acidic Sites } \\
\text { (mmol/g) }\end{array}$ \\
\hline SBA-15_0.0_no DS ${ }^{a}$ & 920 & 11.2 & 1.19 & 13.6 & 0.003 \\
\hline SBA-15_0.0_1DS & 948 & 8.9 & 1.10 & 11.2 & 0.024 \\
\hline SBA-15_0.0_2DS & 898 & 10.2 & 1.11 & 12.6 & 0.009 \\
\hline SBA-15_0.0_4DS & 870 & 10.4 & 1.07 & 13.6 & 0.020 \\
\hline SBA-15_0.0_20DS & 951 & 11.3 & 1.22 & 14.1 & 0.008 \\
\hline SBA-15_0.0_carbon temp ${ }^{b}$ & 697 & 9.8 & 0.86 & 12.9 & - \\
\hline SBA-15_0.0_CMK-5 & 521 & 9.4 & 0.68 & 12.4 & - \\
\hline SBA-15_0.0_CMK-5_SO3H & 462 & 9.3 & 0.63 & 12.5 & 0.191 \\
\hline
\end{tabular}

a Reference SBA-15_0.0 from the same batch as the directly sulfonated materials. ${ }^{\mathrm{b}}$ SBA-15_0.0 template for the carbon infiltration.

To study the versatility of the DiG films, an SBA-15_0.0 film was functionalized with a thin carbon layer on the pore walls, similar to CMK-5 [24]. To form the carbon layer, the films were exposed to furfuryl alcohol vapor, instead of the commonly used induced incipient wetness impregnation, since the incipient wetness technique yielded carbon aggregates on the film surface (data not shown). As can be seen in Figure 8a, the film morphology was kept during the carbonization process. However, the unit cell was shrinking during the carbonization, most probably due to densification at $800^{\circ} \mathrm{C}$. Nitrogen adsorption (Figure 8b) indicated that the carbon infiltration resulted in a $2 \AA$ thick coating, seen as a reduced surface area and pore size compared to the parent SBA-15_0.0, see Table 1. The silica/carbon film was further functionalized by exposure to $\mathrm{H}_{2} \mathrm{SO}_{4}$, which resulted in a $0.191 \mathrm{mmol} / \mathrm{g}$ of sulfonic acid sites.
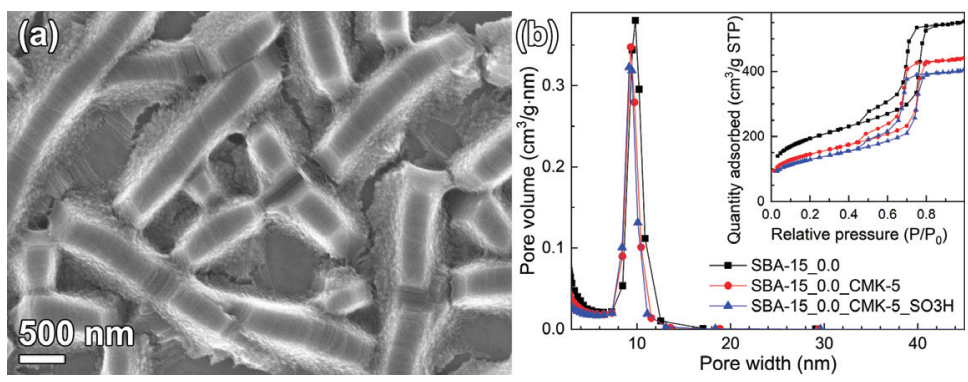

Figure 8. SEM micrograph of (a) SBA-15_0.0_CMK-5, and (b) pore size distributions and physisorption isotherms of SBA-15_0.0, SBA-15_0.0_CMK-5, and SBA-15_0.0_CMK-5_SO3H. 


\subsection{Catalytic Performance}

To confirm the success of carbon infiltration and functionalization, a $100 \mathrm{~mm}$ silicon wafer coated with an SBA-15_CMK-5_SO3H DiG film was prepared. This model system was then tested as a catalyst for esterification of acetic acid and ethanol. The conversion of acetic acid with and without a catalyst is presented in Figure 9. When the film was used as a catalyst, nearly $30 \%$ of the acetic acid was converted within one hour, which was a significant increase compared to the $\sim 5 \%$ conversion when no catalyst was used.

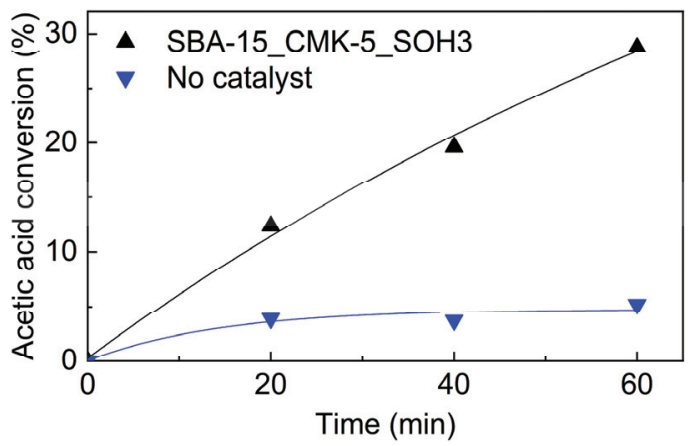

Figure 9. Conversion of acetic acid in the esterification reaction with ethanol at $80^{\circ} \mathrm{C}$, with and without a DiG film catalyst.

The catalytic reaction was repeated with a new solution after cleaning the catalyst with water and ethanol. An acetic acid conversion of $11.5 \%$ was obtained in the second cycle. The morphologies of the used films are shown in Figure 10. A majority of the film was intact, except for some areas where particles are removed.
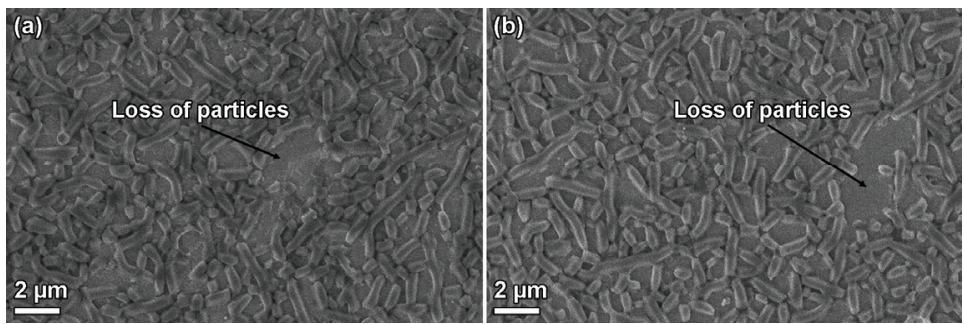

Figure 10. SEM micrographs of SBA-15_0.0_CMK-5_SO3H after (a) one cycle and (b) two cycles in the esterification reaction.

\section{Discussion}

\subsection{Film Formation}

This work shows that it is possible to synthesize DiG films with various thicknesses, which is of interest from an application view point, especially since the films are formed as separate particles with easily accessible pores, also close to the substrate. It has previously been shown that $\mathrm{NH}_{4} \mathrm{~F}$ can be used to control the morphology of SBA-15 particles [10,12], and it is apparent from Figure 2 that the film thickness is correlated to the particle width when the salt concentration is altered. This shows that the films are affected by the solution conditions in the same ways as the particles, indicating a similar formation mechanism. 
The data shows that film growth occurs when the substrates are added to the synthesis solution during the formation of the siliceous network (Figure 3). At this stage, the micelles are still spherical and the hexagonal ordering has not yet started [28]. This indicates that the films are formed by the condensation of silica species directly on the substrate, and not formed by the deposition of pre-synthesized particles. This is further corroborated by the cross-section images of the films in Figure 1.

It is clear from Figure 5 that proper substrate functionalization is needed to achieve the desired DiG film growth. The densest films are synthesized on hydrophobic substrates, functionalized with octadecyl or methyl groups, while the more hydrophilic substrates show no or poor films consisting of sparsely spaced particles in a tissue phase (Figure $5 \mathrm{c}-\mathrm{e}$ ). Mesoscopic simulations have shown that P123 can form hemispherical structures on hydrophobic surfaces [30]. These structures, where the hydrophobic core is in contact with the substrate, and the PEO brushes are directed towards the aqueous solution, can act as nucleation sites for growth of the film, resulting in a dense packing of particles (Figure 5f,g). Liu et al. showed that non-ionic triblock copolymers (P105) can coat hydrophobic surfaces, while micellar structures can adsorb on a hydrophilic surface [31], which is in good agreement with the simulations. The particle growth on the hydrophilic substrates with silanol groups or P123 (Figure 5a,b) can be the result of adsorbed micelles bound to the substrate through silica polymerization.

The stability of the films is shown in the surfactant removal section and also through the catalytic reaction. It is apparent that the films can sustain calcination at $550{ }^{\circ} \mathrm{C}$, ethanol extraction for $24 \mathrm{~h}$ at $78^{\circ} \mathrm{C}$, or ultrasound sonication in methanol at least $5 \mathrm{~min}$, confirming that the particles adhere well to the substrates. During the catalytic reaction, the films were submerged in a stirred, aqueous solution for $1 \mathrm{~h}$ per cycle. During the first cycle, some particles detaches from the substrate, although the vast majority of the film remains intact. The loss of particles suggests variation in adhesion among the particles, perhaps due to contaminants present at the particle/substrate interface causing incomplete attachment of the half hexagon prism to the substrate. The possibility to use various surfactant removal techniques enables functionalization through co-condensation, as the functional groups can be removed upon calcination. It also allows post-functionalization since the ethanol extraction yields more silanol groups after micelle removal [32]. $\mathrm{H}_{2} \mathrm{O}_{2}$ oxidation has been shown to be an efficient method for removing P123 and other organic groups from SBA-15 [11,33]. It also removes the DiG film from the substrate. The reason for this can be decomposition of the functional organic layer between the film particles and the substrate.

\subsection{Functionalization}

During the direct sulfonation of SBA-15, it is apparent that the addition time of the MPTMS + $\mathrm{H}_{2} \mathrm{O}_{2}$ strongly affects both the morphology and acidity of the final material, as seen in Figure 7 and Table 1. For SBA-15_0.0, the optimum addition time is $4 \mathrm{~h}$, which yields a material with relatively high acidity and the desired morphology of both films and particles. Adding the reagents as early as $1 \mathrm{~h}$ into the synthesis strongly affects the particle formation, and small aggregated particles are formed, while an addition time of $2 \mathrm{~h}$ yields a narrower platelet morphology compared to the non-functionalized material. This is most likely due to the fact that the particles at these time points are not completely formed [28]. During the co-condensation of MPTMS, MPTMS will condense on the silanol groups in the siliceous network [34] and hinder further silica condensation at these sites. One hour into the reaction, the siliceous network is forming, but the hexagonal ordering of the micelles has not started. At this time point, particle formation is governed by the addition of MPTMS silica species. When the MPTMS $+\mathrm{H}_{2} \mathrm{O}_{2}$ is added after $2 \mathrm{~h}$, the hexagonal framework has formed, but the particles are still growing through side-by-side attachment of the silicated micelles. The MPTMS attaches to the surface silanols of the silica, and therefore locks the surface from further condensation, resulting in narrower platelets. When the MPTMS $+\mathrm{H}_{2} \mathrm{O}_{2}$ is added after $4 \mathrm{~h}$ or directly prior to the hydrothermal treatment, the particle morphology is already set, and no alteration is visible in the SEM micrographs 
(Figure 7e,g). However, the acidity of these samples is different, which is likely related to the silica condensation also progressing after $4 \mathrm{~h}$ [28]. Such condensation enables larger amounts of hydrolysed MPTMS to bind to the silica particles, compared to when the condensation of particles is completed. This is in good agreement to the results by Nassor et al. [35], who showed that it is easy to wash away the MPTMS when it is added at a late stage of the synthesis.

The difference in physicochemical properties of SBA_0.0_no DS and SBA-15_0.0_carbon templates is due to the different methods for removal of the micelles, which were ethanol extraction and calcination, respectively. No external carbon features were detected when the furfuryl alcohol vapor method was used to coat the SBA-15 (Figure 8a). This method yielded a $2 \AA$ thick carbon layer in the mesopores after carbonization (Table 1), without generating additional plugs in the pores (Figure $8 b$ ). Hence, the method of using furfuryl alcohol vapor to form CMK-5 structures in mesoporous SBA-15 films shows promising results, which also broadens the application range of DiG films.

\subsection{Catalytic Performance}

Introducing sulfonic acid groups in the mesoporous films result in a substantial increase in the catalytic performance of the film. A conversion of $\sim 5 \%$ of acetic acid during 1 hour of reaction, when no sulfonic acid groups are present, is in good agreement with other studies [13]. This value is boosted by a factor of approximately 6 times when sulfonic acid groups are present in the pores. The results confirm that the mesoporous silica DiG films are successfully coated with carbon using the evaporation technique and that the pores are accessible for both functionalization and catalytic reactions.

SEM micrographs of the used catalyst show that the film is intact after $1 \mathrm{~h}$ of reaction, except for a minor particle loss. It is well known that silica dissolves in water, and this reaction may result in loss of particles that have formed with defects towards the substrate. There is no observable additional particle loss after the second reaction cycle, indicating that the remaining particles are well-adhered to the substrate. The catalytic activity decreases after the first reaction cycle. Other studies of esterification reactions using sulfonated carbon catalysts show a similar trend [36,37], and the reduction can be attributed to loss of active sites of the catalyst, either by desorption of sulfonic groups [37], or formation of sulfonic esters on the catalyst surface [38].

\section{Conclusions}

We have shown that monodispersed SBA-15 particles with various aspect ratios can be grown onto silicon wafers using the DiG method. The film thickness follows the particle width and can be tuned between $80 \mathrm{~nm}$ and $750 \mathrm{~nm}$ by changing the $\mathrm{NH}_{4} \mathrm{~F}$ concentration in the synthesis solution. The addition of salt affects the material formation rate, and therefore the substrate addition time must be adjusted so that the substrates are added during the formation of the siliceous network. It has been concluded that hydrophobic substrates are required for a dense film growth, but that substrates with surface silanols or P123 can bond smaller particles to the surface. The film growth is consistent over surfaces larger than $75 \mathrm{~cm}^{2}$, and it is possible to coat rough substrates.

We have also shown that the films can be functionalized by co-condensation of MPTMS $+\mathrm{H}_{2} \mathrm{O}_{2}$, but the addition time of the functional reagents must be adjusted so as to not affect the film morphology. The reagents must be added after the formation of the hexagonal order, during the final condensation, to yield a material with high acidity and accessible pores. A CMK- 5 structure can also be formed in the films after exposure to furfuryl alcohol vapor. The sulfonated version of the CMK-5 film was shown to work as an efficient catalyst in the esterification reaction of acetic acid and ethanol, showing the accessibility to the pore system, even though the pores are perpendicular to the substrate, due to the separation of the grown particles. The film is stable upon the catalytic reaction, with only a minor loss of particles. Recycling experiments show, however, reduced catalytic activity after the first cycle. As an outlook, one can imagine DiG film growth on other substrates than Si-wafers, e.g. glass or titanium, and utilizing these films as catalyst hosts or drug carrying coatings for implants. 
Supplementary Materials: The following are available online at http://www.mdpi.com/2079-4991/9/4/562/s1, Methods for substrate functionalization, methods for surfactant removal, Figure S1: Pore size distributions, physisorption isotherms, and small angle x-ray diffractograms for materials synthesized with NH4F/P123 molar ratios of $0.0-1.8$, Figure S2: Pore size distributions, physisorption isotherms, and small angle x-ray diffractograms for direct sulfonated SBA_0.0s, Table S1: Physiochemical properties and acidity of materials synthesized with $\mathrm{NH} 4 \mathrm{~F} / \mathrm{P} 123$ molar ratios of $0.0-1.83$.

Author Contributions: The individual contributions by the authors are: conceptualization, E.M.B. and P.M.; validation, P.-H.W.; investigation, P.-H.W.; resources, M.O.; writing-original draft preparation, P.-H.W., E.M.B.; writing - review and editing, P.M. and M.O.; supervision, E.M.B. and P.M.; funding acquisition, E.M.B. and M.O.

Funding: This research was funded by the Swedish research council (VR), grant number 2015-00624, the Swedish Energy Agency (grant no P42022-1), Vinnova (FunMat-II project grant no. 2016-05156), the Swedish Government Strategic Research Area in Materials Science on Functional Materials at Linköping University (Faculty Grant SFO-Mat-LiU grant no 2009-00971), and Knut and Alice Wallenberg Foundation, grant number KAW 2012.0083.

Acknowledgments: Rickard Melin at Ionbond Sweden AB is acknowledged for the support in blasting silicon wafers.

Conflicts of Interest: The authors declare no conflict of interest.

\section{References}

1. Walcarius, A. Silica-Based Electrochemical Sensors and Biosensors: Recent Trends. Curr. Opin. Electrochem. 2018, 10, 88-97. [CrossRef]

2. Wagner, T.; Haffer, S.; Weinberger, C.; Klaus, D.; Tiemann, M. Mesoporous Materials as Gas Sensors. Chem. Soc. Rev. 2013, 42, 4036-4053. [CrossRef]

3. Innocenzi, P.; Malfatti, L. Mesoporous Thin Films: Properties and Applications. Chem. Soc. Rev. 2013, 42, 4198-4216. [CrossRef] [PubMed]

4. Mutschler, A.; Stock, V.; Ebert, L.; Björk, E.M.; Leopold, K.; Lindén, M. Mesoporous silica-gold films for straightforward, highly reproducible trace-level monitoring of mercury traces in water. Nanomaterials 2019, 9, 35. [CrossRef] [PubMed]

5. Wiltschka, O.; Scheitenberger, P.; Lindén, M. Control of Particle Uptake Kinetics from Particulate Mesoporous Silica Films by Cells through Covalent Linking of Particles to the Substrate - Towards Sequential Drug Delivery for Tissue Engineering Applications. J. Mater. Chem. B 2016, 4, 7669-7675. [CrossRef]

6. Ehlert, N.; Mueller, P.P.; Stieve, M.; Lenarz, T.; Behrens, P. Mesoporous Silica Films as a Novel Biomaterial: Applications in the Middle Ear. Chem. Soc. Rev. 2013, 42, 3847-3861. [CrossRef] [PubMed]

7. Cauda, V.; Mühlstein, L.; Onida, B.; Bein, T. Tuning Drug Uptake and Release Rates through Different Morphologies and Pore Diameters of Confined Mesoporous Silica. Microporous Mesoporous Mater. 2009, 118, 435-442. [CrossRef]

8. Song, S.; Liang, Y.; Li, Z.; Wang, Y.; Fu, R.; Wu, D.; Tsiakaras, P. Effect of Pore Morphology of Mesoporous Carbons on the Electrocatalytic Activity of Pt Nanoparticles for Fuel Cell Reactions. Appl. Catal. B Environ. 2010, 98, 132-137. [CrossRef]

9. Zhao, D.; Feng, J.; Huo, Q.; Melosh, N.; Fredrickson, G.H.; Chmelka, B.F.; Stucky, G.D. Triblock Copolymer Syntheses of Mesoporous Silica with Periodic 50 to 300 Angstrom Pores. Science 1998, 279, 548-552. [CrossRef] [PubMed]

10. Cao, L.; Kruk, M. Facile Method to Synthesize Platelet Sba-15 Silica with Highly Ordered Large Mesopores. J. Colloid Interface Sci. 2011, 361, 472-476. [CrossRef]

11. Johansson, E.M.; Cordoba, J.M.; Oden, M. The Effects on Pore Size and Particle Morphology of Heptane Additions to the Synthesis of Mesoporous Silica Sba-15. Microporous Mesoporous Mater. 2010, 133, 66-74. [CrossRef]

12. Björk, E.M.; Söderlind, F.; Odén, M. Tuning the Shape of Mesoporous Silica Particles by Alterations in Parameter Space: From Rods to Platelets. Langmuir 2013, 29, 13551-13561. [CrossRef] [PubMed]

13. Björk, E.M.; Militello, M.P.; Tamborini, L.H.; Coneo Rodriguez, R.; Planes, G.A.; Acevedo, D.F.; Moreno, M.S.; Odén, M.; Barbero, C.A. Mesoporous Silica and Carbon Based Catalysts for Esterification and Biodiesel Fabrication-the Effect of Matrix Surface Composition and Porosity. Appl. Catal. A Gen. 2017, 533, 49-58. [CrossRef] 
14. Pirez, C.; Caderon, J.-M.; Dacquin, J.-P.; Lee, A.F.; Wilson, K. Tunable Kit-6 Mesoporous Sulfonic Acid Catalysts for Fatty Acid Esterification. ACS Catal. 2012, 2, 1607-1614. [CrossRef]

15. Gustafsson, H.; Johansson, E.M.; Barrabino, A.; Odén, M.; Holmberg, K. Immobilization of Lipase from Mucor Miehei and Rhizopus Oryzae into Mesoporous Silica-The Effect of Varied Particle Size and Morphology. Colloids Surf. B Biointerfaces 2012, 100, 22-30. [CrossRef] [PubMed]

16. Zhu, Y.; Li, H.; Zheng, Q.; Xu, J.; Li, X. Amine-Functionalized Sba-15 with Uniform Morphology and Well-Defined Mesostructure for Highly Sensitive Chemosensors to Detect Formaldehyde Vapor. Langmuir 2012, 28, 7843-7850. [CrossRef]

17. Grosso, D.; Cagnol, F.; Soler-Illia, G.J.A.A.; Crepaldi, E.L.; Amenitsch, H.; Brunet-Bruneau, A.; Bourgeois, A.; Sanchez, C. Fundamentals of Mesostructuring through Evaporation-Induced Self-Assembly. Adv. Funct. Mater. 2004, 14, 309-322. [CrossRef]

18. Brinker, C.J.; Lu, Y.; Sellinger, A.; Fan, H. Evaporation-Induced Self-Assembly: Nanostructures Made Easy. Adv. Mater. 1999, 11, 579-585. [CrossRef]

19. Bottein, T.; Loizillon, J.; Grosso, D. Full Investigation of Angle Dependence in Dip-Coating Sol-Gel Films. J. Phys. Chem. B 2017, 121, 6220-6225. [CrossRef] [PubMed]

20. Dunphy, D.R.; Sheth, P.H.; Garcia, F.L.; Brinker, C.J. Enlarged Pore Size in Mesoporous Silica Films Templated by Pluronic F127: Use of Poloxamer Mixtures and Increased Template/Sio2 Ratios in Materials Synthesized by Evaporation-Induced Self-Assembly. Chem. Mater. 2015, 27, 75-84. [CrossRef]

21. Wiltschka, O.; Böcking, D.; Miller, L.; Brenner, R.E.; Sahlgren, C.; Lindén, M. Preparation, Characterization, and Preliminary Biocompatibility Evaluation of Particulate Spin-Coated Mesoporous Silica Films. Microporous Mesoporous Mater. 2014, 188, 203-209. [CrossRef]

22. Znamenskaya Falk, Y.; Schmitt, J.; Alfredsson, V. Langmuir-Blodgett Monolayers of SBA-15 Particles with Different Morphologies. Microporous Mesoporous Mater. 2018, 256, 32-38. [CrossRef]

23. Björk, E.M.; Söderlind, F.; Odén, M. Single-Pot Synthesis of Ordered Mesoporous Silica Films with Unique Controllable Morphology. J. Colloid Interface Sci. 2014, 413, 1-7. [CrossRef]

24. Kruk, M.; Jaroniec, M.; Kim, T.W.; Ryoo, R. Synthesis and Characterization of Hexagonally Ordered Carbon Nanopipes. Chem. Mater. 2003, 15, 2815-2823. [CrossRef]

25. Margolese, D.; Melero, J.A.; Christiansen, S.C.; Chmelka, B.F.; Stucky, G.D. Direct Syntheses of Ordered SBA-15 Mesoporous Silica Containing Sulfonic Acid Groups. Chem. Mater. 2000, 12, 2448-2459. [CrossRef]

26. Aldana-Pérez, A.; Lartundo-Rojas, L.; Gómez, R.; Niño-Gómez, M.E. Sulfonic Groups Anchored on Mesoporous Carbon Starbons-300 and Its Use for the Esterification of Oleic Acid. Fuel 2012, 100, 128-138. [CrossRef]

27. Tamborini, L.H.; Militello, M.P.; Balach, J.; Moyano, J.M.; Barbero, C.A.; Acevedo, D.F. Application of Sulfonated Nanoporous Carbons as Acid Catalysts for Fischer Esterification Reactions. Arabian J. Chem. 2015. [CrossRef]

28. Björk, E.M.; Mäkie, P.; Rogström, L.; Atakan, A.; Schell, N.; Odén, M. Formation of Block-Copolymer-Templated Mesoporous Silica. J. Colloid Interface Sci. 2018, 521, 183-189. [CrossRef]

29. Pirez, C.; Wilson, K.; Lee, A.F. An Energy-Efficient Route to the Rapid Synthesis of Organically-Modified SBA-15 Via Ultrasonic Template Removal. Green Chem. 2014, 16, 197-202. [CrossRef]

30. Song, X.; Zhao, S.; Fang, S.; Ma, Y.; Duan, M. Mesoscopic Simulations of Adsorption and Association of PEO-PPO-PEO Triblock Copolymers on a Hydrophobic Surface: From Mushroom Hemisphere to Rectangle Brush. Langmuir 2016, 32, 11375-11385. [CrossRef]

31. Liu, X.; Wu, D.; Turgman-Cohen, S.; Genzer, J.; Theyson, T.W.; Rojas, O.J. Adsorption of a Nonionic Symmetric Triblock Copolymer on Surfaces with Different Hydrophobicity. Langmuir 2010, 26, 9565-9574. [CrossRef]

32. Bae, Y.K.; Hee Han, O. Removal of Copolymer Template from SBA-15 Studied by 1 h MAS NMR. Microporous Mesoporous Mater. 2007, 106, 304-307.

33. Kecht, J.; Bein, T. Oxidative Removal of Template Molecules and Organic Functionalities in Mesoporous Silica Nanoparticles by $\mathrm{H}_{2} \mathrm{O}_{2}$ Treatment. Microporous Mesoporous Mater. 2008, 116, 123-130. [CrossRef]

34. Wu, J.; Ling, L.; Xie, J.; Ma, G.; Wang, B. Surface Modification of Nanosilica with 3-Mercaptopropyl Trimethoxysilane: Experimental and Theoretical Study on the Surface Interaction. Chem. Phys. Lett. 2014, 591, 227-232. [CrossRef]

35. Nassor, E.C.O.; Ávila, L.R.; Pereira, P.F.S.; Ciuffi, K.J.; Calefi, P.S.; Nassar, E.J. Influence of the Hydrolysis and Condensation Time on the Preparation of Hybrid Materials. Mater. Res. 2011, 14, 1-6. [CrossRef] 
36. Tamborini, L.H.; Casco, M.E.; Militello, M.P.; Silvestre-Albero, J.; Barbero, C.A.; Acevedo, D.F. Sulfonated Porous Carbon Catalysts for Biodiesel Production: Clear Effect of the Carbon Particle Size on the Catalyst Synthesis and Properties. Fuel Process. Technol. 2016, 149, 209-217. [CrossRef]

37. Rocha, R.P.; Pereira, M.F.R.; Figueiredo, J.L. Carbon as a Catalyst: Esterification of Acetic Acid with Ethanol. Catal. Today 2013, 218-219, 51-56. [CrossRef]

38. Fraile, J.M.; García-Bordejé, E.; Roldán, L. Deactivation of Sulfonated Hydrothermal Carbons in the Presence of Alcohols: Evidences for Sulfonic Esters Formation. J. Catal. 2012, 289, 73-79. [CrossRef]

(C) 2019 by the authors. Licensee MDPI, Basel, Switzerland. This article is an open access article distributed under the terms and conditions of the Creative Commons Attribution (CC BY) license (http:/ / creativecommons.org/licenses/by/4.0/). 
Article

\title{
Straightforward Immobilization of Phosphonic Acids and Phosphoric Acid Esters on Mesoporous Silica and Their Application in an Asymmetric Aldol Reaction
}

\author{
Christian Weinberger, Tatjana Heckel, Patrick Schnippering, Markus Schmitz, Anpeng Guo, \\ Waldemar Keil, Heinrich C. Marsmann, Claudia Schmidt *, Michael Tiemann * and \\ René Wilhelm*

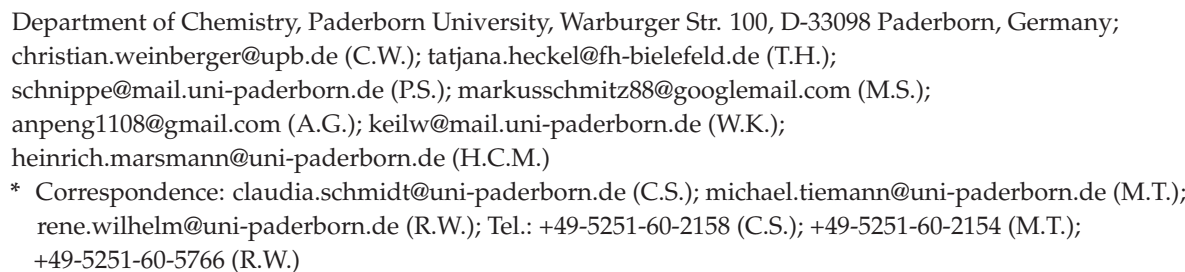

Received: 31 December 2018; Accepted: 4 February 2019; Published: 12 February 2019

\begin{abstract}
The combined benefits of moisture-stable phosphonic acids and mesoporous silica materials (SBA-15 and MCM-41) as large-surface-area solid supports offer new opportunities for several applications, such as catalysis or drug delivery. We present a comprehensive study of a straightforward synthesis method via direct immobilization of several phosphonic acids and phosphoric acid esters on various mesoporous silicas in a Dean-Stark apparatus with toluene as the solvent. Due to the utilization of azeotropic distillation, there was no need to dry phosphonic acids, phosphoric acid esters, solvents, or silicas prior to synthesis. In addition to modeling phosphonic acids, immobilization of the important biomolecule adenosine monophosphate (AMP) on the porous supports was also investigated. Due to the high surface area of the mesoporous silicas, a possible catalytic application based on immobilization of an organocatalyst for an asymmetric aldol reaction is discussed.
\end{abstract}

Keywords: mesoporous silica; organocatalysis; host-guest materials; magic-angle spinning NMR (MAS-NMR)

\section{Introduction}

Ordered mesoporous silica $\left(\mathrm{SiO}_{2}\right)$ materials, such as SBA-15 [1] or MCM-41 [2], are frequently used as support matrices for a large variety of organic functional groups [3]. They are synthesized via sol-gel chemistry-based methods, employing self-assembled arrays of amphiphilic species as porogenic structure directors. The pore sizes can by tuned using various synthesis parameters, such as choice of porogen, utilization of swelling agents, or variation of the reaction temperature. The resulting uniform pore widths typically range from $2 \mathrm{~nm}$ to $10 \mathrm{~nm}$, with specific surface areas up to ca. $1000 \mathrm{~m}^{2} \cdot \mathrm{g}^{-1}$. The pore walls exhibit free silanol groups $(\mathrm{Si}-\mathrm{OH})$ that may serve for functionalization with organic moieties. Functionalized mesoporous materials have high potential in fields such as drug delivery [4-6], separation [7,8], sensing [9], nanotechnology [10], or heterogeneous catalysis [11-14]. In the latter case, the defined pore diameters allow control over the selectivity of a reaction [15]. In addition, pure silica can also be applied as a catalyst without functionalization [16].

Post-synthetic grafting of linker groups onto the surface of (porous) silica is one of the most frequently employed techniques [3]. The most applied linker moieties are trialkoxylsilane compounds 
that are linked to $\mathrm{SiO}_{2}$ under the release of alcohol [17] or chlorosilanes that form a covalent bond with $\mathrm{SiO}_{2}$ under the release of $\mathrm{HCl}$ [18]. Yet, these linker precursors have some drawbacks, such as instability toward moisture. Phosphonic acids, on the other hand, are moisture-stable and easy to handle. They are currently standard linkers for various oxidic support materials $[19,20]$. However, for $\mathrm{SiO}_{2}$, just a few complicated procedures of creating covalent bonds with the surface were reported, including adsorption of phosphonic acids via hydrogen bonding, followed by annealing at $120-140{ }^{\circ} \mathrm{C}$ for several hours [20-25]. In one example, phosphorus acid analogs were attached to a commercial silica gel for chromatography; however, the silica gel needed to be dried extensively prior to use [26]. In addition, phosphonic acids ere attached to fumed silica in anhydrous acetonitrile under $\mathrm{N}_{2}$ atmosphere [27]. One simple example was reported that involved immobilization of a phosphonate ester via re-esterification; yet, it was not studied in detail whether a covalent bond was formed [28].

Here, we present a comprehensive study of a straightforward method of immobilizing several phosphonic acids and phosphoric acid esters on various mesoporous silica materials using a Dean-Stark apparatus with toluene as the solvent. This approach can lead to covalently functionalized mesoporous silicas (Scheme 1). A covalent functionalization would have the advantage over adsorption that long-term stability could be reached and that a broader solvent spectrum could be applied with the functionalized material. Since the procedure involves azeotropic distillation, there is no need to dry any of the reactants (phosphonic acids, phosphoric acid esters), the solvents, or the silicas prior to use for the reaction. Our study includes model phosphonic acids, the biomolecule adenosine monophosphate (AMP), and an organocatalyst for an asymmetric aldol reaction.
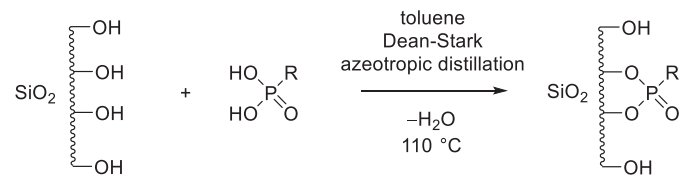

$\mathrm{R}=\mathrm{Alkyl}$, Aryl

Scheme 1. Functionalization of (mesoporous) silica with a phosphonic acid derivative via azeotropic distillation in a Dean-Stark apparatus.

\section{Materials and Methods}

Unless noted otherwise in this section, all reagents were commercially acquired. Solvents and chemicals were used without further purification. The (2R,4S)-4-(phosphonooxy)-pyrrolidine2-carboxylic acid (5) was prepared according to a literature procedure [29]. LiChrosorb SI 100 silica gel was purchased from Merck. Mesoporous silicas (SBA-15 [1], MCM-41 [2], and monoliths [30]) were prepared using literature procedures; their specifications are listed in Table 1. Synthesis details and structural characterization (porosity) are shown in the Supplementary Materials. For some reactions, the silicas were pre-dried in a drying cabinet overnight at $100{ }^{\circ} \mathrm{C}$ (indicated by "dried"). Since no difference was observed between dried and non-dried silicas, subsequent reactions were performed with the as-obtained material. Loading of the silica was determined by elemental analysis of the carbon content (indicated by $m_{\mathrm{C}}$ ) or, where possible, also of the nitrogen content (indicated by $m_{\mathrm{N}}$ ).

Characterization: ${ }^{1} \mathrm{H}$ and ${ }^{13} \mathrm{C}$ solution-state NMR spectra were recorded on a Bruker AVANCE 500. The deuterated solvents used were deuterium oxide, chloroform, or deuterated methanol. The chemical shifts are given in parts per million (ppm). For solid-state ${ }^{29} \mathrm{Si}$ and ${ }^{31} \mathrm{P}$ NMR measurements, carried out at 25 or $30{ }^{\circ} \mathrm{C}$; a 300-MHz Tecmag Apollo spectrometer equipped with a wide-bore Oxford magnet was used. The measuring frequencies were $59.563 \mathrm{MHz}$ for ${ }^{29} \mathrm{Si}$ and $121.368 \mathrm{MHz}$ for ${ }^{31} \mathrm{P}$. A standard magic-angle spinning (MAS) probe for rotors with a diameter of $4 \mathrm{~mm}$ was used. Unless noted otherwise, ${ }^{29} \mathrm{Si}$ spectra were obtained at a rotation frequency of $6 \mathrm{kHz}$, whereas ${ }^{31} \mathrm{P}$ spectra were recorded at rotation frequencies of 2 or $8 \mathrm{kHz}$ under proton decoupling. The signal of hydroxy apatite at $2.3 \mathrm{ppm}$ was used as an external chemical shift reference for ${ }^{31} \mathrm{P}$; chemical shifts 
reported have an error margin of $\pm 0.1 \mathrm{ppm} .{ }^{31} \mathrm{P}$ chemical shift tensors were obtained from side-band patterns by means of a Herzfeld-Berger analysis [31] using HBA software [32]. $\mathrm{N}_{2}$ physisorption analysis was conducted at $77 \mathrm{~K}$ with a Quantachrome NOVA 4000e apparatus. Prior to measurement, samples were degassed at $393 \mathrm{~K}$ for $24 \mathrm{~h}$. Pore size evaluation was achieved using the NLDFT-based silica (cylindrical pores) kernel. Fourier-transform infrared (FT-IR) spectra were recorded on a Bruker Vertex 70. Elemental analysis was carried out on a vario MicroCube (elementar) CHNOS analyzer. Powder X-ray diffraction was carried out with a Bruker AXS D8 Advance diffractometer with $\mathrm{Cu} \mathrm{K} \alpha$ radiation $(40 \mathrm{kV}, 40 \mathrm{~mA})$.

General Functionalization: Silica (300 mg), phosphonic/phosphoric compound (0.1 equiv.), and absolute toluene $(40 \mathrm{~mL})$ were refluxed under $\mathrm{N}_{2}$ in a Dean-Stark apparatus for $16 \mathrm{~h}$. Thereafter, the toluene was decanted from the solid. The remaining solid was washed three times with toluene, methanol, and dichloromethane. After this treatment, the solid was dried at $70{ }^{\circ} \mathrm{C}$ in a drying cabinet. The level of functionalization and spectral data for each material are presented in the Supplementary Materials.

2-(Hydroxy(4-nitrophenyl)methyl)cyclohexanone. (4R)-4-Phosphonooxy-L-proline functionalized silica $(30 \mathrm{mg}), p$-nitrobenzaldehyde $(0.20 \mathrm{mmol}, 30 \mathrm{mg})$, and cyclohexanone ( $9.93 \mathrm{mmol}, 0.1 \mathrm{~mL})$ were added to a DMF-water (90-10) volume mixture and stirred for $4 \mathrm{~d}$ at 37 ${ }^{\circ} \mathrm{C}$. The resulting crude product was isolated via column chromatography (eluent: petrol ether-ethyl acetate, 60-40). For silicas, yields, and selectivities, see Table 5.

\section{Results and Discussion}

To evaluate different phosphonic acid and phosphoric acid ester analogs with alkyl and aryl substituents, phenylphosphonic acid (PPA, 1 in Scheme 2), the biomolecule adenosine monophosphate (AMP, 2), $n$-dodecylphosphonic acid (DPA, 3), and di- $n$-butyl phosphate (DBP, 4) were chosen. Also, (4R)-4-phosphonooxy-L-proline (5) [29] was used for a catalytic application.

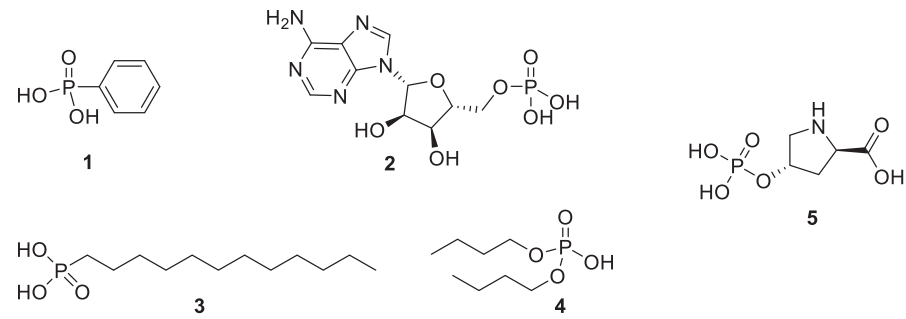

Scheme 2. Phosphonic acid and phosphoric acid ester analogs used for functionalization of silica via azeotropic distillation.

In addition to the application of different organic moieties, a variety of porous silica materials were also used. Their textural properties are summarized in Table 1.

Table 1. Textural properties of porous silica materials.

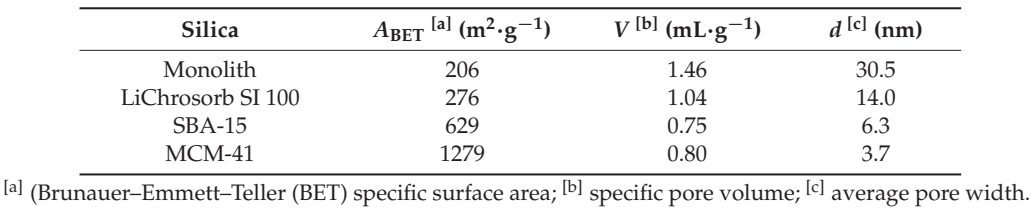

Before studying phosphonic acids and phosphoric acid esters, preliminary tests were carried out by functionalizing some silica materials with trimethoxysilane as a standard linker via a condensation 
reaction [17] for comparison. For this purpose, the silicas were dried at $100{ }^{\circ} \mathrm{C}$ for $24 \mathrm{~h}$ prior to use. The results are shown in Table 2. The data suggest that the pore size has an impact on the loading level. Even though the silica monolith has a smaller Brunauer-Emmett-Teller (BET) surface than SBA-15 silica, a higher loading was achieved. This observation is consistent with the literature [33]. Smaller pores are less accessible for larger molecules. In addition, smaller pores go along with larger specific BET surface areas, which promotes condensation of trimethoxysilane with itself due to surface-adsorbed water and, hence, blocking of the pores, which prevents further functionalization inside the pores. In addition to their pore sizes, the materials may also exhibit differences in the silanol group density (per pore wall area), which might provide further explanation of the different loading levels.

Table 2. Functionalization of silicas with trimethoxysilane.

\begin{tabular}{cc}
\hline Silica & Loading $\left(\mathbf{m m o l}^{\cdot} \mathrm{g}_{\mathrm{SiO}_{2}}{ }^{-\mathbf{1}}\right)$ \\
\hline Monolith & 0.777 \\
LiChrosorb SI 100 & 0.562 \\
SBA-15 & 0.508 \\
\hline
\end{tabular}

Results for the functionalization with phosphonic acids and phosphoric acids esters are shown in Table 3. This functionalization was achieved using a straightforward method. The various reactants and the respective porous silica materials were stirred in toluene under reflux for $16 \mathrm{~h}$ in a Dean-Stark apparatus (Scheme 1), without further pre- or post-synthesis procedures. It was found that pre-drying the silica materials did not result in higher levels of functionalization; the silicas can be applied as prepared in the procedure. The data in Table 3 reveal mostly high levels of loading of the various silica materials with the compounds 1-4 from Scheme 2. The functionalization with PPA (1) and DBP (4) was similar for all silicas, except for MCM-41. Here, a much lower degree of loading was observed despite the very large BET surface area of MCM-41. This finding may be explained by the fact that MCM-41 exhibited the smallest pores of all silica samples (see Table 1). Obviously, the small pore diameter significantly constrains access of the reactants to the pores as well as their diffusion though the pores. Taking into account that PPA (1) reacts very fast with the silanol groups, the PPA (1) would react first with the silanol groups at the opening endings of the pores. Thereby, the pore entry becomes too small for further PPA (1) to diffuse to the inner part of the pore. For DBA, the effect is smaller due to the fact that DBP (4) reacts slower with the silanol groups. The highest level of loading was achieved with AMP (2) for all silica materials including MCM-41. This is consistent with the large number of functional groups within this molecule that can form hydrogen bonds. In addition to the AMP molecules chemically bound to the silica surface, additional layers may be formed via $\mathrm{H}$-bonds between adjacent molecules. Lower degrees of loading with DBP (4) were observed for all silica materials than with DPA (3). This is attributed to the fact that DBP (4) exhibits only one hydroxy function to form a bond with the silica surface, which results in a lower binding strength.

Table 3. Functionalization of the silicas with different phosphonic and phosphoric analogs. PPA—phenylphosphonic acid; AMP—adenosine monophosphate; DPA— $n$-dodecylphosphonic acid; DBP—di- $n$-butyl phosphate.

\begin{tabular}{ccccc}
\hline \multirow{2}{*}{ Silica } & \multicolumn{4}{c}{ Loading (mmol·g $\mathrm{SiO}_{\mathbf{2}}{ }^{-\mathbf{1}}$ ) } \\
\cline { 2 - 5 } & PPA (1) & AMP (2) & DPA (3) & DBP (4) \\
\hline Monolith & 0.527 & 2.489 & - & - \\
LiChrosorb SI 100 & 0.742 & 1.035 & 0.636 & 0.470 \\
SBA-15 & 0.561 & 0.999 & 0.568 & 0.422 \\
MCM-41 & 0.010 & 1.049 & 0.466 & 0.264 \\
\hline
\end{tabular}


The formation of covalent bonds between the silica phases and the respective guest molecules was investigated by FT-IR spectroscopy and by solid-state MAS-NMR spectroscopy. Figure 1 shows example IR spectra of pure silica (monolith) and of the respective PPA(1)-functionalized sample. Characteristic absorption bands of amorphous silica appear at $3450 \mathrm{~cm}^{-1}$ (s, $\mathrm{Si}-\mathrm{OH}$ and $\mathrm{H}_{2} \mathrm{O}$ ), $1640 \mathrm{~cm}^{-1}$ (w, Si-OH and $\mathrm{H}_{2} \mathrm{O}$ ), $1180 \mathrm{~cm}^{-1}$ (s, Si-O-Si), $800 \mathrm{~cm}^{-1}$ (m, Si-OH), and $460 \mathrm{~cm}^{-1}(\mathrm{~m}$, Si-O-Si) [34]. The functionalized sample exhibits additional signals at ca. $750 \mathrm{~cm}^{-1}$, assignable to the P-C stretching vibration, as well as at 1439, 1385, 717, and $692 \mathrm{~cm}^{-1}$, assignable to aromatic ring vibrations $[21,35,36]$. This confirms the presence of the guest species, but not necessarily its covalent bonding to the silica surface. Similar results were obtained for the other samples. ${ }^{29} \mathrm{Si}$ MAS-NMR spectra (shown in Supplementary Materials, Figure S4) exhibit weakly resolved Q4 signals with varying fractions of Q3 signals. Due to their low resolution, the ${ }^{29} \mathrm{Si}$ NMR spectra did not provide conclusive information on the presence of covalent bonds between the silica surface and the guest molecules. Hence, ${ }^{29} \mathrm{Si}$ NMR was not further pursued in this study.

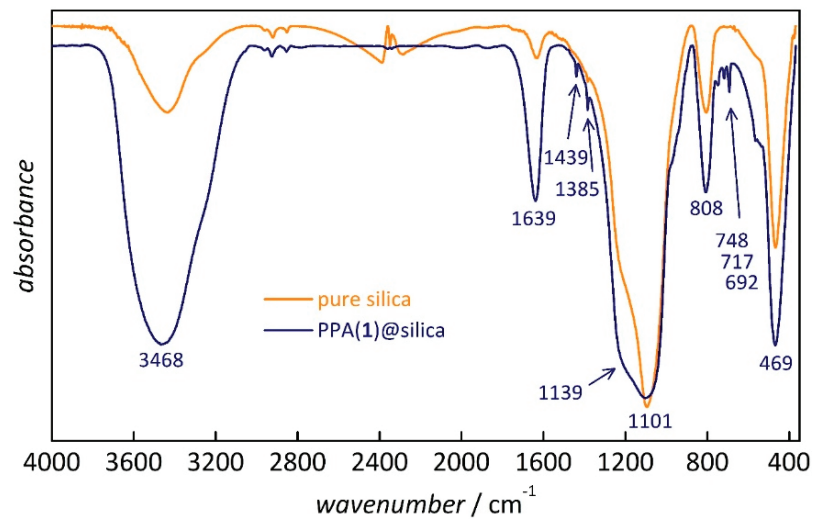

Figure 1. Fourier-transform infrared (FT-IR) spectra of pure silica (monolith) and of the phenylphosphonic acid (PPA) (1)-functionalized silica.

Figure 2 shows an example ${ }^{31} \mathrm{P}$ MAS-NMR spectrum of mesoporous silica (monolith) functionalized with the biomolecule AMP (2) in comparison with the spectrum of pure AMP. For these samples, as well as the other silicas loaded with AMP (cf. Supplementary Materials, Figure S5), a broad pattern of rotational side bands was observed. The large chemical shift anisotropy indicates that the AMP molecules were immobile. Some of the samples show an additional narrow peak, forming a downfield shoulder of the center band and accounting for at most a few percent of the total spectral intensity. For these peaks, no spinning side bands can be recognized; they may result from a small fraction of mobile AMP molecules or a by-product of the reaction. In order to assign the central peak of the side-band pattern, several measurements at different spinning frequencies were performed; an isotropic chemical shift of $-2.0 \mathrm{ppm}$ was determined for all AMP-containing samples. The Herzfeld-Berger analysis [31,32] of the side-band intensities yielded the principal values of the chemical shift tensors, which were 69.2, -1.6, and -73.7 ppm for AMP@LiChrosorb SI 100 and 71.9, -1.8 , and -76.1 for neat AMP. The spectral parameters of these two and the other AMP samples are too similar to support the hypothesis of a chemical binding of AMP to the silica surface. 

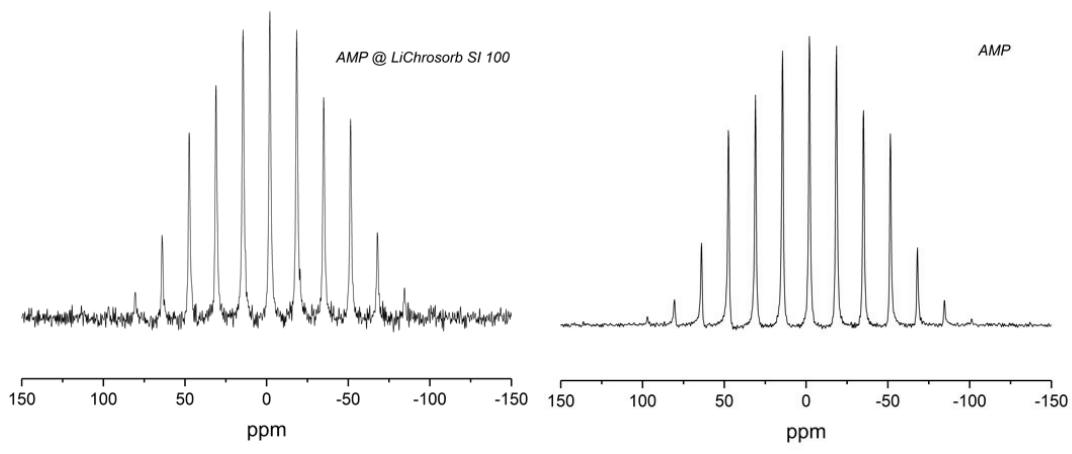

Figure 2. ${ }^{31} \mathrm{P}$ magic-angle spinning (MAS) NMR-spectrum of LiChrosorb Si 100 loaded with adenosine monophosphate (AMP) (2) (left) and of neat AMP (right), measured at a spinning frequency of $2 \mathrm{kHz}$.

In a ${ }^{31}$ P MAS-NMR spectrum with PPA (1), it would be expected that different signals occur due to the presence of different attached phosphorus atoms to the surface of the silica gel [10]. In Figure 3, six different possibilities are shown, while, in the NMR, only two or three different signals were observable for each sample.

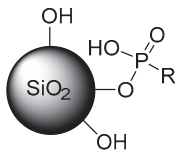

d)

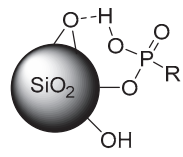

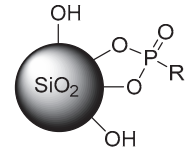

e)

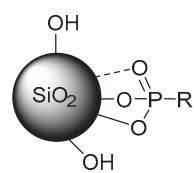

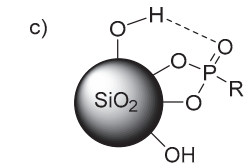

f)

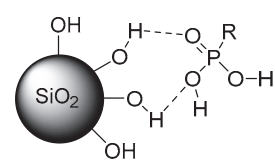

Figure 3. Possible types of attachment of a phosphonic acid to $\mathrm{SiO}_{2}$ : (a) monoester; (b) diester; (c) diester with hydrogen bonding to a silanol group; (d) monoester with hydrogen bonding to a surface oxygen atom; (e) diester with Lewis acid/base interaction with a silicon atom; (f) pure hydrogen bond interactions.

As can be seen in Figure 4 and Table 4, the ${ }^{31} \mathrm{P}$ CP-MAS-NMR spectra of PPA (1) attached to different silica gels consisted of four different signals in the range of about 20 to $0 \mathrm{ppm}$, labeled by increasing numbers from left to right. The peaks outside of this range were spinning side bands. Signals 2 (narrow, between 18.4 and $18.7 \mathrm{ppm}$ ) and 3 (broad, between 9.0 and $9.7 \mathrm{ppm}$ ) were common to all three samples, but the intensity ratios vary. For PPA@MCM-41, an additional shoulder occurred downfield of 2, whereas PPA in monolithic silica showed a very small additional peak close to $0 \mathrm{ppm}$. In the literature, the pattern of three peaks was assigned to physisorbed, monodentate and bidentate, and tridentate binding [27]. 


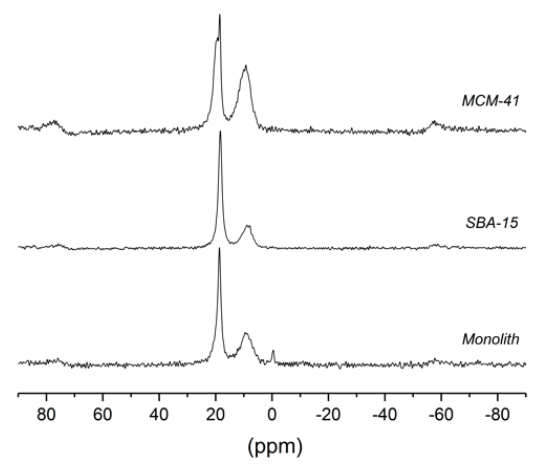

Figure 4. ${ }^{31} \mathrm{P}$ CP-MAS-NMR spectra of MCM-41, SBA-15, and a monolith functionalized with phenylphosphonic acid (PPA, 1). The spectra were measured at a spinning frequency of $8 \mathrm{kHz}$ and exhibit spinning sidebands near 80 and $-60 \mathrm{ppm}$.

Table 4. ${ }^{31} \mathrm{P}$ CP magic-angle spinning (MAS) NMR shifts of monolith, SBA-15, and MCM-41, functionalized with phenylphosphonic acid (PPA, 1).

\begin{tabular}{ccccc}
\hline \multirow{2}{*}{ Silica } & \multicolumn{4}{c}{ Chemical shift/ppm } \\
\cline { 2 - 5 } & Signal 1 & Signal 2 & Signal 3 & Signal 4 \\
\hline Monolith & - & 18.7 & 9.3 & -0.4 \\
SBA-15 & - & 18.4 & 9.0 & - \\
MCM 41 & 19.5 & 18.5 & 9.7 & - \\
\hline
\end{tabular}

The width of the narrow peak (2) was reduced significantly under MAS, which means that the width of this peak is partly caused by a residual chemical shift anisotropy and not only by chemical shift variations due to structural disorder. This is consistent with the spectra of other samples (cf. Supplementary Materials, Figure S6) that show spinning side bands of the narrow peak at a spinning frequency of $2 \mathrm{kHz}$. Thus, the narrow peak may be assigned to partially mobile ligands that cannot reorient isotropically. This could be either a physisorbed species (e.g., via H-bonds) or a monodentate binding; in both cases, the ligand may still be able to rotate about a single bond which reduces the chemical shift anisotropy. The occurrence of two peaks ( 1 and 2 ) for MCM-41 may be explained by the occurrence of both physisorption and monodentate binding. The broad peak (3) can be assigned to immobile ligands attached via bi/tridentate binding that makes orientation about a bond axis impossible. The large width of this peak even under MAS indicates structural disorder (different environments).

Silica samples loaded with DPA (3) and DBP (4) show similar features as PPA (1) in their ${ }^{31} \mathrm{P}$ NMR spectra (Supplementary Materials, Figure S6). Thus, functionalization of the silica surface by these compounds is confirmed. Only AMP (cf. Figure 2) shows a different behavior. It may also be possible that AMP as the largest guest species considered in this study does not enter the pores at all but simply forms crystals outside of the pore system, which are not removed by the washing sequence (see Section 2). The high "loading" found for AMP (cf. Table 3) would then not entirely correspond to material inside of the pores.

Immobilization of organic moieties in porous silica materials is particularly interesting for heterogeneous organocatalysis. To explore this aspect, (4R)-4-phosphonooxy-L-proline (5) was immobilized on various porous silica materials in the same way as compounds $1-4$. The highest degrees of loading were achieved with LiChrosorb SI $100\left(1.234 \mathrm{mmol} \cdot \mathrm{g}_{\mathrm{SiO}_{2}}{ }^{-1}\right)$ and SBA-15 $\left(1.162 \mathrm{mmol} \cdot \mathrm{g}_{\mathrm{SiO}_{2}}{ }^{-1}\right)$. These two samples were applied in an asymmetric aldol reaction as shown in Scheme 3; this reaction is catalyzed by L-proline derivatives [37,38]. A heterocatalytic application of 5 in an asymmetric aldol reaction was reported for zirconium oxide as the support material [29]; however, the catalyst could not be recycled due to hydrolysis of the covalent linker bond between 5 
and $\mathrm{ZrO}_{2}$. It was also shown that a phenylphosphonic acid derivative can be attached permanently to zirconium phosphate [39].

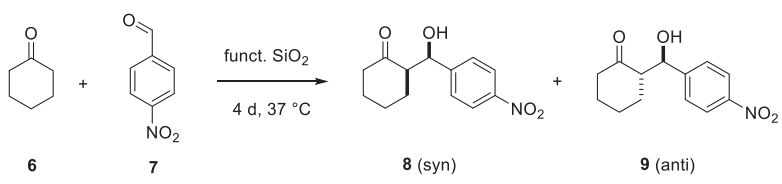

Scheme 3. Asymmetric aldol benchmark reaction.

For the reaction, $20 \mathrm{~mol}$ \% of the functionalized material, 20 equivalents of cyclohexanone and one equivalent of $p$-nitrobenzaldehyde were applied. The spectral data for the obtained two diastereomeres (anti and syn) were consistent with literature values [40-42]. The reaction with the pure catalyst (5) in solution resulted in a good yield and high selectivities. Slightly lower yields were obtained for the two heterogenic systems of (5) immobilized in LiChrosorb SI 100 silica or in SBA-15 silica, respectively (Table 5). The latter resulted in the lowest yield, consistent with its lower degree of loading as compared to the LiChrosorb system. Most remarkably, the immobilization of the organocatalyst does not have any negative effect on the diastereoselectivity $(d r)$ or enantioselectivity (ee), which is often a problem when chiral catalysts are immobilized. A possible mechanism of the catalyzed reaction is shown in Scheme 4, in analogy to the homogeneous systems [43].

Table 5. Asymmetric aldol reaction carried out by using (4R)-4-phosphonooxy-L-proline (5) as a catalyst in solution or immobilized in porous silica materials.

\begin{tabular}{|c|c|c|c|c|c|}
\hline \multirow{2}{*}{ Catalyst } & \multirow{2}{*}{$\left.\underset{\left(\mathrm{mmol} \cdot \mathrm{gSiO}_{2}\right.}{\text { Loading }}-1\right)$} & \multirow{2}{*}{ Yield $^{[a]}(\%)$} & \multirow{2}{*}{$\begin{array}{c}d r^{[\mathrm{b}]}(\%) \\
\text { anti/syn }\end{array}$} & \multicolumn{2}{|c|}{$e e^{[\mathrm{c}]}(\%)$} \\
\hline & & & & anti & syn \\
\hline Pure 5 & - & 62 & $93 / 7$ & 96 & n.a. \\
\hline 5@LiChrosorb & 1.234 & 53 & $95 / 5$ & 97 & 12 \\
\hline 5@SBA-15 & 1.162 & 47 & $92 / 8$ & 97 & 5 \\
\hline
\end{tabular}

[a] $\overline{\text { isolated yield; }{ }^{[b]} \text { determined by }{ }^{1} \mathrm{H} \text { NMR; }{ }^{[c]} \text { determined by chiral HPLC; n.a.-not applicable }}$

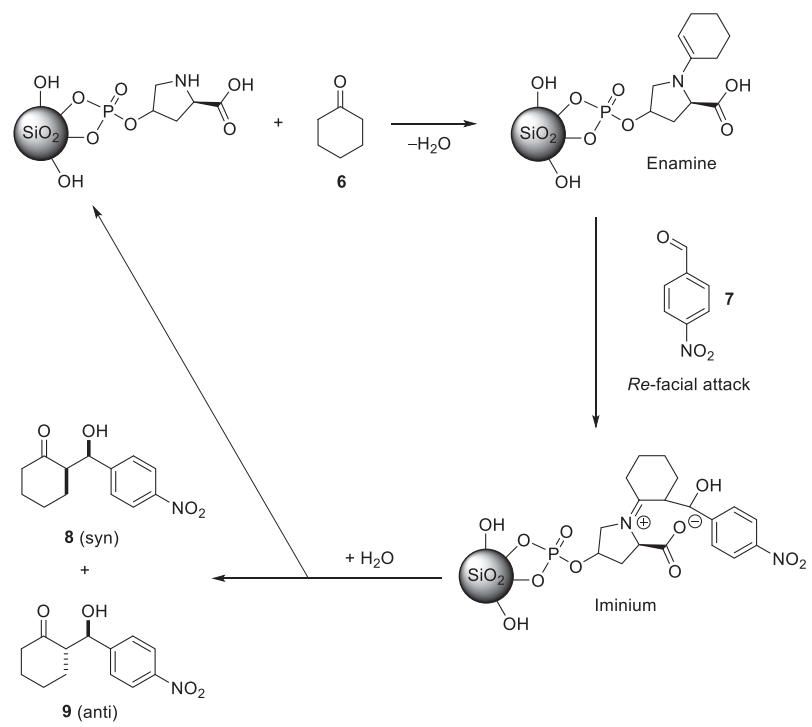

Scheme 4. Proposed mechanism of the hetero-catalyzed asymmetric aldol reaction. 
The recycled 5@SBA-15 material turned out not to be catalytically active. Therefore, we investigated the stability of the functionalized materials from Table 3 against hydrolysis. The materials were exposed to an acidic aqueous solution, five equivalents of a $1 \mathrm{M}$ solution of $\mathrm{HCl}$ at room temperature for $24 \mathrm{~h}$. The phosphonic-acid-functionalized materials showed the same level of loading after this treatment, while the materials functionalized with phosphate esters were not stable, as indicated by the absence of carbon in the elemental analysis. Hence, future work will focus on stable organocatalysts linked to the silica substrate via phosphonic acid functions.

\section{Conclusions}

A straightforward method to functionalize various mesoporous silica materials with phosphonic acids and phosphoric acid esters in a Dean-Stark apparatus was presented. The formation of covalent bonds was proven by ${ }^{31} \mathrm{P}$ CP-MAS-NMR spectroscopy. These results were exploited to tether a homogeneous organocatalyst via a phosphoric ester group to porous silica, which resulted in good yields and high selectivities in an asymmetric aldol reaction.

Supplementary Materials: The following are available online at http:/ www.mdpi.com/2079-4991/9/2/249/s1: Synthesis procedures for SBA-15, MCM-41, and silica monoliths, as well as their functionalization; Figure S1: physisorption data porous silica materials; Figure S2: low-angle X-ray diffraction (XRD) data of SBA-15 and MCM-41; Figure S3: FT-IR spectra; Figure S4: ${ }^{29}$ Si-MAS-NMR spectra; Figures S5 and S6: ${ }^{31}$ P-MAS-NMR spectra.

Author Contributions: R.W. conceived the research idea; C.W., H.C.M., C.S., M.T., and R.W. developed conceptual strategies and evaluated the data; T.H., P.S., M.S., A.G., W.K., and C.W. carried out synthesis and characterization, and evaluated the data.

Funding: This research received no external funding.

Conflicts of Interest: The authors declare no conflict of interest.

\section{References}

1. Zhao, D.; Feng, J.; Huo, Q.; Melosh, N.; Fredricksen, G.H.; Chmelka, B.F.; Stucky, G.D. Triblock Copolymer Syntheses of Mesoporous Silica with Periodic 50 to 300 Angstrom Pores. Science 1998, 279, 548-552. [CrossRef] [PubMed]

2. Kresge, C.T.; Leonowicz, M.E.; Roth, W.J.; Vartuli, J.C.; Beck, J.S. Ordered Mesoporous Molecular Sieves Synthesized by a Liquid-crystal Template Mechanism. Nature 1992, 359, 710-712. [CrossRef]

3. Hoffmann, F.; Cornelius, M.; Morell, J.; Fröba, M. Silica-based Mesoporous Organic-Inorganic Hybrid Materials. Angew. Chem. Int. Ed. 2006, 45, 3216-3251. [CrossRef] [PubMed]

4. Vallet-Regí, M.; Balas, F.; Arcos, D. Mesoporous Materials for Drug Delivery. Angew. Chem. Int. Ed. 2007, 46, 7548-7558. [CrossRef] [PubMed]

5. Rosenholm, J.M.; Sahlgren, C.; Lindén, M. Towards Multifunctional, Targeted Drug Delivery Systems Using Mesoporous Silica Nanoparticles-Opportunities \& Challenges. Nanoscale 2010, 2, 1870-1883. [PubMed]

6. Croissant, J.G.; Fatieiev, Y.; Almalik, A.; Khashab, N.M. Mesoporous silica and organosilica nanoparticles: Physical chemistry, biosafety, delivery strategies, and biomedical applications. Adv. Healthcare Mater. 2018, 7. [CrossRef] [PubMed]

7. Qiu, H.; Liang, X.; Sun, M.; Jiang, S. Development of Silica-based Stationary Phases for High-performance Liquid Chromatography. Anal. Bioanal. Chem. 2011, 399, 3307-3322. [CrossRef]

8. Triantafillidis, C.; Elsaesser, M.S.; Hüsing, N. Chemical Phase Separation Strategies towards Silica Monoliths with Hierarchical Porosity. Chem. Soc. Rev. 2013, 42, 3833-3846. [CrossRef]

9. Wagner, T.; Krotzky, S.; Weiß, A.; Sauerwald, T.; Kohl, C.D.; Roggenbuck, J.; Tiemann, M. A High Temperature Capacitive Humidity Sensor Based on Mesoporous Silica. Sensors 2011, 11, 3135-3144. [CrossRef]

10. Cattani-Scholz, A. Functional Organophosphonate Interfaces for Nanotechnology: A Review. ACS Appl. Mater. Interfaces 2017, 9, 25643-25655. [CrossRef]

11. Schmidt, W. Solid Catalysts on the Nanoscale: Design of Complex Morphologies and Pore Structures. Chem. Cat. Chem. 2009, 1, 53-67. [CrossRef]

12. Tüysüz, H.; Schüth, F. Ordered Mesoporous Materials as Catalysts. Adv. Catal. 2012, 55, 127-239. 
13. Soundiressane, T.; Selvakumar, S.; Ménage, S.; Hamelin, O.; Fontecave, M.; Singh, A.P. Ru- and Fe-based $\mathrm{n}, \mathrm{n}^{\prime}$-Bis(2-pyridylmethyl)-n-methyl-(1s,2s)-1,2-cyclohexanediamine Complexes Immobilised on Mesoporous MCM-41: Synthesis, Characterization and Catalytic Applications. J. Mol. Catal. A 2007, 270, 132-143. [CrossRef]

14. Van Der Voort, P.; Esquivel, D.; de Canck, E.; Goethals, F.; Van Driessche, I.; Romero-Salguero, F.J. Periodic mesoporous organosilicas: From simple to complex bridges; a comprehensive overview of functions, morphologies and applications. Chem. Soc. Rev. 2013, 42, 3913-3955. [CrossRef] [PubMed]

15. Jones, M.D.; Raja, R.; Thomas, J.M.; Johnson, B.F.G.; Lewis, D.W.; Rouzaud, J.; Harris, K.D.M. Enhancing the Enantioselectivity of Novel Homogeneous Organometallic Hydrogenation Catalysts. Angew. Chem. Int. Ed. 2003, 42, 4326-4331. [CrossRef] [PubMed]

16. Kamitori, Y. A Convenient and Facile Synthesis of 3-Trifluoromethyl-1,2,5-oxadiazoles with the Use of Silica Gel as an Effective Catalyst. Heterocycles 1999, 51, 627-630. [CrossRef]

17. Dash, S.; Mishra, S.; Patel, S.; Mishra, B.K. Organically Modified Silica: Synthesis and Applications due to its Surface Interaction with Organic Molecules. Adv. Interface Colloid Sci. 2008, 140, 77-94. [CrossRef]

18. Hair, M.L.; Hertl, W. Reactions of Chlorosilanes with Silica Surfaces. J. Phys. Chem. 1969, 73, 2372-2378. [CrossRef]

19. Guerrero, G.; Alauzun, J.G.; Granier, M.; Laurencin, D.; Mutin, P.H. Phosphonate Coupling Molecules for the Control of Surface/Interface Properties and the Synthesis of Nanomaterials. Dalton Trans. 2013, 42, 12569-12585. [CrossRef]

20. Pujari, S.P.; Scheres, L.; Marcelis, A.T.M.; Zuilhof, H. Covalent Surface Modification of Oxide Surfaces. Angew. Chem. Int. Ed. 2014, 53, 6322-6356. [CrossRef]

21. Hanson, E.L.; Schwartz, J.; Nickel, B.; Koch, N.; Danisman, M.F. Bonding Self-assembled, Compact Organophosphonate Monolayers to the Native Oxide Surface of Silicon. J. Am. Chem. Soc. 2003, 125, 16074-16080. [CrossRef] [PubMed]

22. Vega, A.; Thissen, P.; Chabal, Y.J. Environment-controlled Tethering by Aggregation and Growth of Phosphonic Acid Monolayers on Silicon Oxide. Langmuir 2012, 28, 8046-8051. [CrossRef] [PubMed]

23. Alphazan, T.; Mathey, L.; Schwarzländer, M.; Lin, T.-H.; Rossini, A.J.; Wischert, R.; Enyedi, V.; Fontaine, H.; Veillerot, M.; Lesage, A.; et al. Monolayer Doping of Silicon through Grafting a Tailored Molecular Phosphorus Precursor onto Oxide-passivated Silicon Surfaces. Chem. Mater. 2016, 28, 3634-3640. [CrossRef]

24. Longo, R.C.; Cho, K.; Hohmann, S.; Thissen, P. Mechanism of Phosphorus Transport through Silicon Oxide during Phosphonic Acid Monolayer Doping. J. Phys. Chem. C 2018, 122, 10088-10095. [CrossRef]

25. Hofmann, M.; Cattani-Scholz, A.; Mallorqui, A.D.; Sharp, I.D.; Morral, A.F.; Codinachs, L.M. Development and Characterization of EIS Structures Based on $\mathrm{SiO}_{2}$ Micropillars and Pores before and after their Functionalization with Phosphonate Films. Phys. Status Solidi A 2011, 208, 1333-1339. [CrossRef]

26. Lukes, I.; Borbaruah, M.; Quin, L.D. Direct Reaction of Phosphorus Acids with Hydroxy of a Silanol and on the Silica Gel Surface. J. Am. Chem. Soc. 1994, 116, 1737-1741. [CrossRef]

27. Davidowski, S.K.; Holland, G.P. Solid-state NMR Characterization of Mixed Phosphonic Acid Ligand Binding and Organization on Silica Nanoparticles. Langmuir 2016, 32, 3253-3261. [CrossRef] [PubMed]

28. Raster, P.; Schmidt, A.; Rambow, M.; Kuzmanovic, N.; König, B.; Hilt, G. Immobilisation of Photoswitchable Diarylcyclohexenes Synthesised via Cobalt-mediated Diels-Alder Reaction. Chem. Commun. 2014, 50, 1864-1866. [CrossRef] [PubMed]

29. Calolgero, S.; Lanari, D.; Urrú, M.; Piermatti, O.; Pizzo, F.; Vaccaro, L. Supported l-Proline on Zirconium Phosphates Methyl and/or Phenyl Phosphonates as Heterogeneous Organocatalysts for Direct Asymmetric Aldol Addition. J. Catal. 2011, 282, 112-119.

30. Smått, J.-H.; Schunk, S.M.; Lindén, M. Versatile Double-Templating Synthesis Route to Silica Monoliths Exhibiting a Multimodal Hierarchical Porosity. Chem. Mater. 2003, 15, 2354-2361. [CrossRef]

31. Herzfeld, J.; Berger, A.E. Sideband Intensities in NMR Spectra of Samples Spinning at the Magic Angle. J. Chem. Phys. 1980, 73, 6021-6030. [CrossRef]

32. Eichele, K. Herzfeld-Berger Analysis, User Manual; University of Tübingen: Tubingen, Germany, 2015.

33. Hara, K.; Akahane, S.; Wiench, J.W.; Burgin, B.R.; Ishito, N.; Lin, V.S.-Y.; Fukuoka, A.; Pruski, M. Selective and Efficient Silylation of Mesoporous Silica: A Quantitative Assessment of Synthetic Strategies by Solid-State NMR. J. Phys. Chem. C 2012, 116, 7083-7090. [CrossRef] 
34. Socrates, G. Infrared and Raman Characterisitcs Group Frequencies: Tables and Charts; John Wiley \& Sons: Weinheim, Germany, 2001.

35. Thissen, P.; Peixoto, T.; Longo, R.C.; Peng, W.; Schmidt, W.G.; Cho, K.; Chabal, Y.J. Activation of Surface Hydroxyl Groups by Modification of H-terminated Si (111) Surfaces. J. Am. Chem. Soc. 2012, 134, 8869-8874. [CrossRef] [PubMed]

36. Barrio, L.; Campos-Martín, J.M.; Fierro, J.L.G. Spectroscopic and DFT Study of Tungstic Acid Peroxocomplexes. J. Phys. Chem. A 2007, 111, 2166-2171. [CrossRef] [PubMed]

37. List, B.; Lerner, R.A.; Barbas, C.F. Proline-catalyzed Direct Asymmetric Aldol Reactions. J. Am. Chem. Soc. 2000, 122, 2395-2396. [CrossRef]

38. Tang, Z.; Yang, Z.-H.; Chen, X.-H.; Cun, L.-F.; Mi, A.-Q.; Jiang, Y.-Z.; Gong, L.-Z. A Highly Efficient Organocatalyst for Direct Aldol Reactions of Ketones with Aldedydes. J. Am. Chem. Soc. 2005, 125, 9285-9289. [CrossRef] [PubMed]

39. Angeloni, M.; Piermatti, O.; Pizzo, F.; Vaccaro, L. Synthesis of Zirconium Phosphonate Supported l-Proline as an Effective Organocatalyst for Direct Asymmetric Aldol Addition. Eur. J. Org. Chem. 2014, 1716-1726. [CrossRef]

40. Ricci, A.; Bernardi, L.; Gioia, C.; Vierucci, S.; Robitzer, M.; Quignard, F. Chitosan Aerogel: A Recyclable, Heterogeneous Organocatalyst for the Asymmetric Direct Aldol Reaction in Water. Chem. Commun. 2010, 46, 6288-6290. [CrossRef] [PubMed]

41. Hernández, J.G.; Juaristi, E. Asymmetric Aldol Reaction Organocatalyzed by (s)-Proline-containing Dipeptides: Improved Stereoinduction under Solvent-free Conditions. J. Org. Chem. 2011, 76, 1464-1467. [CrossRef]

42. Wu, C.; Fu, X.; Ma, X.; Li, S.; Li, C. Threonine-Surfactant Organocatalysts for the Highly Diastereo- and Enantioselective Direct anti-Mannich Reactions of Hydroxyacetone. Tetrahedron Lett. 2010, 51, 5775-5777. [CrossRef]

43. Bahmanyar, S.; Houk, K.N. The Origin of Stereoselectivity in Proline-catalyzed Intramolecular Aldol Reactions. J. Am. Chem. Soc. 2001, 123, 12911-12912. [CrossRef]

(C) 2019 by the authors. Licensee MDPI, Basel, Switzerland. This article is an open access article distributed under the terms and conditions of the Creative Commons Attribution (CC BY) license (http:/ / creativecommons.org/licenses/by/4.0/). 

MDPI

St. Alban-Anlage 66

4052 Basel

Switzerland

Tel. +41616837734

Fax +41 613028918

www.mdpi.com

Nanomaterials Editorial Office

E-mail: nanomaterials@mdpi.com www.mdpi.com/journal/nanomaterials

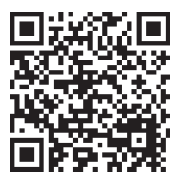



MDPI

St. Alban-Anlage 66

4052 Basel

Switzerland

Tel: +41 616837734

Fax: +41 613028918

www.mdpi.com 